\title{
TEACHERS' PERCEPTIONS OF THE
}

IMPLEMENTATION OF MULTICULTURAL

\section{EDUCATION IN PRIMARY SCHOOLS IN CHEGUTU}

DISTRICT, ZIMBABWE

\section{By}

Francis Muchenje

\section{UNIVERSITY OF SOUTH AFRICA}

JUNE 2014 
TEACHERS' PERCEPTIONS OF THE IMPLEMENTATION OF MULTICULTURAL EDUCATION IN PRIMARY SCHOOLS IN CHEGUTU DISTRICT, ZIMBABWE

By

FRANCIS MUCHENJE

Submitted in accordance with the requirements for the degree of

DOCTOR OF EDUCATION

in the subject of

EDUCATION MANAGEMENT

at the

UNIVERSITY OF SOUTH AFRICA

Supervisor: DR. P.J.HEERALAL

JUNE 2014 


\section{DECLARATION}

Student number: 49256084

I, declare that Teachers' perceptions of the implementation of multicultural education in primary schools in Chegutu district Zimbabwe is my own work and that all the sources that I have used or quoted have been indicated and acknowledged by means of complete references.

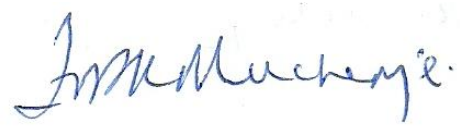

Francis Muchenje

Date: $30 / 05 / 14$ 


\section{DEDICATION}

This work is dedicated to my parents Mr. William Kawara and Mrs. Elizabeth Kawara in recognition of their love and support that has guaranteed my success in education. This work is also dedicated to my dear wife Clementine and our children, Elizabeth, Rutendo, Simbarashe and Nicole for their patience and understanding during the course of my studies. 


\section{ACKOWLEDGEMENTS}

The successful completion of this study was a result of the contribution of many people as well as organisations. I would also like to thank the Almighty God for His guidance and protection throughout the research process.

My supervisor Dr. P.J. Heeralal was a source of inspiration at all stages of my doctoral studies. His incisive and constructive criticisms enabled me to gain new insights in conducting this study.

I would like to thank all the research participants who took part in this study. Without them this study would not have been a success.

I also express my heartfelt gratitude to the following people and organisations:

- The Ministry of Primary and Secondary Education for granting the permission to conduct this study;

- The heads of the five participating primary schools for granting access;

- Colleagues in the Faculty of Education at the University of Zimbabwe who proof read the manuscript;

- Mr. J. Mutambwa and Mr. T. Gama for language editing services; and

- My family for all the inconveniences endured during the course of this study. 


\begin{abstract}
This study explored teachers' perceptions on the implementation of multicultural education in Zimbabwean primary schools. The sample consisted of twenty teachers (10 male and 10 female) selected through purposive sampling technique. Teachers in the sample had a minimum of five years post qualifying experience. The study focused on five selected primary schools in Chegutu district. Qualitative research was chosen as the research method with phenomenology as the research design. Data collection instruments consisted of unstructured in-depth interviews and focus group discussions. Interviews were conducted with the teachers at their respective schools. Focus Group Discussions were also conducted with the teachers soon after the unstructured interviews at their schools. Data analysis consisted of a thematic approach where common themes were identified in participants' responses.

A number of findings emanated from this study. Teachers were found to have a narrow focus in terms of their conceptualisation of multicultural education. The study revealed that multicultural education is being implemented at a superficial level as the participants felt that it is being implemented to a limited extent. Some school textbooks particularly those in the Languages, Social Studies, Religious and Moral Education and Environmental Science were seen as reflecting the multicultural character of Zimbabwe. In terms of the language policy, the teaching of marginalised indigenous languages such as Tonga, Nambya, Kalanga and others was seen as a way of addressing the needs of learners in a linguistically diverse nation. The study found out that parental participation in school activities involves parents from culturally diverse backgrounds.

The study recommends that multicultural education should be part of the curriculum in initial teacher education. Seminars and workshops should be hosted by the Ministry of Primary and Secondary Education to conscientise teachers on the practice of multicultural education. Book publishers should liaise closely with the Ministry of Primary and Secondary Education so as to ensure that the content of textbooks is multicultural in every respect. There is need to consider the teaching of Chewa particularly in those communities where it is commonly spoken. A policy framework regulating the practice of multicultural education needs to be put in place.
\end{abstract}

Key words: multicultural education, gender, curriculum issues, phenomenology, perceptions, implementation 


\section{TABLE OF CONTENTS}

Declaration $\quad$ i

Dedication $\quad$ ii

Acknowledgements

Abstract iv

Table of contents $\quad \mathrm{V}$

List of abbreviations $\quad$ xi

List of tables $\quad$ xii

List of figures xiii

Chapter 1: The problem and its setting 1

1.1 Background to the study 1

1.2 Statement of the problem 8

$\begin{array}{ll}1.3 \text { Research objectives } & 10\end{array}$

$\begin{array}{ll}1.4 \text { Research questions } & 10\end{array}$

$\begin{array}{ll}1.5 \text { Motivation for the study } & 11\end{array}$

$\begin{array}{ll}1.6 \text { Importance of the study } & 12\end{array}$

$\begin{array}{ll}1.7 \text { Contributions of the study } & 13\end{array}$

$\begin{array}{ll}1.8 \text { Expected results } & 14\end{array}$

$\begin{array}{ll}1.9 \text { Limitations of the study } & 14\end{array}$

$\begin{array}{ll}1.10 \text { Demarcation of the study } & 14\end{array}$

1.11 Aim of the study 15

$\begin{array}{ll}1.12 \text { Research methods and design } & 15\end{array}$

$\begin{array}{ll}1.13 \text { Definition of terms } & 16\end{array}$

$\begin{array}{ll}1.14 \text { Chapter divisions } & 17\end{array}$

$\begin{array}{ll}1.15 \text { Chapter summary } & 18\end{array}$

$\begin{array}{lr}\text { Chapter 2: Literature review } & 19\end{array}$

$\begin{array}{ll}2.1 \text { Introduction } & 19\end{array}$

$\begin{array}{ll}2.2 \text { Theoretical framework } & 19\end{array}$

2.3 History of multicultural education 32

2.4 Definition of culture and multicultural education $\quad 40$

2.5 Approaches to the implementation of multicultural education 64 
2.5.1.1 Gibson's model 68

2.5.1.2 Grant and Sleeter's model $\quad 72$

2.5.2 The multicultural education continuum approach 80

2.5.2.1 Bruch et al. Multicultural education continuum approach $\quad 80$

2.5.2.2 Banks multicultural education continuum $\quad 82$

2.5.3 Nieto's characteristics of multicultural education $\quad 86$

2.6 Multicultural education and research studies 91

2.7 Challenges to multicultural education 93

2.8 Curriculum issues in multicultural education for Zimbabwe 100

2.8.1 Knowledge construction $\quad 100$

2.8.2 Selection of curriculum content 102

2.8.3 Textbooks and curriculum instructional materials $\quad 104$

2.8.4 Language policy 106

2.8.5 Teacher attitudes and expectations 111

2.8.6 The school environment $\quad 115$

2.9 Community involvement 118

2.10 Critique of multicultural education $\quad 119$

2.11 Chapter summary 126

Chapter 3: Research methodology 128

3.1 Introduction 128

3.2 Research method 128

3.3 Research design 129

3.3.1 Phenomenology 130

3.4 Sampling 134

3.5 Data collection 136

3.5.1 Unstructured in-depth interviews 137

$\begin{array}{ll}3.5 .2 \text { Focus group discussions } & 139\end{array}$

3.6 Data analysis and interpretation 140

3.6.1 Data Management 143

3.6.2 Immersion in the data and writing memos 143

3.6.2.1 Writing memos 143 
3.7.1 Coding the data 146

$\begin{array}{ll}\text { 3.7.2 Offering interpretations } & 148\end{array}$

$\begin{array}{ll}3.8 \text { Trustworthiness } & 149\end{array}$

$\begin{array}{ll}\text { 3.8.1 Credibility } & 149\end{array}$

$\begin{array}{ll}\text { 3.8.2 Dependability } & 150\end{array}$

$\begin{array}{ll}3.8 .3 \text { Confirmability } & 150\end{array}$

$\begin{array}{ll}3.8 .4 \text { Transferability } & 151\end{array}$

3.9 Ethical considerations 152

3.9.1 Informed consent 152

3.9.2 Confidentiality 153

$\begin{array}{ll}3.9 .3 \text { Privacy } & 154\end{array}$

3.9.4 Anonymity 154

3.9.5 Protection from harm $\quad 155$

$\begin{array}{ll}\text { 3.9.6 The right to withdrawal } & 155\end{array}$

$\begin{array}{ll}3.10 \text { Chapter summary } & 156\end{array}$

Chapter 4: Analysis of data and presentation of findings and discussion 157

4.1 Introduction 157

4.2 Demographic profile of participants 157

4.3 Findings, analysis of data and Discussion: Individual in-depth unstructured

$\begin{array}{ll}\text { Interviews and focus group discussions } & 158\end{array}$

$\begin{array}{ll}\text { 4.3.1 Introduction } & 158\end{array}$

4.3.2 Participants views on the implementation of multicultural education in Zimbabwe 159

4.3.3 Content of the primary school curriculum and Zimbabwe's multicultural $\begin{array}{ll}\text { Character } & 166\end{array}$

4.1 Schools' participation in national Culture Week 180

4.3.4 Differences in curriculum instructional materials used before and after $\begin{array}{ll}\text { Independence } & 185\end{array}$

4.3.5 Portrayal of Zimbabwe's plural character in curriculum instructional $\begin{array}{ll}\text { materials currently in use } & 191\end{array}$ 
4.3.6 Representation of learners from different social groups in curriculum instructional materials

4.3.7 Classroom pedagogy and accommodation of students' cultural diversity

4.3.8 Views on teacher sensitivity to learners' diverse cultural backgrounds

4.3.9 Language in education policy and accommodation of learners' linguistic needs

4.3.10 Encouragement to communicate in mother tongue inside and outside the classroom

4.3.11 The total school environment and the reflection of the nation's cultural diversity

4.3.11.1 Staffing patterns

4.3.11.2 School assembly programmes

4.4.11.3 Selection of prefects

4.4.11.4 Participation in co-curricular activities

4.3.12 Evidence of the school as a multicultural institution

4.3.13 Parental participation in school activities and the nation's multicultural character

4.3.14 Composition of the school development committee

4.4 Chapter summary

\section{Chapter 5: Summary, conclusions and recommendations}

5.2.1 Summary of findings from literature review relating to the origins of multicultural education

5.2.2 Summary of findings from literature review relating to the definition of multicultural education

5.2.3 Summary of findings from literature review relating to curriculum issues in multicultural education

5.3 Summary of findings from qualitative study

5.3.1 Participants' views on the implementation of multicultural education in Zimbabwe

5.3.2 Content of the primary school curriculum and Zimbabwe's multicultural 
character

5.3.3. Portrayal of Zimbabwe's multicultural character in curriculum instructional materials currently in use

5.3.4 Classroom pedagogy and accommodation of students' cultural diversity

5.3.5 Language in education policy and accommodation of learners' linguistic needs

5.3.6 The total school environment and reflection of the nation's cultural diversity

5.3.7 Parental participation in school activities and the nation's multicultural character

5.4 Conclusions

5.4.1 Teacher perceptions on the implementation of multicultural education

5.4.2 Reflection of the nation's plural character in curriculum instructional materials currently in use

5.4.3 Classroom pedagogy and accommodation of cultural diversity

5.4.4 Language in education policy and accommodation of learners' linguistic needs 265

5.4.5 The school environment and reflection of nation's pluralistic character 265

5.4.6 Participation of parents in school activities and the nation's plural character 266

5.5 Recommendations 266

5.5.1 Need for a comprehensive policy on multicultural education 266

5.5.2 Need to include multicultural education in teacher education curricular 266

5.5.3 Enhancing capacity building for teachers in the field through in service Training 267

5.5.4 Review of current textbooks in use

5.5.5 Liaison between book publishers and the Ministry of Primary and Secondary educations

5.5.6 Inclusion of other marginalised indigenous languages onto the school curriculum

5.5.7 Encouragement of communication in the mother tongue in the school 267

5.5.8 Need for multicultural staffing patterns 268 
$\begin{array}{ll}\text { 5.5.9 Conduct of school assembly } & 268\end{array}$

5.5.10 Equity procedures in the selection of prefects 268

5.5.11 Need for evidence of school as a multicultural institution 268

$\begin{array}{ll}\text { 5.5.12 Involvement of parents in school activities } & 268\end{array}$

$\begin{array}{ll}\text { 5.5.13 Recommendations for further research } & 274\end{array}$

$\begin{array}{ll}\text { 5.5.13.1 Comparative studies } & 274\end{array}$

5.5.13.2 Marginalised minority languages particularly Chewa 274

5.5.13.3 Learners' perceptions on the implementation of multicultural education 274

$\begin{array}{ll}\text { References } & 275\end{array}$

$\begin{array}{ll}\text { APPENDICES } & 297\end{array}$

APPENDIX I : Research Ethics Clearance Certificate 297

APPENDIX II: Permission from Ministry of Education Arts and Sports 298

APPENDIX III: Permission from Ministry of Education Arts and Sports Mashonaland West Regional Office 299

APPENDIX IV: Letter seeking permission from school heads 300

APPENDIX V: Informed consent form for teachers 301

APPENDIX VI: Unstructured in-depth interview schedule 303

APPENDIX VII: Focus Group Discussion questions 304

APPENDIX VIII: UMI Publishing Agreement 305

$\begin{array}{ll}\text { APPENDIX IX: Abridged curriculum vitae } & 306\end{array}$ 


\section{List of abbreviations}

UNICEF United Nations Children's Emergency Fund

UNESCO United Nations Scientific and Cultural Organisation

ICRC International Convention on the Rights of the Child

RME Religious and Moral Education

SDC School Development Committee

SDA School Development Association

MoPSE Ministry of Primary and Secondary Education 


\section{List of tables}

Table

Table I
Description

Page

List of participants
158 


\section{List of figures}

Figure

Description

Page

Figure I

Data analysis in qualitative research

142

Figure II

Visual model of coding process

147 


\section{CHAPTER I THE PROBLEM AND ITS SETTING}

\subsection{BACKGROUND TO THE STUDY}

Multicultural education has gained prominence in a number of countries worldwide in the last fifty or so years. It is based on the assumption that there are certain discriminatory practices in education that negatively affect the educational experiences of learners. Such discriminatory practices tend to be based on race, ethnicity, gender, sexual orientation, disability and social class. Hence, some learners, particularly those from minority ethnic backgrounds, become invisible in the content of educational materials as well as classroom pedagogy. Multicultural education attempts to cater for students' cultural diversity and to give students with different characteristics an opportunity to learn (Banks, 2009:4).

Multicultural education is relevant to a number of African countries mainly for two reasons. Firstly, it is recognized that most African countries are multicultural and multi-ethnic where the need to tolerate and appreciate cultural differences is of fundamental importance. Secondly, Africa's colonial experiences saw the imposition of an alien curriculum that was mono-cultural, ethnocentric and Eurocentric in outlook. This curriculum did not give due attention to local circumstances, particularly accommodating the needs of the learners in terms of cultural diversity. Therefore, with the attainment of independence in most African States, there is need for multicultural curricular that accommodate the needs of all learners, particularly in terms of race, ethnicity, gender and social class. Meier \& Hartell (2009:180) state that the increasing cultural diversity in educational institutions necessitates that educationist teach and manage learners with cultures, languages and backgrounds that are unknown to them. Hence educational leaders can no longer pretend not to take 
note of the reality and manifestation of diversity in schools (Lemmer, Meier \& Van Wyk 2006:5).

Zimbabwe is a multiracial, multicultural and multiethnic nation. Zimbababwe's multicultural character is recognized and acknowledged (Nziramasanga Commission Report 1999:357; Ministry of Education, Arts, Sports and Culture, 2004:4). Her population is made up of indigenous Africans, non- indigenous Africans who are from neighbouring countries mainly Malawi, Zambia and Mozambique, Europeans, Asians and Coloureds. It should be noted that all these groups are not homogenous groups. For example, the indigenous African groups comprise the Shona, Ndebele, Kalanga, Tonga, Nambya, Shangaan, Sotho and Venda. This makes Zimbabwe a plural nation. All these groups referred to above are found in the school system at both primary school and secondary school levels. It is generally assumed that the educational reforms that took place at independence in 1980 sought to accommodate the diversity found in the Zimbabwean society.

The Constitution of Zimbabwe outlaws discrimination on any grounds. It should be borne in mind that discrimination can be both overt and covert. Section 56 (3) of the said constitution states that:

Every person has the right not to be treated in an unfairly discriminatory manner on such grounds as their nationality, race, colour, tribe, place of birth, ethnic or social origin, language, class, religious belief, political affiliation, opinion, custom, culture, sex, gender, marital status, age, pregnancy, disability or economic or social status, or whether they were born out of wedlock.

This provision is also reinforced in the field of education by the 1987 Education Act as amended. Section $4(2))$ of this Act states that:

No child in Zimbabwe shall be refused admission to any school on the grounds of race, tribe, colour, religion, creed, and place of origin, political opinion or the social status of his parents. 
Both the Constitution of Zimbabwe and the 1987 Education Act create an enabling environment that celebrates and accommodates the learner diversity that is found in Zimbabwean society. This makes it imperative to adopt multicultural education as an approach that ensures that no learners experiences any form of discrimination in the education system.

Zimbabwe is also a signatory to the International Convention on the Rights of the Child (ICRC). Article 29 of this convention states that children's education should develop each child's personality, talents and ability to the fullest and should encourage children to respect others, human rights and their own and others' cultures. Article 30 states that minority or indigenous children have the right to learn about and practise their own culture, language and religion (UNICEF, 1990). These provisions can be realized through a system of education that acknowledges the plural character of society. It is assumed that Zimbabwe as a signatory to this convention has put in place, multicultural education to accommodate student diversity.

Both the ICRC and the African Charter on Children's Rights recognize the right of all children to education (UNICEF, 1990). This right is also upheld in the constitution of Zimbabwe. Section 75 (1) (a) states that every citizen and permanent resident of Zimbabwe has a right to a basic state funded education and children have a right to education (Constitution of Zimbabwe Section 81 (1) (f). For children to enjoy a right to education, there is need to ensure that the nature of the curriculum is not discriminatory and does not disadvantage some learners in any way whether overtly or covertly. Therefore, multicultural education will enable all learners to fully enjoy the right to education.

Zimbabwe is committed to Education for All as spelt out in the provisions of the 
Jomtien Conference of 1990. The goals of the Jomtien Conference were further renewed and reaffirmed in Senegal at the Dakar Framework of Action of 2000 to which Zimbabwe is also a signatory. Some of the goals of the Dakar Framework of Action include: ensuring that by 2015 all children particularly girls, children in difficult circumstances and those belonging to ethnic minorities have access to and are able to complete primary education ( Little, 2002:13 ) and the elimination of gender disparities by 2015 ( Little, 2002 :14, Ellis, 2002:24). These goals are also part of Zimbabwe's Millennium Development Goals (Government of Zimbabwe, 2004: 23, 29; Government of Zimbabwe, 2009:19; Government of Zimbabwe, 2010:10, 16). The attainment of such goals requires or demands the implementation of multicultural education that motivates learners to attend and complete the primary school cycle.

Most of the reforms initiated in education after independence were meant to address the imbalances induced by discriminatory, Eurocentric, monocultural and ethnocentric policies in the provision and administration of African education. The colonial era in Zimbabwe was characterised by policies of racial discrimination in education and society as well as glaring inequalities in the provision of education and training (Nziramasanga Commission, 1999:1). Colonial education for Africans was meant to protect and perpetuate settler colonial interests.

According to Moyana (1988:19) the education system in Rhodesia was designed to transform the African learner into a humble submissive servant and admirer of the white people. He further argues that:

The official literature of African education from reports of white school principals and reports of provincial inspectors to those of parliamentary secretaries and government commissions is explicit in its denigration of the African background and personality and the need to proletarianise and Anglicise Africans. 
The content of the school curriculum was imported wholesale from Britain. Matsika (2000) cited in Muparutsa (2012:61) laments that the British type of education did not support local traditional culture. Therefore, such a curriculum did not accommodate and celebrate learners' diversity in terms of race, ethnicity, social class and gender. According to Viriri (2003:1), for Cabral (1983), it was therefore inevitable that imperial and colonial rule should seek to obliterate the cultural identity of the colonized people; this was one of the hidden aims of colonial ideology of assimilation.

In light of the foregoing, colonial education has been viewed as a form of cultural imperialism as it devalued African culture and experiences. Europeans transmitted their technology, religion, customs and values through education (Chanaiwa, 1980: 227). This form of education had a negative impact on the colonized Africans. Nyerere (1974) as cited in Moyana (1984: 19) observed that:

Victims of cultural imperialism develop a split personality; they become people of divided emotional, intellectual and physical allegiances. Despising their own culture as something they should be ashamed of rather than a source of pride they develop an admiration of the oppressor whom they try to imitate.

Njobe (1990: 29) made similar observations. He argues that:

... the pupils were treated to lesson presentations designed to show that what is of the coloniser is civilization and superior, while what is indigenous is uncivilised and inferior. The colonized personality being developed by colonial education was intended to accept this premise.

As a result, African learners were subjected to a school curriculum that lacked relevance to their circumstances. No wonder why colonial education has been accused of educating the African learner outside his/her culture. During the colonial era, both the indigenous and racially non-white people and their cultures, in many African countries, already condemned by social Darwinism as backward and primitive and 
thus irrelevant to their use (Foucault, 1980 cited in Vandeyer, 2003:193), were not permitted to enter the privileged space of mainstream culture (Vandeyer, 2003:193). This resulted in the marginalization and subjugation of these cultures hence the need to implement multicultural education with the attainment of independence in many African countries.

In colonial Zimbabwe the manner in which educational provision was administered has been described as a form of educational apartheid which facilitated the provision of a highly privileged and advanced education for European children (Nziramasanga Commission Report 1999:2). A dual system of education existed. Education was administered by two separate departments under one Ministry of Education. There was a Division for African Education and another Division for European, Asian and Coloured Education. Schools were organized on lines of racial segregation. Africans attended their own separate schools. In the European division Asians and Coloureds attended separate schools (Dorsey, 1989:146).

There were very few multiracial schools during this period. These two separate systems derived from the then socio-political philosophy of racism and racial discrimination and separate establishment by the colonial regimes of the time (Nziramasanga Commission Report, 1999:12). Zvobgo (1996:25) argues that the European system was designed to serve and promote white interests and ensure white domination and superiority over blacks. On the other hand, African education was really an education designed to perpetuate the subjugation of the blacks by the whites. In the ultimate analysis, Africans in Rhodesia received an inferior education.

The provision of education for Europeans was the main responsibility of the government from the days of British South Africa Company rule, Responsible 
Government era, the Federation era, right up to the Rhodesia Front era. Provision of education for Africans was championed by the different Christian missionaries. Although this could have been seen as a welcome development from the perspective of Africans, it presented some problems on the motives of the missionaries. The missionaries were mainly concerned with the propagation of the Christian faith. McHarry (1962) in Moyana (1988:19) is of the view that:

The missionary was the realist. He realized that while he kept to his old custom the native was of little use to the white man... Only cultural change could break such apathy, and the message of the church had the power to achieve this.

In such circumstances, African culture and values were not considered at all. Christian values and traditions were emphasized in the education system.

The attainment of independence in April 1980 saw the implementation of a number of reforms in education. At independence the black majority government, inherited an educational system based on inequality of opportunity for the four main racial groups (Dorsey, 1989:144). The dual system of education was abolished and education fell under the administration of one Ministry of Education. In terms of access, all schools at both primary and secondary level were desegregated. Thus, all schools became accessible to all races. In other words, all schools countrywide became multiracial. Most importantly, all the former Group A and Community Schools created by the 1979 Education Act became open to all races since desegregation was effected (Dorsey 1989: 189). In September 1980 a policy of free primary education was announced which saw a huge influx in terms of enrolment figures. New syllabi and curriculum instructional materials were developed in an attempt to make education more relevant to the learner and to rid the curriculum materials of discriminatory, racial and cultural overtones. 
On the basis of the 1987 Education Act, all schools in the country became multiracial and multicultural. There are two issues that emerged as a result of these reforms which deserve special mention in relation to multicultural education. Firstly, education became accessible to a wider section of both the indigenous African and non- indigenous African population. The number of registered primary schools increased by $88 \%$ from 2401 in 1979 to 4504 in 1989 (Government of Zimbabwe, 2009:19). At the same time enrolments increased in primary schools from 820266 in 1979 to 2445516 in 2006, a growth of 198\% (Government of Zimbabwe, 2009:19). As a result of the policy of mass education, many learners were able to access education. Schools were built in remote areas such as Binga, Omay, and Lower Guruve and in farming, mining and other communities that had been shunned by the then colonial government. This further increased cultural diversity in the education system. Secondly, the former predominantly European-only schools were now being attended by learners of all races. In these circumstances teachers found themselves having to interact with increasingly culturally diverse learners.

It can be seen that as a result of the reforms initiated in education after independence, Zimbabwean schools at both primary and secondary school levels are characterized by the presence of many subcultures. The only question that can be posed is whether the system of education accommodates diversity in its entirety. It can be generally assumed that in the thirty two years of independence, commendable effort has been made in the provision of multicultural education. Hence there is a need to explore teacher perceptions on its implementation.

\subsection{STATEMENT OF THE PROBLEM}

Zimbabwe is a multiracial, multiethnic and multicultural nation. It is therefore 
characterized by cultural diversity which needs to be reflected in the content and practice of education. The implementation of multicultural education appears to be problematic not only in Zimbabwe but also in other countries worldwide. It is generally assumed that the desegregation of education that took place at independence in 1980 and was reinforced by the 1987 Education Act (as amended) has made all schools in the country multiracial and, multiethnic. As such, it is generally assumed that multicultural education is being practised in the schools.

The above perspective is problematic since being multiracial and multiethnic does not necessarily guarantee the practice of multicultural education. Furthermore, the bulk of Zimbabwe's school going population at both primary and secondary level is made up of indigenous blacks with some children of black migrant groups. These two groups are not homogenous groups; rather they are heterogeneous. It appears that there has been a tendency to downplay the challenges presented by the ethnic diversity of this student body without also ignoring the demands that a multiracial society places on education. More so, the absence of an official policy on multicultural education makes it difficult to evaluate the extent of its implementation. Therefore, this study seeks to explore teacher perceptions on the implementation of multicultural education in Zimbabwean primary schools. This is significant in that teacher perceptions play an important role in the implementation of multicultural education, more so in situations where the education system has been desegregated. Efficacy of any multicultural education programme depends on several variables; existing literature however suggests that the teacher remains one of the most important determinants (Gwirayi, 2010: 94). Therefore, exploration of teachers' perceptions on the implementation of multicultural education contributes to the formulation of effective policies to guide 
the practice of multicultural education in Zimbabwean primary schools. Lack of knowledge on teachers' perceptions tends to result in the formulation of ineffective policies. Therefore, this study seeks to explore teachers' perceptions on the implementation of multicultural education in Zimbabwean primary schools.

\subsection{RESEARCH OBJECTIVES}

The objectives of the research are to:

1.3.1 identify the perceptions of primary school teachers on the implementation of multicultural education in Zimbabwe

1.3.2 evaluate the extent to which curriculum materials currently in use in primary schools accommodate Zimbabwe's pluralistic character

1.3.3 examine teacher awareness of the current Ministry of Education, Arts, Sports and Culture language policy and its accommodation of linguistic diversity

1.3.4 examine the extent to which the total school environment reflects society's cultural diversity

1.3.5 identify the extent to which parental involvement in school activities through School Development Committees (SDC) and School Development Association (SDA) reflects the pluralistic character of society

\section{$1.4 \quad$ RESEARCH QUESTIONS}

This research seeks to address the following main research question:

1.4.1 What are the perceptions of primary school teachers on the implementation of multicultural education?

The research study also sought to address the following sub research questions:

1.4.1.1 How do curriculum instruction materials currently in use reflect the nation's pluralistic character?

1.4.1.2 How does classroom pedagogy reflect and accommodate cultural diversity 
found in the classroom?

1.4.1.3 How does the current language policy of the Ministry of Education, Arts, Sports and Culture address the linguistic needs of culturally diverse learners?

1.4.1.4 How does the total school environment reflect the pluralistic character of the nation?

1.4.1.5 Does the participation of parents in school activities accommodate society's cultural diversity?

\subsection{MOTIVATION FOR THE STUDY}

The need to undertake this study has been prompted by the realization that literature on multicultural education has focused on countries in the western world such as Canada, the U.S.A., China and others (Yao, Buchanan, Chang, Powell-Brown, \& Pecina 2009:3). Consequently, as Bokhorst-Heng (2007) as cited by Yao, Buchanan, Chang, Brown \& Pecina (2009:3) pointed out, the literature on comparative multicultural education has been dominated by a western paradigm. There is therefore need for studies located within an African context.

At the same time, Zimbabwe has been able to provide education to a wider section of the populace. Provision of such education has meant a heavy investment in terms of financial and human resources. If the goal of such an investment is to be realized, the content of the school curriculum should accommodate learner diversity in its entirety through the implementation of multicultural education. Zimbabwe is a signatory to the Dakar Framework of Action of 2000 whose goals may not be met in the absence of a multicultural school curriculum.

Zimbabwe is committed to the Dakar Framework of Action of 2000 through the Millennium Development Goals. Two targets in the Millennium Development Goals 
assume major importance and these are: universal completion of primary education by 2015 as well as the elimination of gender disparities in education by 2015 (Zimbabwe Government, 2004:23, Zimbabwe Government, 2010: 10, 16). These targets may not be realized; they may remain a pipe dream in the presence of a school environment that does not effectively accommodate and reflect the multicultural character of Zimbabwean society. This has an impact on retention rates in the education system. Policies on multicultural education need to be drawn and revised so as to ensure their successful implementation.

The policy of mass education pursued after independence in 1980 has made education available to a large section of Zimbabwe's multiethnic population. The Education Act of 1987 (Chapter 25:04) outlaws discrimination in any form in the education system. It categorically states that every child in Zimbabwe shall have the right to school education. This piece of legislation is a noble development, which establishes in part, an environment for the effective implementation of multicultural education and in principle, makes all schools in Zimbabwe multiracial and multiethnic. It is therefore imperative that schools accommodate and reflect the nation's cultural diversity.

It needs to be acknowledged that multiracialism is an important component of multicultural education which, when taken on its own, does not guarantee a multicultural approach to education. The success of such policy provisions will, to a large extent; rest on the implementation of a multicultural school curriculum. This tends to promote retention rates in the school and to enhance learner achievement. The practice of education has to live up to this challenge.

\subsection{IMPORTANCE OF THE STUDY}

Zimbabwe has made impressive progress in the provision of education. It is assumed 
that the quantitative goal in the provision of education has been met. The current challenge is to address issues related to the qualitative dimension in education, where curriculum issues need to be looked at among other issues that contribute to quality in education. This study should also be seen as an attempt to ensure quality in education through the accommodation and celebration of learner cultural diversity. Such an approach is imperative if Zimbabwe's goals in education, particularly Zimbabwe's Millennium Development Goals, are to be realized.

The study is also significant for both policy and practice in education. At the level of policy, it is envisaged that the findings of the study will lead to the formulation of policies in the area of multicultural education. Existing policies may be modified in view of the findings of this study so as to regulate the practice of multicultural education.

In terms of the practice of education, the findings of this study may further conscientise teachers on the current developments in the field of multicultural education. It is hoped that these developments will further sharpen teachers' skills in handling cultural diversity in the classrooms.

\subsection{CONTRIBUTIONS OF THE STUDY}

A number of studies aligned to the concept of multicultural education in Zimbabwe have mainly focused on components of multicultural education such as gender (Gordon, 1995a; 1995b; Tichagwa, 1998) and language (Mnkandla, 2000; Ndamba, 2008; Thondhlana, 2002; Gora, Mavunga, Muchinguri \& Waniwa 2010; Peresuh \& Masuku, 2002), leaving out teacher perceptions on the implementation of multicultural education. This current study is unique in that it seeks to explore perceptions that teachers hold on the implementation of multicultural education in 
Zimbabwean primary schools. This is the missing gap in the study of multicultural education in Zimbabwe which this study seeks to fill.

Lemmer, Meier \& van Wyk (2006:5) observed that multicultural education is not a process that happens by chance or by merely desegregating schools so that there is a mixture of cultures. This observation also highlights the importance of exploring teacher perceptions since teachers are the implementers of the school curriculum. Knowledge of the perceptions that teachers hold goes a long way in the formulation of effective policies to guide practice. This study seeks to explore teachers' perceptions on the implementation of multicultural education in Zimbabwean primary schools from a sociological point of view.

\subsection{EXPECTED RESULTS}

The expectation of this study was that multicultural education was being implemented holistically to a greater extent in Zimbabwean primary schools. This view was influenced by the observation that Zimbabwe has been independent for the past thirtytwo years hence there has been ample time to implement multicultural education.

\subsection{LIMITATIONS OF THE STUDY}

It was not possible to create a large sample of schools and participants because of financial and time constraints. The study only focused on five schools in one district and the findings may not be generalized to the country as a whole. However, the findings of this study are significant as they shed light on the status of multicultural education in Zimbabwean primary schools.

\subsection{DEMARCATION OF THE STUDY}

The study was limited to only teacher perceptions on the implementation of 
multicultural education in five primary schools in Chegutu district Mashonaland West province. The study was only confined to primary schools. Secondary schools were not included in the study.

\subsection{AIM OF THE STUDY}

The aim of the study was to explore teacher perceptions on the implementation of multicultural education in Zimbabwean primary schools. The aim of this study was realised through conducting a comprehensive literature review as well as conducting an empirical study in the selected five primary schools in Chegutu district.

\subsection{RESEARCH METHOD AND DESIGN}

Research design can be thought of as a matter of figuring out what kind of data is needed to answer a research question or a set of questions and specifying approaches for gathering or generating that data ( Gibson \& Brown, 2009:47).

The research method adopted for this study is the qualitative research paradigm with emphasis on a phenomenological research design. The purpose of qualitative research is to develop an understanding of individuals and events in their natural state, taking into account the relevant context (Marshall \& Rossman 2006:2; Patton, 2002:39). Qualitative research places an emphasis on natural settings (Marshall \& Rossman, 2006:2; Silverman, 2006:56; Creswell, 2007:18). The study is essentially descriptive in nature where the thrust is to describe the perceptions that teachers hold on multicultural education in the broad context of the phenomenological research paradigm.

Data collection methods consisted of the interview and focus group discussions. The interview has been defined as a conversation with a purpose (Khan \& Carnell in Marshall \& Rossman, 2006:101; Webb \& Webb in Legard, Keegan \& Ward, 
2008:145). It has been described as one of the main data collection tools in qualitative research and a good way of accessing peoples' perceptions, meanings, definition of situations and construction of reality (Punch, 2004:174). In this study, unstructured in-depth interviews were conducted with participants in their respective schools in line with the qualitative research paradigm.

A focus group discussion presents a more natural environment than that of the individual interview because participants influence and are influenced by others just as they are in real life (Kreuger \& Casey cited in Finch \& Lewis, 2008:171). Morgan in Punch (2004:177) argues that the hallmark of focus groups is the explicit use of group interaction to produce data and insights that would be less accessible without interaction found in the group. Focus group discussions were conducted with the participants in their respective schools. The focus group discussion was adopted in this study as a form of triangulation to guarantee trustworthiness of the research findings.

\subsection{DEFINITION OF TERMS}

Multicultural topics: According to Yao, Buchanan, Chang, Powell-Brown \& Pecina (2009:4), these are topics that pertain to the history, lifestyle and tradition of people different from the dominant group in a society, including ethnic minority people and people from other countries.

Gender: Gender is normally seen as socially constructed differences between men and women leading to masculine and feminine roles. Gender is the term for socioculturally constructed characteristics of masculinity and femininity (Somekh \& Lewin, 2011:323).

Ethnicity: According to Giddens (2009:1118), ethnicity refers to cultural values and 
norms which distinguish members of a given group from others.

Desegregation: Ornstein, Levin \& Gutter (2011:508), state that this refers to attendance by students of different backgrounds in the same school and classroom.

Social class: According to Kiter (2003: 87 ), it is the social, structural position that groups hold relative to the economic, social, political and cultural resources of a society.

Prejudice: Prejudice is a set of assumptions about an ethnic group which people are reluctant to change even when they receive information which undermines those assumptions (Browne, 2008:507).

Assimilation: This is the process by which individuals adopt the behaviours, values, beliefs and lifestyle of the dominant culture (Lasswell, Burma \& Aronson in Domnwachukwu, 2010:62).

Multiculturalism: This refers to the presence of many cultures in the same society. Portera (2011:16) states that it is a state in which human beings with ethnic, cultural and religious differences decide to live together in mutual respect and understanding.

\subsection{CHAPTER DIVISIONS}

This study is made up of five chapters as follows:

Chapter 1 presents an introduction to the study. It presents the statement of the problem, research objectives, research questions, limitations, demarcations, and definition of terms.

Chapter 2 presents a review of related literature relating to multicultural education. It provides the theoretical perspective that informs the study as well as literature related to the research problem.

Chapter 3 deals with the research methodology where issues such as the research 
design, data collection techniques; data analysis and presentation, population and sample, trustworthiness and ethical considerations are discussed.

Chapter 4 presents the research findings as well as data analysis and interpretation.

Chapter 5 gives the summary of the findings, conclusions and the recommendations of the study.

\subsection{CHAPTER SUMMARY}

Chapter 1 has presented an overview of the research problem and its setting. The background to the problem, statement of the problem, research questions and research objectives have been described. The importance of the study, limitations and demarcations, as well as a brief summary of the research design have been elaborated. The next chapter presents the theoretical framework as well as a review of related literature on multicultural education. 


\section{CHAPTER 2: LITERATURE REVIEW}

\subsection{INTRODUCTION}

The preceding chapter has presented the introduction to the study. This chapter presents the literature review. Marshall \& Rossman (2006:44) argue that a thoughtful and insightful discussion of related literature builds a logical framework for the research and locates it within a tradition of inquiry and a context of related studies. In this regard, through literature review, the study stays on focus. According to Gibson \& Brown (2009:34), exploring related research helps researchers to refine and extend their ideas and gives them a clearer sense of what has been achieved in the field in which they are proposing to work and how it has been achieved. This is important as previous research works tend to guide new efforts. In this context, literature review can be described as a conversation between the researcher and the literature (Marshall \& Rossman, 2006:44). This chapter presents the review of related literature on multicultural education under the following subheadings: theoretical framework, definition of multicultural education, approaches to multicultural education, challenges in multicultural education, and curriculum issues in multicultural education and concludes with a critique of multicultural education. This research sought to address the following main research question: What are the perceptions of primary school teachers' on the implementation of multicultural education?

\subsection{THEORETICAL FRAMEWORK}

This study is informed by the post modernist theoretical perspective. Postmodernism has become increasingly influential in sociology since the 1980s (Haralambos \& Holborn, 2013:14). Plumer (2010:62) concurs and states that postmodernism became a buzzword of the 1980s and helped shape the ways in which we now see different 
cultures as fragmented. This view has an important implication in the study of multicultural education. The fragmentation of different cultures demands an approach in education that appreciates and celebrates cultural diversity found in the school and classroom situations. Gall, Gall \& Borg (2007: 30) state that post modernism can be seen as a reaction to modernism. They further argue that postmodernism which developed as a reaction against modernism is a broad social and philosophical movement that questions the rationality of human action, the use of positivist epistemology and any human endeavour, e.g. science that claims progress in the search for truth. Postmodernism is built on the pioneering work of Derrida, Foucault and Roy (Beck, 1993), Lyotard and Baudrillard (Haralambos \& Holborn, 2013: 988) and Jameson (Ritzer (2009: 632). The postmodernist perspective provides the theoretical lens through which issues related to multicultural education are going to be viewed. The term postmodernism does not refer to a unified movement, several ideas feature prominently (Robson, 2011:16). Postmodernism began as an architectural and aesthetic movement that was dedicated to intermingling architectural styles, embellishing modernist architecture with borrowings from earlier periods (Agger, 2006:34). In other words, postmodernism was emphasizing the importance of accepting diversity although postmodernism arose in the arts and architecture, its effects cannot be limited to art and logically it should have an effect on education as well. (Kurt, 2006). Ornstein, Levine \& Guter (2011: 172) are of a similar opinion as they state that postmodernism exerts a pervasive intellectual influence today, especially on contemporary philosophy, education, women's studies and literature. Robson (2011:16) has observed that the movement known as postmodernism has permeated the arts, literature and architecture. Today these ideas are now becoming increasingly influential in social sciences, particularly sociology. Postmodernism 
therefore, has implications in the study of education, particularly multicultural education.

Postmodernism as a theoretical perspective has been defined and viewed differently by different scholars. Kneller cited in Ritzer, (2009:616) argues that there is nothing like a unified postmodern social theory but rather a plurality of different postmodern theories and positions. Robson (2011:16) concurs with Kneller in Ritzer (2006:616). He posits that although by no means a unified approach (postmodernism) several ideas feature prominently. Therefore, postmodernism can be seen as a rough composite of ideas from Lyotard, Derrida, Foucault and Roy (Beck, 1993). Post modernism can best be understood as a state of mind, and a critical self- referential posture and style; a different way of seeing and working rather than a fixed body of ideas; a clearly worked out position or a set of critical methods and techniques (Usher, 1995:3). In this regard, postmodernism can be seen as a philosophy that influences one's worldly outlook and perception of reality.

Lyotard defines postmodernism as 'incredulity towards meta- narratives' (Newall 2005). This definition gives an overview of the stance taken towards meta- narratives such as Marxism and functionalism. Lyotard in Haralambos \& Holborn (2013:989) states that meta-narratives of human emancipation, self-fulfilment and social progress are undermined by the advent of postmodernism hence an 'incredulity towards metanarratives' develops. Lyotard in Giddens (2009:755) argues that the great metanarratives of modernity, scientific truths, progress and history are now in decline. Advocates of postmodernism therefore argue that the era of big narratives and theories is over (Flick, 2009:12). Problems associated with the definition of postmodernism are to be expected since postmodernism places emphasis on 
differences in society. Jencks in Slattery (2006:23) is of the view that postmodernism can only be defined by recognising that postmodernism is in continual growth and movement; no firm definitions are possible at least until it stops moving. Hartman (1996) says that postmodernism is an anti Enlightenment position where its adherents believe that what has gone as ' modernism' is inappropriately dependent on reason, rationalism and wisdom and is, therefore, inherently elitist, non- multicultural and therefore oppressive. There is need for a broad inclusive perspective that incorporates divergent views.

Slattery (2006:17) is of the view that postmodernism is built on a number of perspectives which include the following:

- an emerging historical period that transcends the modern industrial technological age;

- a contemporary aesthetic style in art and architecture that is eclectic, kaleidoscopic, ironic, and allegorical;

- a philosophical movement that seeks to expose the internal contradictions of meta-narratives by deconstructing modern notions of truth, language and power;

- an acknowledgement and celebration of otherness, particularly from racial and gendered perspectives.

Jameson (1991) in Cohen, Manion \& Morrison (2011:27) argues that postmodernism has several distinguishing hallmarks which include:

- the absence of 'grand narratives' (meta-narratives) and grand designs, laws and patterns of behaviour;

- the valorization of discontinuity, difference, diversity, variety, uniqueness, subjectivity, distinctiveness and individuality;

- the importance of temporality and context in understanding phenomena: meanings are rooted in time, space, cultures, societies and not universal across these;

- the celebration of depthlessness, multiple realities and the rectitude of individual interpretations and meanings;

- relativism rather than absolutism in deciding what constitutes worthwhile knowledge; and the view of knowledge as a human social construct. 
Beck (1993) points out that postmodernism as a general cultural phenomenon has such features as the challenging of convention, mixing of styles, tolerance of ambiguity, and emphasis on diversity, acceptance (celebration) of innovation and change and stress on the constructedness of reality.

These views discussed above emphasise the importance of embracing differences and diversity in society. Ballantine \& Hammack (2012:18) argue that postmodernists call for respect and understanding of human differences. The emphasis on diversity in society provides the rationale for the adoption and implementation of multicultural education.

Analysed within the context of this definition, postmodernism can be seen as a theoretical perspective that emphasises the acceptance of diversity in society (Taylor, Richardson, Yeo, Marsh, Trobe \& Pilkington, (2011:401). Such diversity has to be acknowledged and celebrated.

Postmodernism is characterised by poly-vocality, which suggests that everything can be said differently, indeed in multiple ways that are not inherently superior or inferior to one another (Bakhtin in Agger, 2006:34). This observation fits in with the ideas and concerns of multicultural education where the anchoring point is the need to accommodate learner diversity in its entirety in the education system. Education has always been seen as key to the management of cultural diversity (Joshee, Peck, Thompson, Chareka \& Sears, and 2010:1). This means the curricular should be interdisciplinary, and represent diverse interests, that universal skills such as critical theory should be stressed and that individual children should reach a common goal by different paths (Ballantine \& Hammack, 2012:19). To emphasise the importance of diversity, Hartman (1998) states that the phrase postmodernism implies a national 
state challenged by new worldviews such as feminism, multiculturalism, environmentalism; old scientific certainties are called into question, and are replaced with cybernetic ones. The reference to feminism and multiculturalism in this definition once more highlights the importance of recognising and acknowledging differences. This recognition and acknowledgement of differences should permeate the education system. In the end, postmodernism rejects the assumptions of the Enlightenment, modifying the discourses of modernity (Waugh, 1992 in Punch, 2004:144) and challenging previous conceptions of reality and knowledge.

Postmodernism is relevant to sociology as well as the practice of multicultural education. From the perspective of postmodernism, the world is viewed as pluralistic, split into a multitude of sovereign units and sites of authority, it emphasises indeterminacy, euphemerality, fragmentation and reinvention along with diversity, the celebration of difference 'a tolerance of ambiguity and mixing of styles' (Punch 2004:144). Slattery (2006:23) points out that whether critics like it or not, society has become a global plurality of competing subcultures and movements where no one ideology and episteme (understanding of knowledge) dominates. Along the same line of thought, Bauman (2007:36) argues that in postmodernism there is emphasis on multiple pathways and plurality, on diversity and difference; and on partiality of all knowledge.

Indeed, Ritzer (2009:617) observed that postmodernists argue that it is the difference that lies at the heart of the world; and that the goal becomes the study of differences rather than the search for unity. Ballantine \& Hammack (2012:18) state that postmodernism honours human diversity, including the variations and ambiguity in the way different people learn and see the world. 
Lyotard (1984) in Ritzer (2009:617) argues, 'let us wage war on totality; let us activate the differences'. The emphasis on differences means that society is plural in character and this makes the practice of multicultural education imperative. This becomes significant when viewed against the background of multicultural education, which is seen as an attempt to accommodate society's multicultural character. Therefore postmodern theories of education call for teachers and students to explore differences between what may seem like inherently contradictory positions in an effort to achieve understanding respect and change (Sadovnik, 2007:15).

In the words of Lyotard (1984) in Ritzer (2009:617), postmodern knowledge is not simply a tool for authorities; it refines our sensitivity to differences and reinforces our ability to tolerate the incommensurable. The search to discover the way social meanings are constructed has highlighted the importance of difference and the tendency for people to define those they see as different ('other') in opposition to their own perceived strengths (Marchand \& Parpart, 1995:3).

Huyssens (1984) in Harvey (2001:176), advises that postmodernism has been particularly important in acknowledging the multiple forms of otherness as they emerge in differences in subjectivity, gender and sexuality, race and class, temporary (configurations of sensibility) and spatial geographic locations and dislocations. Accommodating differences lies at the heart of multicultural education. Failure to accommodate such differences in the education system results in the creation of the 'other' who more often than not, is not only regarded as different but also inferior. Therefore, there is in postmodernism acknowledgement and celebration of otherness, particularly from racial and gendered perspectives (Slattery, 2006:24). According to 
Daniel (2002), education performs a number of functions in the context of postmodernism:

... education must be a window to the world; it must draw out the potential of each individual and develop the skills and knowledge that will help her to find fulfilment in the various fields of life. Secondly, education must build bridges between individuals and communities; it must help people learn to live together, to create methods and social relationships and to work together in communities for the common good. These views are subsumed in the aims and goals of multicultural education where the thrust is to accommodate and appreciate differences in terms of culture. At the same time education should help the individual to realise his or her potential to the maximum as well as promoting intercultural understanding.

The nature of social reality is questioned by postmodernist scholars. Observations in this area highlight the plural character of social reality. Gubrium \& Holstein in Silverman (2010:108) assert that the common theme of postmodernism is how and through what cultural forces we come to understand and accept certain representations as being 'true', 'legitimate' or acceptable. This becomes very important, considering the view that reality is socially constructed. Beck (1993) argues that reality does not exist objectively 'out there', it is part of human creation, and is in part culture dependent, dynamic and changing over time. Postmodernism holds the view that realities are multiple, all are subject to endless formation, reformation, construction and reconstruction, including those of the self, family and the groups to which we are aligned (Grbich, 2004:26). Postmodernists therefore question the power relations and the political rhetoric embedded in the representations and constructions of social reality (Silverman, 2010: 108). This observation has an implication for multicultural education. A multicultural curriculum seeks to show learners that plural realities exist in society.

The practice of education has to accommodate multiple realities held by learners. Corbin \& Holt (2011:113) posit that in a postmodern world nothing is 'real' and 
everything is subject to multiple viewpoints. The concept of truth is also subjected to scrutiny. An analysis of postmodern views shows that truth is not an absolute phenomenon. Rather, truth is relative. Kvale (1995:2) in Robson (2011:16) argues that moderate postmodernists reject the idea of universal truth; they are likely to accept 'the possibility of specific, local, personal, and community forms of truth'. According to Lyotard, postmodernism is at least sceptical at the very possibility of finding one story that explains the world for others (Newall, 2005). Truth is seen as simply a partial, localised version of reality transformed into a fixed form in the long process of history (Focault in Marchand \& Parpart, 1995:3).

The postmodernist view of knowledge provides further insight into the relevance of multicultural education. By its very nature a multicultural school curriculum should enable learners to realise that knowledge is socially constructed and, therefore, relative. According to Haralambos \& Holborn (2013:14) postmodernists argue that knowledge is essentially subjective it expresses viewpoints that can never be proved to be correct.

Geertz in Flick (2009:12) states that in postmodernism, knowledge and practice are studied as local knowledge and practices. Ornestein, Levine \& Guter (2011: 172) are of a similar opinion as they state that as a human construction, our knowledge is always tentative, conjectural and subject to ongoing revision. Different forms of knowledge should then be incorporated into the school curriculum as a way of accommodating cultural diversity. Lather in Slatterry (2006:27) contends that society is in the midst of a shift away from the concept of an objective, knowable, factual world 'out there' towards a concept of constructed worlds where knowledge is contested and partial. Silverman (2010:108) is of a similar opinion and states that the 
most important insight of postmodernism is an emphasis on the rhetorical and constructive aspects of knowledge, that is, the realisation that facts are socially constructed in particular contexts. This view is shared by Lyotard in Kirby et al. (1997:719) who points out that all knowledge is relative; all is as good as any other. Kincheloe (1993) cited in McGovern (1999:17) posits that a foundational principle of postmodern theory states that there is no universal knowledge beyond that which is developed within political, ideological and economic conditions of particular social and cultural formations. In line with this view, the school curriculum should therefore reflect the plural character of knowledge. At the same time, Lyotard sees a close relationship between knowledge and power and argues that knowledge and power are two sides of the same coin (Kirby et al. 1997:719; Sarup, 1993:132). Aronwitz \& Giroux (1991) argue that what meanings are considered the most important, what experiences are deemed the most legitimate, and what forms of writing and reading matter, are largely determined by those groups who control the economic and cultural apparatus of a given society. Questions such as: Who decides what knowledge is? and Who decides what needs to be decided; take centre stage (Sarup, 1993:132).

Foucault also makes important observations on the relationship between knowledge and power (Appelrouth \& Edles, 2008: 643; Ritzer, 2009: 630). His views on the relationship between knowledge and power are similar to Lyotard's cited in Kirby et al (1997:719). In Foucault's view, knowledge is never separate from power but is a means of exercising power by constituting people as subjects and then governing the subjects with the knowledge (Ritzer 2009: 630). Kirby et al (1997:718) is of a similar opinion as they argue that according to Foucault power and knowledge directly imply one another; that there is no power relation without the correlative constitution of a 
field of knowledge. Sadovnik (2007:15) is of a similar opinion and argues that postmodernist theorists believe that all social and political discourses are related to structures of power and domination. These observations are similar to the Marxist view where Marx argues that in every historical epoch dominant ideas are ruling class ideas. It follows that other knowledge forms are down played due to lack of power by their members. Young, in Haralambos \& Holborn (2013:643), argues that those with power are able to impose and legitimise their own knowledge forms. This represents discrimination in terms of class. Knowledge has to be viewed in the context of power and consequently the relationships between writers, readers and texts have to be understood as sites at which different readings, meanings and forms of cultural production take place (Aronwitz \& Giroux, 1991). Thus in society, certain groups tend to be marginalised in terms of the validation of their different knowledge forms. Multicultural education meets this challenge by celebrating the diverse forms of knowing found in society through the celebration of differences.

According to Slattery $(2006: 27)$ postmodern curriculum development therefore begins with the deconstruction of master narratives that impose knowledge through unequal power relations, where students must be subordinate and submissive to teachers. It then moves to the emancipation of both teachers and students who have been disempowered by this structure. A multicultural school curriculum seeks to let learners appreciate that knowledge is socially constructed and that what is taken as valid knowledge is just a selection from a number of possible options available. Constructivism becomes an important concept in multicultural education. Ornstein, Levine \& Guter (2011:172) state that postmodernists and constructivists agree that we make or construct our beliefs about knowledge from our experience of interacting 
with our environment. Newall (2005) argues that we do not receive knowledge through our senses or through discussion; instead we build it up for ourselves from these and other inputs we construct knowledge rather than discover it.

Lyotard in Marchand \& Parpart (1995:2) asserts that a struggle for universal knowledge is abandoned; a search has begun for previously silenced voices for the specificity and power of language (s) and their relation to knowledge, context and loyalty. Mustafa (2006:93) expresses a similar opinion when he argues that education from this time forth should appeal to dissimilar voices and the voices of 'put aside' should be heard in all educational processes as well. Thus, postmodern theory becomes identified with the critique of universal knowledge and foundationalism (Sarup, 1993:132). In this regard, humanity is moving to a new zone of cognition with an expanded concept of the self in relation (Slatterry, 2006:17). Therefore, postmodern analysis includes the examination of assumptions and concepts associated with modernity, as well as the exploration of forms of knowledge, practices and experiences that have not received recognition or appreciation within the dominant framework of knowledge creation and legitimation (McGovern, 1999:17). The education system, through the school curriculum, has to accommodate the plural character of knowledge found in society.

The concept of meta- narratives is also criticised by postmodernism. Postmodernism rejects the grand meta-narratives (Bauman, 2007:18; Daniel, 2002; Aronwitz \& Giroux, 1991; Walliman, 2011). Grand issues of the past, whether liberal or Marxist, have been dismissed as the product of an age when Europeans mistakenly believed in their own invincibility, meta- narratives of such thought are no longer seen as the 'truth' but simply as privileged discourses that deny and silence competing dissident 
voices (Lyotard in Marchand \& Parpart, 1995). Ballantine \& Hammack (2012:18) are of the view that while modernism attempted all encompassing explanations of the world and progress based on science and technology, postmodernists stress the importance of theories relevant to local situations. Generally such theories are used by groups of people to impose their ideas on other people (Haralambos \& Holborn, 2013:15). The Centre for a Post-Modern World 1990, in Slattery (2006:20) posits that humanity must transcend modernity in ways that include: a post Eurocentric view that the values and practices of European tradition will no longer be assumed to be superior to those of other traditions or forcibly imposed upon others but combined with the wisdom embedded in all other cultures. It follows that the explanation of phenomena in universal terms is rejected as post modern thinkers reject universal, simplistic definitions of social phenomena, which they argue essentialise reality and fail to reveal the complexity of life as a lived experience ( Marchand \& Parpart, 1995:3). Thus the values and practices of other traditions should be incorporated into the school curriculum. In this regard, in postmodernism the accent shifts towards theories and narratives that fit specific, delimited, local, historical structures and problems (Flick, 2009:19).

In summing up the key ideas of postmodernism, Punch (2004: 141) makes the following observations:

... postmodernism greets all the grand narratives of western civilisation with increasing incredulity; knowledge is seen as constantly changing and is partial, fragmented, local rather than general and universal; different sources of knowledge are valued and acknowledged; the world is viewed as pluralistic; it emphasises indeterminacy, euphemerality, fragmentation and reinvention along with diversity and the celebration of differences.

However, postmodernism as a theoretical perspective has attracted criticism. The major criticism is on the stance taken by postmodernist scholars such as Lyotard 
(Giddens, 2009:755; Haralambos \& Holborn, 2013: 989; Sadovnik, 2007:15; Punch, 2004:143) on grand meta-narratives. There is the view that whilst postmodernism rejects these meta-narratives it is in itself a meta-narrative. Strinati in Kirby et al (1997: 417 poses the following question: How can postmodernist be so confident in announcing the end of modernist beliefs unless implicitly they argue from the vantage point of their own meta-narrative. Skeggs (1991) in Kirby et al (1997) concurs and argues that theorists like Lyotard claim that one purpose of postmodernism is to destroy meta-narratives (grand theories) yet he simply constructs another called postmodernism. Whilst these criticisms are valid there is need to observe the differences in the postmodernist position. Flick (2009:19) argues that in postmodernism the accent shifts towards theories and narratives that fit specific, delimited, local, historical situations and problems. It is this thrust that makes postmodernism relevant in the effective practice of multicultural education through the accommodation and celebration of diversity.

Another criticism emanates from the character of postmodern theory. There is an argument that postmodernism is not a unified social theory but rather a plurality of different postmodern theories and positions (Kneller, in Ritzer, 2009: 616). Robson (2011: 16) concurs and posits that several ideas feature prominently in postmodernism. As a result postmodernism is difficult to map (Punch, 2004: 143). This weakness can be overcome by looking at the specific views of the different scholars in the field such as Foucault (Appelrouth \& Edles, 2008: 643; Ritzer, 2009:630) and Lyotard (Marchand \& Parapart, 1995:2; Kirby, et al 1997: 719) among many other scholars. 


\subsection{HISTORY OF MULTICULTURAL EDUCATION}

Gollnick \& Chinn (2012:27) argue that in the United States of America, multicultural education is not a new concept as it is a relatively new name for concepts that have existed since the 1920s. Grant (2008:2) concurs and argues that one effective way to examine the historical developments and evolution of multicultural education is to view it as a chain of linked actions (for example Movements, court decisions, legislation, publications, constitutional mandates, code of conduct) that embrace principles of social justice to support the elimination of poverty, racism, classism, religious bigotry and sexism in the United States. In his view, this makes it difficult to assign a specific date for the birth of multicultural education. In Grant's (2008:3) view, multicultural education was born as a result of the impact of education on African Americans, Native Americans, Asian Americans and Mexican Americans. According to Grant (2008:2), the effect of education was to conscientise the different groups on their position in society and this enabled them to resist and survive oppression and racism. Banks (1991), in Grant (2008:3), identifies twenty-four publications from 1882 to 1954 that promoted the growth of multicultural education. These publications which dealt with serious social justice and human rights inequities include: George Washington Williams (1892), History of the Negro Race in America; and W.E.B. Dubois' (1899) The Philadelphia Negro. Hence, Nieto (2009:82) argues that the work of African American intellectuals laid the foundation of the Civil Rights Movement of the 1950s that led to ethnic studies and later multicultural education.

From Grant's (2008:4) point of view two movements had a direct impact on the emergence of multicultural education in the United States of America. These are the Intercultural Education Movement and the Intergroup Education Movement. These 
movements influenced the emergence of multicultural education long before the Civil Rights Movement of the 1960s. The Intercultural Education Movement provided knowledge about ethnicity, immigration, assimilation and, social mobility and prejudice. The Intergroup Education Movement came about as a result of the Second World War that saw many blacks migrating to the cities. This migration brought about changes in the demographic composition of cities, contributing to racial tensions. According to Taba et al. (1952), in Banks (2004:20), the aim of the Intergroup Education Movement was to minimise ethnic cultures and affiliations, to help students become mainstream and effective Americans and to teach racial and ethnic tolerance. Therefore, the Civil Rights Movement of the 1960s can be seen as a culmination of a process that had begun a long time before. However, there appears to be a general consensus among scholars that multicultural education became more pronounced in the United States in the 1960's and 1970's ( Banks , 2009 ; Cushner, McClelland \& Safford, 2008:20; Lemmer, Meier \& van Wyk 2006: 2; Haynes Writer, 2008:3; Zimmerman, 2004: 2; Yao, Buchanan, Chang, Powell-Brown \& Pecina 2009:3 Vandeyer, 2003:194; Sleeter \& McLaren 2011: 17; Nieto, 2009: 18).

As alluded to above multicultural education originated in the United States out of the Civil Rights Movement in the late 1960s as various ethnic groups challenged and confronted unconscionable oppressions and inequities enacted upon them historically and continued through individual, institutional and structural discrimination (Haynes Writer, 2008:3). Multicultural education in the United States, United Kingdom, Australia and Canada has its roots in the problems of slavery, immigration as well as the slavery, colonisation and the subjugation of the indigenous populations (Vandeyer, 2003:194). As a consequence of these experiences, the indigenous Indian 
population found itself being displaced in the United States of America. Multicultural education is usually considered in the context of global diversity, migration and the displacement of indigenous peoples (Banks, 2009 in McKinney \& Soudien, 2010:6; Banks 2009:5). Nkomo \& Vandeyer (2009:6) are of a similar opinion. They state that diversity in most contemporary societies has its roots in colonial times as imperial powers typically European carved up the Asian, Latin America and African continents, for example new countries were created with little regard to their traditions and social or cultural integrity. In New Zealand, for example, colonial assimilation policies were responsible for a rapid decline in Maori language and culture (Mugisha, 2013:2). These observations have relevance in the study of multicultural education in Zimbabwe. Colonialism and colonial policies and practices resulted in migration not only from outside the continent particularly Europe but also from other neighbouring countries in Southern Africa such as Zambia, Mozambique and Malawi among others. This contributed to the cultural diversity of the country.

The development of multicultural education in the United States can be traced through three successive waves. The United States of America is credited with being a leader in the field of multicultural education owing to the Brown versus Board of Education ruling of 1956 ( Gay, 2004; and Grant, 2004 cited by Yao , Buchanan, Chang, Powell-Brown \& Pecina, 2009:6;).The Brown decision challenged citizens of the United States to take responsibility for eliminating divisions among themselves (and) to accept both their differences and similarities ( Gay, 2004 cited by Yao, Buchanan, Chang, Powell- Brown \& Pecina, 2009; Banks 2004:24). The Supreme Court v. Topeka Board of Education (1954) ruled that the segregation of blacks and white learners was unconstitutional (Manning \& Baruth, 2008:12) and this paved way for 
desegregation in the education system. The Brown versus Board of Education ruling represented a watershed in the development of multicultural education as it provided an impetus in the analysis of social inequities. Thus the significance of the Brown v. Board of Education lies in the fact that for the first time civil and voting rights given to Africans under the law carried significance as the law now gave them equal access to educational facilities and resources (Domnachukwu, 2010:87).

During the first wave of the Civil Rights Movement in the 1960s, African Americans began to challenge discrimination and segregation in public institutions. Banks (1994) cited in Lemmer, Meier \& van Wyk (2006:4) states that the major goal of the Civil Rights Movement was to eliminate discrimination in all spheres of society, especially in employment, housing and education. Education as a social institution was not spared from demands of equity. Civil Rights activists demanded reforms in education; up to the 1950s, education for the different racial and cultural groups was not only separate but also unequal (Lemmer, Meier \& van Wyk, 2006:3). Civil Rights activists demanded curricular reform to enable their achievements and contributions to be reflected in curricular texts. They also recommended the hiring of African American teachers as well as the right to administer their own schools. Ethnic groups demanded that schools hire more black and brown teachers and administrators so that their children could have more successful role models, they also demanded community control of schools in their neighbourhoods and for the revision of textbooks to make them reflect the diversity of people in the United States ( Banks , 1994; Gorski 1999 ).

As a result of these activities, educational reform was carried out in the following areas: desegregation, multicultural and bilingual education, mainstreaming students with special needs into regular classrooms and gender sensitive education (Cushner, 
McClelland \& Safford, 2008:35). The reform effort was also aided by the Civil Rights Act of 1964. This Act prohibited public institutions receiving state and federal funds from assigning students to public schools based on their race, colour, religion, or national origin (Grant (2008:7). Franklin \& Moore (1988), in Banks (2004:24), call the Civil Rights Act the most far reaching and comprehensive law in support of racial equality ever enacted by Congress. Other Acts also aided the development of multicultural education. These include the passage of the Voting Rights Act of 1965 that restored voting rights to any eligible citizen, and the Civil Rights Act of 1968 that banned discrimination in the sale or rental of housing (Grant, 2008:7).

During the second wave, the apparent success of the Civil Rights Movement encouraged other groups who were also marginalised in American society to make similar demands. These groups included Mexican Americans, Puerto Ricans, American Indians and Asian Americans (Banks, 1993:10).

The third wave of multicultural education involved women and people with disabilities who were also encouraged by the success of the Civil Rights Movement and the activities of other victimised groups. In the late 1960s and early 1970s, the women's rights movement pushed for educational reform, demanding curricular more inclusive of their histories and experiences (Gorski, 1999:1). The result of all these efforts was the initial practice of multicultural education where it was realised that a broad based approach to accommodating cultural diversity was needed.

The history of the implementation of multicultural education can be categorised into four phases (Banks, 1993:9; Gollnick \& Chinn, 2012:28; Lemmer Meier \& van Wyk, 2006:4; Vandeyer 2003:195; Manning \& Baruth, 2008:12). 
The first phase has been described as the ethnic studies phase. At first, attention was given to the development of "ethnic study courses which were generally single group studies and usually electives chosen by learners who were members of the group on whom the course was based ( Lemmer, Meier \& van Wyk, 2006:4). Learners who participated in ethnic studies were members of those groups being studied. Ethnic study programmes focused on the various ethnic histories and cultures, with the main objective of providing students with insight and instilling pride in their own racial and ethnic backgrounds and only one ethnic group was studied ( Gollnick \& Chinn, 2012:28). Ethnic study courses adopted a 'celebratory' approach, and focused on one ethnic group termed the 'Single Group Studies' (Sleeter \& Grant, 1994 cited in Vandeyer 2003:195). According to Nieto (2009:84) the ethnic study movement began with the recognition that African American children had long been educationally neglected and abused.

The second phase has been described as the multiethnic studies phase. The multiethnic study phase came about as a result of a realisation that students from the dominant culture also needed to learn about the history and culture of oppressed groups. Therefore, the ethnic study programme was expanded into multiethnic studies. Multiethnic education was designed to bring about structural and systemic changes in the total school environment to increase educational equality for all students (Nieto 1995, in Vandeyer 2003: 195). A number of changes were made: teachers were encouraged to develop curricular that included the contributions of oppressed groups along with those of the dominant group; textbooks were rewritten to represent more accurately, the multiethnic nature of the United States, and learners were to be exposed to perspectives of oppressed groups through literature, history, 
music and other disciplines integrated throughout the regular school programme. Multiethnic studies phase provided courses that focused on several minority groups and viewed experiences from comparative perspectives (Manning \& Baruth, 2008:12). Sleeter \& McLaren (2011:17) further note that multiethnic education was used to bridge racial and ethnic groups.

The third phase in the history of multicultural education emerged as a result of the views of other groups who felt they were oppressed (Banks, 1993:10). Vandeyer (2003:195) says that the third phase emerged when other groups who viewed themselves as victims of the society and schools, such as women and people with disabilities demanded the incorporation of their histories, cultures and voices into the curricular and structure of the schools, colleges and universities. It can be seen that the approach to multicultural education was expanding in scope to accommodate the diversity found in the American society.

The fourth phase corresponds with the current phase of multicultural education. Lemmer, Meier \& van Wyk (2006:4) argue that many educationists felt that the emphasis on ethnic studies was insufficient and unlikely to bring about equal educational opportunity. They further state that many educationists believed that a more comprehensive, all embracing approach to education was needed which addressed not only racial and cultural inequalities but also socio economic and gender based inequalities. Manning \& Baruth (2008:12) argue that some educators became interested in an even broader development of pluralistic education that focused on reform of the total school environment. This phase is concerned with multicultural education. The current phase consists of the development of theory, research and practice that interrelate variably connected to race, class and gender (Banks \& Banks, 
1993; Grant \& Sleeter, 1986, cited by Banks, 1993:11). This phase is applicable to a number of countries including Zimbabwe.

Manning \& Baruth (2008:12) add a further fifth phase in the development of multicultural education. They state that the fifth phase is a slowly occurring process that includes strategies designed to increase the pace and scope of institutionalisation of multiethnic and multicultural education within schools. This phase appears to be concerned with implementation of multicultural education. The practice of multicultural education in Zimbabwe can also be located in this phase.

The developments in the field of multicultural education, which began in the United States of America, were felt in other western countries such as Canada, Australia and Britain (Lemmer, Meier \& Van Wyk, 2006:4). Mattai, in Vandeyer (2003:195), argues that discursive shifts have also occurred inside the movements. She states that although racism was the main concern of the Civil Rights Movement of the 1960s, the discourse of multicultural education has shifted away from racism towards culture, away from systemic oppression and towards attitude change. Thus, the focus of multicultural education is on the accommodation and celebration of cultural diversity in society as well as the tolerance of those who are culturally different.

\subsection{DEFINITION OF CULTURE AND MULTICULTURAL EDUCATION}

In order to put the concept of multicultural education into its proper perspective, there is a compelling need to analyse the concept of culture. Culture defies a single universal definition and has therefore been defined in numerous ways. In the framework of postmodernism, this is acceptable as there is an emphasis on diversity,

difference, plurality and euphemerality. Keating, Martin \& Szabo (2002) cited in Dunne (2011:610), point out that as far back as 1952, Kroeber and Kluckhohn 
identified more than 160 definitions of culture. This absence of consensus on a definition has immediate consequences not only for how culture may be operationalised for research purposes, but on how ideas derived from culture such as intercultural curriculum should be conceptualised ,implemented and assessed (Dunne, 2011:610).

Ndura (2004) in Ndura, (2006:2) defines culture as the acquired complex knowledge that individuals and communities use to affirm and interpret the values, beliefs, customs and practices that distinguish them from other people and groups in society. Taylor in Bennet, ( 2003:42 ), defines culture as " that complex whole which includes knowledge, beliefs, art, morals, law, custom and any other capabilities and habits acquired by man as a member of society". Manning \& Baruth (2008:44) are of the view that culture refers to peoples' values, language, religion, ideals, and artistic expressions, patterns of social and interpersonal relationships, and ways of perceiving, behaving and thinking. Brown (1963) in Grant \& Brueck, (2011:3) states that culture is a body of common understandings ... (that are) the sum total and... arrangement of... (a) groups' way of thinking feeling and acting. Ngara (1991) in Viriri, (2003:3) argues that culture is the expression of people's social activities in relation to their struggle with their environment, with the elements and with human forces that threaten their survival or their way of life; culture is born in the struggle to survive and to conquer nature and human fetters. A common theme that runs through all these definitions is that culture can be seen as the total way of life of a given community. Culture refers to a human made part of the environment as opposed to aspects that occur in nature (Cushner, MacClelland \& Safford, and 2008:61). It 
provides a blueprint that governs human interaction in society as well as the interaction with both the physical and natural environment.

Ngugi wa Thiongo cited by Odora-Hoppers, (1998) summarises the concept of culture by stating that:

A people's culture is the carrier of values evolved by the community in the course of their economic and political life. The values they hold are the basis of their world outlook, the basis of their collective and individual image of self, their identity as a people who look at themselves and to their relationship to the universe in a certain way. (Vandeyer, 2003:193).

Mazrui ( 1990) in Ndolera ( 2005) identifies seven functions of culture, it provides people with: lenses of perception and cognition, motives of behaviour, criteria for evaluation, a basis of identity, a mode of communication, a basis of stratification and a system of production and consumption (Nyoni \& Nyoni, 2010: 148).

Culture therefore spells out the lifestyle of a group; it is unique to a particular social group. To this end, Galtung (1996) in Vandeyer, (2003:193) argues that the imposition of one's cultural code onto another people's culture is a debilitating experience that leads to gross alienation or 'culturocide'.

The way people behave, think and perceive reality is, to a great extent, influenced by their cultural upbringing. People from different cultural backgrounds view social reality in different ways. Culture has two components namely, material culture and non- material culture. Material culture is tangible and consists of things that do not occur naturally in the physical environment. For example, artefacts such as automobiles, mortars, winnowing baskets and many others are made by people to provide solutions to the problems of living. Non-material culture is intangible and includes language, norms, values, belief systems and knowledge forms. This part of culture has to be learnt through the process of socialisation. Therefore, culture gives 
an individual an identity that has to be validated in society. A multicultural school curriculum needs to validate this cultural identity. Vandeyer (2003:193) argues that an ideal form of multicultural education is one that does not only recognise and acknowledge diversity, practices, tolerance and respect of human rights but also works to liberate cultures that have been subjugated. This means that all cultures have to be given equal status in the classroom and school environment particularly those that have been traditionally marginalised. This is so because culture forms the basis of the individual's identity.

The definitions of culture referred to earlier on tend to point towards the fact that in any given society culture is not homogenous. Rather, it is heterogeneous. This heterogeneity arises as a result of the presence of different social or ethnic groups who, whilst subscribing to the dominant or mainstream culture retain certain norms and values that are peculiar to their social or ethnic group. This leads to their identification as a distinct group. These groups form society's sub-cultural groups. A subculture is a social group with shared characteristics that distinguish it, in some way, from the larger group in which it is embedded (Cushner, MacClelland \& Safford, 2008:62). Banks (2009:11) is of the view that micro cultures or subcultures share most of the core values of the nation state but these values are often mediated by the various micro cultures and are interpreted differently within them. Ethnicity should be seen as a key factor in the formation of micro cultures or sub- cultures.

In the Zimbabwean context, the following indigenous ethnic groups can be identified: Zezuru, Kalanga, Manyika, Korekore, Ndebele, Tonga, Shangaan, Karanga, Nambya, Sotho and others. To this list non- indigenous black African groups who came into the country as a result of colonial migrant labour policies such as the Chewa from Malawi 
and others from Zambia and Mozambique as well as Europeans and Asians should also be added. Thus, Zimbabwe is a diverse multicultural and racial society that has co-existed peacefully for centuries owing to the dignity given to various ethnic groups within our communities (Ministry of Education, Arts, Sports \& Culture, and 2004:4).

A society with many subcultures is a multicultural or plural society and is characterised by multiculturalism. Multiculturalism seeks to create an environment in which the different sub cultural groups accommodate and tolerate one another (Lemmer, Meier \& van Wyk 2006:4; Bennet, 2003:14). Multiculturalism recognises and accepts the rightful existence of different cultural groups and views cultural diversity as an asset and a source of social enrichment rather than as a disability or a social problem (Lemmer, Meier \& van Wyk 2006:4). In a culturally pluralistic society, members of different ethnic groups are permitted to retain many of their cultural traditions such as language, religion and food preferences as long as they conform to those practices deemed necessary for social harmony and the survival of society as a whole ( Bennet, 2003:20). Multiculturalism encourages cultural preservation.

Hernandez in Pai \& Adler (1997:107) defines cultural pluralism as:

... a state of equal coexistence in a mutually supportive relationship within the boundaries or framework of one nation of people of diverse cultures with significantly different patterns of beliefs, behaviour, colour and in many cases with different languages. To achieve cultural pluralism there must be unity within diversity.

The concept of multiculturalism brings cultural diversity to the fore. Most if not all societies are characterised by cultural pluralism. This pluralism should be reflected in the content and practice of education. Postmodernism scholars argue that there should 
be celebration of diversity and difference in any society (Bakhtin in Agger 2006:34; Bauman 2007:36).

The classroom should be viewed as an environment, not only characterised by cultural diversity, but also as a culturally saturated environment. It is the responsibility of educators to ensure that cultural differences are viewed in an egalitarian mode rather than a superior- inferior mode. All cultures should be validated in the classroom because culture forms the basis of the individual's identity. From a multicultural perspective, the task of the teacher is to respect the culture the child brings from home, to guide the students' learning of the basic skills and attitudes of the dominant culture, and to nourish the students' self esteem (Campbell, 1996:26). Murrell (2001) in de Souza (2010:9) argues that teachers must become "community teachers" by acquiring knowledge of the culture of the students they serve so they can draw on this knowledge to create core-teaching practices necessary for effectiveness in diverse settings. Classrooms that value students and their culture foster feelings of self worth, a sense of belonging and higher academic performance (Heath, 1983; Nieto, 1999; Thomas, 1998; cited by Ndura, 2006:1).

Culture then plays an important part in the education of the child. The rights of children to education in a cultural context familiar to them are also found in the Conventions on the Rights of Indigenous People and Preservation of Indigenous Knowledge (United Nations 2005, cited by Shizha, 2007:303). The importance of cultural diversity is also expressed in the UNESCO (2005:3) Convention on the Protection and Promotion of Cultural Expressions. Some of the objectives of this convention are: to foster inter-culturality in order to develop cultural interaction in the spirit of building bridges among people and to promote respect for the diversity of 
cultural expressions and raise awareness of its value at the local, national and international levels. Education through a multicultural school curriculum goes a long way in the achievement of these objectives that emphasise the need to uphold cultural diversity in society.

Similar to the concept of culture, multicultural education has been defined in a number of ways. The concept is derived from multiculturalism. Admittedly, it is a difficult concept to define due to the number of approaches that have been suggested for its implementation. The concept of multicultural education today is considered multidimensional, embracing issues such as race, ethnicity, gender, socio economic status, disability and equal opportunity (Banks, 2001; Pang, 2001 in Gwirayi, 2010:13). In fact, there is a problem with coming up with a single definition with a universal appeal.

According to Manning \& Baruth (2008:47), one debate among multiculturalists concerns the inclusiveness of the definition of multicultural education. Pope (1995) in Manning \& Baruth, (2008:47) argues that one side favours an inclusive definition of multiculturalism (including race, ethnicity and sexual orientation); the other side supports an exclusive definition, or one favouring ethnic and racial minorities. It should be noted that multicultural education seeks to address diversity in its entirety. As such, a broad based all encompassing definition is required. Multicultural education sets out to create equal educational opportunities for students from diverse racial, ethnic, social class and cultural groups by acknowledging difference (Vandeyer, 2010:345). Although sexual orientation is included in the definition and practice of multicultural education in western countries, it tends to present problems 
particularly in countries such as Zimbabwe where gay rights are not recognised, further disadvantaging gay learners.

Multicultural education presents difficulties in terms of definitions. According to Zimmerman (2004:1), a survey of the literature (Bruch et al. 2004; Banks 2002; Bennet 2003; Gollnick \& Chinn, 2002; Grant \& Gomez, 2001; Hernandez, 2001; Nieto, 2000; Sleeter \& Grant, 1999; Tiedt \& Tiedt, 2005) indicates the complexity, and even contradictions of creating a definition for multicultural education without going into how to teach or implement it. Sleeter \& Grant in Banks (1993:4) noted lack of consensus in the field and concluded that focus on the education of people of colour is the only common element among the many different definitions of multicultural education. In view of the foregoing it can be seen that multicultural education is quite complex to define since there is no universally agreed definition for it (Maatta, 2008:8). However, the differences are not as great, confusing, or contradictory as some critics and analysts claim; many of these differences are more semantic than substantive, a reflection of the developmental level in the field and the disciplinary orientation of advocates (Gay, 1994).

Problems encountered in the definition of multicultural education present challenges in terms of its implementation. According to Nieto, (2002:28), when multicultural education is mentioned, many people think of lessons in human relations and sensitivity training, units about ethnic holidays, education in inner city schools or food festivals. She further states that if limited to these issues the potential for substantive change in schools is severely diminished. This more often than not leads to the practice of multicultural education at a superficial level in a number of countries, Zimbabwe included. Multicultural education is an approach informed by the 
conviction that there are certain discriminatory practices in education that prevent learners from realising their full potential. Such discriminatory practices tend to be based on race, gender, social class, ethnicity and disability, among many others. As such, multicultural education should be seen as an approach that seeks to accommodate these variables in the practice of education in an endeavour to provide all learners with equal educational opportunities. The education system and the classroom in particular, has to ensure that learners reach their full potential. In the Zimbabwean context, multicultural education should be seen as an approach to education that seeks to accommodate learner diversity in terms of ethnicity, race, gender, social class and ability/ disability in the education system. In the following section, a number of different definitions are going to be explored.

According to Banks (2009:25), multicultural education is at least three things: an idea or concept, an educational reform movement and a process. Multicultural education is an idea stating that all students regardless of the groups they belong to such as those related to gender, ethnicity, race, culture, language, social class, religion or exceptionality should experience educational equality in schools. According to Domnachukwu (2010:84) this definition by Banks (2009:25) highlights the argument that some students because of race, gender and social class have a better chance to learn in schools as they are currently structured than do students who belong to other groups or who have different cultural characteristics. Multicultural education is also a reform movement designed to bring about a transformation of the school so that students from both genders and from diverse cultural experience, language and ethnic groups have an equal chance to experience educational success. Banks (2009:25) concludes by saying that multicultural education is also a continuing process because 
the idealised goals it tries to actualise, such as educational equality and the eradication of all forms of discrimination, can never be achieved in society. Therefore, the implementation of multicultural education may not realise some of the goals of multicultural education.

Baptiste cited in Lemmer \& Squelch (1993: 3) defines multicultural education as:

The transference of the recognition of our culturally pluralistic society into our education system. Furthermore, multicultural education is the operationalising of the education system in such a fashion that it appropriately and in a rightful manner includes all racial and cultural groups. Therefore multicultural education has been regarded as a process which guides the total education enterprise (Lemmer, Meier \& van Wyk, 2007:4).

Gollnick \& Chinn (2002) in Maatta (2008:9) define multicultural education as a strategy in which pupils' cultural backgrounds are used in order to develop effective school environments and classroom instruction. Gorski \& Covert (2010) define multicultural education as a progressive approach for transforming education that holistically critiques and responds to discriminatory policies and practices in education. It is grounded in ideals of social justice, educational equity, critical pedagogy and a dedication to providing educational experiences in which all students reach their full potential as learners and as socially aware and active beings, locally, nationally and globally. Finally, Manning \& Baruth (2008:5) state that multicultural education is both a concept and a deliberate process designed to:

(i) teach learners to recognise, accept and appreciate differences in culture, ethnicity, social class, sexual orientation, religion, ability/disability and gender

(ii) instil a sense of responsibility and commitment to work in learners during their crucial development years and a commitment to work toward the democratic ideals of justice, equality and democracy

A common theme that runs across all these definitions is the idea that multicultural education is an approach that seeks to accommodate learner diversity in its entirety in the practice of education. Banks (2005) in Runhare \& Mulaudzi, (2012:194) states that multicultural education guides the young generation to immerse themselves in 
other cultures, engage with difference, and acquire diverse cultural competence. Therefore, the aim of multicultural education is to provide a climate conducive for all learners so that they can thrive academically and reach their full potential. These definitions of multicultural education have implications for its practice in Zimbabwe. Accordingly, learners, irrespective of their socio economic characteristics, should be accorded an equal opportunity to achieve academically. According to Matsumoto (2013:2), the multicultural education approach is now spread all across the world because it provides one of the most promising methods by which groups belonging to different cultures, races, religions and social classes can coexist with each other in a peaceful interactive way. Multicultural education is relevant for Zimbabwe when looked at in the context of Zimbabwe's Cultural Policy whose objectives include to promote Zimbabwean culture in a multicultural society, and take into account the different ethnic, linguistic and religious groups and promote cultural expressions of different linguistic and religious groups (Ministry of Education, Sport, Arts \& Culture, 2004:6). These objectives emphasise the need to accommodate cultural diversity and hence the importance and relevance of multicultural education in Zimbabwe.

Banks has identified five dimensions of multicultural education (Banks, 1993:4; Banks, 2009:20-22; Yao, Buchanan, Chang, Powell-Brown \& Pecina, 2009:2; Matsumoto, 2013:1; Nieto, 2009:81). These dimensions are content integration, knowledge construction, prejudice reduction, equity pedagogy and empowering school culture and social structure (Banks, 2009:20). Content integration refers to the use of examples and topics from different cultures and ethnic groups to illustrate concepts and theories in a subject area. It deals with the infusion of various cultures, 
ethnicities and other identities to be represented in the curriculum (Bode, 2010). In the Zimbabwean context, classroom pedagogy should draw examples from the different ethnic and racial groups that constitute Zimbabwean society. This also applies to the content of textbooks and classroom instructional materials in use. Knowledge construction focuses on the way knowledge is created in various subject areas and how one's cultural assumptions, experiences and perspectives influence the knowledge constructed (Banks, 2009:20). The main thrust is to show learners that knowledge is socially constructed. In terms of postmodernism, emphasis should be on the plurality of knowledge forms as well as constructivism and social constructivism. Prejudice reduction is to help learners examine their preconceptions about other people, especially people in the minority groups and develop positive attitudes towards all human beings (Banks, 1993:4; Banks, 2009:21). It also refers to the way in which teachers help learners develop positive and anti-biased attitudes about people of different backgrounds (Nieto, 2009:81). Equitable pedagogy is achieved when the teacher is able to match teaching strategies with student learning styles (Yao, Buchanan, Chang, Powell-Brown \& Pecina 2009:2; Banks, 2009:22). This ensures the academic success of all students. Two types of learning styles namely; field dependent and field independent have been identified (Bennet, 2003:186) and educators have to accommodate these diverse styles in terms of classroom pedagogy in order to enhance equitable pedagogy. An empowering school culture and social structure requires the culture and organisation of the school to be structured in a way that ensures equality and empowerment for students from all groups (Banks, 2009:22). The school culture should be able to accommodate all students from diverse cultural backgrounds. 
Wang \& Phillion (2009:10) have used Banks's five dimensions of multicultural education and have come up with a model that can be used as a guideline by Chinese policy makers, school administrators and teachers. Their model has the following components: language and culture inclusion in the curriculum, curriculum knowledge constructed from the perspectives of minority groups, teaching approaches adopted to minority students needs in order to promote minority students' success, prejudice reduction through the inclusion of minority perspectives and the creation of an empowering school and social structure. This model is also relevant and applicable to Zimbabwe as a multicultural society and can also be applied in the successful practice of multicultural education.

Bennet (2003:14) has provided a framework for multicultural teaching. This framework is similar to Banks's (2009:21), five dimensions of multicultural education and should be seen as complementing Banks's (2009:20) contribution. The framework has four dimensions which are; multicultural competence, equity pedagogy, curriculum reform and teaching towards social justice. Equity pedagogy aims at achieving fair and equal educational opportunity for all children, the youth, particularly among ethnic minorities and economically disadvantaged. It "attempts to transform the total school environment, especially the hidden curriculum that is expressed in teacher expectations for students' learning, as well as grouping of students and instructional strategies, school disciplinary policies and practices, school community relations and classroom climates" ( Bennet 2003:14). Curriculum reform requires the development of a curriculum that includes knowledge and contributions of different ethnic groups. In the practice of multicultural education, it is imperative for the curriculum to be reformed so that learner diversity and needs are 
accommodated. The curriculum should accommodate the plural character of society and portray the different social groups positively. Multicultural competence enables the individual to function effectively in a cultural environment other than one's own (Bennet 2003:14). Thus, the individual develops competencies in multiple ways of perceiving, evaluating, believing and doing.

Multicultural education requires culturally responsive teaching. Culturally responsive teaching also known as culturally responsive pedagogy 'refers to an instructional approach that uses the cultural knowledge, prior experiences, and performance and learning styles of ethnically diverse students to make learning more appropriate and effective for them' (Bevan-Brown, 2003; Castagno \& Brayboy, 2008; Gay, 2010; Ladson-Billings, 1995; Rios \& Stanton, 2011; Sheets, 2005; Sleeter \& Cornbleth, 2011 in Mugisha, 2013:5). Gay (2000) in Maatta, (2008:22) defines culturally responsive teaching as making learning relevant and effective for ethnically diverse pupils by using the cultural knowledge, previous experience and performance styles. He further argues that culturally responsive teaching is multidimensional because it takes into account the curriculum content; learning context, pupil-teacher relationship, classroom climate, instructional techniques, and performance assessments and this also enables pupils to be more successful learners. Gay (2000: 30-31) in Maata, (2008:22) and Rose \& Potts (2011:3) state that culturally responsive teaching is a concept that teachers must respond differently to students based on diverse cultural identities and learning needs. Gay (2002) in Herrera, Holmes \& Kavimandan, (2012:2) states that at the most basic level culturally responsive teaching can be defined as using the cultural characteristics, experiences and perspectives of ethnically diverse students as conduits for teaching them more effectively. Wang \& 
Phillion (2009:11) are of the view that culturally responsive teaching will provide a supportive environment for minority students as it takes into consideration minority students' learning styles. Culturally responsive teaching can be seen as accommodating the five dimensions of multicultural education outlined by Banks (2009:20). The essence of culturally responsive teaching is the accommodation of learner diversity which should be viewed as strength by teachers. This tends to produce a classroom environment conducive to multicultural learning. Cultural responsive pedagogies begin with the premise that teachers have faith in the human dignity and intellectual capacity of their students and will build bridges between the curriculum content and the cultural experiences of ethnically and racially diverse students in an attempt to make education accessible to all students (Nkomo, Vandeyer, Malada, Phatlane, Thabane, \& Phurutse, 2009:43).

Montgomery (2001:4) in Maatta, (2008:23) suggests that culturally responsive classrooms acknowledge the presence of culturally diverse children and their need to relate to each other and the subject matter and the tasks they are asked to perform. Within research aimed at promoting equitable practices in education, culturally relevant teaching has emerged as a good teaching strategy to improve achievement (Schemeichel, 2012:211). This enhances the academic success of all learners. Montgomery (1997) in Stoicovy, Fee \& Fee, (2012:4) states that to maximise learning opportunities, it is important that teachers gain knowledge of the cultures represented in their classrooms and translate this knowledge into instructional practice. He goes on to say that this helps students find relevant connections among themselves and with the subject matter and the tasks teachers ask them to perform. Therefore, handling diversity in education is complex; it is proposed that educators need to 
recognise the validity of differences (Meier \& Hartell, 2009:180). Multicultural education should embed the learners' diverse ways of thinking and living as representatives of the different groups' design for living (Nobles, 1985 in Vandeyer, 2003:193); ensure the transmission of the normative heritage of different groups of people from one generation to the next (wa Thiongo, 1981 in Vandeyer, 2003:193), and to make certain that these are ingrained into the core curriculum; and finally, that it should inform the ethos and daily practices of teachers (Vandeyer 2003:193). Banks (1975) in Nkomo, Vandeyer, Malada, Phatlane, Thabane \& Phurutse (2009:45) advises that schools should stop conducting 'business as usual', they should respect the cultural and linguistic capital of students and change the curriculum so that it will reflect the learning and cultural style of students and this enhances student achievement. Richards, Brown \& Forde, 2004 in de Souza, (2010:3) states that other researchers have pointed out the benefit of incorporating elements of the students' home culture into the curriculum. Such an approach tends to enhance student achievement.

Ghosh (2002:2-3) provides the following tenets on the nature of multicultural education. Firstly, she argues that multicultural education is a right to difference. Students' differences built around social class, gender and cultural differences among others must be validated because they are an important part of one's identity. In the Zimbabwean context the content of the school curriculum should accommodate learner differences. Secondly, multicultural education is not only for minority groups. A significant goal of multicultural education is to teach all students critical consciousness so that they can question the conditions in society that allow inequalities to exist with the democratic rhetoric of social justice. Thirdly, 
multicultural education should deal with the total culture of the school. It must be aware of the differential treatment of students who have very dissimilar experiences because of certain differences based on race, gender, culture or class. Fourthly, multicultural pedagogy must create new spaces in what Gadamer (1992) in Ghosh, (2002:3) calls fusion of horizons. This implies that the school should not create the 'Other' by making borders around group differences. Fifthly, multicultural education must aim to transform, not merely reform, the relations and meanings in education.

According to Manning \& Baruth (2008:8-9), multicultural education makes the following assumptions, which are largely drawn from the ideas of Banks (1988) and Hernandez (1989):

- Cultural diversity is seen as a positive enriching element in society because it provides individuals with increased opportunities to experience other cultures and thus to become fulfilled as human beings.

- Teaching is seen as a cross cultural encounter. All teachers and students have their own cultural baggage - their backgrounds, values and customs, perceptions and perhaps prejudices which are brought into the learning and teaching situation and have an influence over learning outcomes.

- Multicultural education should permeate the total school curriculum rather than be doled out in a 'one course' or a teaching unit approach. In other words, multicultural education has to be reflected in all school subjects as well as all activities inside and outside the curriculum.

- Schools will continue to experience and reflect increasing cultural diversity because of influxes of immigrants and refugees and high birth rates of some cultural groups.

- Finally, elementary and secondary schools have a responsibility to implement appropriate multicultural education programmes.

These programmes must contribute to better understanding of cultural differences, show the dangers of stereotyping and to reduce racism, sexism and classism.

Multicultural education has goals that have to be met. These goals are necessary if multicultural education is to be a meaningful experience for all learners. Banks, (1993:3) states that a major goal of multicultural education is to reform the school and other educational institutions so that students from diverse racial, ethnic and social 
class groups will experience educational equality. Banks (2009:12) expresses a similar goal when he says that a major goal of multicultural education is to change teaching and learning approaches so that students of both genders and from diverse cultural, ethnic and language groups will have equal opportunities to learn in educational institutions. Bennet (2003:19) states that the major goal of multicultural education is the development of the intellectual, social and personal growth of all students to their highest potential. These goals build the spirit of tolerance and appreciation of cultural differences and are reflected in Grant \& Sleeter's (2009:64) human relations approach in multicultural education. This goal is also seen in the various approaches to multicultural education advocated by Banks (2009:237-249); Bruch et al. in Zimmerman (2004:2); and Grant \& Sleeter (2009: 62-68). Multicultural education should help learners to develop multiple perspective taking skills and to consider the perspectives of different groups. Multicultural education seeks to promote equality in educational access, representation in curriculum knowledge, staff compositions, academic achievement, treatment of learners, and teachers' competence to handle global classes (Runhare \& Mulaudzi, 2012:194). These goals seek to develop multicultural competence (Bennet, 2003:2) and represent Banks's (2009:240) transformative level.

Educators and teachers in particular have the burden of implementing multicultural education. Their perception of difference becomes very important as they tend to influence the way and manner in which multicultural education can be implemented. Manning \& Baruth (2008:50) have identified three models of teacher perceptions of differences. These models include the cultural deficit model, the cultural mismatch model and the culturally different model. 
In the cultural deficit model, students who are culturally different are thought of as 'deprived' 'disadvantaged' and 'socially deprived' only because their behaviour, language and customs are different from those of middle class values (Manning \& Baruth 2008:50). Diversity is not acknowledged and assimilation may be the end result. Domnwachukwu (2010:7) argues that in this model teachers may see themselves as agents of assimilation. Therefore learners, whose beliefs and behaviours do not match those of the successful mainstream learners, are seen as lacking in ability, prior knowledge, motivation or communication skills.

The cultural mismatch perspective assumes that cultures are inherently different but not necessarily superior or inferior to one another. It assumes that people from culturally different backgrounds fail to achieve academically because their cultural traits do not meet those of the dominant culture in the school (Manning \& Baruth 2008:50). De Souza (2010:3) argues that in the cultural mismatch model some of the skills acquired in the home culture may be transferable to the new culture while other home-based skills may be neither expected nor valued by members of the target culture. In this regard, there is need for effort to accommodate both the school and home culture. Teachers as accommodators tend to make accommodations in their teaching to facilitate learning (Domnwachukwu, 2010: 7).

The 'culturally different' model recognises differences as strengths that are valuable and enriching to schools and society as a whole. This forms the basis of a reformed multicultural school curriculum. Teacher perceptions of difference have an impact on the implementation of multicultural education. For example, the cultural deficit model may result in a situation in which assimilation is emphasised; the culturally different model may also contribute to a situation where the learner culture is accommodated in 
the classroom. Consequently, as argued by McLaren (1998) in Ndura (2006:2), teachers perform a social function that is never innocent because it is coloured by their own frame of reference.

According to Lemmer, Meier and van Wyk (2006:4-5), multicultural education has the following characteristics. It:

- recognises and accepts rightful existence of different cultural groups;

- encourages acculturation and cultural preservation;

- encourages mutual interaction and cooperation;

- views cultural diversity as an asset rather than a disability;

- acknowledges the equal rights of all cultural groups in a society;

- advocates equal educational opportunities;

- encompasses many dimensions of human difference;

- requires the total reform of the school environment;

- is an approach to education and should therefore permeate the entire teaching and learning process; and

- is synonymous with effective teaching.

The characteristics of multicultural education outlined above are all geared towards the provision of a conducive school and classroom environment for all learners. This becomes very important in the sense that all learners need a conducive environment in order to realise their full potential.

Gollnick \& Chinn (2012:29) offer characteristics of multicultural education that are similar to those presented by Lemmer, Meier \& van Wyk (2006:4-5). They argue that a multicultural school should have the following characteristics:

- the composition of the faculty, administration and staff would accurately reflect the composition of society;

- differences in academic achievements would disappear between males and females, dominant and oppressed group members, and upper middle class and poor students;

- the school curriculum would be unbiased and would incorporate the contributions of all cultural groups;

- instructional materials would be free of bias , omissions or stereotypes;

- cultural differences would be treated as differences rather than deficiencies that must be addressed through compensatory programmes;

- students would be able to use their own cultural resources and voices to 
develop new skills and critically explore the subject matter;

- students would learn to "'take risks to struggle with ongoing relations of power, to critically appropriate forms of knowledge that exists outside their immediate experience and to envisage visions of a world which is 'not yet' in order to be able to alter the grounds upon which life is lived;

- the faculty, administrators and staff would see themselves as learners enhanced and changed by understanding, affirming and reflecting cultural diversity; and

- teachers and administrators would be able to deal with questions of race and intergroup relations and controversial realities on an objective frank and professional basis

These characteristics are concerned with establishing a conducive environment which accommodates all learners, irrespective of their differences as highlighted in the definitions of multicultural education. The dimensions of these characteristics highlight the importance of adopting a holistic approach in the successful implementation of multicultural education. However, the first characteristic tends to present problems in terms of its implementation not only in Zimbabwe but also elsewhere.

In Zimbabwe, teachers generally tend to prefer to work in environments where they are comfortable with the language and culture. Other teachers, because of financial constraints, also prefer to work nearer their homes. For example, teachers of Shona or Ndebele origin would be unwilling to work in Matabeleland and Mashonaland respectively due to linguistic, cultural and communication problems. Sometime in the past there was a government policy in which initial teacher deployment after college was done by the Ministry of Education, Sports, Arts, and Culture at head office level. Such a policy ensured that teachers from different ethnic groups were deployed countrywide. What is needed currently in Zimbabwe is a scenario where all the languages spoken in the country are taught in schools and teachers' colleges. This 
would enable teachers to gain the linguistic and cultural competence that would enable them to teach countrywide.

The benefits of teaching all languages spoken in the country in teachers' colleges will be realised in the composition of school staff that reflects the plural character of Zimbabwean society. All the characteristics outlined by Gollnick \& Chinn (2012:29) may not all be present in a school although the ideal situation is one in which these characteristics are all present. In the implementation of multicultural education, this is understandable when multicultural education is viewed as a process from the viewpoint of Banks (2009:25). This implies that in the evaluation of the implementation of multicultural education, the thrust is to assess the progress made in attaining these characteristics.

Banks (2009:2) maintains that in order to attain the ideals and characteristics of multicultural education, there is need for a number of reforms. These reforms would include the school culture, power relationships, the curriculum materials and the attitudes and beliefs of staff must be changed in ways that will allow the school to promote educational equality for learners from diverse groups. An analysis of this agenda for reform in schools shows that the successful implementation of multicultural education demands a broad based holistic approach. These reforms are concerned with the creation of a conducive school and classroom environment. Therefore, multicultural education involves change in the total school environment; it is not limited to curricular changes (Banks 2009:4).

A practice that could obtain in some schools is one where some school issues are reformed whilst others are left intact. The results of such a practice may be disappointing as the whole essence of multicultural education is lost. Meier \& Hartell 
(2009:181) argue that research studies show that schools' response to diversity and changes are inadequate. The agenda for reform places a burden on the shoulders of educators who interface with a number of learners from diverse cultural backgrounds. Therefore, multicultural education places value on how to effectively teach diverse students and what to teach them (Gay, 2004 in Bode, 2010). Within the Zimbabwean context, multicultural education has relevance as well as an important role to play. According to the Nziramasanga Commission Report (1999) Zimbabwe is part of a global community " to become full citizens in the global village, to understand and appreciate its challenges, we must learn to live together by developing an understanding of others, their cultures, traditions, history, spiritual values" . Bennet (2003: xi) concurs and states that "we are in urgent need of national and global citizens who possess multicultural competence and who are committed to the achievement of worldwide social justice and economic equity as a foundation for lasting peace on the planet". The school becomes an important starting point in a journey to realise these ideals.

Having looked at the characteristics of multicultural education and the multicultural school, there is need to analyse how schools have responded to cultural diversity and multicultural education following desegregation. Although these observations were made in an American setting, they have relevance for Zimbabwe. Schools have responded in at least four ways (Bennet, 2003:24-25) which are: business as usual; assimillationist response; pluralistic co-existence; and integrated pluralism. These responses are characterised by the nature of the content of the school curriculum. In Zimbabwe, the curriculum is determined and changed at national level through the Ministry of Education, Sports, Art and Culture's Curriculum Development Unit 
(C.D.U.); it is not a process that takes place at the level of the individual school. What is needed is a set up where the Ministry of Education, Sports, Art and Culture continuously undertakes curriculum reform to keep pace with the demands of multicultural education. However, school based practices should accommodate learner diversity.

In the business as usual approach, interracial schools try to maintain the basic curriculum and the same academic standards that prevailed under segregation (Bennet 2003:24). This type of response fails to recognise the undesirability of old rules and procedures. In Zimbabwe, this type of response may be found to prevail in some schools that fail to acknowledge the presence of ethnic minority and racially different learners in the learner body. Although the Education Act of 1987 outlaws discrimination on whatever grounds, some educators may fail to provide a learning environment for learners coming from an ethnic minority background. Such learners continue to constitute the 'put aside' (Mustafa, 2006:93).

The assimilationist response holds the view that integration will have been achieved when the minority group can no longer be differentiated from the majority in terms of economic status, education or access to social institutions and other benefits (Bennet 2003:24). Those who do not assimilate end up dropping out or being expelled. The pluralistic coexistence response involves resegregation; it is based on the separation of different racial or ethnic groups. Learners are allowed to maintain different styles and values but within the school environment comprising different turfs of different racial groups (Bennet, 2003:24). This approach may fail to eliminate prejudice due to lack of mutually benefiting interaction. Finally, integrated pluralism seeks to avoid re- 
segregation of learners. It is pluralistic in the sense that it recognises the diverse racial and ethnic groups in society but does not denigrate them (Bennet, 2003:25).

These response types can be construed as an ideal type, a yardstick to assess how Zimbabwean primary schools have responded to cultural diversity in the learner population. There are some schools that may manifest the 'business as usual' approach. Such schools may fail to acknowledge the presence of ethnically and racially diverse learners in the school. In other words, learners find it difficult to be accommodated in the school. Some schools may reflect the pluralistic co-existence model not primarily based on race but on ethnicity. Learners may continue to form pockets around ethnic lines. In such settings learners from the same ethnic group, particularly ethnic minority groups, may come together and strengthen friendship patterns along those lines. The ideal situation is one of integrated pluralism where the school acknowledges diversity in its entirety. For such a scenario to prevail there is need for a supportive school environment as suggested by Gollnick \& Chinn (2012:29) and where Banks's (2009:2) reform agenda has been implemented.

\subsection{APPROACHES TO THE IMPLEMENTATION OFMULTICULTURAL EDUCATION}

There are a number of approaches that have been suggested for the implementation of multicultural education. Implementation of multicultural education ranges from easiest to implement and least likely to lead to the goals of multicultural education, to most challenging and offering the most potential (Cumming-McCann, 2003:12). Literature reveals an array of approaches to multicultural education and teaching about diversity (Zimmerman, 2004:1). Most of the approaches in the practice of multicultural education are a response to the numerous definitions offered in the field. 
Gorski (2010:2) argues that in order to make sense of the variations of definitions, more importantly, the way in which these definitions are operationalised, scholars such as Banks (1995), Grant \& Sleeter (2006) and McLaren (1995) have constructed typologies of approaches to multicultural education. The extent to which these typologies are fully implemented is an issue of debate. This has led to a mismatch between theory and practice, resulting in a situation where all the ideals of multicultural education are not realised. Gay in Banks, (1993:3) points out that there is a tremendous gap between theory and practice in the field of multicultural education. In her view, theory development has outpaced development in practice and a wide gap exists between the two. This can be seen as a problem of the implementation process which has not moved fast enough to keep pace with trends and developments in the field.

Gorski, (2010:3) argues that although the typologies differ in terminology, they each offer an operational continuum ranging from the contributions approach that celebrate diversity with slight curricular shifts while maintaining the hegemonic status quo, to a reconstructionist approach that demands the elimination of social and educational inequities. This is where the problem of the dichotomy between theory and practice lies. Implementation approaches in some instances may fail to live up to the end of the continuum which is the reconstructionist phase. There are instances where implementation remains stuck at the celebratory phase and fails to move up to incorporate other phases. These problems reflect the status of the practice of multicultural education as an emergent discipline (Banks 1993:3).

According to Banks (1993:3), although there is an emerging consensus about the aim and scope of multicultural education, the variety of typologies, conceptual schemes 
and perspectives within the field reflects its emergent status and the fact that completes agreement about its aims and boundaries has not been attained (Baker, 1983; Bennet, 1990; Garcia, 1991; Gollnick \& Chinn, 1990 in Banks, 1993:3). This observation is significant when one recognises that since its earliest conceptualisations in the 1960s, multicultural education has been transformed, refocused, reconceptualised, and is in constant state of evolution in both theory and practice (Gorski \& Covert, 2010).

Gary (1995) has identified three categories of multicultural education typology as it is practised in the United States. Typologies are helpful conceptual tools because they provide a way to organise and make sense of complex and disparate data and observations (Banks, 1993:3). These categories are content oriented programmes; student oriented programmes and socially oriented programmes. The primary goal of content oriented programmes is to include content about different cultural groups in the curriculum and educational materials to increase student knowledge about these groups (Gay, 1995). These programmes have three goals: to develop multicultural content throughout the disciplines; incorporate a variety of different viewpoints and perspectives in the curriculum; and to transform the canon ultimately developing a new paradigm for the discipline. Such programmes take the form of "single group studies" (Sleeter \& Grant in Gary, 1995).

Student oriented programmes move away to address the academic needs of carefully defined groups of students, often minority students (Gary, 1995). Gibson's (2010::95) education for the culturally different is an example of this approach. Student oriented programmes are intended to increase the academic achievement of different ethnic and cultural groups and they do not involve significant changes in curriculum content. 
As Sleeter \& Grant (2003) describe them many of these programmes are designed not to transform the curriculum or the social context of education, but to help culturally or linguistic different students make the transition into the educational mainstream (Gary, (1995). Socially oriented programmes seek to reform both schooling and the cultural and political context of schooling, aiming neither simply to enhance academic achievement nor to increase the body of multicultural knowledge but to have much broader impact of increasing cultural and racial tolerance and reducing bias ( Gary, 1995).

Four approaches to multicultural education have been identified. These four approaches can be categorised into two broad groups and these are: the multicultural education model and the multicultural education continuum approach. The multicultural education model approach comprises the work of Gibson (2010:95-113) and Grant \& Sleeter in Banks and Banks (2009:62-68; Grant \& Sleeter 2004:7-13). The multicultural education continuum approach includes the works of Banks (2009:237-249) and Bruch et al. cited in Zimmerman, (2004:3-4). Each of these scholars offers a definition of multicultural education that frames it explicitly in terms of the reconstructionist end of their respective continuum (Gorski, 2010:3). A fifth approach to multicultural education is provided by Nieto, (1997:46-47; 2002:31-42; 2009:82) who has identified seven characteristics of multicultural education.

\subsubsection{MULTICULTURAL EDUCATION MODELS}

The multicultural education models approach is seen as being made up of distinct categories. These categories have evolved as a result of the review of literature on the practice multicultural education in the United States. They all reflect Gary's (1995) 
typologies. What is significant about this approach is that a category or categories of the model approach can be selected and applied in the school setting.

\subsubsection{GIBSON'S MODEL}

Gibson's model is a result of her review of multicultural education practice in the United States. She identified five general approaches to multicultural education (Nieto, 2009:81). The models outlined by Gibson( 2010: 94-119, Gibson 1984 in Pai \& Adler 1997:113-115) were drawn largely from a review of the publications of The American Association of Colleges for Teacher Education and articles found in Educational Resource Information Centre. Therefore it is important to note that the approaches cited by Gibson 1984 in Pai \& Adler (1997:113-115), and Gibson 2010: 94-119) are a result of the review of literature on multicultural education as it is practised in the United States of America. The approaches cited all fall into the three categories of typologies on multicultural education cited by Gary (1995). Gibson (1984 in Pai \& Adler 1997:113-115, and Gibson, 2010:94-119) has identified the following four approaches to multicultural education: education for the culturally different; or benevolent multiculturalism; education about cultural differences; education for cultural pluralism and bicultural education (Gibson, 1984: 95 in Pai \& Adler, 1997: 113-115; Gibson, 2010:94-119). These approaches are a result of Gibson's study of the literature on multicultural education, bilingual education, education for pluralism and ethnic studies in the United States (Pai \& Adler, 1997:113).

The first approach, which is education for the culturally different or benevolent multiculturalism aims to provide equal educational opportunities for the culturally different. The approach is based on the premise that learners from certain ethnic 
minority groups continue to fail academically because of the unique learning difficulties experienced by such students. The purpose of the approach is to equalise educational opportunities for culturally different students and is a result of the rejection of cultural and genetic deficit hypothesis regarding student school failure (Gibson, 2010:95-98). In terms of this approach, there is need to identify the unique learning difficulties experienced by culturally different learners usually minority learners. For example, failure could be a result of the language of instruction or a classroom and school environment that is not conducive due to failure to accommodate society's cultural diversity. In other words, a conducive classroom and school environment as well as appropriate learning materials and teaching strategies tend to provide a solution to the problem of learner failure.

The incorporation of Banks's (2009:21) dimensions in the teaching approach, particularly content integration and equity pedagogy may provide a solution to problems associated with learner failure. However, Gibson (1984) in Pai \& Adler (1997:114) identified two weaknesses in this approach. Firstly, she argues that there is no empirical evidence to support the view that cultural differences are the cause of minority groups' failure and that multicultural education provides a solution. The second weakness is that there is an unwarranted belief that implementing multicultural education will lead to parity of power, which may not be the case.

The second approach, which is education about cultural differences or cultural understanding focuses on cultural differences. The primary goal of this approach is to educate the young to recognise the value of cultural diversity and to understand and respect other cultures and to accept the right of others to be different. Gibson (2010:98) argues that in this case the purpose of multicultural education is to teach 
students to value cultural differences, to understand the meaning of the culture concept and to accept the right of others to be different. It is in this regard that Ghosh (2002:2) asserts that multicultural education is a right to difference. At the same time, education for cultural understanding will enrich the lives of all students, decrease racism, prejudice and discrimination and increase social justice (Gibson 1984, in Pai \& Adler, 1997:113). The key assumption underlying this approach is that schools should be oriented towards the cultural enrichment of all students, that multicultural education will provide such enrichment by fostering understanding and acceptance of cultural differences and that these will decrease racism and prejudice and increase social justice (Gibson, 2010:99). In this regard, education about cultural differences meets the goals and ideals of multicultural education where accommodation and appreciation of cultural differences is of paramount importance. It is related to the five dimensions of multicultural education posited by Banks, (2009:21).

This approach has its own shortcomings. Gibson in Pai \& Adler (1997:113) argues that programme changes within established schools alone cannot bring about radical changes in the existing social order. There is no particular reason to assume that courses directed towards ethnic literacy and cultural appreciation will halt prejudice and discrimination or solve the fundamental problem of inequity (Banks, 1974 in Gibson, 2010:101). This argument is valid when multicultural education is seen as a continuum ranging from the contributions phase to the social reconstructionist phase (Gorski, 2010:3). Another shortcoming of this approach identified by Gibson (1984:100-101), in Pai \& Adler, (1997:114) is that the emphasis on cultural differences to the exclusion of similarities may lead to unintended stereotyping of 
culturally different groups. In this case, the approach tends to work against the goals and ideals of multicultural education.

The third approach, education for cultural pluralism appears to be broader in scope (Gibson, 1984 in Pai \& Adler, 1997:113). The purpose of this approach from the point of view of Gibson (2010:102-103) is to preserve and extend cultural pluralism in America. This approach arises from the rejection of the 'melting pot' ideal or the rejection of assimilationism. This approach seeks to promote cultural diversity which should be accommodated in the school curriculum. Education for cultural pluralism is seen as preserving boundaries between groups.

The fourth approach is bicultural education. According to Gibson (1984) in Pai \& Adler, (1997:113-114), the primary purpose of bicultural education is to develop learner's language competencies in their primary or native language and in the language of the mainstream society. The purpose of bicultural education is to produce learners who have competencies in and can operate successfully in two different cultures (Gibson, 2010:107). This view is related to the concept of multicultural competence which is emphasised by Bennet (2003:15). At the same time it helps children to function effectively in two cultures, their own and the dominant group. It is an approach that may lead to intercultural understanding as well as intercultural literacy. Bicultural education rejects the ideology of the 'melting pot'. Gibson ( 1984) in Pai \& Adler ( 1997:115), argues that the bicultural education approach tends to equate culture with language or ethnic group, thereby over emphasising ethnic identity, running the risk of preventing students from choosing from other identities.

The approaches identified by Gibson (1984 in Pai \& Adler (1997:113-114) seem to form distinct categories which can be selected and implemented. However, these 
approaches may fail to meet the demands presented by the numerous definitions of multicultural education.

\subsubsection{GRANT AND SLEETER'S MODEL}

Grant \& Sleeter's (2009:59-80) model, just like Gibson's (2010:95-113) approach, consists of five distinct categories (Nieto, 2009:82). They found four distinct categories of efforts described under the label of multicultural education that were commonly found in schools 1987-2003 (Cushner, McClelland \& Safford, 2008:48) and added a fifth. These categories emerged after an extensive review of literature on multicultural education that were commonly found in schools (Cushner, McClelland \& Safford, 2008:48) in the United States. These categories are: teaching of the exceptional and the culturally different, single group studies, human relations approach, multicultural education and they added, multicultural education that is social reconstructivist (Cushner, McClelland \& Safford, 2008:48; Campbell 1996:22; Caraballo, 2009:8).

The last two categories of their approach can be seen to form a continuum. Their typology fairly represents a wide variety of conceptual approaches and typologies that are used by educational pluralists in attempting to advance the cause of a positive educational approach to cultural diversity (Cushner, McClelland \& Safford, 2008:48). These categories are seen as distinct categories (Cushner, McClelland \& Safford, and 2008:48) and may not constitute a continuum. The last two categories can be seen as overlapping, making it difficult to draw a dividing line between them and can be seen to be part of a continuum. However, Campbell (1996:22) is of the view that the model developed by Sleeter and Grant no longer adequately encompasses the rapidly 
emerging field. The categories developed by Sleeter and Grant also fit into the categories of typologies identified by Gary (1995).

Teaching of the exceptional and the culturally different seeks to increase the achievement of minority groups. Teaching the culturally different is more process oriented than content oriented (Gay, 1994). This approach builds bridges between the capabilities of the student and the demands of the wider society so that the students can learn to function successfully in these contexts (Grant \& Sleeter, 2004:7) This is based on the belief that a teacher's responsibility is to prepare students irrespective of their socio economic characteristics to fit into the classroom and adult society. The goals of this approach are to equip students with the cognitive skills, concepts, information, language and values traditionally required by US society; and to enable students to hold a job and to function within the society's institutions and culture (Grant \& Sleeter 2009:63). Proponents of this approach are concerned with helping students from different cultural backgrounds, including those with disabilities adapt to the mainstream demands of public schooling and society (Grant \& Sleeter, 1988:17). According to Grant \& Sleeter (2009:63), teachers using this approach begin by determining the achievement levels of students, comparing their achievement to grade level norms and then working diligently with those who are behind to catch up. In other words, teachers using this approach start from where the learners are in terms of performance and achievement. This approach can be seen as a remedial approach, in a sense where the idea is to ensure equality in terms of achievement. Grant \& Sleeter (1988:10) noted that:

As a result of remediation, educators who work within this paradigm use what information, skills, learning styles, languages ( which may include the implementation of Transitional Bilingual Education) students possess, as well 
as creative teaching strategies, only to the extent that they act as vehicles for more efficient transferring the learner into the so called regular classroom.

Therefore this approach, seeks to accommodate prior learner experiences into the classroom so as to increase the compatibility between the school and the home. The emphasis is on students who are behind and need to catch up where the starting point is where the students are and using instructional techniques familiar to students (Grant \& Sleeter, 2009:63).

There are some criticisms that have been directed against the culturally different approach. In the U.S.A this model is based on the assimilationist agenda and this is clearly the case when any and all materials that are relevant to learners from different backgrounds are analysed temporarily and ultimately discarded (Grant \& Sleeter, 1988:7). In this regard this model may not meet the ideals and goals of multicultural education as the multicultural education movement arose as a reaction to the ideology of assimilation or the melting pot ideal.

Teaching of the exceptional and the culturally different implicitly works from a deficit-model orientation that equals different cognitive and learning styles, literacies, language use and low academic achievement of students from certain groups with individual or group pathology, cultural deprivation or genetic limitations (Grant \& Sleeter, 1988:9). Critics point out that it has a tendency to emphasise an assimilationist perspective that positions students as holding deficits (Bode, 2010).

A deficit model orientation does not give all subcultures equal status. On the other hand, it implies that certain intervention strategies in the form of compensatory programmes, for example, Headstart in the United States of America, are needed to 
correct that deficit (Grant \& Sleeter, 1988:9). In this context, teaching the culturally different can be viewed as a compensatory programme.

The human relations approach is designed to enable learners to live harmoniously in school and society by appreciating and tolerating cultural differences. It is based on the belief that a major purpose of the school is to help students learn to live harmoniously in a world that is becoming smaller and smaller and that greater social equality will result if students learn to respect one another regardless of race, class, gender and disability ( Grant \& Sleeter, 2009:64). The human relations approach is the least controversial of several approaches to education and the one that requires the least change of world view on the part of teachers (Campbell, 1996:130). According to Grant \& Sleeter (2004:7), the human relations approach is concerned with helping students to get along with one another by appreciating each other and themselves. The goal of the human relations approach is to promote a feeling of unity, tolerance and acceptance among people (Grant \& Sleeter, 2009:64). Advocates of this approach suggest that it should be comprehensive, integrated into several subject areas and school wide (Grant \& Sleeter, 2009: 64). Caraballo (2009:8) argues that Grant and Sleeter conceptualise this approach as multicultural education that emphasises the need for people to get along and appreciate each other's differences, but does not address concerns about social stratification, poverty, institutional discrimination and powerlessness. This means that this approach fails to address issues of equity and inequality in society. The Human Relations approach to multicultural education emphasises our common humanity, the enormous similarities in physical, psychological and social patterns among humans and builds lessons to 
emphasise human similarity (Campbell, 1996:130). Grant \& Sleeter (2004:8) emphasise that this approach concentrates on building positive feelings among people.

The human relations approach targets the development of each student's self concept and thus classrooms should reflect individual differences although they are in danger of what is known as tourist museum in which there are certain days set aside to recognise cultures in terms of food, clothing or folk tales ( Sleeter \& Grant, 2003 ). This approach is based on the belief that a major purpose of the school is to help students learn to live together harmoniously in a world that is getting smaller and smaller (Grant \& Sleeter, 2009:64). The human relations approach seeks to reduce prejudice which is one of the five dimensions of multicultural education identified by Banks (1993:4).

The human relations approach has its own shortcomings. Caraballo (2009:8) argues that this approach assumes that work done in the classroom, and better communication among different groups, will lead to cooperation between whites and people of colour, eventually working to diminish inequality. This observation seems to suggest that there are other issues that have to be addressed so as to overcome inequality. By using the word human in place of cultural, this educational model avoids any kind of engagement with antagonistic intergroup relations, collapsing into a kind of benign universal humanism (Caraballo, 2009:9). In this regard the political dimension to culture tends to be underplayed. The human relations approach also teeters very close towards assimilation; cultural differences are only taught to the extent necessary to improve students' self-concepts (Sleeter \& Grant, 2003). The concept of assimilation goes against the ideals of multicultural education as it fails to 
accommodate cultural diversity. In fact, the emergence of multicultural education was a rejection of the ideology of assimilation and the 'melting pot' concept.

Single group studies are meant to highlight the contributions of the group under study. According to Carjuzza (2012:13), the 'single group study' is characterised by in-depth and comprehensive study of a particular minoritised population in order to highlight its lack of equity with respect to the dominant population and to support social change efforts. The single group studies approach emphasises awareness, respect and acceptance for the group receiving attention (Grant \& Sleeter, 2009:65). The thrust is on building the self-esteem of the members of the group under study. Grant \& Sleeter (2004:8) argue that the single group studies approach attempts to change attitudes and provide a basis for social action by exposing information (in this case through schooling) about particular groups and about the effects of discrimination on that group. This approach also has some weaknesses as it may lead to a superficial form of multicultural education. Grant and Sleeter (1988:14) state that a softer form of this model often turns into "the four Fs: fairs, festivals, food and folktales" which do not count much in addressing issues to do with racism and inequality in society.

The last two models identified by Grant and Sleeter (2009:66-69) can be seen as part of a continuum. Multicultural education seeks to accommodate learner diversity in the classroom and give all learners an equal opportunity to achieve. It is similar to Gibson's (2010:102-103) education for cultural pluralism. According to Grant \& Sleeter (2004:4), multicultural education synthesises ideas of the previous three approaches. Its goals are to reduce prejudice and discrimination against oppressed groups; to work towards equal opportunity and social justice for all groups; and to 
effect an equitable distribution of power among members of the different cultural groups (Grant \& Sleeter, 2009:66).

In order to implement multicultural education Grant \& Sleeter (2004:7) argue that a number of changes are necessary. They state that the approach suggests changes to most existing school practices for all students so that the school and classroom may become more concerned with human diversity, choice and equal opportunity (Grant and Sleeter, 2004:7). According to Grant \& Sleeter (2009:66), the goals of multicultural education are actualised by attempting to reform the total schooling process for all children regardless of the school. These changes are meant to create a conducive classroom and school environment in which all students are accommodated. Such a conducive classroom and school environment tends to give all learners equal opportunity in learning. Provision of equal educational opportunities is another goal of multicultural education (Banks, 2009:1). However, this approach has some shortcomings as outlined by Grant \& Sleeter, (1988:13):

Multicultural education endeavours to affirm diversity and identities through positive images of subordinated groups and does so in a limited fashion by focusing on colour coordination (disconnected from issues of ideological differences among people from the same racial/ ethnic group) food festivals (in which multicultural education is reduced to having fun) cut-and paste add ons to the existing canon, and group based methodologies ( which often essentialise and objectify students by making them fit to the method rather than the other way round.

The last and fifth approach identified by Grant \& Sleeter (2004:8) is education that is multicultural and social reconstructionist. However, Grant \& Sleeter (2009:67) have renamed this last approach 'multicultural social justice education'. The two terms shall be used interchangeably as they have similar goals. This is the fifth approach to multicultural education which they added. According to Grant \& Sleeter (2009:67) multicultural social justice education deals more directly, than the other approaches 
with oppression and social structural inequality based on race, social class, gender and disability. In this way this approach seeks to create equity for all social groups in society. The highlights of this approach include: students learn how to analyse institutional inequality within their own life circumstances, students learn to engage in social action so they can change unfair social processes and bridges are built across various oppressed groups so that they can work together to advance common interests (Grant \& Sleeter 2009:68-69). In this approach, students learn to engage in social action in an attempt to address unfair practices in society. Sleeter \& Grant (2003) argue that multicultural education must be both multicultural and social reconstructionist. This approach is an extension of the multicultural education approach. Its purpose is to prepare future citizens to take action to make society better serve the interests of all groups of people especially those who are of colour, poor, female or have disabilities (Grant \& Sleeter, 2009:67). It educates learners to become analytical as well as critical thinkers who can initiate change in society. Whilst multicultural education seeks to accommodate students' diversity and provide all learners with an equal opportunity to achieve, multicultural social justice education seeks to bring about change in society by focusing on inequality and inequities (Sleeter \&Grant 2009:67).

Such a redesign recommends addressing issues and concerns that affect students of diverse groups, encouraging students to take an active stance by challenging the status quo and calling on students to collectively speak out and effect change by joining with other groups in examining common or related concerns (Sleeter \& Grant 1987, 2006, in Bode 2010). Students need to be equipped with skills that will enable them to examine their societies. After school, students will need skills that will help them to 
challenge society (Sleeter \& Grant, 2003). The approach is rooted in social reconstructionism which seeks to reconstruct society towards greater equity in race, class, gender and disability (Grant \& Sleeter, 2009:67). In this way, multicultural education leads to social transformation.

\subsubsection{THE MULTICULTURAL EDUCATION CONTINUUM APPROACH}

The multicultural education continuum approach comprises approaches that are seen to be located along a continuum. One approach leads into the next approach. This continuum ranges from contributions to the transformative phase. These phases in the continuum can be taken as the basis for the construction of a spiral curriculum in multicultural education that covers, for example, the primary school and secondary school phases.

\subsubsection{BRUCH et al. MULTICULTURAL EDUCATION CONTINUUM} APPROACH

Bruch et al.'s (2004) cited in Zimmerman, (2004:2) approach is similar to the Banks $(1993: 13 ; 2009: 237-248)$ approach which is going to be discussed later. The only difference is that Banks's (1993:13; 2009:237-248) continuum approach consists of four phases whereas Bruch et al.'s approach in Zimmerman (2004) consists of three phases. According to Zimmerman (2004:1) Bruch et al.'s (2004) consists of the following phases: celebratory approach, critical approach and the transformative approach.

The celebratory approach moves away from defining differences as deficiencies and traditional assimilationist idea to 'highlighting the positive accomplishments and aspects of many different cultures and social groups' ( Bruch et al. 2004 cited in Zimmerman , 2004:2). This is an approach that places emphasis on the celebration of 
differences that is the accomplishments of the different ethnic groups are highlighted and celebrated. This is a way in which the self esteem of all learners is boosted. In many ways, this approach is quite similar to the single group studies suggested by Grant \& Sleeter, (2009:65). Bruch et al. cited in Zimmerman (2004:3) have criticised this approach. They argue that this approach is an essentialist perspective, which can separate groups even further, and it falls short as it tends to celebrate without examining and critiquing the power relations inherent in society. Given these observations, it follows that the celebratory approach may fail to meet the goals and ideals of multicultural education in society. Other issues in society such as asymmetrical power relations may not be addressed in terms of this approach.

The critical approach examines and challenges power and privilege and their role in society. This approach questions the status quo and critiques power relations within a society (Bruch et al. 2004 cited in Zimmerman, 2004:4). This approach addresses what Gramsci cited by in Zimmerman, (2004:4) referred to as 'the struggle over ideological hegemony' in a society by examining the role of education in transmitting and maintaining societal norms. In this regard, the school has to provide learners with skills that will enable them to critically examine power and privilege in society. The objective is to bring about change in society to ensure equity and social justice. This can also be seen as similar to the multicultural social justice education, suggested by Grant \& Sleeter (2009:67). However, Bruch et al. cited in Zimmerman (2004:3) are of the view that overemphasis on domination in this approach can be counterproductive, demoralising students and creating resistance in them.

According to Bruch et al. (2004), cited in Zimmerman, (2004:3), the transformative approach seeks to critique domination and to take action, to find ways to transform 
domination for the good of all. The transformative approach focuses on, not just trying to assimilate the 'other' to the dominant view but to transform society so that the "other" has an equal voice and existence (Zimmerman, 2004:6). This approach is similar to multicultural social justice education suggested by Grant \& Sleeter (2009:67). The main focus of this approach is to bring about social change where a lot of demands are placed on the school and may not be attainable. Zimmerman (2004) says that these views are dismissed as being too visionary, even outlandish and not practical.

\subsubsection{BANKS'S MULTICULTURAL EDUCATION CONTINUUM}

Banks's (1993:13; 2009:237-248) approach to multicultural education represents a continuum approach with the contributions approach on one end and the transformative phase on the other end. According to Herrera, Holmes \& Kavimandan (2012:2) Banks (1989, 1998) ground breaking work has helped educators see how their instruction and their efforts to diversify the school curriculum might be conceptualised along a continuum of approaches (contributions, ethnic additive, transformation and decision making and social action. Banks has suggested four successive levels of integration of ethnic content which provide teachers with an easily infusible stepladder entry into the ongoing process of multicultural education (Reissman, 2006). The difference with Bruch et al's. approach in Zimmerman (2004:2-4) is that Banks's $(2009: 237-248 ; 1993: 13)$ approach consists of four levels instead of the three identified by Bruch et al. in Zimmerman (2004:2-4). Banks has identified the following levels: contributions, additive, transformative and social action level (Banks, 1993: 2009; Banks 2006; 2008 in Yao, Buchanan, Chang, Powell-Brown \& Pecina, 2009:2). 
The contributions level features the use of lessons and activities that celebrate heroes, holidays and special events of certain cultures (Yao, Buchanan, Chang, Powell-Brown \& Pecina, 2009:3) It is similar to Bruch et al.s' (2004) (cited in Zimmermann 2004: 2-4) celebratory phase. According to Banks (2009:237), the contributions approach is characterised by the insertion of ethnic heroes and discrete cultural artefacts into the curriculum selected using criteria similar to those used to select mainstream heroes and cultural artefacts. It is important to note that these contributions do not involve change in the curriculum. The structure of the curriculum remains unchanged. The goal of the contributions approach is to include the experiences of all learners as a way of accommodating the cultural diversity present in the classroom. It is a way of uplifting the self-esteem of all students in the classroom. This may then involve the study of foods, dances, music and artefacts of different ethnic groups. The contributions approach provides teachers with a way to integrate ethnic content into the curriculum quickly, thus giving some recognition to ethnic contributions to United States society and culture (Banks, 2009: 238). This observation is also applicable to the Zimbabwean situation where all primary schools are expected to construct a 'culture hut'. In the "culture hut" various artefacts are displayed and these tend to highlight the accomplishments of different groups in society. However, Richards, Brown \& Forde (2004) in de Souza (2010:3) have pointed out the benefit of incorporating elements of students' home culture into the curriculum, which goes beyond acknowledging holidays, and sharing traditional recipes.

One weakness of this approach is that the mainstream curriculum remains unchanged in its basic structure, goals and salient characteristics (Banks, 2009:238). Another weakness to note is that in spite of the inclusion of these topics, diverse views are not 
stressed (Yao, Buchanan, Chang, Powell-Brown \& Pecina, and 2009:3). Teaching about heroes and holidays does not ensure any discussion of oppression, social inequality and struggles with racism and poverty (Cumming-McCann, 2008:3). Given these shortcomings, the contributions level may fail to bring about meaningful change in society and thus fail to realise the goals of multicultural education. Contributions approach often results in the trivialisation of ethnic cultures and the study of their strange and exotic cultures (Banks, 2009:238).

The additive level adds diversity to the curriculum by incorporating literature by or about people from diverse cultural groups into the mainstream curriculum (Yao, Buchanan, Chang, Powell-Brown \& Pecina, and 2009:3). According to Banks (2009:240), the ethnic additive approach is accomplished by the addition of a book or unit, or a course to the curriculum without changing it substantially. This may result in a situation where multicultural topics are added in the various subject areas and particularly the languages. The rationale behind this approach is that learners will be able to learn about other cultures and this tends to promote intercultural understanding further developing multicultural competence. One weakness of this approach is that the curriculum remains unchanged, which means that the curriculum may run counter to the goals and aims of multicultural education. Curriculum reform is imperative in multicultural education (Bennet, 2003:2). Banks (2009:240) has observed two weaknesses of this approach. Firstly, it usually results in the viewing of ethnic content from the perspective of mainstream historians, writers, artists and scientists because it does not involve restructuring of the curriculum. Secondly, it fails to help students to view society from diverse cultural and ethnic perspectives and understand the ways that the histories and cultures of nations, diverse ethnic, racial, cultural and 
religious are connected. Consequently, this approach may fail to reduce prejudice. However, the additive approach can be the first phase in a more radical curriculum reform effort designed to restructure the total curriculum and to integrate it with ethnic content, perspectives and frames of reference (Banks, 2009:240).

The transformative level approach changes the basic assumptions of the curriculum and enables students to view concepts, issues, themes and problems from several ethnic perspectives and points of view (Banks, 2009:242). The transformative level encourages students to adopt perspectives of minority groups (Yao, Buchanan, Chang, Powell-Brown \& Pecina, 2009:3). This approach tends to promote intercultural understanding resulting in the reduction of prejudice in society. The goal of the transformative approach is to enable students to view concepts and issues from more than one perspective and from the point of view of the cultural, ethnic and racial groups that were the most active participants in or were most cogently influenced by the event, issue or concept being studied (Banks, 2009:243). This approach encourages multiple perspectives taking.

The last approach is an extension of the transformative level. The social action level represents a step further by asking students not only to understand views and perspectives of others, but also to take action to bring about social change (Yao, Buchanan, Chang, Powell-Brown \& Pecina, and 2009:3). This includes all elements of the transformative approach but adds components that require students to make decisions and take actions related to the concept, issue or problem studied in the unit (Banks, 2009:245). In this regard, multicultural education will contribute to change in society as all its different components are brought under scrutiny with social action being undertaken. The social action level is similar to Grant \& Sleeter's (2009: 67) 
multicultural social justice education model. The major goal of the social action approach is to help students acquire knowledge, values and skills they need to participate in social change so that the victimised and excluded ethnic and racial groups can become full participants in the United States (Banks, 2009:246).

The major challenge facing this approach is that it requires a fully entrenched and supportive democratic political environment. Banks' (1993:13; 2009:237-249) approach to multicultural education can be taken as the basis of a spiral curriculum in multicultural education. One approach such as the 'contributions approach', can be used as a vehicle to move to other, more intellectually challenging approaches such as the transformation and social action approaches (Banks, 2009:246). For example, in the Zimbabwean context, in the infant grades, that is, grades one and two, emphasis could be on the contributions approach. In grades three and four, the emphasis could be on the additive level with the transformative level being emphasised in grades five and six. The social action level could then be a feature of the last primary school class, that is, grade seven.

It is important to note that the four approaches for the integration of ethnic content into the curriculum are often mixed and blended in actual teaching situations and the move from the first to higher levels of ethnic content integration is likely to be gradual and cumulative (Banks, 2009:248).

\subsubsection{NIETO'S CHARACTERISTICS OF MULTICULTURAL EDUCATION}

Another approach to multicultural education is provided by Nieto $(1997: 46 ; 2002: 31$ 46) who has identified seven characteristics of multicultural education. Nieto (2002:29) argues that the characteristics of multicultural education underscore the role that multicultural education can play in reforming schools and providing an equal and 
excellent education for all students. These characteristics are also reflected in some of the approaches that have been suggested in multicultural education in both the multicultural education model approach as well as the multicultural education continuum approach. These characteristics look at multicultural education as: antiracist education; basic education; important for all students; pervasive; education for social justice; a process and, critical pedagogy (Bode, 2010; Nieto, 1997:46; 2002:27-46; Nieto, 2009:82; Reissman, 2006).

Multicultural education as anti-racist education (Nieto, 2002:31) makes antidiscrimination explicit in the curriculum and teaches learners to combat racism and other forms of oppression. According to Henry et al. ( 2000) in Kirova ( 2008:106), anti-racist education challenges systemic racism, which consists of the policies and practices of organisations that directly or indirectly operate to sustain the advantages of people of certain 'social races'. According to Mathai Thomas (1994:73), Nieto observes that racism and discrimination are destructive and demeaning not only for those who suffer, but also everybody in society. Nieto (2004: 4) in Zimmerman (2004:4) asserts that multicultural education must "confront issues of power and privilege in society... challenging racism and other biases as well as the structures, policies and practices in schools". This is linked to the goals of multicultural education where the need to address racism is of paramount importance. Nieto (1997:46) observed that non-racist or non-discriminatory education implies that no learner will either benefit or be prejudiced in comparison with others in any educational activity. Educators have the responsibility to design curriculum materials that combat racism and discrimination. For example, there is need to accommodate all learners from diverse backgrounds in a multicultural nation like Zimbabwe. 
Multicultural education as basic education advances the basic right of all learners to engage in core academics and the arts. Multicultural literacy is an indispensable for living in today's world as reading, writing, arithmetic and computer literacy (Nieto, 2002:35). It addresses the urgent need for learners to develop social and intellectual skills to expand understanding in a diverse society. Nieto (2002:35) argues that monocultural education is at best, partial education, it deprives all students of the diversity that is part of our world. Therefore, multicultural literacy is recognised as a basic component in addition to arithmetic, writing and reading skills (Nieto, 1997:46). Diversity therefore needs to be emphasised in the content and practice of education. This enables pupils to function effectively in different cultural settings.

Multicultural education is seen as important for all students (Nieto, 2002:37). This challenges the commonly held assumptions that it is only for students of colour, multilingual students or special interest groups. Nieto (2000) in Gorski (2006:167) argues that people from the dominant group benefit most from multicultural education; it is people from dominant groups after all who tend to be the most misled, miseducated citizens when it comes to socio-political and socio historical realities. Therefore as multicultural education implies about everybody, it is also inevitably for everybody, irrespective of ethnicity, language, religion, gender, race or social class (Nieto, 1997:46). This emphasises the view that multicultural education is for all learners where all students should experience an equal opportunity to learn.

Multicultural education, as pervasive, emphasizes an approach that permeates the entire educational experience. The pervasiveness of multicultural education can be appreciated when considering that multicultural education is not something that happens at a set period of the day or another subject area to be covered (Nieto, 
2002:39). This includes school climate, physical environment, curriculum and relationships. Multicultural education must permeate school climate, culture and practice, that it must be visible everywhere, including decision making processes such as textbook adoption, behaviour policies and programme assessment (Nieto, 2000 in Gorski, 2006: 165). It should be seen as a philosophy, a way of looking at the world, not simply a programme or a class, or a teacher (Nieto, 2002:39).

Multicultural education for social justice demands a situation where teachers and their students put their learning into practice (Nieto, 2002:40). Students learn that they have the power to make change as apprentices in a democratic society. In this context, multicultural education should lead to the transformation of society. Developing a multicultural perspective means learning how to think in more inclusive and expansive ways, reflecting on what we learn, and applying that learning to real situations (Nieto, 2002:40). Learners have to be equipped with the necessary skills to take action to transform society for the benefit of all its members. (Nieto, 2000 in Gorski, 2006:167). Nieto (1992: 216) in Mathai Thomas, (1994:74) argues that “developing a multicultural perspective means learning how to think in more inclusive expansive ways, reflecting on what we learn, and putting our learning into action”. Multicultural education invites learners and teachers to put their learning into action for social justice. Multicultural education can therefore, be seen as bringing about social transformation of society.

Multicultural education as a process highlights the ongoing organic development of individuals and educational institutions involving relationships among people. Nieto (2002:42) observes that multicultural education is a process because it concerns such intangibles as expectations of students' achievement, learning environments, students' 
learning preferences and other cultural variables that are absolutely essential for schools to understand. These variables have to be addressed in the effective implementation of multicultural education. Multicultural education therefore requires a holistic approach if it is to be implemented successfully.

Multicultural education as critical pedagogy draws upon experiences of students through their cultural, linguistic, familial, academic, artistic and other forms of knowledge. Nieto (2002:42) argues that knowledge is neither neutral nor apolitical yet it is generally treated by teachers and schools as if it were. It also takes students beyond their own experience and enables them to understand perspectives, with which they disagree as well as to think critically about multiple viewpoints leading to praxis or reflection combined with action (Nieto, 2002:30). By nurturing this awareness, multicultural education uncovers policies and practices that are advantageous for some students at the expense of others (Nieto, 2000 in Gorski, 2006:167). Critical pedagogy acknowledges rather than suppress cultural and linguistic diversity (Nieto, 2002:42). Kincheloe (2008:7) argues that in critical pedagogy teachers must not only understand subject matter in a multidimensional and sophisticated manner, but must also be able in diverse settings to view such content from the vantage points of culturally and psychologically different students.

Having looked at the different approaches to multicultural education, there is need to look at how multicultural education is currently practised. Vandeyer (2003) has identified the following five different strands of multicultural education in its contemporary manifestation: teaching the culturally different; human relations; single group studies; multicultural education approach and education that is multicultural and social reconstructionist. These different strands show that multicultural education 
is implemented in a variety of ways. In other words, there is difference in the approach to multicultural education, a situation which is acceptable in the context of postmodernism. Research studies carried out elsewhere have shown differences in approach.

\subsection{MULTICULTURAL EDUCATION AND RESEARCH STUDIES}

Research studies carried out by Zimmerman (2004:10) in the United States have shown that the responses of the teachers in her sample confirm that teachers viewed multicultural education from the perspective of the celebratory and none of them talked about it in a way that demonstrated awareness of multicultural education as transformative. Diaz-Rico (1998) in Gorski (2006:163) concurs and argues that the multicultural education most often practised by teachers, administrators, staff developers and others in the United States is a conservatised, depoliticised version that does more to sustain inequities than to demolish them. According to Zimmerman (2004:18), the responses by the teachers about their perceptions of multicultural education support the assessment of researchers (Mulner, et al. 2003; Bruch et al., 2004; Brown, 2004, cited by Zimmerman, 2004:18) that there is a gap between theory and practice, which reflects a disconnection between how multicultural education is viewed by in service teachers and specialists.

Vandeyer (2003:195) has observed that in South Africa a recent report released by the South African Human Rights Commission states that the practice of multicultural education in South Africa is a far cry from any effort in equitable cultural trade. In her view, multicultural education is in the celebratory approach (Banks, 2009:237 contributions approach) in which parents are invited to a 'multicultural day at the school where a panorama of cultures, the dances, the dress, the dialect, the dinners are 
put on display. Meier \& Hartell (2009:189) are of the view that while the contribution approach is popular in South African schools, it appears this does not meet the demands of multicultural education. Van Heerden (1989) and Vandeyer (2006) in Meier \& Hartell (2009:181) points out that a 'cultural day' at school, such as a Zulu or Indian day, with a variety of foods or stringing together medleys of verses of songs in different languages as an effort by schools to signal acceptance of 'new' learners, is a superficial add on gesture that does little to bring about unity in diversity.

Gorski (2006:167) states that a majority of well-intentioned advocates of multicultural education in the United States respond that multicultural education is about 'learning about other cultures' or 'celebrating the joys of diversity'. He goes on to state that although such lessons and celebrations may be valuable, educationally they do not, when unattached from a transformative vision, move a classroom or school towards authentic multicultural education. There is need for fundamental changes in the school curriculum and environment for the realisation of authentic multicultural education. The problem is not that schools start at the celebratory/ contribution level but that they often stop here: what schools need to do is to move very quickly and steadily transform the curriculum (Meier \& Hartell, 2009:181).

At the same time in South Africa, Meier and Hartell (2009:181) argue that an approach that is adopted in most schools is known as the assimilationist approach that entails that the learners are expected to adapt to the existing character of the school and to curricular that has been implemented for a different learner population. Vandeyer (2010:344) concurs with Meier \& Hartell (2009:181). In her research study in South Africa, she found that the teaching strategy adopted by teachers in her sample was aligned to the hegemonic culture of the school (former white school 
culture would be of white students; former Indian school culture would be of the Indian culture) and fostered an assimilatory approach. Such an approach fails to accommodate student diversity and may result in a situation where all learners are not given an equal opportunity to achieve.

Haynes Writer (2008:3) argues that multicultural education may be thought of as a continuum with the superficial form on the one end, and on the other end is multicultural education as social justice. The superficial form adds a unit on minority 'Others' here and there, maintaining and supporting privilege of the dominant society (Haynes Writer 2008:3). This is similar to the celebratory/ contributions approach which fails to address curriculum reform. Pease-Windy Boy (a former tribal college president and Crow Nation citizen in the United States) addressed the superficiality of multicultural education by saying:

All too often the mainstream educational institutions regard cultural diversity as a few learning units that are cosmetically brown or black in complexion or as a few festivals that celebrate the food, clothing or dance of minorities (Haynes Writer, 2008:3).

In such circumstances, the goals of multicultural education may fail to bring about the transformation of society or address critically, such issues as racism and asymmetrical power relations in society. Therefore, multicultural education has to move beyond the celebratory approach. According to de Souza (2010:3), other researchers have pointed out the benefits of incorporating the students' home culture in the curriculum (Richards, Brown and Forde, 2004) cited by de Souza 2010) which goes beyond acknowledging holidays and sharing traditional recipes.

\subsection{CHALLENGES TO MULTICULTURAL EDUCATION}

The successful implementation of multicultural education faces a number of challenges (Bennet, 2003:xi; Manning \& Baruth, 2008:21; Banks, 2009; Zimmerman, 
2004:2; Vandeyer, 2003:195; Vandeyer, 2010:345; McKinney \& Soudien, 2010:7 and Haynes Writer, 2003:3). These challenges are concerned with the definition and operationalisation of multicultural education as well as the perceptions of teachers and administrators.

The definition of multicultural education has proved to be problematic as it has not been possible to come up with one universal definition. In the view of postmodernism, this is to be expected and should be construed as a normal situation. As a result there are numerous definitions that have been put forward for this concept. Maata (2008:8) argues that multicultural education is quite complex to define since there is no universally accepted definition for it. Zimmerman (2004:2) also argues that multicultural education has different definitions because people do not agree on the form of diversity it addresses. Lemmer, Meier, \& Van Wyk (2006:3) argue that multicultural education has been defined and interpreted in numerous ways and from a variety of perspectives by various individuals; as a result many educators have come to view multicultural education as ill defined and lacking in substance. They have therefore, been hesitant to adopt it as a sound educational approach, thus failing to see its value. However, despite the numerous definitions advanced for the concept, the different approaches to multicultural education appear to offer the solution to numerous definitions presented.

Banks (1993:3) and Bruch et al. in Zimmerman (2004:2) have observed that there is a gap between theory and practice in the field of multicultural education. Critical pedagogy theorists (Brown \& Kysilka, 1994; Cole, 1986; May, 1994; and Wilhem, 1994 in Kirova, 2008:106) also identify this gap, between theory and practice, as a major weakness of multicultural education. According to Gay in Banks (1993:3), 
theory development has outpaced developments in practice and as such, a wide gap exists between the two. May (1999) in Haynes Writer (2008:3), concurs and posits that as the multicultural education movement spread, it 'promised much but delivered little' because it was often presented and practiced superficially. This challenge arises as a result of failure by educators to fully implement multicultural education. For example, Banks's (2009:237-249) approach which has been named the multicultural education continuum approach may lack full implementation.

All the phases on this continuum may not be implemented; therefore the gap arises as a result of the nature and extent of implementation. Sleeter (1998) in Gorski (2006:164) advises that one must distinguish between an approach as formulated by (multicultural education) main theorists and superficial applications of it that one often finds in school as well as in literature. This has seen a situation where some superficial approaches in multicultural education end up at the contributions or celebratory phase. A solution suggested by Bruch et al. (2004) in Zimmerman (2004:4) is to integrate the different levels of implementation. In terms of Bruch et al. (2004) in Zimmerman (2004:4) approach, which is also part of the multicultural education continuum approach, the contributions, critical and transformative levels could be integrated. As argued in this thesis, these levels become one with the implementation of such a spiral curriculum, starting in the first grade of primary school.

Vandeyer (2003:195; 2010:345) and McKinney \& Soudien (2010:7) are of the view that multicultural education does not challenge power relations in society. These power relations are asymmetrical since power is unevenly distributed in society. This could be as a result of the view that multicultural education places a lot of emphasis 
on cultural diversity while other issues or variables of multicultural education tend to be overshadowed. Carrim \& Soudien (1999) in McKinney \& Soudien (2010:7) are of the view that multicultural education essentialises culture and in the process, depoliticises it. Torres in May (2009: 34) is of a similar opinion. He argues that there is a tendency for multiculturalism to concentrate on culture at the expense of structural concerns such as racism and socio economic inequality. Critics argue that the concept of culture is simplified and reified to fit multicultural discourses that support visions of personal, ethnic, or national cultural identity that are fixed, essentialised, stereotyped and normalised (Bateson,1994; Perry, 1992; Musgrove, 1982; Turner, 1993; and Wax, 1993 in Kirova, 2008:107). According to Banks (1993:3), critical multicultural education presents a solution to this problem. Critical multiculturalism addresses the shortcomings of the multicultural education approach by; attempting to theorise ethnicity in non-essentialist ways, acknowledging unequal power relations and critiquing state constructions of culture (Bruch et al. (2004) in Zimmerman, 2004:4).

There is a view that cultural pluralism is dangerous to society because it heightens ethnic group identity and leads to separatism, polarisation and intergroup antagonism (Bennet, 2003:56). This appears to be a misinformed assumption. The opposite is valid in the sense that policies such as assimilation and cultural integration tend to fuel internecine ethnic strife if the events in the Great Lakes regions of Africa in the early 1990s are anything to go by. One of the goals of multicultural education is to foster the tolerance of the 'other' who, in most cases, is not only considered culturally different but also inferior as well. Cultural pluralism should not be considered to be a danger to society in a multicultural environment where different ethnic groups view 
their different cultures in an egalitarian mode as opposed to a superior inferior mode. The involvement of the community in the affairs of the school, where members of different ethnic groups cooperate for a common purpose may show multiculturalism at work and this enhances tolerance and appreciation of cultural diversity.

Bennet (2003: xi), argues that a few schools have become multicultural in their visions or practice. Such schools are hampered by societal policies and practices beyond their control that impede reform of the formal and the hidden curricular. It follows that the socio political environment plays an important part in initiating curriculum reform. Most African countries, Zimbabwe included, initiated curriculum reforms with the attainment of independence. The goal was to make the curriculum more relevant and meaningful to the learner. However, the extent to which such reforms reflect the plural character of the society is a matter of debate. At the same time, in some countries in Africa and other parts of the world where a democratic political environment is absent, such curricular reform efforts may be misconstrued as part of an imperialist sponsored regime change agenda. Educators have to persistently lobby their national governments for the realisation of the importance of multicultural education.

Shortage of funds and lack of understanding have made it difficult for some schools to replace or supplement biased or outdated books (Bennet, 2003: xi). Wideen \& Barnad ( 1999) in Kirova ( 2008:107) say that in the past decade , however, concern has increased among the general public researchers and practitioners that schools are poorly equipped to cope with increased diversity and that instead of playing a role in facilitating equity and belonging, they may become locations that foster isolation and replicate racialised forms of injustice. In some countries the challenge is not on the 
shortage of funds only, it is also on book publishers who may continue to churn out volumes and volumes of books whose content is at variance with the ideals of multicultural education. This creates an unfavourable situation where issues dealt with in the classroom on multicultural education are not reinforced by the content of curriculum instructional materials. Because of this the successful implementation of multicultural education hinges on the multicultural competence of the teacher, as well as the perceptions and attitudes of the teacher towards multicultural education. In certain instances, such attitudes may not always be positive. This state of affairs may also be exacerbated by low levels of remuneration and the conditions of service whose cumulative effect has a negative impact on teacher motivation. Therefore schools are left with little option, mobilisation of the parental body through their elected representatives in the School Development Association (SDA) or School Development Council (SDC) is called for.

Teachers and administrators may also present challenges for the implementation of multicultural education (Bennet, 2003: xi). This scenario tends to arise due to the presence of teachers and administrators who are ill informed about cultural diversity and whose knowledge of history and current events is mono-cultural in scope (Bennet, 2003: xi). In most situations, for example, in Zimbabwe, a multicultural school curriculum may be a departure from their own experiences and against their prejudices. This can be overcome by conscientising members of the school administration on the importance and relevance of multicultural education.

Ramsey, in Manning \& Baruth $(2008 ; 21)$ points out that some parents who identify with the mainstream culture feel threatened by the arrival of different people (in the school). Such parents may resent efforts to have their children think positively about 
these groups (Ramsey, 1987 in Manning \& Baruth, 2008:21). This situation is reminiscent of the developments that took place in Zimbabwe soon after independence following desegregation in 1980. After nearly a century of racial discrimination and entrenched white privilege, most whites could not accommodate the idea of blacks and whites learning in the same classroom. As a result, a significant number of white parents withdrew their children from low density urban schools they were attending some of which had become community schools in terms of the provisions of the 1979 Education Act. They went ahead and established private schools such as Lomagundi College in Mashonaland West Province, Bryden Country School in Mashonaland West, Falcon College in Matabeleland South, St. Johns College in Harare and Hillcrest in Manicaland among many others. This reaction by some white privileged members of society has also been experienced elsewhere in South Africa and the United States of America.

Vandeyer (2010:344) observed that in South Africa, as African students flocked to historically white and Indian schools in search of quality education, a large percentage of students migrated to model $\mathrm{C}$ white schools. She further states that admission was by proxy as affluent previously white public schools subsequently reacted by raising the school fees in an attempt to keep black students out. In Lousiana, East Baton Rouge Parish in the United States of America under desegregation mandate, there was a white exodus from public schools and by the late 1990s nearly two thirds of the students in the public schools of Baton Rouge were minority students and the trend seemed continuing and accelerating (Bankston \& Caldars, 2002 in Asher, 2007:66). Even with desegregation, some mainstream black Zimbabwean parents may also loathe the inclusion of pupils from certain ethnic backgrounds as a result of 
ethnocentrism. In such a scenario, a lot of effort has to be made to convince parents and other stakeholders on the need to accommodate cultural diversity in schools.

\subsection{CURRICULUM ISSUES IN MULTICULTURAL EDUCATION FOR ZIMBABWE}

The successful implementation of multicultural education requires due attention to a number of curriculum issues. The curriculum has to be reformed in order to reflect and accommodate the cultural diversity of society. Therefore, a number of issues need consideration and these include knowledge construction, language policy, selection of curriculum content, textbooks and instructional materials, the school environment and community involvement in the affairs of the school.

\subsubsection{KNOWLEDGE CONSTRUCTION}

Postmodernism places emphasis on the plural character of knowledge as well as its ephemeral nature. It needs to be acknowledged that knowledge is socially constructed during social interaction and is therefore relative (Lyotard in Kirby et al, 1997:719). It follows that what may be taken as knowledge in one society may not necessarily be so in another society. What is taken as knowledge in society should be seen as a selection from a number of possible options. With the advent of colonialism in Zimbabwe and elsewhere, western Eurocentric forms of knowledge were imposed on the colonised. Kincheloe (2008:5) argues that one of the central dimensions of western colonial domination has involved its production of 'universally valid' knowledge that worked to invalidate the ways of knowing that had been developed by all peoples around the world. Local forms of knowledge or indigenous knowledge forms were not emphasised. In fact, local knowledge forms and ways of knowing were denigrated and dismissed. Therefore, postmodern theory questions the validity 
of Eurocentric knowledge as being the exclusive reference point of judging all learning (Ghosh, 2002:49). Giroux (1991) in Ghosh (2002:50) argues that there is no tradition or story that can speak with authority and certainty for all humanity.

Educators therefore need to recognise the diverse and plural nature of knowledge. McKinney \& Soudien (2010:43), state that May (2009) draws attention to the need to examine knowledge structures in the school curriculum and the ways in which these align with those in power. May (2009: 43) in McKinney \& Soudien (2010:7) states that:

In particular, attention needs to be paid to the processes by which alternative cultural knowledges come to be subjugated principally through the hegemonies and misrepresentations (...) which invariably accompany such comparisons (of hegemonic and subjugated knowledges).

This shows that there is a link between knowledge and power with those in power defining what knowledge is. Postmodernist theorists acknowledge that there is a relationship between knowledge and power.

In Zimbabwe and other parts of Africa, colonialism emphasised western Eurocentric forms of knowledge. A Eurocentric viewpoint ignores the contemporary and historical contributions of most of the world's people, especially those in Africa, Asia, Central and Latin America (Ghosh, 2002:49). This shows that knowledge is not neutral and what is taken as valid knowledge is a selection from a number of possible options available. It should be emphasised that knowledge is embedded within a certain cultural context. Therefore, both the teachers and the curriculum must validate the home and community knowledge that learners bring to school (Campbell, 1996:22) in an attempt to accommodate diversity in society. Minority students need teachers who are transformative intellectuals, who take seriously, the need to give students an active voice in their learning experiences; teachers who understand that knowledge is power 
and that students must be afforded the opportunity to understand themselves critically as part of society (Giroux, 1988 in Ndura, 2006:1).

Given these views, it becomes important for learners to be given an active voice in the learning situation. In a research on social studies text books conducted by Yao, Buchanan, Chang, Powell- Brown \& Pecina (2009:7-12) in Mexico, United States, Canada and China, it was established that in terms of knowledge construction there was a general lack of authentic voices in the textbooks with the exception of Canada. Educators have a responsibility to ensure that learners' authentic voices are heard in the learning and teaching situation. Moll et al. (1992) and Moll \& Gonzalez, 2004 in de Souza 2010:3) state that when teachers get to know their students and find ways to incorporate their home based expertise or 'funds of knowledge' in the classroom, students are better able to make connections between topics and across languages thus maximising their learning. This should enable students to appreciate that knowledge is socially constructed. The teacher needs to understand the nature of knowledge and to understand that knowledge is a process (Banks in Lockwood, 1992, cited by Reissman (2006).

\subsubsection{SELECTION OF CURRICULUM CONTENT}

Banks's (2009:20, 1993:13) dimensions of multicultural education and Bennet's (2003) views on multicultural teaching highlight the importance of selection of curriculum content. The selection of curriculum content should be informed by culturally responsive teaching as well as culturally responsive pedagogy. (Banks 2009:234) argues that a mainstream-centric curriculum has negative consequences for mainstream students as it reinforces their false sense of superiority, gives them a misleading conception of their relationship with other racial and ethnic groups. It also 
denies them an opportunity to benefit from the knowledge, perspectives and frames of reference that can be gained from studying and experiencing other cultures and groups. Effective multicultural education therefore calls for curriculum reform. Curriculum reform strives to expand traditional course contents that are primarily mono-ethnic (in the United States), Anglo-European through the inclusion of multiethnic and global perspective (Bennet, 2003:2). In Zimbabwe, the Nziramasanga Commission Report (1999) found out that Zimbabwe's education system can best be described as Eurocentric in its cultural content and orientation. This emphasises the need for curriculum reform.

Ghosh (2002:3) argues that change in curriculum is necessary. This is because not only a more comprehensive picture of culture and the world would enrich the education of students, but that it is also necessary because the principle that all human beings have equal value demands that some students should not be given demeaning pictures of themselves in school through the curriculum and school environment. According to Nieto (2002:35), mono-cultural education; is at best partial education, it deprives all students of the diversity that is part of our world. In this regard, curriculum reform is imperative. Gollnick \& Chinn (2012:30) argue that each subject area must be taught from a multicultural perspective. This means that multicultural education must permeate all subjects in the school curriculum. In fact, multiculturalism should be such a basic part of the school that it becomes a natural and accepted aspect of daily routine (Manning \& Baruth, 2008:8). The selection of curriculum content should be done in such a way that it celebrates the plural character of society. 


\subsubsection{TEXTBOOKS AND CURRICULUM INSTRUCTIONAL MATERIALS}

In the implementation of multicultural education, textbooks play a very important role, given the various approaches to multicultural education that have been discussed in this thesis. These various approaches to multicultural education demand that certain content be included in the textbooks. The bottom line is that all textbooks used in the school should reflect the plural character of society. Apple (1993) in McGovern (1999:20) argues that the textbook is one artefact that plays a major role in defining whose culture is taught. Therefore, school textbooks should be multicultural in all respects. Ideally, multicultural education, according to the Banks (2009) model, would be infused throughout education content and experiences (Yao, Buchanan, Chang, Powell- Brown \& Pecina, 2009:12). This applies to all textbooks used in the primary school although subjects such as the languages, Social Studies and Religious and Moral education can be considered to be ideal carrier subjects for multicultural education. Sleeter \& Grant (2003) state that multiculturalism does not belong exclusively in social studies or in museums field trips, but is part of every teacher's epistemology. All school subjects should therefore be taught from a multicultural perspective.

The experiences of all ethnic and social groups have to be reflected in textbooks that pupils read, which means that all textbooks should be saturated with multicultural topics that reflect the plural character of the country. If students seldom see representations of themselves, their families or their communities, it becomes difficult to believe that the academic content has any meaning or usefulness for them; it will appear that the subject matter has been written and delivered for a different group of students (Gollnick \& Chinn, 2012:310). Ghosh (2002:57) states that students are 
valued and devalued through their presence in the curriculum, for example, when a student finds no reference point in texts which she can identify, or if her ethno cultural group is portrayed in a negative light, then she feels devalued. Carjuzza (2012:5) is of the view that many minority groups and American Indians are often inaccurately portrayed and their contributions are inadequately represented in standard k-12 public school curricular. portrayed .Therefore, in the Zimbabwean context, the experiences of ethnic groups such as the Tonga, Kalanga, Venda, Sotho, Nambya, Shangaan and others should be included in the curriculum and instructional materials used country wide ( Muchenje, 2008:14).

This should lead to intercultural understanding as well as appreciation of multicultural differences. At the same time, learners are provided with an opportunity to tolerate and appreciate cultural differences. The challenge facing multicultural educators is to select textbooks and other materials that objectively represent various groups and people who either have been traditionally ignored or misrepresented (Manning \& Baruth, 2008:210). In China, Wang ( 2003:10), building on the work done by Apple \& Smith ( 1991) and Banks ( 2007), theorises that the exclusion of minority groups' knowledge, language and cultures from school textbooks conveys a message to both minority and Han students that minority knowledge, language and culture are not important and not worth learning ( Wang cited by Wang \& Phillion, 2009:10). Such a situation tends to lower the self-esteem of minority learners and falls short of the goals of multicultural education. The importance of textbooks in multicultural education is shown by the fact that it was an issue of concern during the Civil Rights Movement in the United States. Advocates of ethnic studies sought the replacement of the primacy of whiteness in textbook content and illustrations and an increased 
accuracy in reporting the history and culture of African Americans, Native Americans, Asian Americans and Latinos (Grant, 2008:7). Educators therefore have a responsibility in the selection of relevant curriculum content.

\subsubsection{LANGUAGE POLICY}

The question of which language to use as the official language, as well as the language of instruction in the education system, is an emotive issue. The question of which indigenous language is to be taught in the education system adds a further dimension to this emotive issue. At the broadest level, mismatches between the language of learning and teaching and the linguistic resources learners bring with them to school create real problems of access to the curriculum for many learners (McKinney \& Soudien, 2010:11). Multicultural education has to accommodate society's linguistic diversity. Nieto (2002:46) argues that what is evident to proponents of diversity education however is that an imposed language that neglects languages other than the lingua franca is in direct contradiction with the very nature of social justice and equal rights. All languages need to be given due priority in the education system. Zimbabwe has sixteen indigenous languages (Hachipola, 1998 in Viriri, 2003:2; Gora, Mavunga, Muringani \& Waniwa, 2010:87). In terms of the Constitution of Zimbabwe Section 6 (1) these languages are the officially recognised languages of Zimbabwe and the state must promote and advance the use of all languages used in Zimbabwe, including sign language, and must create conditions for the development of those languages ( Constitution of Zimbabwe Section 6 (4). This presents challenges to efforts directed at accommodating linguistic diversity.

Linguistic problems faced by many countries in Africa are a result of colonialism. Education across ethno linguistic groups was not necessary until the arrival of 
colonialism and western education when formal schools were introduced and children who spoke different languages were often placed in the same classroom (Sa, 2007:2).

This has presented problems on the choice of languages to be used in education. The problem to accommodate linguistic diversity is not only limited to Zimbabwe. In China the Han Chinese make up $92 \%$ of the total population, formal education is delivered in Mandarin Chinese, the language used by the educated Han Chinese and the quickest way to wealth and modern life in the country (Geary \& Pan, 2003 in Yao, Buchanan, Chang, Powell-Brown \& Pecina, 2009:5). This presents problems as other minority languages in China tend to be marginalised. As a result of colonialism, western languages assumed superiority over indigenous languages. Western languages and cultures were assumed to be richer and more civilised because, having evolved from the Greek and Latin literacy heritage (Treftgarne 1978 in Rwantabangu, 2011:2), they gradually marginalised and dominated indigenous cultures and languages which were thought to be 'crude and heathen' (Spencer, 1971 in Rwantabangu, 2011:2). Indigenous languages then tended to suffer.

Instruction in the mother tongue in the education system has been seen to bring a number of benefits. The UNESCO Committee of Experts in 1953 stated that the best medium for teaching a child is the mother tongue which children understand better and express themselves freely (Ndamba, 2008:175; Fasold, 1987, in Gora, Mavunga, Muringani \& Waniwa, 2010:91). This means that language policies in multicultural states that practise multicultural education have to accommodate the mother tongue. It should be appreciated that language is a carrier of culture which gives individuals an identity. Use of the mother tongue as a medium of instruction in lower grades engenders an appreciation of their cultural values more than is the case when they are 
taught about the world around them in another language (Gora, Mavunga, Muringani \& Waniwa, 2010:91).

Zimbabwe's language in education policy is enshrined in the 1987 Education Act as amended. This noble piece of legislation is a departure from the language policy pursued in the colonial era. The Judges Commission which had been tasked to look into the African Education system had recommended that children should learn to write and read English from the first day of grade one, Shona and Ndebele therefore had been used as media of instruction until 1962 (Ndamba, 2010:246). After independence the government realised the role played by the mother tongue in learning, thus an educational policy raised the status of indigenous languages (Ndamba, 2008:242). For the first time the place of indigenous minority languages in the education system was acknowledged.

In terms of the 1987 Education Act, indigenous minority languages such as Tonga, Venda, Kalanga, Nambya and Shangaan are to be taught up to grade three levels in those areas where they are commonly spoken and understood. It follows that these languages are also the media of instruction up to grade three in these same areas. From grade four pupils revert to either Shona or Ndebele as the case may be. In addition, English remains the official language as well as the medium of instruction in education. Zimbabwe's official education language policy for grades 1 to 3 falls under the transitional and delayed immersion programme (Ndamba, 2008:173). This is so as English as a language is introduced later after learners have received instruction in the mother tongue.

Although the Education Act of 1987 has been described as a noble attempt to address the country's linguistic diversity, it results in subtractive bilingualism for all the 
learners coming from indigenous language backgrounds. Subtractive bilingualism occurs when the acquisition of a second language and culture takes place at the expense of the first language, which according to Cummins (2000) has been associated with disabling educational settings for minority language speakers (Molosiwa , 2009:4; Ndamba, 2008:172,). In Zimbabwe as elsewhere in Africa, bilingualism has tended to be subtractive because socio cultural attributes of indigenous languages have been denigrated in favour of those of the colonial language, which is considered to be more prestigious (Thondhlana, 2002:34). Cummins (2001) cited by Diaz-Rico \&Weed (2010) in de Souza (2010:3) argues that schools that accept and appreciate the home languages and cultures of students help them to develop additive bilingualism and strong identities, whereas schools that allow for disrespect and discrimination to take place hinder both social and emotional development. What is required is a policy of additive bilingualism which refers to the maintenance of the home language alongside effective acquisition of the additional language (McKinney \& Soudien, 2010:12).

There is also need to consider those learners whose mother tongue is not used as a medium of instruction up to grade three levels. Such learners whose mother tongue is not taught and recognised in the education system in terms of the 1987 Education Act do not benefit from instruction in the mother tongue, for example ,pupils whose mother tongue is Chewa/ Nyanja. In addition to subtractive bilingualism such pupils also experience transitional submersion. For children from minority groups, it is a transitional submersion programme in that their L1 is not used at all (Adeyemi, 2008:24). As a result, learners' educational experiences are negatively affected. Freire in Goduka (1998) as cited in Muchenje, Goronga \& Bondai (2013:502) argues that 
negating the native language and its potential benefits in the development of student's voice is a form of psychological violence and functions to perpetuate control over subordinate language groups through various linguistic forms and 'cultural invasion'. However, it is heartening to note that subsection 4 of the 1987 Education Act empowers the Minister to authorise the teaching of minority languages in addition to those specified in subsections 1, 2 and 3 of the same Act. Thus, the 1987 Education Act creates an environment for the teaching of indigenous languages for the benefit of all pupils in the country.

A further amendment to the 1987 Education Act was added in 2006 and states that prior to form one, indigenous languages may be used as a medium of instruction (Ndamba, 2010:243).This enables Zimbabwe to celebrate linguistic diversity although this policy amendment is still to be put into practice. However, Thondhlana (2002:33) argues that recognition of the 1987 Education Act is largely in word only since in Zimbabwe most schools prefer to use English, which is considered the language of power and economic well-being. What is required is the political will to bring about such positive changes.

There have been further developments in terms of language policy since the 1987 Education Act; the Secretary's Circular Minute Number 3 of 2002 has made further positive provisions. In terms of this Circular Minute, Tonga, Kalanga, Sotho, Nambya and Shangaan were to be taught up to grade seven levels by 2005. A lot of progress has been recorded in the teaching of indigenous languages in primary schools with the first grade seven Tonga examinations being written in 2010. It is only Tonga that has been examined at grade seven level at the time of writing. The same Circular Minute acknowledges Nyanja, Sotho, and Swahili as languages to be 
taught at secondary school level. The question of language in education policy needs to be seriously considered. The Nziramasanga Commission Report (1999: 168) has made the following important recommendations: there is need to recognise linguistic rights as human rights which all citizens should enjoy; there is need to protect and promote respect for all community languages regardless of the number of speakers and their level of development. Nieto (2002:42 offers a similar view. She argues that critical pedagogy acknowledges rather that suppress cultural and linguistic diversity. These recommendations, if taken on board, will go a long way in addressing Zimbabwe's linguistic diversity. The teacher must therefore validate students' own language, not blame them or judge them as being deficient for not knowing the dominant languages (Ghosh, 2002:50).

\subsubsection{TEACHER ATTITUDES AND EXPECTATIONS}

Teacher attitudes and expectations play an influential part in the successful implementation of multicultural education. These attitudes and expectations will influence, to a great extent, their perceptions of the dimensions of multicultural education as well as the different approaches that have been outlined in the implementation of multicultural education. In the United States of America Gorski (2006:167), found out that responses of multicultural education professionals in the definition of multicultural education typically reflect more of a compassionate conservative consciousness than an allegiance to equity and justice. This has implications for the implementation of multicultural education. Their attitudes and perceptions of differences will inform the way and manner in which multicultural education is implemented. 
It has to be noted that teacher learner interaction lies at the heart of the educational process. Ndura (2006:9) argues that teacher-student relationship is pivotal to the teaching and learning experience; for culturally diverse students, this relationship takes an even greater sense of urgency since educators are major gatekeepers in the system. It is through this process of interaction that some learners feel either important or worthless. La Belle in Schmeichel (2012:216) contends that good teachers in an ideal school would promote attitudes and behaviour patterns conducive to providing equal opportunities for all pupils. Teachers need to accommodate learners' cultural diversity in the classroom. Accepting every child as a valuable individual is the foundation for multicultural education and a significant goal for teachers (Jokikoko, 2005; Koppinen, 1999 as cited in Maatta, 2008:14). This creates a classroom environment that is conducive for all learners to thrive academically to their maximum potential. In this context, teachers must be free of racial prejudice and ethnocentrism if they are to be effective with students of diverse cultural, racial or socio economic backgrounds (Bennet, 2003:20). This becomes important when viewed in the context that teaching is a cross cultural encounter; all teachers and students have their own cultural baggage, their background, values, customs, perceptions and perhaps prejudices ( Hernandez in Manning \& Baruth, 2008:8).

In South Africa, Vandeyer (2010:348), in her research, found out that there seemed to be a general apathy and non committal to multicultural education among the majority of teachers in terms of creating a warm and welcoming environment for all learners. On the other hand, a Finnish study undertaken by Mietten \& Pitkanen in Maata (2008:16) revealed that one third of the sample thought that the fact of having immigrant children in the classroom will increase the tolerance of cultural diversity. 
These differing situations tend to affect teacher learner interaction. A major goal of multicultural education is the development of the intellectual capacity of the learner. The attainment of this goal depends on the teachers' attitudes and behaviour, and whether he or she provides equitable opportunities for learning, changes the monocultural curriculum and helps all students become more multicultural (Bennet, 2003:14).

Teachers' perceptions of multicultural education are very important in its implementation. Banks (2009:239) argues that multicultural and sensitive teaching materials are ineffective in the hands of teachers who have negative attitudes towards different cultural groups. This highlights the importance of teacher attitudes, perceptions and expectations. The effective multicultural educator should posses relevant knowledge, skills and attitudes (Manning \& Baruth, 2008:8; Martines, 2005:10). In terms of knowledge, there is need for educators to understand individual learners' culture and this demands multicultural competence on the part of educators. In terms of skills, there is need to recognise and respond appropriately to learners' strengths and weaknesses. Relevant attitudes demand that educators develop positive outlooks and values as well as creating culturally appropriate environments. Teachers need to show positive attitudes towards learner diversity and validate the differences that different learners bring into the classroom situation. Denigrating learners who come from other cultural backgrounds works against the ideals of multicultural education. This may arise out of a situation where educators' perceptions, attitudes and personal experiences may fundamentally be at odds with the experiences of their learners who come from a different background in class, religion, gender and culture (Rios, 1996 in Meier \& Hartell, 2009:187). 
Teachers have to handle diversity in education and this requires a reappraisal of educators' own personal and institutional ideologies and perceptions and a frank conviction and dedication to facilitate and manage learner diversity (Meier \& Hartell, 2009:189). This demands that teachers must have an in depth knowledge about ethnic cultures and experiences to integrate ethic content, experiences and points of view into the curriculum (Banks , 2009:236).

Teachers' expectations in terms of achievement of pupils from different cultural backgrounds have a profound impact on multicultural education. In a number of cases teachers tend to harbour lower expectations for learners from certain cultural backgrounds. Lower teacher expectations for particular racial or ethnic groups are based on negative racial or ethnic prejudice and teachers, like all people, are often not aware of their prejudice that is they may not be aware of their lower expectations for some students (Bennet, 2003:26). This situation can affect learners' educational experiences negatively. In western countries such as the United States of America, Canada and others, teachers claim that they treat all learners equally, they do not see colour. This is an approach that does not do cognitive justice to culturally diverse learners; and within this approach some learners may continue to be marginalised. In a Zimbabwean setting, some teachers, particularly those in rural areas and high density urban schools, may claim to treat all learners equally and that they do not see colour and ethnicity. This view ignores the cultural diversity inherent in the learner body where some learners, even though they are black indigenous Africans, continue to be disadvantaged and marginalised. Beairsto \& Carrigan (2004:3) argue that some educators try to be 'colour blind' and treat students equally. They further argue that this confusion of equality with equity is, often just as harmful as racial prejudice 
because denying differences also denies students' unique needs and abilities, which makes it impossible to respond constructively to them. When educators claim that their top priority is to treat all children like human beings regardless of ethnic identity and cultural background, they are creating a paradox (Gay, 1994). In order to provide an equitable classroom environment, teachers should demonstrate multicultural competence.

Multicultural teachers seek intercultural competence, inter-culturally competent teachers are aware of the diversity within racial, cultural and socio economic groups, they know that culture is ever changing and they are aware of the dangers of stereotyping (Bennet, 2003:42). Teachers' view of diversity has an impact on multicultural education. Zimmerman (2004:17) in a research in the United States of America found out that teachers' simplistic view of diversity allows them to comfortably celebrate diversity without having an awareness of, much less critiquing and transforming, the social injustices and educational inequities that exist in our society ( Zimmerman, 2004:17).

\subsubsection{THE SCHOOL ENVIRONMENT}

The total school environment should reflect the plural character of society. Multicultural education must deal with the total culture of the school. Multicultural education demands that the whole school becomes a culturally competent educational system, which means there is need for support from the school administrator (Brown, 2007 in Maatta, 2008:21). Multicultural education must deal with the total culture of the school; it must be aware of the differential treatment of students who have very dissimilar experience because of certain differences based on race, gender, culture or class ( Ghosh, 2002:3)). This is important in the sense that multicultural education 
developments taking place inside the classroom should be reinforced by the school environment.

Bennet (2003:23-25) has outlined how some schools have responded to cultural diversity following desegregation and she come up with five typologies of responses all of which have an impact on multicultural education efforts. In this regard, the school environment can be indicative and suggestive of the type of school response according to Bennet's (2003:23-25) typology. According to Manning \& Baruth (2008:225), the school environment includes all experiences with which learners come into contact: content, instructional methods, the actual teaching and learning process and environment, the professional staff and auxiliary staff members as well as the actions and attitudes of other students. Ethnographic research in many Canadian schools reveals that students who are different experience a 'chilly climate' in school, the hostile climate results when some students are excluded from the content and method of learning but also from the culture of the school through messages that they are unimportant and have second class status (Ghosh, 2002:69). Gay, (1994) concurs and states that if students feel that the school environment is alien and hostile towards them or does not affirm and value who they are (as many students of colour believe), they will not be able to concentrate as thoroughly as they can on academic tasks.

Educators need to recognise that the school should be a cultural environment in which acculturation takes place; teachers and students should assimilate some of the views, perspectives, and ethos of each other as they interact (Banks, 2009:236). The school environment should be conducive and should accommodate learners from diverse backgrounds. Schools establish the conditions under which some individuals and groups define the terms by which others live, resist, affirm and participate in the 
construction of their own identities and subjectivities (Giroux 1988, in Ndura, 2006:1). Schools therefore create a culture of either empowerment or denigrating conformity to the status quo (Ndura, 2006).

The school environment has to reflect ethnic diversity. Ghosh (2002:69) argues that schools should be organised for the needs of children, not for the benefit of educational administrators. Ethnic diversity should be reflected in assembly programmes, classrooms, hallways, and entrance decorations, cafeteria menus, counselling interactions and extra-curricular activities (Manning \& Baruth, 2008:243). There are a number of variables that need to be examined. Banks (1993:5) argues that among the variables that need to be examined are: grouping practices (Braddock, 1990; Oakes, 1995 cited in Banks, 1993:5); labelling practices (Mercer, 1989 cited in Banks, 1993:5); the social climate of the school; and staff expectations for student achievement (Brookover, Beady, Flood, Shweitzer \& Wisenbaker 1979 as cited in Banks, 1993:5). These variables create a school culture that empowers students from diverse ethnic and cultural groups.

In providing a conducive school environment, the following issues should reflect the plural character of society and should be considered: assembly programmes, language used on bulletin boards, participation in co-curricular activities and the selection of students to the prefects body. Assembly programmes should highlight society's cultural diversity. Notices on bulletin boards should use all languages commonly spoken by the learners apart from English. All learners, irrespective of their ethnic groups and gender, should be afforded an opportunity to participate in the schools' cocurricular programme. Selection of learners to the prefects' body should be done in such a way that learners are drawn from diverse backgrounds. The composition of the 
school staff should also reflect society's multicultural character. For, it is within the confines of the school as a microcosm society that seeds of a socially just and democratic society are planted, germinate and are nurtured to blossom into a healthy and flourishing tree that would weather any storm and provide magnanimous shade against the harsh rays of the sun ( Vandeyer, 2010).

\subsection{COMMUNITY INVOLVEMENT}

Parents and other members of the community are key partners and important stakeholders in the education of their children. They have a role to play in the implementation of multicultural education. MacDonald (1998) in Lemmer Meier \& Van Wyk (2006:131)) states that parental involvement is a dynamic process whereby educators and parents work together for the ultimate benefit of learners. Thus Gollnick \& Chinn (2102:327) argue that a school that affirms multiculturalism will integrate the community in its total programme. Parents and other stakeholders should participate in the affairs of the school as voluntary workers, guest speakers and resource persons. According to Banks (2009:419) parent involvement is important because it acknowledges the importance of parents in the lives of their children. She goes on to say that parental involvement recognises the diversity of values and perspectives within the community and provides a vehicle for building a collaborative problem solving structure. Parental involvement is generally seen as encompassing a broad array of activities both at home and at school, as well as parents' transmission of their own skills, knowledge, attitudes and values to learners (MacDonald (1998) in Lemmer, Meier, \& VanWyk, 2006:132). The community is a reservoir, containing many educational resources which the school can tap (Nziramasanga Commission Report (1999:31). Manning \& Baruth (2008:245) are of the view that efforts to 
provide multicultural education curricular and environments must extend beyond the confines of the school; children and adolescents need to perceive evidence of recognition and respect for cultural diversity in the home and in the community. Thus, the selection of parents for such activities should reflect the plural character of society. All school committees, teams and organisations should be representative of the diversity of students, staff and communities; and all members must have equal status and equal power to speak and be heard (Ghosh, 2002:72). This means that parental involvement should cut across race, ethnicity, social class, gender and disability. In Zimbabwe, Statutory Instrument Number 70 of 1993 paves way for the establishment of School Development Associations (SDA) or School Development Committees (SDC) whose members are parents of children enrolled at a school. The selection of parents to the SDC or SDA should be done in a way and manner that reflects the plural character of the school.

\subsection{CRITIQUE OF MULTICULTURAL EDUCATION}

Multicultural education has some benefits for society. It is an approach that seeks to provide all learners with an equal opportunity to achieve. Ogbu (1992:5) states that, taken together, multicultural education fosters pride in minority cultures, helps majority students develop new insights into their culture, reduces prejudice and stereotyping and promotes intercultural understanding. Multicultural education sets out to create equal educational opportunities for students from diverse racial, ethnic, social class and cultural groups by acknowledging difference (Vandeyer, 2010:345). This results in the creation of a conducive classroom and school environment. In the Zimbabwean context, it enables the nation to reap the benefits of the policy of mass education pursued soon after independence. At the same time, Zimbabwe will be able 
to realise the Millennium Development Goals through education. However, there are certain shortcomings of multicultural education that have been identified. These shortcomings tend to be associated with the multiplicity of definitions for multicultural education that have been put forward as well as the different approaches in the implementation of multicultural education. There are some observations that have been made on the shortcomings of multicultural education (Van Vuuren \& Van Der Westhuizen, 2007:346; Vandeyer, 2003:195, 2010:345; Ogbu, 1992:5; Meier \& Hartell, 2009:182 and Manning \& Baruth, 2008:220; Matsumoto 2013:2).

Kehoe (2004:4) argues that the essence of criticisms of multicultural education is that it is inadequate, naive, fallacious and counterproductive. He further states that one of the most serious criticisms has been that it has done nothing to redress unemployment and material inequities between minorities and the majority. The first observation has more to do with the way multicultural education has been defined and conceptualised. Lack of a universal definition has led to the emergence of a multiplicity of definitions which have also engendered a number of different approaches. It is these numerous definitions and approaches that tend to contribute to a situation where multicultural education is seen as naïve. The second observation arises from the level of implementation of the different approaches. For example, according to Banks, $(1993: 13,2009: 237-248)$ the implementation of multicultural education can be located along a continuum with the contributions level on one end and social action on the other end. Lack of full implementation, particularly at the social action level, may result in a situation where multicultural education may not realise its ideals. The social transformation qualities of multicultural education have not been universally 
understood and embraced, the uneven understanding of multicultural education theory have led to some critiques in the field (Bode,2010).

Ogbu (1992:5) is of the opinion that multicultural education programmes are rarely based on actual study of minority cultures and languages. In his view, many proponents of multicultural education have not studied minority cultures in minority communities although they have studied minority children and some minority group members. This has an impact on the approaches to multicultural education that are suggested. This observation seems to refer to the various approaches to multicultural education put forward by Gibson (2010:95-113); Grant \& Sleeter, (2009:59-82); Banks, (1993:4; 2009: 223-258) and Bruch et al. in Zimmerman, (2004:2-4). The approaches presented by Gibson (2010:95-113) and Grant \& Sleeter (2009:59-82) were a result of an analysis of the practice of multicultural education in the United States and were not based on the variables identified by Ogbu (1995:2). Banks (1993:4) argues that his approach represents an ideal type in a Weberian sense. The characteristics of this ideal type may not be all present in terms of implementation. Therefore, the observation by Ogbu (1992:5) has some relevance. However, it should be noted that all the approaches provided have had an impact on the reduction of prejudice and have increased the tolerance of cultural diversity. In other words, they have had an impact in providing learners with equal opportunities to achieve.

Troyna (1987), and Mitchell (2003) in Van Vuuren \& Van Der Westhuizen (2007:346), have made some observations on the shortcomings of multicultural education. Troyna (1987, in Van Vuuren \& Van Der Westhuizen, (2007:346) argues that the emancipatory advantages credited to multicultural education by learning about other cultures is misleading. The opposite of this intervention may be realised, 
for example, more knowledge of other cultures may enhance a feeling of 'otherness' that reinforces the isolation of a given culture (Troyna, 1987) in Van Vuuren \& Van Der Westerhuizen, 2007:346). The inverse of this observation may also be realised in a situation where cultural diversity is not accommodated in the classroom. Knowledge of other cultures is indeed effective in enhancing tolerance and appreciation of cultural differences. In the Zimbabwean context, there is need for educators to show the interconnectedness of the different sub cultural groups, further upholding tolerance and appreciation of cultural differences. Such an approach and focus should work to eliminate feelings of 'otherness' which may be generated by lack of intercultural understanding. This results from a situation of alienation which some learners may experience in the school and classroom environment. In the context of multicultural education, this alienation may be based on learners' ethnicity, social class and gender among other issues. Grant \& Sleeter (1998) in Gorski (2006:166) state that multicultural education does not value separatism, but cultural pluralism, a sharing of cultures for the benefit of the school community. This enhances intercultural understanding.

Mitchell (2003:392) in Van Vuuren \& Van Der Westhuizen (2007:347) argues that multiculturalism has always carried the risk of creating 'culturally relativist' citizens who are no longer strongly oriented to a bigger context of unity, but prefer to align themselves with narrower cultural concerns. According to Bloom (1988), Huntington, (2004); Schlesinger (1998) cited by Matsumoto (2013:2) critics claim that multicultural education destroys the sense of civic solidarity, propagates value relativism and nihilism among students, and turns schools and colleges into arenas of racial outbursts. The chances of this becoming a reality will, to a great extent, hinge 
on the approach taken in multicultural education. Multicultural education is not only confined to the accommodation and learning of minority cultures. All learners should be given an opportunity to learn the dominant/ mainstream culture whilst at the same time learning their own minority culture. This is one of the goals of multicultural education. This promotes intercultural or multicultural competency as learners get an opportunity to function effectively in the mainstream culture as well as in their own.

Multicultural education has been criticised for failure to address issues of inequities in power as well as failure to address deep seated racism in society (Vandeyer, 2003:195, 2010:345; Meier \& Hartell, 2009:182 and Manning \& Baruth, 2008:220). Vandeyer (2003:195) argues, that looking at the international experiences, multicultural education attempts to bring about a sense of tolerance and harmony among different cultures but ignores and underplays the inequality in power between different cultures. Sleeter \& Benal, 2004 in Bode (2010) state that "Ironically (given its historical roots) a good deal of what occurs within the arena of multicultural education today does not address the power relations, critically and particularly racism". The failure of multicultural education to address inequities in power can be appreciated by looking at Foucault's ideas on the relationship between knowledge and power discussed on page 28 of this thesis (Section 2.2). Foucault argues that there is a relationship between knowledge and power (Appelrouth \& Eadles, 2008: 643; Ritzer, 2009:643; Kirby et al., 1997:718). Such a situation presents obstacles in the attainment of the ideals of multicultural education. Vandeyer (2010:310) adds that multiculturalism is seen as depoliticising culture and ignoring the power and structural dimensions of racism. Therefore multicultural education as currently being practised in South Africa and overseas, has little hope of enhancing the life chances of 
children from black groups because it ignores issues of power, social class, the economy and politics (Vandeyer, 2003:195). Giroux (2001) in Kirova (2008:110) argues that the ability of multicultural education to become a vehicle for achieving justice, liberty and equality that pervade the social, economic and political life of society has been challenged since its inception. It is quite debatable whether multicultural education will be able to eliminate inequalities in power. However, the level of implementation of multicultural education becomes a major determinant in addressing inequities in power. Therefore, there is need to implement multicultural education at the social action and transformative levels, (Banks, 1993:13, 2009:196197, Bruch et al. in Zimmernman ,2004:3) in order to address issues aligned to inequities in power. Such an approach gives learners an opportunity to critically analyse inequities of power within society.

Multicultural education has been criticised for failure to address racism (Vandeyer, 2003:195; Meier \& Hartell, 2009:182; McLaren \& Torres, 1999 in Bode; and Sleeter \& Benal, 2004 in Bode (2010). Squelch (1993) in Meier \& Hartell (2009:182) states that scholars criticise multicultural education for failure to bring about significant structural reform and to address deep seated racism in society. McCarthy (1988) in Vandeyer (2003:195) argues that by focusing on sensitivity training and on individual differences, proponents of multicultural education typically skirt the very problem which multicultural education seeks to address: racism'. Carrim (1998) and Zafar (1998) in Vandeyer (2003:195) are of the view that as a strategy to integrate schools , multicultural education does not address the deep seated racism that characterise these institutions and society as a whole. The preceding paragraph has underscored the importance of practising multicultural education at the transformative and social 
action levels articulated by Banks (2009: 196-197) as a way of addressing inequities found within society. Lack of full implementation in terms of Banks's (2009: 196197) results in situations where issues such as inequities in power and racism remain unchallenged.

McLaren \& Torres (1999) in Bode (2010:44) argue that 'in general, discourse in the United States that deal with multiculturalism deal very little with the concept of racism and focus instead on the politics and affirmation of difference'. The ideal situation is one where racism is addressed. The extent to which multicultural education will address racism depends on the approach taken. Obviously, the contributions dimension outlined by Banks (1993:13, 2009:237) may fail to address issues to do with racism. There is need therefore to fully implement multicultural education based on the approaches suggested. At the same time, Meier \& Hartell (2009:182) state that multicultural education is taken to task for regarding racism as an outcome of individual ignorance and prejudice rather than focusing on inherent structural factors in society. One aim of multicultural education is to enhance tolerance and appreciation of cultural diversity in its entirety. However, it is extremely difficult to attribute the prevalence of racism to individual ignorance.

Multicultural education is also criticised for essentialising culture. Kirova (2008:110) identifies the following critical theorists: Cole, (1986), May, (1994) and McCarthy, (1994) among many others. Critical theorists challenge multicultural education for its obsessive concern with culture, which they claim masks political and social conditions that contribute to real inequity in contemporary plural societies, thereby making multicultural education a safe way of side stepping the important issues ( Kirova, 2008:110). Multicultural education tends to focus on the weak assumption 
that cultural understanding will lead to greater tolerance and racial harmony (Fante, 2003; Squelch, 1993; in Meier \& Hartell, 2009:182). Vandeyer (2003:195) is of the opinion that multicultural education operates on the mistaken assumption that all cultures enjoy equal status in society; prejudice and discrimination are attributed to ignorance and a lack of knowledge of other cultures while multicultural teaching is seen as a solution for this. Banks (1993:4) argues that critical multicultural education provides a solution for this state of affairs.

As a result of these criticisms, multicultural education is seen as serving as a vehicle for social control more than social change (Olneck, 1990 in Vandeyer, 2003:195); it provides only a veneer of change rather than the transformation of educational processes and institutional structures (Tactor \& Henry, 1991 in Vandeyer, 2003:195). Despite these criticisms, multicultural education has a role to play in the transformation of society through multicultural education.

\subsection{CHAPTER SUMMARY}

This chapter has presented postmodernism as the theoretical framework guiding this study. The key ideas of postmodernism with its emphasis on diversity have been discussed and their relevance to multicultural education have been outlined. Literature related to multicultural education has been discussed in detail. In order to appreciate multicultural education as a field of practice, the history of multicultural education, which originated in the United States of America, has been outlined. The concept of culture has been discussed at length so as to place the concept of multicultural education into its proper perspective. Multicultural education as a concept was defined and the problems of establishing a universal definition have also been highlighted in order to expose the multiplicity of definitions of multicultural 
education. The aims, goals and characteristics of multicultural education were articulated. Different approaches to the implementation of multicultural education have been outlined. Challenges facing multicultural education as a field of study were presented with suggestions to overcome them being presented as well. Curriculum issues that need to be reformed were also reviewed. The major criticisms of multicultural education were also discussed. Literature review has also confirmed the view that most of the studies on multicultural education have been carried out in Western countries. It appears that not much has been written in African countries. Hence, this study seeks to explore teacher perceptions of the implementation of multicultural education in an African context. This is one of the gaps in the practice of multicultural education that the study seeks to fulfil. The literature review has been undertaken in an attempt to address the major and sub research questions (see 1.4). The next chapter presents the research methodology. 


\section{CHAPTER THREE: RESEARCH METHODOLOGY}

\subsection{INTRODUCTION}

The previous chapter presented a review of literature related to the research. This chapter presents the research methodology that was used to address the research questions identified in Chapter 1. The major research question was: What are teacher perceptions on the implementation of multicultural education in Zimbabwean primary schools with reference to Chegutu district? Therefore, this chapter deals with the following issues: research design, qualitative research, phenomenological approach, sampling, data collection, and data analysis and presentation.

\subsection{RESEARCH METHOD}

Qualitative research was chosen as the research method for this study. Qualitative research is mainly concerned with meanings that participants have for situations, events or phenomena. Uncovering these meanings is the goal of qualitative research. In this research, the main focus lay on discovering the meanings that the research participants (teachers) held on the implementation of multicultural education in Zimbabwean primary schools, with reference to Chegutu district hence the selection of the qualitative research paradigm. According to Denzin \& Ryan (2008:580),

... qualitative research is multi method in focus, involving an interpretive, naturalistic approach to its subject matter. This means that qualitative researchers study things in their natural settings, attempting to make sense of or interpret these things in terms of the meanings people bring to them.

Minichello \& Kottler (2010:12) concur with Denzin \& Ryan (2008:580) as they state that,

... qualitative researchers observe people in their natural setting so that they can learn from them about what they are thinking, and more importantly, why they think and act the way they do.

Therefore, qualitative research is a naturalistic inquiry that studies people in their natural settings (Marshall \& Rossman, 2006:2; Patton, 2002; Punch, 2004:148; 
Gibson \& Brown, 2009:8). In this study, the researcher went out to study the research participants (teachers) in their natural environment which was their respective schools. The main aim was to capture the perspectives of the research participants (emic view) (teachers) with regard to the implementation of multicultural education in Zimbabwean primary schools.

Rossman \& Kallis (2003), in Marshall \& Rossman (2006:12), have identified the following characteristics of qualitative research. It is:

- naturalistic;

- draws on multiple methods that respect the humanity of participants in the study

- focuses on context;

- is emerging and evolving; and

- is fundamentally interpretive

These characteristics of qualitative research were observed in the process of this study. Qualitative researchers have certain preferences. Hammersly (1992) in Silverman, (2006:56) highlights the following:

- a preference for qualitative data- understood simply as the analysis of words and images rather than numbers;

- a preference for naturally occurring data- observation rather than experiment, unstructured versus structured interviews;

- a preference for meanings rather than behaviour- attempting to document the world from the point of view of people studied;

- a rejection of natural science as a model; and

- a preference for inductive hypothesis generating research rather than hypothesis testing;

These preferences reinforce the view that qualitative research is a naturalistic enquiry that seeks to discover the meanings that people have for different phenomena.

\subsection{RESEARCH DESIGN}

The research design can be construed as a strategy or procedure that seeks to provide answers to the research questions. It can also be considered as a plan for the research 
(Punch, 2004:149; Kumar, 2005:84). According to Punch (2004:149), a research design is the overall plan for a piece of research, including four main ideas: the strategy, the conceptual framework, the question of who or what will be studied, and the tools to be used for collecting and analysing empirical materials. Kumar (2005:84) concurs with Punch (2004:149) and states that a research design is a plan, structure and strategy of investigation so conceived as to obtain answers to research questions and problems. Yin (2003) in Creswell (2007:5) argues that a research design is the logical sequence that connects the empirical data to a study's initial research questions and ultimately, to its conclusion.

A well conceived research design is essential for the success of any research. Lewis (2008:47) observes that a good qualitative research design is one which has a clearly defined purpose, in which there is coherence between research questions and the methods or approaches proposed and which generates data that is valid and reliable. Therefore, a research design has two main functions: it relates to the identification and or development of procedures and logistical arrangements required to undertake a study and it emphasises the importance of quality in these procedures (Kumar, 2005:84). However, it is important to note that in qualitative research the research design is not a discrete stage which is concluded early in the life of a study: it is a continuing process which calls for constant review of decisions and approaches (Lewis, 2008:47). The research design chosen for this study was the phenomenological research design.

\subsubsection{PHENOMENOLOGY}

This research study used phenomenology as a research design. Phenomenology is an approach that focuses on people's lived experiences regarding a phenomenon under 
study. Therefore, phenomenology has an interest in lived experiences (Marshall \& Rossman, 2006:104; Patton, 2002:104). Johnson \& Christensen (2008:395) posit that phenomenology refers to the description of one or more individual's consciousness and experience of a phenomenon. Creswell (2007:59) is of the view that phenomenology describes the meaning of several individuals of their lived experiences of a concept or phenomenon. Morgan \& Embree (2004:2) argue that phenomenology may be initially characterised in a broad sense as seeking an unprejudiced, descriptive account of consciousness, precisely in the manner in which it appears. Schwandt in Patton, (2002:114) states that phenomenology in qualitative research aims to identify and describe the subjective experiences of respondents. He further argues that it is a matter of studying everyday experiences from the point of view of the subjects.

All these definitions emphasise the view that phenomenology focuses on the study of individual lived experiences of a phenomenon from the point of view of the participants involved. It is therefore subjective as it emphasises on an emic view. The purpose of phenomenological research is to obtain a view into research participants' life worlds and to understand their personal meanings constructed from their lived experiences (Johnson \& Christensen, 2008:396). This research study showed a heavy bias towards the phenomenological approach. This was so because the objective was to explore teacher perceptions on the implementation of multicultural education in Zimbabwean primary schools, from the point of view of those involved in the actual teaching and these were the teachers themselves.

The data collection methods that were employed in this research study were consistent with the phenomenological view of research. In-depth unstructured interview 
questions and focus group discussions sought to elicit responses related to teachers' views of their lived experiences in the implementation of multicultural education in Zimbabwean primary schools. Phenomenologists generally assume that there is some commonality in human experience and they seek to understand this commonality (Johnson \& Christensen, 2008:397). Moran (2000) in Minichielo \& Kottler (2010:25) concurs with Johnson \& Christensen (2008:397). He states that the aim of phenomenological research is to understand the meaning that people attach to their experiences, but the focus is to investigate more deeply, the internal world as it is seen, felt, intuited, and thought by the individual.

Two types of phenomenology have been identified and these are: hermeneutical phenomenology and transcendental phenomenology. Hermeneutical phenomenology describes research as oriented towards lived experience (phenomenology) and interpreting the 'texts' of life (hermeneutics) (van Manen, 1990 in Creswell, 2007:58). Transcendental phenomenology is focused less on the interpretations of the researcher and more on the descriptions of the experiences of participants (Moustakas, 1994 in Creswell, 2007:58). This study adopted both types of phenomenology as this enabled the research to yield information pertaining to the lived experiences of the participants.

In phenomenological research, the concept of epoche has important significance. Kantz (1998) in Patton, (2002:485) observes that epoche enables the researcher to investigate a phenomenon from a fresh and open viewpoint, without prejudice or imposing meaning too soon. Epoche involves bracketing or suspending one's experiences and prejudices regarding the phenomenon under study. This enables researchers to set aside their experiences in order to take a fresh perspective towards 
the phenomenon under examination (Creswell, 2007:485). This is in line with transcendental phenomenology where transcendental means in which everything is perceived freshly, as if for the first time (Moustakas, 1994 in Creswell, 2007:484). Morgan \& Embree (2004:3) are of the view that an important first step is to put aside or bracket one's initial assumptions, including all the information one has on a subject from cultural, religious and scientific traditions. Moustakas (1994) in Patton, (2002:484) says that in the epoche, everyday understandings, judgements and knowings are set aside, and the phenomena are revisited, visually, naively, in a wide open sense, from the vantage point of the pure transcendental eye. Thus, the phenomenon is given a fresh look. In this study the researcher tried all means possible to suspend his experiences gained during the course of his teaching career in primary schools spanning some eighteen years.

In phenomenological research, there are two concepts that deserve special mention and these are constructivism and constructionism. Patton (2002:96) says that constructivism focuses on the meaning making activity of the individual mind and constructionism focuses on the collective generation and transmission of meaning. Crotty ( 1998) in Patton, ( 2002:96) goes on to say that constructivism suggests that each one's way of making sense of the world is valid and worthy of respect as any other, thereby tending to scotch any hint of the critical spirit. Social constructivism is a concept used by Creswell (2007:21). According to Creswell (2007:21), individuals develop subjective meanings of their experiences directed towards certain objects or things, these subjective meanings are negotiated socially and historically. A common theme that emerges in these definitions is that social reality is socially constructed. 
Guba \& Lincoln (1990) in Patton, (2002:96) summarise the constructivist perspective as being ontologically relativist, epistemologically subjectivist and methodologically hermeneutic and dialectical. Thus, most qualitative researchers take a constructivist view of society; looking at the ways people give meaning to their experiences and their interaction with others (Sarbia \& Kitsuse, 1994 in Minichielo \& Kottler, 2010:23). This study adopted the two concepts of constructivism/ social constructivism and constructionism in the design of the research methodology. The data gathering tools, which included individual unstructured in-depth interviews and focus group discussions, met the demands of constructivism/ social constructivism and constructionism respectively. This was also evidenced in the report findings where the voices of the participants were quoted verbatim. Direct quotations are a basic source of raw data in qualitative inquiry revealing respondents' depth of emotion, the way they have organised their world, their thoughts about what is happening, their experiences and their basic perceptions (Patton, 2002:21).

\subsection{SAMPLING}

The question of sample size is debatable in qualitative research. It appears that there is a general consensus that there is no formula for sample size as the most important issue is the in-depth study of the phenomenon under consideration. Patton (2002:244) and Shizha, (2007:310) contend that in qualitative research, sample size is typically small. Kumar (2005:165) is of the view that in qualitative research the issue of sampling has little significance as the main aim of most qualitative enquiries is either to explore or describe the diversity in a situation, phenomenon or issue. Given these views on sample size, the sample for this study consisted of twenty teachers (ten male and ten female), who were all selected on the basis of purposive sampling. Purposive 
sampling is based on the characteristics that the participants hold, and which are deemed by the researcher to be crucial to understanding the phenomenon being investigated (Singleton \& Straits, 2010:173; Ritchie, Lewis \& Elam, 2008:78; Barbour, 2008:52). The aim of purposive sampling is to select participants who are knowledgeable with regard to the phenomenon under investigation. Ball (1994) as cited by Cohen, Manion \& Morrisson (2011:157) posits that in many cases purposive sampling is used to access 'knowledgeable' people that is those who have in-depth knowledge about particular issues, by virtue of their professional role, power, access to networks, expertise or experience. According to Patton (2002:230), the logic and power of purposeful sampling lie in selecting information rich cases for study in depth. In this research, the phenomenon under investigation was teacher perceptions on the implementation of multicultural education in Zimbabwean primary schools.

Purposive sampling consisted of two aspects, namely, the selection of schools to be included in the study as well as the selection of research participants, who were all practising teachers in the field. The purposive selection of schools was done in such a way that a school was selected from each of the following categories: urban high density, urban low density, communal lands, farm/ mining community, and mission/ church school in Chegutu district. This enabled the inclusion of five schools from different settings in the Zimbabwean context. Secondly, the selection of the research participants was done in such a way that only qualified teachers with at least five years post qualifying experience were selected from each school, giving a total number of twenty teachers. Four teachers (two male and two female), were selected from each of the five schools participating in the study. It was assumed that such teachers had gained meaningful experience in the field of education to reflect on the 
implementation of multicultural education in Zimbabwean primary schools. In the discussion of the findings the five schools and twenty teachers were given different pseudonyms as a way of providing anonymity of participants as well as enhancing confidentiality.

\subsection{DATA COLLECTION}

Data for this study was collected in the field, from the schools which are in the naturalistic setting of the teachers. This approach reinforced the view that qualitative research is a naturalistic enquiry. Lofland (1971) in Patton, (2002:28) has identified four people oriented mandates in collecting data. These are:

- the qualitative methodologist must get close enough to the people and situation being studied to personally understand in depth the details of what goes on;

- qualitative methodologists must aim at capturing what actually takes place and what people actually say: the perceived facts;

- qualitative data must include a great deal of pure description of people activities, interactions and settings, and

- qualitative data must include direct quotations from people, both what they speak and what they write down

Data was collected through the use of unstructured in-depth interviews and focus group discussions in the field so as to meet the criteria of people oriented mandates outlined above. The use of unstructured in-depth interviews with open ended questions and the use of focus group discussions emphasised the acknowledgement of the concepts of constructivism/social constructivism and constructionism respectively. These two methods enabled the researcher to gain an emic (insider's) perspective on teacher perspectives on the implementation of multicultural education in Zimbabwean primary schools. At the same time these two methods of data collection enhanced triangulation which ensures trustworthiness of research findings. 


\subsubsection{UNSTRUCTURED IN-DEPTH INTERVIEWS}

Interviews, particularly unstructured in-depth interviews, are recommended as one of the data collection methods in qualitative research. The primary strategy of in-depth interviewing is to capture the deep meaning of experience in the participants' own words (Marshall \& Rossman, 2006:101). Kahn \& Cannel (1957) in Marshall and Rossman (2006:101), define an interview as a conversation with a purpose. In other words, in interviewing there is a goal to be pursued. Taylor \& Bogdan (1998) in Kumar (2005:123) posit that in-depth interviewing is a repeated face to face encounter between the researcher and informants, directed towards understanding informants' perspectives on their lives, experiences or situations as expressed in their own words. The goal is to obtain an account of the research participants' lived experiences regarding a phenomenon.

Qualitative interviewing begins with an assumption that the perspective of the other is meaningful, knowable and able to be made explicit (Patton, 2002:341). Mason (2002:62) holds a similar view. He argues that most qualitative research operates from the perspective that knowledge is situated and contextual, and therefore the job of the interview is to ensure that the relevant contexts are brought into focus so that situated knowledge can be produced. Punch, (2004:174) is of the view that an interview is a good way of accessing people's perceptions, meanings, definitions of situations and constructions of reality. According to Jones (1985:46) in Punch (2004:174);

... in order to understand other persons' constructions of reality we would do well to ask them ... and to ask them in such a way that they can tell us in their terms (rather than those imposed rigidly on a priori by ourselves) and in depth which addresses the rich context that is the substance of their meaning.

In-depth unstructured interviews, therefore, play a crucial role in qualitative research as they enable the perceptions and experiences of research participants to be known. 
Lewis (2008:58) is of the view that in-depth qualitative interviews provide an opportunity for a detailed investigation of each person's perspective, for in- depth understanding of the personal context within which the research phenomenon is located and for very detailed subject coverage. Therefore, for qualitative researchers, the main purpose of interviewing is to:

- obtaining unique information or interpretation held by the person interviewed;

- collecting numerical aggregation of information from many persons; and

- finding about 'a thing' that the researchers were unable to observe themselves (Stake, 2010: 95).

In this study in-depth unstructured interviews were conducted with all the twenty teachers at their different schools. These unstructured in-depth interviews lasted for forty to forty five minutes. In three of the participating schools (two urban and one rural) these were conducted in a room provided by the school authorities. This was done as a way of creating a conducive noise free environment to enable the use of a tape recorder. In the other two schools (one urban and one rural) the interviews were conducted outside under some shade in a place where there was little interference from noise. This approach was taken due to shortage of room and office space. The researcher did not want to disrupt the smooth running of the school by asking for some enclosed space. A tape recorder was used to capture the proceedings of the interviews which were later transcribed. Although in-depth qualitative interviews are recommended as a way of obtaining data in qualitative research, they have their own merits and demerits. In this research, interviews were seen as a way of obtaining data quickly.

In-depth qualitative interviews have the following advantages: they yield data in quantities quickly, they make immediate follow up and classification possible 
(Marshall \& Rossman, 2006:101), they are the most appropriate way for studying complex and sensitive areas and questions can be explained (Kumar, 2005:131).

Interviews have disadvantages in that cooperation is essential and the interviewer may not ask questions that evoke long narratives (Marshall \& Rossman, 2006:103). These disadvantages also applied to this study as some of the participants tended not to provide long narratives during the pilot study phase carried out at a primary school in Chegutu District. This limitation was overcome by using the participants' responses in the pilot study phase to refine the interview schedule in order to obtain meaningful long narratives.

\subsubsection{FOCUS GROUP DISCUSSION}

The focus group discussions were conducted under the same conditions as the unstructured in- depth interviews. These focus group discussions lasted for about an hour and were conducted under the same conditions as the unstructured in-depth interviews discussed in the preceding section. Focus group discussions were conducted after unstructured in-depth interviews as a form of methodological triangulation. Lewis (2008:61) is of the view that focus group discussions could be used after in-depth interviews to discuss the issues at a more strategic level, perhaps focusing on underlying cases and possible solutions; they offer an opportunity to validate data. The assumption behind the use of focus group discussions is that an individual's attitudes do not form in a vacuum; people often need to listen to others' opinions, and understand, in order to form their own (Marshall \& Rossman, 2006:114). Lewis (2008:58) is of a similar opinion and argues that focus group discussions provide the social context within which a phenomenon is experienced, and they can display the way in which the context can shape peoples' views, showing 
how data are generated through conversation with others. This approach highlights the importance and relevance of constructionism.

In a focus group discussion one explores the perceptions, experiences and understandings of a group of people who have some experience in common with regard to a situation or event (Kumar, 2005:130). In this research study focus group discussions were conducted with research participants in their schools on the same day, following the conclusion of unstructured in-depth interviews at the respective schools. Focus group discussions have the following advantages:

- interaction among participants enhances data quality, and

- focus groups tend to be enjoyable to participants (Patton, 2002:386)

A number of disadvantages of focus group discussions have been identified. Marshall \& Rossman (2006:114) highlight the following:

- the interviewer has less control over a group interview, and

- time can be lost while dead end or irrelevant issues are discussed

These disadvantages, outlined above also applied to this study. The pilot study phase at one primary school in Chegutu district showed that time was lost as the participants focused and discussed peripheral issues. At the same time some participants displayed tendencies to dominate the discussion. Therefore the researcher and the participants established some housekeeping rules that were intended to ensure that the discussions remained on course, and that all participants had an opportunity to contribute to the issues under discussion. The researcher posed pertinent questions to guide the discussion and this ensured that the discussions remained focused.

\subsection{DATA ANALYSIS AND INTERPRETATION}

Data for this study was collected using a tape recorder. The responses of the participants were transcribed manually in preparation for data analysis. Qualitative 
research produces voluminous amounts of raw data that do not have meaning on their own. The purpose of data analysis is to give meaning to these huge amounts of data. According to Strauss \& Corbin (1987) in Marshall \& Rossman, (2006:154), qualitative data analysis is a search for general statements and underlying themes: it builds grounded theory. Hitchcock \& Hughes (1989:99) in Stephens, (2009:99) define data analysis as 'what the researcher does with data in order to develop explanations of events, so that theories and generalisations about the causes, reasons and processes of any piece of social behaviour can be developed'. However, it is important to note that data analysis in qualitative research is an ongoing, emerging and iterative, or no linear process (Henning, 2004:127).

Data analysis involves data reduction. Patton (2002:432) observes that qualitative analysis transforms data into findings, the challenge of qualitative analysis lies in making sense out of the huge amounts of data. Qualitative data analysis seems to focus on inductive analysis. Bernad (2000) in Patton, (2002:453) argues that Bacon (1561-1626) is known for his emphasis on induction, which is the use of direct observation to confirm ideas and the linking together of observed facts to form theories or explanations of how natural phenomena work. Data analysis in this study placed emphasis on inductive analysis, which involves uncovering patterns, themes and categories in one's data (Patton, 2002:453). Punch (2004:201) states that in analytic induction, concepts are developed inductively from the data and raised to a higher level of abstraction, and their interrelationships are then traced out. There is also need to recognise that data analysis is not an activity that takes place entirely at a certain stage. 
Spencer, Ritchie \& O'Connor (2008:199) advise that analysis is an inherent ongoing part of qualitative research; it begins at the start of the research study and ends up while writing the results. Johnson \& Christensen (2008:531) concur with Spencer, Ritchie \& O’Connor (2008:199), and quote Miles \& Huberman (1994) who posit that there is a cyclical or recursive process of collecting data, analysing the data, collecting additional data, analysing those data throughout the research project as illustrated in the diagram below.

Fig. I: Data Analysis in Qualitative Research.

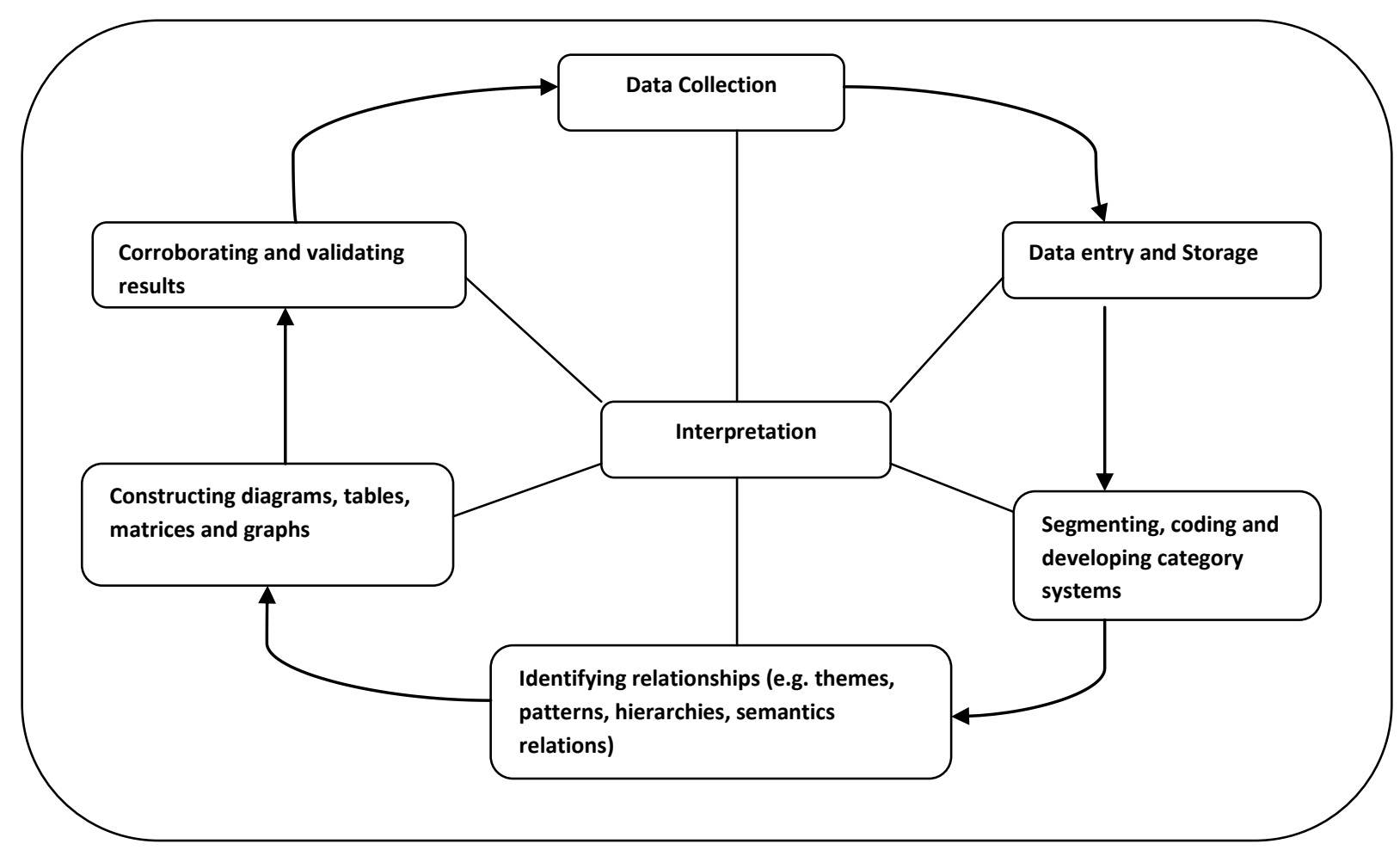

Adapted from Johnson \& Christensen, (2008: 531).

In this research study, data were analysed in terms of the three phases of data analysis outlined by Creswell (2007:150-151) which are: data management; immersion and writing memos; describing and classifying. These phases appear to be a summary of the phases outlined by Marshall \& Rossman (2006:153-163) which are: organising the data; generating categories and themes; immersion in the data; coding the data; 
offering interpretations through analytic memos; and searching for alternative understandings. Data analysis culminated in writing the final report.

\subsubsection{DATA MANAGEMENT}

According to Patton (2002:440), getting organised for analysis begins with an inventory of what one has and the question to be posed is: Are the field notes complete? Creswell (2007:150) is of a similar opinion and says that data management is the first step researchers need to organise their data into file folders, index cards or computer files. In this regard the researcher has to visit the huge amounts of data generated. In this study, the researcher went on to record on note cards, the data that was generated in the study and separated interview data from focus group discussion data. Minor editing was done to make the field notes coherent.

\subsubsection{IMMERSION IN THE DATA AND WRITING MEMOS}

During this phase, the researcher wanted to establish intimate familiarity with the data generated in the study. Researchers should immerse themselves in the details and try to get a sense of the interview as a whole before breaking it into parts (Agar, 1980 in Creswell, 2007:150). It also involves perceiving the data from the point of view of participants. In this regard, the researcher read and re-read the data because the researcher wanted to establish familiarity with the data on teacher perceptions on the implementation of multicultural education in Zimbabwean primary schools. Familiarity with the data was seen as an important step that would greatly aid the phases of coding as well as generating categories and themes.

\subsubsection{WRITING MEMOS}

Writing analytic memos should also be seen as an ongoing process that takes place at all phases of data analysis. Clarke (2005) cited in Saldana (2009:32) states that 
memos are sites of conversation with ourselves about our data. Johnson \& Christensen (2008:532) say that memos are reflective notes that researchers write to themselves about what they are learning from their data. Analytic memos can, thus, be seen as notes that one writes either in the margin or text of the data as a way of capturing significant issues that one is learning. Therefore, throughout the process of data analysis, it is a good idea to engage in memoing that is, recording reflective notes about what one is learning from the data. Miles \& Huberman (1994:72) and Glaser (1978: 83-4) in Punch (2004: 206) provide further insight into the role of memos. They state that:

... a memo is the theorising write up of ideas about codes and their relationship as they strike the analyst while coding...it can be a sentence, a paragraph or a few pages... it exhausts the analyst's momentary ideation based on data with perhaps a little conceptual elaboration.

Therefore throughout the process of data analysis, it is a good idea to engage in memoing, which is recording reflective notes about what one is learning from the data (Henning, 2004:138).

In this study, the researcher went on to write analytic memos in the margins of the transcribed in-depth interview data and focus group discussions as the process of coding was under way. These memos were helpful as they illuminated the process of data analysis.

\subsection{DESCRIBING, CLASSIFYING AND INTERPRETING}

Qualitative data needs to be sorted into themes and categories, and this can also be seen as a process of segmenting data. Segmenting involves dividing the data into meaningful analytic units (Johnson \& Christensen, 2008:532). According to Marshall \& Rossman (2006:150), the researcher generates categories through prolonged engagement with the data, and these categories become buckets into which segments 
of data are stored. As a result of immersion in the data, the researcher was able to establish categories of teacher perceptions on the implementation of multicultural education in Zimbabwean primary schools. The main thrust was to identify categories that had internal homogeneity and external homogeneity regarding the phenomenon under study. Internal homogeneity concerns the extent to which the data that belong to a certain category hold together or 'dovetail' in a meaningful way, whereas external homogeneity concerns the extent to which differences among categories are bold and clear (Patton, 2002:465).

The identification of themes was tied to the generation of categories. Gibson \& Brown (2009:126) maintain that thematic analysis refers to the process of analysing data according to commonalities, relationships and differences across data set. This calls for content analysis which is a process in which both the content and context of documents are analysed. Themes are also identified with the researcher focusing on the way the theme is presented as well as the frequency of its occurrence. Gibson \& Brown (2009:126) provide the following aims of thematic analysis;

- examining commonality in the data and this involves finding ways to pool together all examples from across a data set to be categorised;

- examining differences where the aim is to find and analyse peculiarities and contrasts within a given data set and to examine their potential relevance for the specific issues being explored; and

- examining relationships in which researchers examine the relationships between the various elements of their analysis

Data were read in an attempt to establish themes related to teacher perceptions of the implementation of multicultural education in Zimbabwean primary schools. The search for categories and themes was very important for the development of codes which were extensively used in data analysis. 


\subsubsection{CODING THE DATA}

Codes are tags, names or labels; and the process of coding involves attaching names or labels to pieces of data. Punch (2004:204) states that coding is the concrete activity of labelling data which gets the data analysis under way, and which continues throughout the analysis. Saldana (2009:3) posits that in qualitative research a code is most often a word or short phrase that symbolically assigns a summative, salient, essence. In the same vein, Gibson \& Brown (2009:130) acknowledge that to code is to create a category that is used to describe a general feature of data: a category that pertains to a range of data examples. Flick (2002:77) contends that coding represents the operations by which data are broken down, conceptualised and put together in new ways. Strauss (1981) in Spencer, Ritchie \& O'Connor (2008:199), is of the view that coding 'fractures' the data, freeing the researcher from description and forcing interpretation to higher levels of abstraction. These definitions show that coding involves attaching labels and tags to a data set. Coding opens up the data for analysis and interpretation.

Two forms of codes have been identified and these are: a priori codes and empirical codes. A priori codes are defined prior to the examination of data and empirical codes are generated through the examination of data itself (Gibson \& Brown, 2009:130). Johnson \& Christenen (2008:539) have also identified inductive codes which are very similar to empirical codes as these are generated by the researcher directly examining data. In this research, empirical codes were used. Codes therefore take several forms: abbreviations of key words, coloured dots and numbers (Marshall \& Rossman, 2006:160). In this research dealing with teacher perceptions on the implementation of 
multicultural education in Zimbabwean primary schools, abbreviations of key words and colour codes were used to code teacher responses as follows:

- YIMP -Yes multicultural education is being implemented (colour code: green);

- NIMP-No it is not being implemented (colour code red);

- LIMP-It is being implemented to a limited extent (colour code: blue); and

- U- Undecided, not sure (colour code: yellow).

These codes were developed so as to adequately capture the multiplicity of teacher perspectives on the implementation of multicultural education. This becomes significant when it is realised that coding is the analysis strategy many qualitative researchers employ in order to help them locate key themes, patterns, ideas and concepts that may exist within their data (Biber \& Leavy, 2006:349). The process of coding is summarised in the following diagram.

Fig II: Visual Model of Coding Process

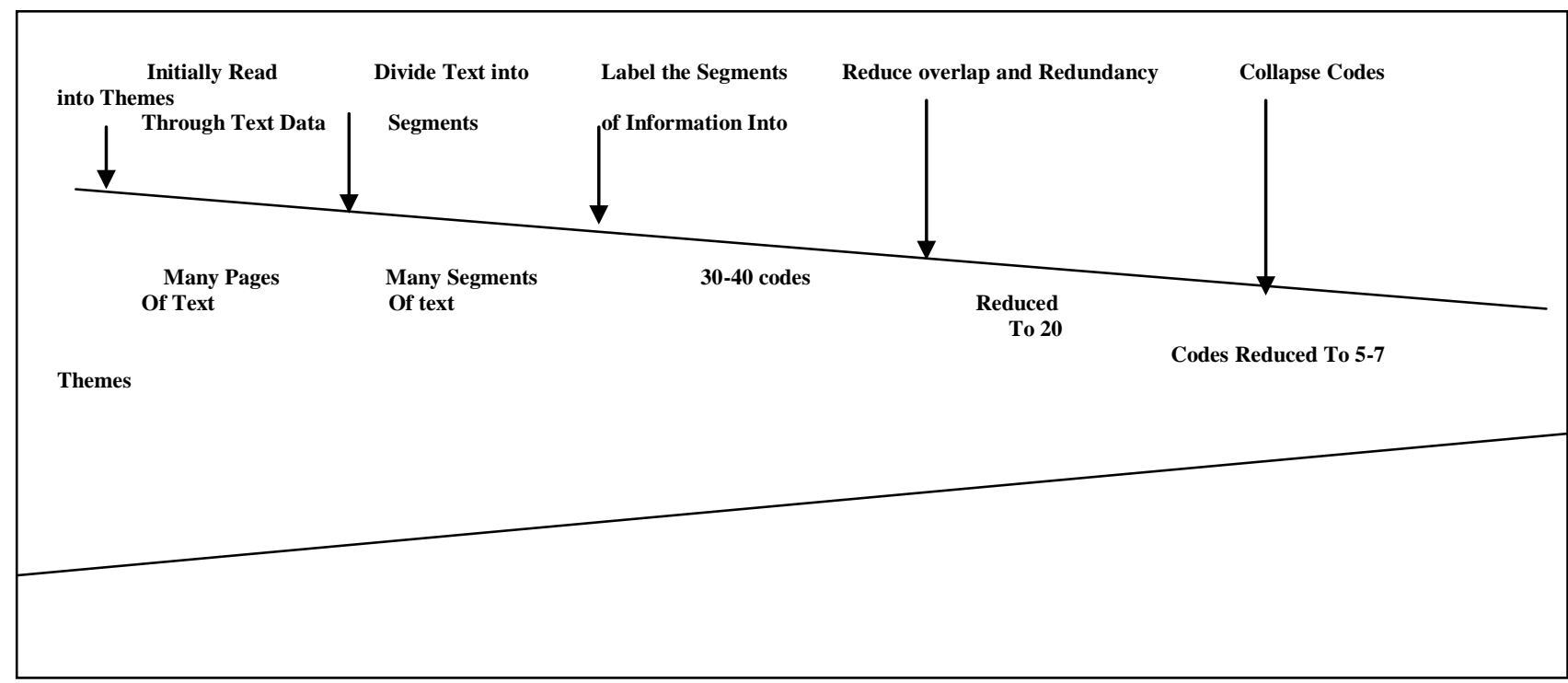

Adapted from Creswell (2005:238). 


\subsubsection{OFFERING INTERPRETATIONS}

As alluded to before, qualitative data have no inherent meaning, so interpretation gives meaning to qualitative data. According to Marshall \& Rossman, (2006:161) interpretation is referred to as 'telling the story', interpretation brings meaning and coherence to the themes, patterns, categories, developing linkages and a story line that makes sense and is engaging to read. Patton (2002:432) concurs with Marshall \& Rossman (2006:161) and states that interpretation means attaching significance to what was found, making sense of the findings, offering explanations, drawing conclusions, extrapolating lessons, making inferences, considering meaning and otherwise imposing order. Gibson \& Brown (2008:5) posit that interpretation involves trying to give sense to the data by creatively producing insights about it. Therefore the researcher's intent is to make sense of (or interpret) the meanings others have about the world. This is why qualitative research is often called 'interpretive' research (Creswell, 2007:39).

In this study, the researcher put together the responses of the research participants (teachers). Based on the themes and categories identified, he went on to present a holistic picture of teacher perceptions on the implementation of multicultural education in Zimbabwean primary schools. These categories and themes were analysed and interpreted against the background of the literature review presented in Chapter two. Marshall \& Rossman ( 2006:162) advise that during this phase, the researcher should determine how useful the data segments drawn on to support the emerging story are, in illuminating the questions being explored and how they are central to the story that is unfolding about the social phenomenon. Data interpretation was done in the context of hermeneutic and transcendental phenomenology. 


\subsection{TRUSTWORTHINESS OF RESEARCH FINDINGS}

Qualitative research has to address issues of trustworthiness. Trustworthiness deals with the degree to which one can depend on and trust given research findings (Shank, 2006:114). Therefore, trustworthiness as delineated by Lincoln \& Guba (1985 in Moss, 2004:362), is concerned with the following issues: credibility; dependability; confirmability; and transferability (Shank, 2006:114-115; Tasshakkori \& Teddlie, 2009:301; Trochim, 2006:1; Shenton, 2004:64-72; Hall, 2004:2; Creswell, 2007:204).

\subsubsection{CREDIBILITY}

Credibility in qualitative research means that the results of a qualitative study are believable and trustworthy from the perspective of a participant in the research (Hall, 2011:1; Trochim, 2006:1; Zhang \& Wildemuth, 2007:6). Lincoln \& Guba (1985) in Shenton (2004:64) are of the view that ensuring credibility is one of the most important factors in establishing trustworthiness. Krefting (1991:219) has outlined a number of activities that enhance credibility of qualitative research and these include: prolonged and varied field experience; triangulation; and member checking among others. These are the activities that were utilised in this study to enhance credibility. The researcher spent a long time in the field, conducting unstructured in-depth interviews and focus group discussions with the research participants (teachers) in order to gain their perspectives on the implementation of multicultural education in Zimbabwean primary schools. Research participants (teachers) were given an opportunity to read the compiled findings as a way of member checking to validate them. Focus group discussion was included as a way of gathering data in order to enhance triangulation. 


\subsubsection{DEPENDABILITY}

Shank (2006:114) posits that dependability is the ability to know where the data in a given study comes from, how it was collected and how it was used. It can also be seen as a way in which the researcher accounts for changing conditions in the phenomena (Trochim, 2006:2; Zhang \& Wildemuth, 2006:6; Shenton, 2004). Lincoln \& Guba (1985) in Shenton, (2004:71), contend that there are close ties between credibility and dependability and state that in practice, a demonstration of the former goes some distance in ensuing the latter. There are a number of activities that can be utilised to ensure dependability and these include: dense description of research methods; triangulation; and peer examination (Krefting, 1991:216). In this study detailed description of research methods were presented. Triangulation was enhanced through multiple methods of data gathering which included unstructured interviews and focus group discussions which is a form of methodological triangulation (Patton, 2002:247). Patton, (2002:247) further argues that triangulation strengthens a study by combining methods. Member checking (Shank, 2006:114) was also employed to ensure dependability.

\subsubsection{CONFIRMABILITY}

In qualitative research the concept of confirmability refers to the degree to which the results of the research can be confirmed or corroborated by others (Trochim, 2006:2; Shenton, 2004:72; Zhang \& Wildemuth, 2007:6). Confirmability deals with the details of the methodology used (Shank, 2006:114). Shenton, (2004:72) posits that in enhancing conformability, steps should be taken to ensure that as far as possible the work's findings are the result of the experiences and ideas of informants, rather than the characteristics and preferences of the researcher. A number of activities can be 
used to enhance confirmability. These include: triangulation (Krefting, 1991; Shenton, 2004:72), detailed methodological description (Shenton, 2004:72) and another researcher taking the role of 'devil's advocate' (Trochim, 2006:2). In this study, the research methodology was described in detail in order to enhance dependability. (See Chapter 3 pages $128-146$.

\subsubsection{TRANSFERABILITY}

Transferability refers to the extent to which the results of qualitative research can be transferred or generalised to another setting (Trochim, 2006:1; Shenton, 2004:69; Shank, 2006; Zhang \& Wildemuth, 2006:6, Hall, 2004). Lincoln \& Guba (1985) in Shank, 2006:115) see transferability as the degree to which the results of a qualitative study can be transferred to a different setting, or used with a different population. Transferability can be enhanced through dense description of research methods (Krefting, 1991:218; Shank, 2006:115; Zhang \& Wildemuth, 2007:6).

In this study detailed description of the research methods employed was provided. Lincoln \& Guba (1985) and Firestone (1995) in Shenton, (2004:69) contend that it is the responsibility of the investigator to ensure that sufficient contextual information about the fieldwork sites is provided to enable the reader to make such a transfer. Shenton (2004:69) goes further to say that sufficient thick description of the phenomenon under investigation should be provided to allow readers to have a proper understanding of it, thereby enabling them to compare the instances of the phenomenon described in the research report with those that they have seen emerge in their situations. Thus, in this study sufficient details were provided on the concept of multicultural education. Furthermore, the research methodology and the findings were also sufficiently detailed. However, it should be noted that transferability from a 
qualitative research point of view is primarily the responsibility of one doing the generalising (Zhang \& Wildemuth, 2007:6; Trochim, 2006:1).

\subsection{ETHICAL CONSIDERATIONS}

Before the commencement of data collection, the researcher had to apply for an Ethical Clearance Certificate (see appendix) from the University of South Africa. This application was made through the supervisor and once granted the researcher proceeded to collect data. This was done as a way of ensuring that all relevant ethical issues were going to be observed. Research studies have to take into cognisance, a number of ethical issues. Punch (2004:281) is of the opinion that all social research involves ethical issues since it involves collecting data from people about people. Sieber (2009:106) concurs and states that applied research examines and experiments with issues that directly affect peoples' lives and must therefore respect the interests of subjects and their communities. Research ethics consists of standards of right and wrong; they tell researchers to act in morally responsible ways and ethics come from two sources which are: society at large and research professions (Singleton \& Straits, 2010:47).

The following ethical issues have been identified: informed consent; confidentiality, privacy, anonymity, protection from harm; and the right to withdraw (Barbour, 2008:53; Gibson \& Brown, 2009:60 Sieber, 2009:106-117; Ruane, 2005:16-19; Patten, 2009:25; Cohen, Manion \& Morrison, 2011:75-104). These ethical considerations were upheld in this study as discussed in the following sections.

\subsubsection{INFORMED CONSENT}

Informed consent demands that research participants are fully informed about the purpose of the research as well as their role. In every discipline, it is considered 
unethical to collect information without the knowledge of participants and their expressed willingness and informed consent (Kumar, 2005:212). Ryen (2004: 231) in Silverman, (2006: 319) posits that:

... informed consent ... means the research subjects have the right to know that they are being researched, the right to be informed about the nature of the research and the right to withdraw at any time ... The right to be informed means that potential research subjects should be given a detailed but non technical account (in a format that they understand) of the nature and aims of the research.

Kumar (2005:212) is of a similar opinion and states that:

... informed consent implies that subjects are made adequately aware of the type of information the researcher wants from them, why the information is being sought, what purpose it will be put to, how they are expected to participate in the study, and how it will directly and indirectly affect them.

According to Cohen, Manion \& Morisson (2011:77) the principle of informed consent arises from the subject's right to freedom and self determination. In this research the written consent of the participants was sought (see Appendix V, pp. 301-302). Participants were individually informed about the purpose of the study and their role in the research. It was emphasised to the participants that their participation was voluntary.

\subsubsection{CONFIDENTIALITY}

Confidentiality deals with the disclosure of the information supplied by the research participants. Patten (2009:25) is of the view that researchers have an obligation not to disclose the information to others. Sieber (2009:117) concurs and states that confidentiality is an extension of the concept of privacy; it concerns data about the person and an agreement, as to how the data are to be handled in keeping with the subjects' interests in controlling the access of others to information about themselves. These views have an implication on data storage and information dissemination. The researcher ensured that data (the tapes) were stored in a secure place which was not 
accessible to any other person other than the researcher. The findings of the research were used for the purposes of the study only.

\subsubsection{PRIVACY}

Privacy refers to person's interest in controlling the access of others to themselves (Sieber, 2009:117). Singleton \& Straits (2010:60) have similar views as they state that the right to privacy is the individual's right to decide when, where, to whom, and to what extent his or her attitudes, beliefs and behaviour will be revealed. The researcher first of all sought the informed consent of the research participants so that the data gathering process occurred with their full knowledge. A tape recorder was used extensively in this research and the permission of the participants to use this device was sought. No hidden device, electronic or otherwise, was used to record the unstructured in-depth interviews and focus group discussions. Participants were also assured that the data they provided were only to be used for research purposes only. This was very important as participants need to know that their privacy and sensitivity will be protected and to know what is going to happen with the information after recording (Henning, 2004:6).

\subsubsection{ANONYMITY}

Anonymity involves the protection of the identity of the research participants so that their identities remain unknown by people outside the study. Lewis (2008:67) says that anonymity means the identity of those taking part is not known outside the research team. The essence of anonymity is that information provided by participants should in no way reveal their identity (Cohen, Manion \& Morrison 2011: 91). To meet the principle of anonymity, the collection of data should be done in such a way that the researcher cannot link specific information with individuals who provide it 
(Ruane, 2005:19). According to Singleton \& Straits (2010:61) anonymity can be ensured by removing names and other identifying information from the data as soon as possible, by not disclosing individuals identities in any reports of the study. In this study the identity of the research participants was protected through the use of pseudonyms where the need arose in writing the report. The respective schools taking part in the study were assigned numbers that were used in writing the report.

\subsubsection{PROTECTION FROM HARM}

Research participants need to be protected from any forms of harm be they physical, psychological and emotional. Bailey (1978: 384) in Kumar, (2005:212) says that harm includes not only hazardous medical experiments but also any social research that might involve such things as discomfort, anxiety, harassment, invasion of privacy, or demeaning or dehumanising procedures. Diener \& Crandall, (1978) in Singleton \& Straits, (2010:48), are of a similar opinion and posit that people can be harmed personally (by being humiliated or embarrassed, by losing their self esteem) and socially (by losing their trust in others) through their participation in research that may never threaten their physical being. In this study the researcher ensured that participants were protected from all forms of harm by upholding the personal dignity of all the research participants during interaction. The strict observance of the principles of confidentiality, anonymity, privacy and informed consent was also a way of protecting the research participants from harm.

\subsubsection{THE RIGHT TO WITHDRAWAL}

The right of participants to withdrawal means that research participants are free to withdraw from the research process at any time. Creswell (2005:12) states that participants have the right to refuse to participate in a study and can withdraw at any 
time. In this study, when the informed consent of the participants was sought, it was also impressed upon them that participation was voluntary and that they could withdraw from the research at any time.

\subsection{CHAPTER SUMMARY}

This chapter presented the research methodology that was used to obtain data for the study. The research design adopted, that is, qualitative research and the phenomenological view, were identified and discussed at length. Data collection instruments as well as the analysis and interpretation of data were all discussed in detail. Measures to enhance the trustworthiness of the research findings were identified. Finally, research ethics that need to be upheld in the study were also discussed. The next chapter presents the research findings. 


\section{CHAPTER 4: ANALYSIS OF DATA AND PRESENTATION OF FINDINGS}

AND DISCUSSION

\subsection{INTRODUCTION}

The previous chapter outlined the research methodology that was used to obtain data for this study. This chapter presents the findings of the study. These findings were discussed in the context of the literature review undertaken in Chapter 2. The study sought to answer the following main research question: What are the perceptions of primary school teachers on the implementation of multicultural education in Zimbabwean primary schools? In presenting the findings this chapter focused on one of the approaches outlined by Taylor \& Bogdan (1984) in Marshall \& Rossman, (2006:163). This approach involves the presentation of data gathered through indepth interviews where the perspectives of the participants are presented and where their world view structures the report. In this respect, the views of the participants shall be presented verbatim. Emphasis was placed on transcendental phenomenology in which everything is perceived freshly as if for the first time (Moustakas 1994, in Creswell, 2007:58), and followed by a discussion.

\subsection{DEMOGRAPHIC PROFILE OF PARTICIPANTS}

The twenty teachers who took part in this research study were all allocated numbers (see Table I). This was done to enhance anonymity and confidentiality of participants. Numbers were also assigned to the participating schools as a way of enhancing anonymity. School 1 is a former whites' only school in an urban low density residential area. School 2 is a peri-urban farm school in a farming community. School 3 is an urban high density school in a high density residential area. School 4 is a church school in a farming community and School 5 is a rural school in the communal lands in Mhondoro, Chegutu district. A low density residential area is a suburban 
residential environment with low population concentration whilst a high density residential area is an urban environment with a high population concentration.

\section{TABLE I: LIST OF PARTICIPANTS}

\begin{tabular}{|l|l|l|l|l|l|}
\hline $\begin{array}{l}\text { Participant } \\
\text { Number }\end{array}$ & Sex & Age & $\begin{array}{l}\text { Professional } \\
\text { qualifications }\end{array}$ & $\begin{array}{l}\text { Teaching experience } \\
\text { in years }\end{array}$ & School \\
\hline 1 & Male & 42 & B.Ed., Dip. Ed. & 14 & 1 \\
\hline 2 & Male & 46 & C.E. & 24 & 1 \\
\hline 3 & Female & 44 & C.E. & 23 & 1 \\
\hline 4 & Female & 45 & C.E., B.Ed., M.Sc. & 21 & 1 \\
\hline 5 & Male & 55 & C.E. & 29 & 2 \\
\hline 6 & Male & 37 & Dip.Ed., B.Comm & 13 & 2 \\
\hline 7 & Female & 42 & Dip.Ed. & 15 & 2 \\
\hline 8 & Female & 42 & Dip. Ed. & 6 & 2 \\
\hline 9 & Male & 56 & C.E., B.Ed. & 29 & 3 \\
\hline 10 & Female & 59 & C.E., B.A. & 29 & 3 \\
\hline 11 & Male & 59 & T3 & 35 & 3 \\
\hline 12 & Female & 48 & C.E., B.Sc. & 21 & 4 \\
\hline 13 & Male & 51 & Dip.Ed. & 10 & 4 \\
\hline 14 & Male & 41 & Dip.Ed. & 13 & 4 \\
\hline 15 & Female & 32 & Dip. Ed. & 6 & 4 \\
\hline 16 & Male & 64 & T3, Dip.Ed. & 42 & 5 \\
\hline 17 & Female & 38 & Dip.Ed. & 10 & 5 \\
\hline 18 & Female & 33 & Dip.Ed. & 7 & 5 \\
\hline 19 & Male & 32 & Dip.Ed. & 6 & 7 \\
\hline 20 & Male & 34 & Dip.Ed. & & 5 \\
\hline
\end{tabular}

\subsection{FINDINGS ANALYSIS OF DATA AND DISCUSSION: INDIVIDUAL} UNSTRUCTURED INTERVIEWS AND FOCUS GROUP DISCUSSIONS

\subsubsection{INTRODUCTION}

A tape recorder was used to record the responses of the participants in this study. Data obtained was analysed using inductive and colour codes (Section 3.6.3.1). Data were transcribed manually. The data were analysed in order to identify the themes that emerged from the responses of the participants which were used in writing this report. The main themes that emerged from the analysis of data are as follows:

- practice of multicultural education in Zimbabwe;

- cultural diversity and the content of the primary school curriculum; 
- curriculum reforms;

- portrayal of Zimbabwe's multicultural character in curriculum instructional materials;

- $\quad$ representation of cultural diversity in curriculum materials;

- classroom pedagogy and cultural diversity;

- cultural sensitivity to diverse cultural backgrounds;

- language in education policy;

- communication in mother tongue in the classroom;

- $\quad$ school environment and cultural diversity;

- $\quad$ school as a multicultural institution; and

- parental participation in school activities

\subsubsection{PARTICIPANTS VIEWS ON THE IMPLEMENTATION OF MULTICULTURAL EDUCATION IN ZIMBABWE}

All the participants were of the view that multicultural education is being practised in Zimbabwean primary schools to varying degrees. This is shown in terms of multicultural enrolment patterns, content of different subject areas and the language policy.

The language in education policy was seen as evidence to suggest that multicultural education is being practised. However textbooks were seen to be presenting a challenge in the practice of multicultural education. Commenting on the language policy and the content of textbooks a participant had this to say;

I think as a nation the Ministry has taken the right steps in trying to implement it. The first example is that of the languages that are now being introduced in the primary school syllabus. It is now compulsory for a child in grade 1, ECD (Early Childhood Development), up to grade 3 to be taught using his/her own language (mother tongue) that is culture. I think the Ministry is beginning to 
do that. But I believe more needs to be done in terms of having textbooks that cut across. For example if it is Ndebele textbook, it should also reflect on what is done in other cultures that are not Ndebele maybe through the stories and so on. (Participant 5, School 2)

Another participant expressed similar views by saying;

Yes, after having said this it shows that our direction of the school policy, the direction of the education policy is to consider every cultural aspect of the cultural diversities in Zimbabwe. Especially when I see an item in the Referendum considering sixteen languages it means that in the languages that is where we see cultural diversity. In the languages that is where we see the expression of a culture. So by considering that aspect, considering other languages to be examinable and taught in schools is a direction where consideration is being given. Presently the practise of multicultural education is not very distinct but it is not prohibited, it has not been stagnant, it is in progression. When time comes, when the culture change is needed the teacher is not resistant to that. They are prepared to take up these changes and we feel that even the colleges, the training institutions are considering them so that we can have teachers who can consider diverse cultures in the schools. But as of now, the teacher who is there, who is able to do that will always do it. (Participant 11, School 3)

The need for improvement in terms of implementation was also observed. Another participant emphasised the need for improvement. She observed;

I feel it needs to be improved. We have just started practising multiculturalism, but I feel a lot more still has to be done so that all the different cultures feel they are well represented. They will be taught and pupils will benefit from multicultural teaching. (Participant 10, School 3)

Some constraints in the implementation of multicultural education were observed.

Lack of a government policy on multicultural education and financial constraints were seen as challenges in the implementation of multicultural education in Zimbabwean primary schools. With regard to the constraints faced in the implementation of multicultural education a participant argued;

Multicultural education is being practised to some extent. Some are trying but to some extent they are still not there. Because of financial constraints we don't have the facilities, and we don't have specialist teachers to teach some of the subjects. Looking at our government itself, it does not have policies and laws which are clear and specific to accommodate multicultural education. A start has been made. If you look at the way Cultural Fairs are being held in Zimbabwe, it is something new. So people are recognising their Shona culture 
and therefore try to implement it all over. Most schools like the International School in Harare they have a day for that where they present dishes from various countries. So we are trying, we are moving towards multicultural education. (Participant 3, School 1)

Multicultural enrolment patterns where learners are recruited from different ethnic backgrounds were cited as evidence of the implementation of multicultural education in Zimbabwean primary schools. A participant had this to say about multicultural enrolment patterns;

I think it is being practised. I think it is being practised just in some other schools, not this one, but in some other schools you can see there are coloureds, together with these, with us blacks who are learning in the same schools. Eh, say we go to Bulawayo you will see Shona speaking pupils; they are also in the same class together with Ndebele speaking pupils. They are nixed, so I think that one is being practised. They are taken as one. (Participant 20, School 5)

Similar views were expressed during focus group discussions. Multicultural enrolment patterns, the teaching of some marginalised minority languages and the content of subjects such as Social Studies were once more cited as evidence of the practice of multicultural education in Zimbabwe. One participant opined;

Yah, I feel we are implementing that in the sense that we have pupils from different cultures that is point number one. Eh, we also have the use of language. They use languages of their choice, ah, we also have the books we use, and they cater for different cultures like I have already said. We look at Social Studies, the topic shelter in Social Studies. It looks at shelter from different cultures and even those cultures which are outside our country. So I think our system caters for all groups. (Participant 9, School 3)

Another participant was of a similar opinion. She said that:

I think they are trying to implement the multicultural approach like they are taking all races, children are learning of what is happening in different cultures. Like last time we had the Cultural Week where we were learning, about our own culture and also the culture of different areas. I think it is being implemented. (Participant 14, School 4)

However, there were some challenges that were identified in the implementation of multicultural education. The need for in service teacher training in multicultural education as well as the reform of textbooks were also seen as challenges in the 
effective practice of multicultural education. One participant suggested the following solutions to mitigate challenges in the practice of multicultural education. She remarked;

It is being implemented but not to a large extent. I think there is need for it to be done at a higher level. Teachers should be trained about multicultural education. The textbooks should be modified to cater for everyone. For example if chapter 1 has a Zezuru story, then they can have a Korekore story so that all pupils' cultural backgrounds are covered. (Participant 4, School 1)

Another participant expressed a similar opinion. He suggested;

In my view I think that they should start at the top. To start with a revamp of the syllabi so that it reflects multiculturalism. Textbooks should reflect multicultural education. When the books and the syllabi come to the people it means the teacher will be forced by the subjects to implement multicultural education. (Participant 1, School 1)

The need to address teacher attitudes towards multicultural education was emphasised. One participant expressed the concern that;

I don't think multicultural education is being practised in Zimbabwean primary schools. Because I think from the highest levels documents of these curricular show that it is there but it is not implemented in the school system. This is due to negativity, just being negative. So this is negativity on the part of people who should be learning different cultures. (Participant 12, School 3)

The responses of the participants reflect their understanding and perceptions of multicultural education and confirm that multicultural education in Zimbabwean primary schools is being practised at the additive level (Banks, 2009:239). The additive level is part of Banks's (2009:239-247) continuum of approaches to multicultural education. From the additive level, other levels such as the transformative as well as the social action level can be attained. This is possible when accompanied by relevant curriculum reform as well as the review of curriculum instructional materials to ensure that they fully embrace the multicultural character of Zimbabwean society. The views of the participants acknowledge that multicultural education is being practised in Zimbabwean primary schools. What is needed is to 
ensure that effective curriculum reforms are undertaken to ensure that multicultural education is practised at higher levels of the Banks (2009:237-249) continuum. For the participants the current language in education policy and multicultural enrolment patterns were largely seen as evidence of the practise of multicultural education in Zimbabwean primary schools.

A large number of issues pertinent to multicultural education such as the school environment and pedagogy among many others were not raised in the analysis of the practice of multicultural education in Zimbabwean primary schools. These views on multicultural education could be a result of the numerous ways in which multicultural education has been defined and implemented (Maatta, 2008:8; Zimmerman, 2004:1; Lemmer, Meier \& van Wyk, 2006:2). The numerous ways in which multicultural education has been defined have led to differences in the conceptualisation of the ways in which it is implemented.

This has an impact and implications for the practice of multicultural education in Zimbabwean primary schools. In the conceptualisation of multicultural education by the participants, the social and transformation qualities of multicultural education were not mentioned. This affirms the observations made by Bode (2004) who argues that the social and transformation qualities of multicultural education have not been universally understood and embraced, the uneven understanding of multicultural education theory have led to some critiques in the field. There is a tendency to focus on a limited number of issues; issues such as gender, social class, the school environment as well as the participation of parents in school activities are not included in the conceptualisation of the practice of multicultural education in Zimbabwean primary schools. The implementation of multicultural education in this 
manner may not achieve the desired goals. In this regard multicultural education has attracted a number of criticisms (Vandeyer, 2003:195; \& 2010:345; and McKinney \& Soudien (2010:7).

The views of the participants on the implementation of multicultural education in Zimbabwe reinforce the view in multicultural education scholarship that a gap exists between theory and the practice of multicultural education (Gay, in Banks, 1993:1). Sleeter (1998) in Gorski (2006:164) advises that one must distinguish between an approach as formulated by (multicultural education) main theorists and superficial applications one finds in literature. The participants cited a limited number of issues as evidence of the implementation of multicultural education. It is important to recognise that the concept of multicultural education today is multidimensional and embraces a number of issues (Banks, 2011; Pangs, 2001 in Gwirayi, 2010:93).

There are a number of issues that have to be considered in the successful implementation of multicultural education and these issues include both classroom issues as well as issues found in the school environment. From the responses of the participants it is also apparent that multicultural education is being practised at a superficial level currently. The superficial form of multicultural education adds a unit on minority 'Others' here and there, maintaining and supporting the privilege of the dominant society (Haynes-Writer, 2008:3). This is a situation that could be prevailing in some textbooks and other curriculum instructional materials. Although multicultural education is a process (Banks, 2009:25) there is need for a number of reforms to be undertaken in areas such as the content of school textbooks that are currently in use in an endeavour to ensure that they fully embrace the multicultural character of Zimbabwean society. 
The responses of the participants on their perceptions of the implementation of multicultural education in Zimbabwe are similar to findings of research studies carried out elsewhere. Research carried out by Zimmerman (2004:17) in the United States have shown that the responses of the teachers in her sample confirm that teachers viewed multicultural education from the perspective of the celebratory and none of them talked about it in a way that demonstrated awareness of multicultural education as transformative. Diaz-Rico (1998) in Gorski (2006:163) also found out that the multicultural education most often practised by teachers, administrators and staff developers and others in the United States is a conservatised, depoliticised version that does more to sustain inequities that to demolish them. Gorski (2006:167) also found that in the United States responses of multicultural education professionals in the definition of multicultural education typically reflect more of a compassionate, conservative consciousness than an allegiance to equity and justice. Such a definition of multicultural education may not enable its practice to achieve its intended goals. These different responses are a result of the way in which teachers conceptualise the implementation of multicultural education.

Some of the participants observed that the implementation of multicultural education in Zimbabwean primary schools faces some challenges. The challenges identified include: shortage of funds, absence of laws and policies on the part of government to guide the implementation of multicultural education, lack of textbooks that cut across all cultures and teacher attitudes. These challenges are all critical in the effective implementation of multicultural education; they need to be addressed so that the goals of multicultural education are attained. These challenges are similar to those cited by literature on multicultural education: shortage of funds and inability to replace biased 
or outdated books (Bennett, 2003: xi), teacher attitudes (Bennett, 2003: xi) inability of schools to cope with increased diversity (Wideen \& Barnad, 1999 in Kirova, 2008:119), and the presence of numerous definitions (Lemmer, Meier \& van Wyk, 2006:3; Zimmerman, 2004:1).

\subsubsection{CONTENT OF THE PRIMARY SCHOOL CURRICULUM AND ZIMBABWE'S MULTICULTURAL CHARACTER}

Most of the participants (16) felt that the content of Zimbabwe's primary school curriculum reflects the nation's multicultural character. In their view, this is shown through: multicultural school enrolments, co-curricular activities such as traditional dance and Music, the content of some subjects such as the languages, English and Shona; Social Studies; and Religious and Moral Education (R.M.E.), and the teaching of marginalised indigenous languages such as Tonga, Kalanga, Nambya, Venda and others in some schools around the country.

School subjects such as the languages, Social Studies, Religious and Moral Education were seen to reflect the multicultural character of Zimbabwean society. Social Studies and Shona were seen to accommodate the multicultural character of the nation as one participant observed;

Maybe in terms of the subjects themselves they cut across all the syllabi. For example take social studies, you find that it talks of the Karanga, the Zezuru, the Korekores so as to expose the child to different ethnic groups in Zimbabwe and also try to let the child appreciate that no other child or culture is superior to another culture. So they try to make the child accommodative, to accept other peers or friends and to accept their culture. This approach is strongly felt in Social Studies because here we are talking of how people live, how they relate, but if you look maybe at science many topics don't relate to how people live. They are looking more at application than how people live and in Social Studies it is fully catered for. The same thing maybe for Shona in the sense that they have now catered for all the dialects. (Participant 5, School 2) 
Religious and Moral Education and Social Studies were considered to embrace the multicultural character of the nation. Religious and Moral Education through its emphasis on different religions from different parts of the world was seen to reflect the multicultural character of the nation. Social Studies, through its focus on the way of life of people in different communities, was seen to play a part in showing that Zimbabwe is a multicultural nation. According to another participant Social Studies and Religious and Moral Education accommodate cultural diversity because;

The curriculum in almost every subject shows that there is need for children to be accommodated in their cultures. For example in Religious and Moral Education we teach most of the religions, Christianity, traditional religion, Hinduism and Islam. So this accommodates every child in this area of study. If we go to social studies we learn more about other countries like China, the way of life of the Chinese, the way of life of South American Indians all those areas really show that we accommodate different cultures in our teaching. In most of the subjects this happens because we have what we call integration of subjects. When we teach Science we don't only teach Science but sometimes Home Economics comes in, the way the people eat in China where they use chopsticks also comes in. You see this is how all subjects are integrated, to show different cultures. (Participant 11, School 3)

Similar views were raised during focus group discussions. The accommodation of different dialects, particularly in Shona was seen as a way of accommodating the multicultural character of Zimbabwean society. One participant had this to say about the accommodation of different dialects;

(The curriculum) it is designed in a way that it caters for all dialects in Zimbabwe, the Ndaus, the Karangas, Zezurus, and the Manyikas. Textbooks are designed in such a way that those languages are catered for. Some of the examples in the textbooks are written in Karanga and others in Ndebele. (Participant 17, School 3)

Another participant expressed similar views, by saying;

At grade seven level pupils in Binga (Matabeleland North) are writing Tonga. In some of our stories in the text book we have Tonga stories, Ndebele stories, also in Social Studies every topic in social studies talks about our society, in our country and outside the country. So I think they are using the multicultural approach. (Participant 14, School 4) 
The language policy and the different indigenous languages taught in the primary schools were also viewed as part of a multicultural school curriculum. A number of marginalised indigenous languages are now being taught and this was seen as an attempt to accommodate the nation's multicultural character. This was illustrated by one participant who opined;

Surely it is catering for multicultural groups because you find that there are pupils who are learning other languages that were not taught before here in Zimbabwe like Kalanga, Venda and the like. I can say a multicultural approach is being implemented. (Participant 13, School 4)

In a similar vein another participant observed;

Like in the past it was compulsory to do either Shona or Ndebele, but they have now introduced Kalanga, Tonga, Nambya and others as examinable subjects at grade seven level. So they are trying to cater for those small dialects in terms of exposing the child at an early age to learn languages which they speak at home. (Participant 5, School 2)

These views were supported by responses from focus group discussions where the teaching of marginalised indigenous languages was emphasised. One participant noted;

There is the process of including other minority languages in the curriculum which is in the process of actually being done. But I think the process has to be stepped up to increase the pace so that no one is left in the curriculum. (Participant 6, School 2)

The co-curricular programme in the different schools was seen as one way in which the multicultural character of Zimbabwe was reflected. This was achieved through competition in different traditional dance themes annually at national level. Music competitions are also held annually at national level with the Music pieces being written in different languages. One participant had this to say regarding the cocurricular programme;

I can say culturally our traditional dances encompass many cultural activities. You find that there are some white pupils who are dancing to our own dances like jerusarema (a Zezuru sub cultural dance), jiti (a Korekore sub cultural dance). (Participant 13, School 4) 
Traditional dance themes which are drawn from different sub cultural groups annually were also seen as a way of accommodating the multicultural character of Zimbabwean society. A participant expressed the following views regarding the schools' cocurricular programme;

When it comes to Music pupils from the Shona area like where I am right now are competing with those from the Ndebele area. The Music piece they are doing right now is a Ndebele one. So you see the Shonas here are competing to sing a Ndebele song which is quite plain that they are taking information from different areas. We move to things like traditional dance. Last time we had a dance from Matabeleland South, I am forgetting its name now, yah, amabhiza (Ndebele sub cultural dance). But we had to compete on that one because the idea is to accommodate everyone. Last year but one we had another dance, eh, this one was from Masvingo, pure Karanga that one. The other year we had jerusarema (Zezuru sub cultural dance) which is from Mashonaland East. Now I think that is testimony that different cultures are accommodated in the system. (Participant 9, School 3)

In agreement another participant revealed that;

In co-curricular activities the multicultural character of our society is shown. For example when we teach traditional dance we don't teach traditional dances in Zimbabwe, we also accommodate other cultures within Zimbabwe itself and also outside Zimbabwe. We teach muchongoyo (Shangaan sub cultural dance) we teach all sorts of dances. (Participant 11, School 3)

School enrolment patterns in the schools in the sample are multicultural in terms of ethnicity, gender social class and religion, among others. The participants were of the view that these multicultural enrolment patterns reflect the multicultural character of Zimbabwean society. Commenting on multicultural enrolment patterns in primary schools one participant pointed out that;

Yah, looking at the class I am teaching now, ah, um, it is being reflected that pupils from different cultures are being accommodated. Um, we have Ndebeles, we have Shonas, we also have pupils from different religious backgrounds, Moslems, Christians, from Pentecostal churches, from African Traditional Religion (ATR), and they are accommodated. So I think pupils from different backgrounds are being accommodated. (Participant 9, School 3)

These views by the participants signify a start has been made by the Ministry of Education, Arts, Sports and Culture in the implementation of multicultural education 
in Zimbabwean primary schools. They also reflect the participants' understanding of the concept of multicultural education and its implementation, which appears to be rather narrowly focused. What may be debatable at this juncture is the extent to which multicultural education, as is practised in Zimbabwe currently, embraces the ideals of multicultural education as set out by theorists in the field such as Banks (2009:237249); Nieto (2000) in Gorski (2006:165); Nieto (2002:31-46) and Nieto, (1997:46). The content of the curriculum has to accommodate learner diversity. Nieto (1997:46; 2002:31-46) is of the view that multicultural education should embrace the seven characteristics that she outlines. These characteristics include multicultural education as: basic education, anti-racist and anti- discrimination education, as important for all students, pervasive, education for social justice, a process and critical pedagogy. In terms of the views of the participants the content of the primary school curriculum confirms some of the characteristics of multicultural education put forward by Nieto (1997:46, 2002:31-46) such as multicultural education as: basic education, anti racist and antidiscrimination, important for all students, and a process. Participants mentioned a limited number of school subjects as accommodating cultural diversity and this makes it difficult to conclude that the pervasive nature of multicultural education is met in the content of curriculum instructional materials currently in use.

From the views of the participants, it appears that the content of the primary school curriculum includes the different subcultures that make up Zimbabwean society. It reflects multiculturalism to a certain extent. This is an acknowledgement that Zimbabwe

Is a multicultural nation (Nziramasanga Commission Report, 1999:357; Ministry of Education, Arts, Sports and Culture, 2004:4). The inclusion of different ethnic groups 
into curriculum content as well as the teaching of marginalised indigenous languages can be seen as an acknowledgement of difference in Zimbabwean society. However, Nieto (2002:39) is of the view that multicultural education should be seen as a philosophy, a way of looking at the world, not simply a programme or a class or a teacher. It follows that the implementation of multicultural education has to permeate the entire school curriculum. Multicultural education has to permeate all school subjects and activities because multicultural education is pervasive (Nieto, 1997:46, 2002:39). All the eleven subjects in the primary school curriculum should therefore reflect the nation's multicultural character and be taught from a multicultural perspective.

Multicultural enrolment patterns as practised in the schools in the sample as well as other schools in the country are indeed part of the implementation of multicultural education since all pupils should be given an opportunity to learn. This seems to affirm Banks's (2009:25) view of the practice of multicultural education. From the views of the participants, enrolment patterns in the schools are multicultural. This is seen by the presence of learners from various ethnic backgrounds in the school. This should be seen as a form of integrated pluralism (Bennet, 2003:25). This is an affirmation of difference that is found in society and is in harmony with the ideals of postmodernism (Ritzer, 2009:619). These multicultural enrolment patterns should also be seen as efforts to accommodate diversity, which is one of the goals of postmodernism (Ballantine \& Hammack, 2012:18; Hartman, 1998; Taylor, Richardson, Yeo, Marsh, Trobe \& Pilkington 2011: 411). When these multicultural enrolment patterns are accompanied by meaningful changes in the content of the curriculum, they ensure the successful implementation of multicultural education. 
Multicultural enrolment patterns need to be seen as part of the holistic approach in the effective implementation of multicultural education. In Zimbabwe, in terms of the National Constitution and the Education Act of 1987, discrimination of any learner is outlawed. It can be argued that the legal framework has provided an enabling environment for the practice of multicultural education.

Postmodernists argue that difference lies at the heart of the world (Ritzer, 2009:617). The content of the primary school curriculum in Zimbabwe has made some effort to accommodate difference that is found within society to a certain extent. This is in agreement with the tenets of postmodernism which emphasise acknowledgement of difference (Ritzer, 2009:617; Lyotard 1984 as cited by Ritzer 2009: 617; Cohen, Manion \& Morrison, 2011:26). Such an approach seeks to create a conducive school and classroom environment for all learners where all learners have an equal opportunity to achieve.

The accommodation of difference in the primary school curriculum in Zimbabwe is in harmony with the views of Vandeyer (2010:345) who observed that multicultural education seeks to create educational opportunities for students from diverse racial, ethnic, social class and cultural groups by acknowledging difference. Therefore education can be seen to be fulfilling one function in the context of postmodernism where education must build bridges between individuals and communities where it must help people to learn to live together (Daniel, 2004). Educators have a role to play in the creation of a multicultural society characterised by cultural pluralism. The UNESCO Convention on the Protection and Promotion of Cultural Expressions holds a similar view where one of the objectives is to foster inter-culturality in order to develop cultural interaction in the spirit of building bridges among people (UNESCO, 
2005:3). This interculturality can be fostered by the content of the school curriculum that should be multicultural as well as multicultural enrolment patterns.

The views above stress the importance of multicultural education in promoting understanding, tolerance and appreciation of those who are culturally different. These views are in harmony with the definition of multicultural education put forward by Manning \& Baruth (2008:5) where multicultural education should teach learners to appreciate, tolerate and accept differences in society. In the implementation of multicultural education, these differences should be reflected in the content of curriculum instructional materials. From the views of the participants, the content of the primary school curriculum in Zimbabwe, for example, in subjects like Social Studies and Religious and Moral Education among others, has started to enable pupils to appreciate learner diversity in the classroom and society. This is important for a multicultural society. Lemmer, Meier \& van Wyk (2006:4-5) advise that multicultural education recognises and accepts the rightful existence of different cultural groups and views, cultural diversity as an asset and a source of social enrichment rather than a disability or social problem. From the views of the participants, the content of the primary school curriculum in Zimbabwe can be seen to be meeting this challenge.

Acceptance of different cultural groups can come about as a result of a school curriculum that accommodates student diversity. Some subjects which include the languages that are English and Shona in this case, Religious and Moral Education and Social Studies were identified as ones accommodating the multicultural character of society by the participants. Co-curricular activities such as traditional dance and Music were also seen as reflecting the multicultural character of Zimbabwean society. The range of subjects that was seen to reflect the nation's multicultural character 
appears to be rather narrow and limited. In Zimbabwean primary schools, the curriculum consists of eleven subjects. In their responses, the participants did not cite subjects such as Home Economics, Physical Education, HIV and AIDS Education, Music and Mathematics as reflecting the nation's multicultural character.

This omission tends to reinforce the view that there are some school subjects that tend to reflect the nation's multicultural character more than others. This tends to contradict Manning \& Baruth's (2008:8-9) views that multicultural education should permeate the entire school curriculum rather than be doled out in a 'one course' or a teaching unit approach. This is the trend that appears to be prevailing in Zimbabwean primary schools. In terms of multicultural education .all subjects need to be taught from a multicultural perspective. The effective implementation of multicultural education cannot be confined to certain subjects at the expense of others. So what is required is a holistic view in the implementation of multicultural education where all school subjects reflect the multicultural character of Zimbabwean society.

The schools in the sample participate in co-curricular activities which are seen as one way of accommodating cultural pluralism. The co-curricular programme in the different schools is seen as reflecting the multicultural character of the nation through participation in music and traditional dance. This shows that effort has been made to accommodate the nation's cultural diversity as a way of implementing multicultural education. Although these activities make an attempt to address the nation's multicultural character, there are some challenges that need to be addressed. The activities discussed above are competitive activities which take place on an annual basis in the different schools in the third term. It may take a long time to actually include all the traditional dance genres from the different sub cultural groups found in 
the country. What is needed is an approach directed at curriculum reform where these different traditional dance genres become part of the Physical Education syllabus and the same should apply to Music.

Bennet (2003:2) argues that in order to implement multicultural education, curriculum reform is necessary. In Zimbabwe efforts directed at curriculum reform were instituted with the attainment of independence. These brought some changes to the curriculum. It should be emphasised that curriculum reform should be seen as an ongoing process that has to be attended to from time to time to address changing social and economic situations. In Music, different Music pieces need to be practised from the different sub- cultural groups. So by the end of the school year in each grade, a learner would have had an opportunity to experience different traditional dance and music genres in a single year. Multicultural education has to permeate all school subjects and activities because multicultural education is pervasive (Nieto, 1997:46, 2002:39). Therefore curriculum reform is required in this area and it should be an ongoing activity.

It therefore becomes important for the whole range of primary school subjects as well as co-curricular activities to reflect the nation's multicultural character. Sleeter \& Grant (2003) advise that multiculturalism does not belong exclusively to social studies, but is part of every teacher's epistemology. This observation is also valid since almost all the participants were of the view that Social Studies portrays the multicultural character of Zimbabwean society. The teacher's epistemology has to transcend all subjects in the curriculum as well as co-curricular activities. This way, the implementation of multicultural education in Zimbabwe will meet some of the characteristics outlined by Lemmer, Meier \& van Wyk (2006:4-5). There is also need 
to evaluate the level of implementation of multicultural education in Zimbabwean primary schools in view of the responses of the participants. It can be argued that multicultural education in Zimbabwe is a content oriented programme whose primary goal is to include content about different cultural groups in the curriculum and educational materials to increase student knowledge about these groups (Gary, 1995). This is currently being done to a certain extent in the content of curriculum instructional materials.

Based on the responses of the participants, the implementation of multicultural education in Zimbabwean primary schools can be placed at the additive level (Banks, 1993:13; 2009:239; Banks, 2006; 2008 in Yao, Buchanan, Chang, Powell-Brown \& Pecina, 2009). The additive level adds diversity to the curriculum by incorporating literature by or about people from diverse cultural groups into the mainstream curriculum (Yao, Buchanan, Chang, Powell-Brown \& Pecina, and 2009:3). This approach does not change the curriculum substantially (Banks, 2009:240).This creates a gap between theory and practice (Banks, 1993:1; Bruch et al. in Zimmerman, 2004:2) as the ultimate goal is to reach the social action level. The content of the primary school curriculum in Zimbabwe as currently constituted does not go far enough to include the transformative and social action levels outlined by Banks (1993; 2009; 2006; 2008 in Yao, Buchanan, Chang, Powell-Brown \& Pecina, 2009:3).

The responses of the participants show that effort has been made to recognise marginalised indigenous languages. This has been done by teaching these in those areas where they are traditionally spoken as an acknowledgement of difference. These marginalised indigenous languages are not taught countrywide in Zimbabwe, which is the ideal situation in a multicultural society characterised by linguistic diversity. The 
introduction of marginalised minority languages into the school curriculum should be construed in the context of efforts directed towards the implementation of multicultural education. The state of implementation of multicultural education in Zimbabwe is unlike the situation observed in South Africa (Vandeyer, 2003) and the United States of America (Zimmerman, 2004). In these countries the practice of multicultural education is still in the celebratory (contributions) phase (Vandeyer, 2003; Zimmerman, 2004).

Although most of the participants were of the view that the content of the primary school curriculum accommodates the cultural diversity of the nation, a few participants felt otherwise. In their view, the content of the primary school curriculum falls short in catering for different groups in the following areas: accommodation of learners with different learning styles and lack of portrayal of all ethnic groups in school textbooks.

The content of the primary school curriculum is seen as failing to cater for the different ability levels found in the classroom. This tends to have an impact on efforts directed at ensuring that all learners have an equal opportunity to achieve. In terms of the accommodation of different ability levels in the classroom one participant expressed the concern that;

Like here we have certain children who are far much below to compete with others in terms of ability. They are forced to be in that class because we do not have the facility of a special class here where they can compete at their own level. (Participant 16, School 4)

Another participant expressed similar views by saying:

For example, most of the textbooks are usable with children who are from better off backgrounds. They do not cater for those who are very slow. For example in primary schools we have got the Step in Maths textbook. The teacher would have to actually change the figures because the figures are too large, they do not cater for different abilities. Then the number stories in that 
text are out of touch with the backgrounds of the children, the home background or culture of the children. (Participant 6, School 2)

The aim of multicultural education is to give all learners an equal opportunity to achieve. In this regard, different ability levels as well as different learning styles need to be accommodated in the classroom. The content of the school text books has to ensure this.

There is a challenge that was observed in terms of the inclusion of the different subcultural groups in the textbooks, particularly the language textbooks. Some of the different dialects tend to be overlooked and the teacher has the burden of providing learners with equivalent terms in different dialects to enhance learner understanding. Outlining the role of the teacher in language teaching one participant argued;

The books do not talk about the different sub cultural groups like the Tongas; it is up to the teacher. When teaching, say a story from Nhaka Yeupenyu (a primary school Shona reader) which was written by a Zezuru, you can include vocabulary from other dialects. For example I was teaching Shona yesterday about bwiro (grave). Most of my pupils could not understand what bwiro was but when I explained it using other words from other dialects for what bwiro means they understood. I explained that bwiro is the Karanga name for grave that is when they understood. But here most of the Zezuru people use guva. It is up to the teacher to include that and explain to the children. (Participant 4, School 1)

Lack of accommodation of diversity in terms of ethnicity was re-emphasised by another participant who maintained that;

When we talk of ethnicity, this is where textbooks do not cater for that. Like here in Mashonaland West we teach Shona in particular to every child. There is no speciality for somebody who is coming from a Tonga or Ndebele background. The child is fitted into the syllabi and forced to write examinations whether or not the child is ready. (Participant 12, School 3)

The views expressed by these participants highlight the importance of adopting a holistic approach in the implementation of multicultural education. Their views highlight some challenges that are presented by curriculum instructional materials in the implementation of multicultural education in Zimbabwe. In the implementation of 
multicultural education, a holistic approach that addresses all the variables in multicultural education has to be adopted. All school textbooks have to reflect the cultural diversity of the nation in its entirety. Failure to accommodate cultural diversity may result in the marginalisation of some sub cultural groups and in the process impact negatively on the educational experiences of learners. All textbooks that are in use in Zimbabwe need to be revised so that they accommodate the cultural diversity that is found within the Zimbabwean society. These means that curricular should be interdisciplinary and represent diverse interests that universal skill, and that individual children, should reach a common goal by different paths (Ballantine \& Hammack, 2012: 19).

A review of curriculum instructional materials such as textbooks should be seen as part of an ongoing exercise in curriculum reform. Teachers therefore face a challenge in dealing with school text books that do not fully accommodate learner diversity. Banks (2009:25) argues that multicultural education is an idea or concept, an educational reform movement and a process. Therefore the reform of the school curriculum has to be attended to from time to time. This way, multicultural education seeks to ensure that all learners, regardless of their gender, social class, ethnic, racial or cultural characteristics have an equal opportunity to learn in schools (Banks, 2009:25).

Teachers need to accommodate the learning styles of their learners in order to enhance achievement. This should also be seen as a way to ensure that all learners have an equal opportunity to learn. Bennet (2003:185-186) has identified two learning styles which are field dependent and field independent. Educators have to accommodate these diverse styles in terms of classroom pedagogy in order to enhance 
equity pedagogy. Such an approach will provide learners from diverse backgrounds with an opportunity to achieve. Therefore teachers have a responsibility in selecting relevant and appropriate textbooks that portray the cultural diversity of the nation. Ideally, multicultural education, according to the Banks (2009:237-249) model, would be infused throughout educational content and experiences (Yao, Buchanan, PowellBrown \& Pecina, (2009:2). In other words, all curriculum instructional materials in use should affirm and reflect the cultural diversity found in the nation. This presents a challenge to textbook authors as well as textbook publishers in Zimbabwe who have to ensure that the school textbooks are multicultural in every respect.

\subsubsection{SCHOOL'S PARTICIPATION IN NATIONAL CULTURAL WEEK}

All primary schools in Zimbabwe celebrated Culture Week from 18 to 24 May, 2013. This is an annual event which was celebrated in conjunction with the United Nations World Culture Day that was celebrated on 21 May 2013. Different activities were lined up in some schools. These activities included contemporary music, display of traditional foods, modelling and traditional dance. For the participants, Culture Week is a way of accommodating the nation's cultural diversity.

Some schools did not do much in terms of showcasing diversity during Cultural Week. One participant had this to say about the Cultural Week activities at her school;

We actually talked about it but we didn't have any specific tangible activities. We just emphasised about culture in the classes but we didn't make any event about it. (Participant 10, School 3)

In some schools, there was an emphasis on music by different artists as a way of showing cultural diversity in Zimbabwean society. A participant gave an overview on Culture Week activities in his school. He had the following to say;

Okay, let me say we had a Cultural Fair. We invited different cultural groups. We were dealing with music only. This was music; we had Sulumani 
Chimbetu (a musical artiste) and Jah Prayzah (a musical artiste). All the people, the Charambas (gospel singers) were once here, so it really helped to show that our culture is diversified. (Participant 2, School 1)

A similar view was echoed by another participant who said;

We asked children to come up with what they wanted to do. So from Kensington area (not its real name) we had the nyau (Chewa sub-cultural dance), the mhande (Zezuru sub cultural dance), three types of dances and also the church people and their dances. So it was the children themselves who participated, they brought in whatever they learn from home, so that is how we covered diversity. The staff was informed that this is an ongoing programme because teachers and parents were convinced that children are capable of doing wonders and they enjoy it and they also learn in the process. Because there was drama, that is acting, the children were also learning and trying to respect people from other cultures. (Participant 5, School 2)

Apart from the dances at School 2, modelling and preparation of traditional dishes was also showcased as a way of showing the multicultural character of Zimbabwean society. Elaborating on how her school celebrated Culture Week one participant said;

We grouped pupils into groups that included dances, drama, and modelling fashions of different races and cultural groups. Then at the end of the week that was on Friday, we gathered as a school. Then we asked each group to present what they had practised. So some were showing modelling, some were dramatising, and playing different dances like mhande (Zezuru sub-cultural dance), muchongoyo (Shangaan sub- cultural dance), those dances were covered. There were different dishes which had been prepared mufushwa une dovi (dried vegetables in peanut butter), maputi (roasted maize) and so on. Then those who had cooked were able to give those who had not to taste their food. A bit of muriwo une dovi (vegetables in peanut butter, maputi (roasted maize) mbwirembwire (ground mixture of roasted maize, cow peas and groundnuts) though it was not much was available. (Participant 7, School 2)

Similar views were expressed during focused group discussions. The learning of different cultures was emphasised in the schools. One participant made the following observation;

Like last time we had the Cultural Week where we were learning about our own culture as well as the culture of different areas. (Participant 14, School 4)

The Cultural Week is therefore seen as a way of celebrating and acknowledging the cultural diversity of the nation and is part of the primary school curriculum. It also meets the objectives of Zimbabwe's Culture Policy whose objective is to promote 
Zimbabwean culture in a multicultural society and take into account, different ethnic, linguistic and religious groups (Ministry of Education, Sport, Arts and Culture, 2004:7). This is an acknowledgement and celebration of cultural differences in society. In Zimbabwe, this is an annual event and is seen as part of multicultural education. It gives learners an opportunity to appreciate and celebrate cultural diversity. However Richards, Brown \& Forde cited in de Souza (2010:3) have also pointed out the benefits of incorporating elements of students' home culture into the curriculum that go beyond acknowledging holidays and sharing traditional recipes. What this means is that the National Culture Week should be seen as an important component in the implementation of multicultural education in Zimbabwean primary schools. However this should also be accompanied by curriculum reform so that cultural diversity is reflected in the content of the school curriculum. It should be realised that appreciation of cultural diversity is one of the goals of multicultural education (Manning \& Barth, 2008:5).

The role of activities, such as the Culture Week in Zimbabwe, in the implementation of multicultural education faces challenges that have been observed elsewhere. Vandeyer (2003:195) argues that multicultural education in South Africa is in the celebratory approach (Banks contributions approach) in which parents are invited to a 'multicultural day' at the school where a panorama of cultures, the dances, the dress, the dialect, the dinners are put on display. In Zimbabwe, the Culture Week can be seen to be part of the celebratory approach. The celebratory approach is important because it can be used as a vehicle to move to other, more intellectually challenging approaches such as the transformation and social action approaches (Banks, 2009:237). Van Heerden (1989) and Vandeyer (2006) in Meier \& Hartell, (2009:181) 
point out that a 'cultural day' at school such as a Zulu or Indian day with a variety of foods or stringing together medleys of verses of songs in different languages, is an effort by schools to signal acceptance of 'new learners', albeit a superficial add on gesture that does little to bring about unity in diversity.

In the United States, Gorski (2006:167) found out that a number of well intentioned advocates of multicultural education respond that multicultural education is about learning about other cultures or 'celebrating the joys of diversity'. Although such lessons and celebrations are valuable, educationally they do not, when unattached from a transformative vision, move a classroom or school towards authentic multicultural education (Gorski, 2006:167). These observations show that such events as the Culture Week in Zimbabwe need to be accompanied by fundamental changes in the school curriculum in order to take the practice of multicultural education to higher levels. This facilitates the attainment of the ideals of multicultural education and reduces the gap between theory and practice (Banks, 1993:1; Bruch et al. in Zimmerman, 2004:2). Pease-Windy Boy cited by Haynes Writer (2008:3) argues that:

All too often the mainstream educational institutions regard cultural diversity as a few learning units that are cosmetically brown or black in complexion or as a few festivals that celebrate the food, clothing or dance of minorities.

Nieto (2002:28) holds a similar view. She argues that when multicultural education is mentioned, many people think lessons in human relations and sensitivity training, units about ethnic holidays, education in inner city schools or food festivals. In her opinion, if limited to these issues, the potential for substantive change in schools is severely diminished. Multicultural education in this context is therefore not limited to festivals only but should also deals with the content of the curriculum. Such festivals, when taken on their own, do not meet the ultimate goals of multicultural education which may remain stuck at the celebratory level. The celebratory approach is a 
superficial approach in the practice of multicultural education as it tends to focus on the celebration of ethnic heroes, foods, costumes among others. As such it does not meet the ideals of multicultural education since not much change is effected in the content of the curriculum.

Zimbabwe's Culture Week is slightly different from the situation that obtains in South Africa (Vandeyer, 2003:195) and the United States (Gorski, 2006:167; Nieto, 2002:28). In Zimbabwe, the Culture Week is part of the school curriculum in which effort has been recorded in the accommodation of the multicultural character of Zimbabwean society. As such, the practice of multicultural education in Zimbabwean primary schools is above the celebratory level (Banks, 2009:237).

While the celebratory approach may be regarded as the initial phase in the implementation of multicultural education, it presents some challenges. Meier \& Hartell (2009:182) argue that the problem is not that schools start at the celebratory/ contributions level, but that they often stop here: what schools need to do is to move very quickly and transform the curriculum. This means that, the curriculum in Zimbabwean primary schools needs to be reformed so that it meets the requirements of the transformative and social action levels outlined by Banks (2009:237-249) in the implementation of multicultural education. When activities such as the Culture Week in Zimbabwe are placed in an environment where curriculum reform has taken place, they go a long way in meeting the goals of multicultural education. These observations should not be seen as downplaying the significance and importance of activities such as the Culture Week in Zimbabwean schools. The Culture Week should be seen as part of efforts directed towards the realisation of the ideals of multicultural education. 


\subsubsection{DIFFERENCES IN CURRICULUM INSTRUCTIONAL MATERIALS}

\section{USED BEFORE AND AFTER INDEPENDENCE}

All the participants were of the opinion that, there is a significant difference in the content of curriculum instructional materials used before and after independence. The differences observed were that: the content of the curriculum used before independence was discriminatory and segregatory and alien such that it disadvantaged the black African learner, the cultural background and experiences of the black African learner were not favourably considered. The participants noted that with the attainment of independence curriculum reforms were undertaken so as to accommodate the nation's cultural diversity as well as making the content of education relevant and meaningful to the learner.

The views of the participants emphasised that the content of the curriculum in Zimbabwe before independence was discriminatory and alien. The cultural backgrounds of the learners were not fully appreciated as one participant recounted the following;

Those that were used before independence I can say they were segregatory, because they were not really catering for other small groups. Instead let me say smaller groups, I might be wrong they were not catering for the larger groups like the Africans themselves, they were not being put into the practice of meeting with others, and exposing their cultural abilities to the rest of the world. We were somehow incapacitated. (Participant 13, School 4)

Another participant gave a more elaborate account on the content of the school curriculum before independence which was viewed as segregatory because;

Before independence the books which we used, because I went to school before that time, they were sort of, what can I say segregatory. For the Africans, for the black people the curriculum it was like it had blinkers. I think it didn't give the black people the ability to be diversified in their way of thinking. Myself I did History in the primary school and Geography. We could learn things, Geography and History from European countries and yet we had our own Geography that was not there. We used to do history, British History and we used to do Canadian Geography. I think that one, it was not proper, it 
was not appropriate for us. And yet these days we find that the curriculum is sort of changed, we are doing things of our own, first it is beginning from our local ,it is going out later on as one goes with his/her education. (Participant 12, School 3)

A third participant expressed similar views by saying;

In the past we used to have textbooks that were mainly concerned with European history, especially in primary schools. We didn't have education; I mean we didn't have subjects like Social Studies, whereby we taught our own History, the History of Zimbabwe from before and after independence. Then after independence we started to teach our own History. (Participant 11, School 3)

Similar views were expressed during focus group discussions. The alien nature of the curriculum content used before independence was once more highlighted. One participant pointed out that;

Before independence, the textbooks used to talk about Shakespeare and others. Now the curriculum is designed in such a way that children learn about what is happening here. It is designed according to how we live in Zimbabwe not about oceans such as the Atlantic. It is not included right now but we used to learn about all other areas which do not concern us. For example now the subjects mainly from grade one to seven mainly talk about Africa. But before independence we used to know about the whole world and Britain. The songs, the grade one songs and crèche songs which we sung were English songs from Britain. For example 'Bah, bah black sheep do you have any wool?' (Participant 17, School 5)

In agreement another participant proffered the following views;

The curriculum used before independence was a bit excluding. The Shonas had their own curriculum and Europeans had their own. But after independence they are now the same. The content of textbooks has changed because before independence the stories or the pictures were not gender sensitive, the girls were meant for house hold chores and the boys were for herding cattle and other duties. But these days our books emphasise boys can also do what girls can do and girls can do what the boys can do. (Participant 4, School 1)

The content of the curriculum used before independence did not consider the cultural background of the learner. In other words it was a mono-cultural Eurocentric curriculum in which learner diversity was not acknowledged. With the attainment of independence a number curriculum reforms were undertaken so as to ensure that the 
school curriculum was meaningful and relevant to the learner. One participant narrated the changes that have taken place in curriculum content after independence by stating that;

After independence there has been a lot of opening up of our diverse cultures to show each other how we interact through either dances, through language, through games that we play, sports, and other sporting activities. (Participant 13, School 4)

An attempt to accommodate learner cultural diversity was made with the attainment of independence. Another participant emphasised that;

Then after independence we started to teach our own History. Curriculum materials introduced after independence accommodate learner diversity. For example as I have said there is information on Islam, there is information on Hinduism, there is information on other religions and also on the other cultures we have in our country. So the books are supposed to, in fact are written to fit the kind of material that we are supposed to teach the children. (Participant 11, School 3)

A change in the content of textbooks particularly English readers was observed. This was done to acknowledge the multicultural character of Zimbabwe as one participant remarked;

But looking at the current situation, they are just trying to accommodate everyone. There is a change; the content of the textbooks has changed. In English readers they used to talk of Jennifer and John, Look John, but now we have names like Tatenda, Tarisai, Mr. Moyo, Mr. Mutema and so forth. This is trying to accommodate multiculturalism. We are moving towards multiculturalism, though it has not been fully implemented. (Participant 3 School 1)

The views of the participants show that there are some curriculum reform initiatives that were undertaken with the attainment of independence. These were undertaken in an effort to ensure the relevance of the content of the curriculum. It can be argued that such reforms were a response to the need for a multicultural school curriculum. 
Similar views were expressed during focus group discussions where change in the content of the textbooks was noted. For example indigenous name are used in some of the texts. One participant proffered the view that;

We are now appreciating our own country. Even the names in English readers were those like John, Peter, Mary, but now they are using Ndebele names, Shona names and even Tonga names. (Participant 17, School 5)

Gender sensitivity is an issue that has gained prominence in the curriculum with the attainment of independence. After independence some textbooks have accommodated gender sensitivity because;

The content of textbooks has changed because before independence the stories or the pictures were not gender sensitive, the girls were meant for house hold chores and the boys were for herding cattle and other duties. But these days our books emphasise boys can also do what girls can do and girls can do what the boys can do. (Participant 4, School 1)

The responses of the participants show that the content of the curriculum used before independence did not consider the cultural background of the learner. In other words it was a mono cultural, Eurocentric curriculum in which learner diversity was not acknowledged particularly in terms of cultural background. Hence postmodern theory questions the validity of Eurocentric knowledge as being the exclusive reference point to judge all learning (Ghosh, 2002:49). The views expressed by the participants show that with the attainment of independence in 1980 there has been curriculum reform in the primary school curriculum in Zimbabwe. Curriculum reform is an essential component in the implementation of multicultural education where the content of the curriculum has to be meaningful and relevant to accommodate learner diversity. This is in agreement with the views of Ghosh (2002:3 and Banks, 2009:12)) who advocate for change in the content of the curriculum.

Curriculum reform which took place after independence in Zimbabwe can be seen as an attempt to accommodate learners from diverse backgrounds positively. These 
reforms were intended to make the content of education more meaningful and relevant to all learners as the pre- independence curriculum was Eurocentric (Muparutsa, 2012: 61; Njobe, 1990: 29). Curriculum reform is therefore seen as an important process in the practice of multicultural education (Bennet, 2003:14; Banks, 2009:2). These reforms in the content of the school curriculum are also similar to the demands in curriculum reform made during the Civil Rights Movement (Banks, 1994; Gorski, 1999). In this context reforms initiated in the curriculum after independence can also be seen as the initial phase in an endeavour to ensure that the primary school curriculum becomes multicultural. This becomes important when it is appreciated that imperial and colonial rule sought to obliterate the cultural identity of the colonised people and this was one of the hidden aims of colonial ideology of assimilation (Cabral, 1983) in Viriri, (2003:1). However, the degree to which curriculum reform undertaken so far embrace the ideals of multicultural education remains a debatable issue.

The content of a Eurocentric curriculum that was in place before independence in Zimbabwe had an impact on the education of the African learner. Nyerere in Moyana, (1984:19) posits that it resulted in a situation in which the individual developed a split personality, where individuals would despise their culture as something to be ashamed of rather than a source of pride. Ghosh (2002: 49) advises that a Eurocentric viewpoint ignores the contemporary and historical contributions of most of the world's people especially those in Africa, Asia, Central and Latin America (Ghosh, 2002:49). A school curriculum that is dominated by a Eurocentric view lacks relevance and meaning for the learner. Such an approach works against the ideals of multicultural education hence the relevance of curriculum reforms undertaken after 
independence. Vandeyer (2003:193) advises that indigenous and racially non white people and their cultures, already condemned by social Darwinism as backward, primitive and thus irrelevant to their use (Focault, 1980, in Vandeyer, 2003:193) were not permitted to enter the privileged space of mainstream culture. Colonial education and colonial policies in education did not view the cultural experiences of the African learner positively and these were not included in the content of the school curriculum in a positive manner. This was reflected in the content of the school curriculum in which indigenous Africans were marginalised.

In Zimbabwe curriculum reform was intended to correct this imbalance. Therefore diversity in most contemporary societies has its roots in colonial times as imperialist powers typically European carved up the Asian, Latin American and African continent new countries were created with little regard to their traditions and social or cultural integrity (Nkomo \& Vandeyer, 2009:6). There was no effort to include the cultural experiences of the African learner into the content of the curriculum and this met one of the central dimensions of western colonial domination (Kincheloe (2008:5). The situation is observed by the participants which prevailed in colonial Zimbabwe is similar to what prevailed in the United States of America prior to the Civil Rights Movement of the 1960s. Banks (1994) in Lemmer, Meier \& van Wyk, (2006:4) says that the major goal of the Civil Rights Movement was to eliminate discrimination in all spheres of society, especially in employment, housing and education. As a result Civil Rights activists demanded curriculum reform to enable their achievements and contributions to be reflected in curricular texts among others (Lemmer, Meier \& van Wyk, 2006:3). In Zimbabwe curriculum reforms undertaken after independence have to some extent accommodated the nation's cultural diversity. 
What is debatable is the extent to which the curriculum reforms introduced after independence fully embrace the ideals of multicultural education. It has been noted that Zimbabwe's education system can best be described as Eurocentric in its cultural content and orientation (Nziramasanga Commission Report (1999:367). The responses of the participants (See section 4.2.2 pp. 184-185) confirm the view that there are some challenges in the accommodation of the nation's cultural diversity in curriculum instructional materials. The need to accommodate different ability levels and ethnicity appears to be problematic. This observation reinforces the view earlier mentioned that curriculum reform should be an ongoing process where the goal is to ensure that the content of the primary school curriculum is of relevance to the learner. Therefore curriculum reforms initiated since the attainment of independence, though noble, have not gone far enough to reflect the cultural diversity of the nation in its entirety. There is need for more curriculum reform initiatives so as to effectively embrace the ideals of multicultural education. Banks (2009:25) advises that multicultural education is a process. In this regard curriculum reform should not be seen as a once off event, but is an issue that needs constant revisiting. The content of the primary school curriculum in this regard presents a gap in the implementation and practice of multicultural education that needs to be filled.

\subsubsection{PORTAYAL OF ZIMBABWE'S PLURAL CHARACTER IN THE CURRICULUM INSTRUCTIONAL MATERIALS CURRENTLY IN USE}

Most of the participants (16) were of the view that certain curriculum instructional materials that are currently in use portray Zimbabwe's plural character positively. In their view this is shown in some subjects such as the languages, Music, Social Studies and some co-curricular activities like traditional dance. The textbooks in use tend to 
include learners from diverse cultural backgrounds. Different ethnic groups are portrayed positively. A participant opined;

Yes curriculum instructional materials show that Zimbabwe is a multicultural nation. So all pupils are equal. Because the way the books are written now you find that a certain chapter may cover the Chewa pupils, another chapter Shona pupils. (Participant 19, School 5)

Social Studies was once more cited as a subject area in which pupils from different social groups are portrayed. The role of social studies in portraying the nation's plural character was highlighted by another participant who observed;

Ah! Let me take the topic food and even shelter in Social Studies. We look at shelter for different communities. We look at the rural community first, the huts they live in, the Tonga type of huts, and then we come into urban areas where there are houses which contain some toilets and water system inside. We move on to the skyscrapers and so on. We move on to other countries where we have accommodation like those of the Eskimos, the tents which are used by the Red Indians and so on. The bamboo houses eh, it's also showing the type of shelters used by different communities. If we move on to food, we look at the food that is eaten by people in our local community and then others. Others we are looking at the Chinese or the Japanese eating rice. We move on to Tanzania where they use cassava and so on. I think most communities are accommodated. (Participant 9, School 3)

The languages (English and Shona) were also considered as subject areas in which the different social groups are portrayed. In these subject areas the stories are drawn from different settings in an attempt to accommodate all different social groups. Religious and moral education through a study of world religions was seen as a way of portraying different social groups. A third participant emphasised similar views about the portrayal of the different social groups in the languages as follows;

This is what I have highlighted in the beginning, earlier that in our English language the stories that are contained some cover a global nation. Then the other stories, maybe those are from a traditional setting, and some stories may contain an urban set up. So by that we can see that the syllabus is trying to implement multicultural education. Because in other instances you get stories on digging up mice or herding cattle, or in the city and city lights and you can see that it is in the syllabus. They want pupils to know different settings; other topics may cover life in farms and mining communities, as well as the growing of tobacco and so on. We see that they are trying to accommodate diversity. These issues are mostly covered in the languages. If you go to mathematics we 
have our stories but it is not as much as they do in languages, that is where I see the exposure of multicultural issues. For example if a Chewa (Malawian sub cultural ethnic group) speaking pupil picks a Nhaka Yeupenyu (primary school Shona reader) the child finds that his/her cultural experiences are included, since at times it discusses how Chewa is spoken, and the meaning of words in Shona and Ndebele. Like those UNICEF books, these new books which have recently arrived they can show that kutswa (pounding), and kudzvura (pounding) are equivalent terms and they can give equivalent terms in other dialects. When we go to Religious and Moral Education (R.M.E.) we have all the world religions although a high percentage is Christianity because it is mostly Christian families that are found in Zimbabwe. We ask questions on Islamic religion, Hinduism, African Traditional Religion and also stories on African Traditional Religion like Mbuya Nehanda. (Participant 12, School 3)

Similar views were expressed in focus group discussions where some subjects that portray Zimbabwe's plural character were identified. The languages, Religious and Moral education were seen as subject areas which portray the different social groups found in Zimbabwean society. One participant identified the following subjects as ones that portray Zimbabwe's plural character by remarking;

You want me to specify on the subjects that actually highlight the multicultural character of Zimbabwean society? I think RME, and some content subjects specifically Environmental Science. I think those two subjects actually reflect that combination. Maths actually since it is a subject that is best learnt in English mostly, there is no way we can measure, there is no indication that there is this accommodation of all cultures since only one language is used and that is English language.( Participant 20, School 5)

Another participant shared a similar view. He was convinced that;

We have got social studies and then we also have Environmental Science. Those ones have shown that we are a multicultural society. RME yes to some extent, we have got stories that were maybe taken or written by the Shonas, Manyikas, the Karangas and Ndebeles, so these are there. (Participant 2, School 1)

The role of Social Studies in portraying the plural character of Zimbabwean society was once more raised. This is done through the inclusion of different topics that cater for different cultures as a third participant asserted that;

In Social Studies if you look at the topics there, they cater for different cultures. If I pick say shelter, I have already talked about that, if you look at the topic food, we have food for different cultures. If you look at the topic 
clothes we have clothes for different cultures and occasions. (Participant 11, School 3)

The views expressed by the participants show that there are some subjects in which the plural character of Zimbabwean society is reflected more than in other subjects. These subjects include Social Studies, Religious and Moral Education and the languages. It appears that the subject range that plays a part in the implementation multicultural education remains the same. Participants identified Social Studies, Religious and Moral education and the languages as being the subjects in which the cultural diversity of learners is portrayed. One wonders whether the other subjects such as Home Economics, Physical Education among others do not play a role. These views tend to strengthen the view that there are some subjects in which cultural diversity is more highlighted than in others. This tends to contradict the views of Gollnick \& Chinn (2012:30) who advise that each subject should be taught from a, multicultural perspective. In this regard multicultural education should permeate all school subjects. It therefore becomes imperative once more for a thorough review of school textbooks to be undertaken in order to ascertain the level of accommodation of cultural diversity. The portrayal of pupils in some textbooks should enable pupils to acquire multicultural competence which is a dimension of multicultural education (Bennet, 2003:2).

Mustafa (2006: 93) advises that education from this time forth should appeal to dissimilar voices and the voice of the 'put aside' should be heard in all educational processes. This means that the cultural background and experiences of learners should be reflected in curriculum instructional materials currently in use. The participants indicated that some stories in the textbooks are drawn from diverse settings such as urban areas, rural areas, farming communities and others. This does 
not go far enough in portraying Zimbabwe's multicultural character. It should be observed that these settings are not homogenous communities as there is diversity in terms of social class, ethnicity, gender, religion among others which should feature prominently in the stories that learners read. The different stories should make a deliberate effort to include the diverse cultural experiences of the different social groups. The insertion of multicultural topics in textbooks becomes important. Therefore there is need for the insertion of different multicultural topics pertaining to different social groups in the textbooks used countrywide. This view is in agreement with the observation of Vandeyer (2003:193) who observes that an ideal form of multicultural education is one that does not only recognise and acknowledge diversity, practices, tolerance and respect of human rights but works to liberate cultures that have been subjugated. This becomes significant when considering the view that multicultural education is a right to difference, learners' differences built around social class, gender and cultural differences among others must be validated because they are an important part of one's identity (Ghosh, 2002:2).

Portrayal of the cultural diversity of the nation in curriculum instructional materials can also be analysed in the context of the human relations approach put forward by Grant \& Sleeter (2004:7 2009:64). This approach is directed towards helping students communicate with, accept and get along with people who are different from themselves (Grant \& Sleeter, 2004:7). It is also a way of reducing prejudice which is one of Banks (2009:20) five dimensions of multicultural education. Cultural topics should therefore be infused throughout the different subject areas in the school curriculum. 
Although most of the participants were of the view that Zimbabwe's plural character is portrayed in textbooks there are some who observed some challenges in this area. These challenges were noted in the languages and they have a bearing on the successful implementation of multicultural education. The responses of these participants are significant in an environment where multicultural education should be practised.

The way the books are written particularly in the languages was seen to present some challenges. This results in a situation which makes it rather difficult to find a textbook that caters for all the different subcultures. With regard to the content of vernacular textbooks one participant proffered the following explanation;

But in Shona I think they are trying to introduce that in local languages. All they are saying basically is that there is a textbook in Kalanga as a language for the Kalanga. So the Kalanga textbook caters for stories in their own language and it centres on their culture, the same with Ndebele textbooks. So there is no common textbook in the languages. The textbooks may mix the experiences of the different social groups but the language used will favour the ethnic group for which it is written. So most of the examples will be those that they understand, if we are talking at primary school level. They want children to relate to their environment. So most of the stories will come from what they experience. Stories about other ethnic groups may be there but these are very few. So basically I think it is the perspective of the writer that influences the content. Because the writer is writing for a certain group of people. (Participant 5, School 2)

In the languages there is another challenge that was observed. Multicultural topics tend to be covered more in Shona than in English. This has an impact on the portrayal of different social groups. A participant pursued a similar view by pointing out that;

But when you come to some of the textbooks, yes of course we have textbooks in various languages but they do not fully accommodate the child. So the burden falls on the publisher to accommodate children. When you look at cultural topics, yes as far as the subjects are concerned let's say in Shona they explain in these but when we come to English, usually it is rare to find such topics covering the way people married long back and currently. So there is need for that intervention, at least so that they accommodate the various subcultures. (Participant 3, School 1) 
A bias in the content of curriculum instructional materials in favour of the dominant group was also observed and this presents challenges in the successful implementation of multicultural education. This tends to disadvantage learners from minority backgrounds in terms of ethnicity and social class. This concern was summarised by one participant who argued;

The plural character of Zimbabwean society is not portrayed in curriculum instructional materials. It is like if we look at Zimbabwe the dominant groups are the ones portrayed for example the Shona, any other ethnic group, smaller minorities are not. So it depends on who has written a book. If somebody is Karanga and has written the book it will be focusing on the Karanga, somebody is Zezuru and has written a book it focuses on the Zezuru culture. (Participant 1, School 1)

These responses of the participants are significant with regard to the practice of multicultural education in Zimbabwean primary schools. The implementation of multicultural education in Zimbabwean primary schools faces some challenges with regards to the content of curriculum instructional materials particularly the textbooks.

From the responses of the participants above it appears that the different social groups are not all portrayed in the content of some school textbooks and particularly in the languages. This is similar to the situation observed by Carjuzza (2012:5) in the United States where many minority groups and American Indians are often inaccurately portrayed and their contributions inadequately represented in K-12 pupils' school curricular. Thus, Apple (1993) cited in McGovern (1999:2) posits that the textbook is one artefact that plays a major role in defining whose culture is taught. This tends to create a situation where some groups are marginalised in terms of portrayal in curriculum instructional materials in use in schools. The content of the different textbooks particularly in the languages should reflect the multicultural character of the nation in its entirety. 
All the different ethnic and social groups should be accommodated in the textbooks despite who the book has been written for. This calls for closer collaboration between educators and book publishers to ensure that school textbooks are multicultural in every sense. Manning \& Baruth (2008:8-9) argue effectively that multicultural education should permeate the total school curriculum rather than be doled out in a 'one course' or a teaching unit approach. This means that all subjects including languages should reflect the multicultural character of Zimbabwe to a greater extent. Multicultural education according to the Banks model should permeate the content of all curriculum instructional materials currently in use (Yao, Buchanan, Chang, Powell-Brown \& Pecina 2009:2). This will enable students to develop more positive attitudes towards different cultural, racial, ethnic and religious groups. May (2009:43) in McKinney and Soudien, (2010:7) argues that:

In particular, attention needs to be paid to the processes by which alternative cultural knowledges come to be subjugated principarily through hegemonies and misrepresentations (...) which invariably accompany such comparisons (of hegemonic and subjugated knowledges).

This observation is significant when analysing the content of school textbooks that are currently in use.

All school textbooks should accommodate the nation's cultural diversity. In light of the views of the participants regarding the portrayal of different groups in curriculum instructional materials there is need to adopt Banks's (2009:240) views. Banks (2009:240) has observed that there is need to avoid a mainstream-centric curriculum which has negative consequences for mainstream students as it reinforces their false sense of superiority, gives them a misleading conception of their relationship with other racial and ethnic groups and denies them an opportunity to benefit from the knowledge, perspectives and frames of reference that can be gained from studying 
and experiencing other cultures and groups. Therefore multiculturalism should be such a basic part of the school that it becomes a natural and accepted daily routine. It also needs to be recognised that what meanings are considered the most important, what experiences are deemed the most legitimate, and what forms of writing and reading matter, are largely controlled by those groups who control the economic and cultural apparatus of a given society (Aronwitz \& Giroux, 1991). Book publishers and authors need to take it upon themselves to avoid bias in the content of textbooks. The bias takes a number of forms (Sadker \& Sadker, 1978 in Gollnick \& Chinn, 2012:320).

\subsubsection{REPRESENTATION OF LEARNERS FROM DIFFERRENT SOCIAL GROUPS IN CURRICULUM INSTRUCTIONAL MATERIALS}

Most of the participants (16) were of the view that all social groups are represented in the content of curriculum instructional materials currently in use. This representation is shown in the different subjects and is in harmony with the preceding section on reflection of cultural diversity. Subjects such as Social Studies, Environmental Science and Religious and Moral Education (content subjects) and Shona were seen as playing a part in the representation of learners from different social groups. A participant had this to say about the content subjects;

Yes the textbooks portray different social groups. There are certain areas where the books contain the stuff especially in General Paper, in the General Paper (content subjects) textbooks. Here we see some of the huts, some of the shelters and some of the equipment used elsewhere illustrated. They are shown in the textbooks so that for example the Tonga child is no stranger in the textbook. He/she will always find some stuff that he /she uses in his/her local language, local setting. In language now it is widely considered because according to our recent referendum we have to consider about 16 indigenous languages now, about 16, they may be thirteen , but nearer to that number. (Participant 11, School 3)

In support of the above view another participant articulated the following views; 
For example religion, religion is not a problem, in RME we talk about the multi faith approach. There is the textbook again, it has those different religions. So in RME when talking about religion that is where all the children see that everyone is covered. We talk about African Traditional Religion (ATR), Hindus, Moslems, Christians and so on. So everyone there finds his/her own group, that one is covered. This subject RME, this religion, Christianity, we talk about different religions. So religion is covered. (Participant 7, School 2)

Shona was seen to represent students from the different social groups. The Shona text book in use contains stories about different ethnic groups as a way of showing cultural diversity in Zimbabwean society. One participant had this to say concerning the content of some Shona textbooks;

But we have some stories in that Shona, Nhaka Yeupenyu (Shona primary school reader) about a Ndebele family discussing their social life, a story about the Ndebele people, and a story about the Chewa people in those books. In one or two pages we may know about their ethnic group. Even in Shona we have sometimes lessons where we will be talking about different things. (Participant 14, School 4)

Similar views were expressed during focus group discussions. The language textbooks were identified as representing students from different social groups through the inclusion of stories from different settings. A participant had this to say about some examples in language textbooks;

When they give examples in languages they also talk about the different areas; they do not stick to one area. For example, they don't talk about Harare only or Chegutu only or rural areas only. In another story they might talk about rural areas, in another story they may talk about towns. They give examples from different areas. (Participant 17, School 5)

Co-curricular activities such as traditional dance tend to provide an avenue for the representation of students from different social groups. The dance themes are drawn from different parts of the country on an annual basis. The role of traditional dance in accommodating cultural diversity was emphasised by one participant who indicated that;

For example in the third term, in third term we participate in traditional dance. Every year they give a topic which caters for every culture. For example last 
year pupils competed in a dance from Bulawayo, amabhiza (a Ndebele subcultural dance). This year the dance is from Murehwa (Mashonaland East). (Participant 18, School 5)

The views of the participants show that students from different social groups are represented in the content of the primary school curriculum. Learners' diverse cultural backgrounds are accommodated in curriculum instructional materials. This is catered for in the content of some textbooks such as English, Shona, Social Studies and Religious and Moral Education, as well as the school's co-curricular programme particularly traditional dance. Maybe the question that can be posed is the extent to which this representation is being currently practised. It appears that this is being practised to a limited extent. A multicultural school has a number of characteristics. Gollnick \& Chinn (2012:29) argue that in a multicultural school the school curriculum would be unbiased and would incorporate the contributions of all cultural groups and instructional materials would be free of bias, omissions or stereotypes. The responses of the participants seem to suggest that diversity is accommodated to a certain extent. This tends to affirm Nieto's views (Nieto, 2000 in Gorski, 2006:167; Nieto, 2006:42) that multicultural education is also seen as critical pedagogy. It is based on the experiences of diverse groups. It therefore becomes important to ensure that all students from diverse cultural backgrounds in the nation are portrayed positively in the content of curriculum instructional materials.

Ghosh (2002:57) advises that students are valued and devalued through their presence in the curriculum, for example, when a student finds no reference point in texts which she can identify, or if her ethno cultural group is portrayed in a negative light, then he/she feels devalued. From the participants' views the accommodation of cultural diversity in curriculum instructional materials promotes the self esteem of the learners. When this happens the goal of multicultural education of giving all students 
an opportunity to achieve regardless of their diverse backgrounds is met (Banks, 2009:12).

There are some participants who felt that students from all social groups are not portrayed in the content of curriculum instructional materials currently in use. This tends to arise out of a situation in which some subcultures are not highlighted in curriculum instructional materials. One participant registered the following complaint about the content of some curriculum instructional materials;

It is not like that. Other cultures are not even mentioned in the content of curriculum instructional materials in the text books. The burden falls on the teachers, but what happens mostly is that teachers just follow what is in the syllabus and textbooks. Like I said before this is not even talked about at teachers' colleges except for teachers who have gone on to improve themselves academically, they have gone on to acquire degrees those are the teachers who may talk about multicultural education.(Participant 1, School 1)

This view was supported by another participant who insisted that;

The various social groups are not represented. They are not because from what I have just said about the fact that you may not find a Chewa reading about the culture of the Chewa in this set up. So I don't think they are fully represented. For an example in terms of pupils with disabilities here they don't even have books in braille. (Participant 12, School 3)

These views are significant in the context of multicultural education where the need to accommodate learners from diverse cultural backgrounds in curriculum instructional materials assumes major importance. They also highlight some of the challenges facing the accommodation of cultural diversity in the text books in use. Manning \& Baruth (2008:6) argue that students need curricular materials appropriate to their cultural backgrounds. They further state that these materials should enhance students' self concept, engage student interest in classroom learning and provide examples, vocabulary and models that relate to students cultural backgrounds. Portrayal of the different social groups in curriculum instructional materials has a history in the field 
of multicultural education. It was an issue in the United States of America during the Civil Rights movement of the 1960s.

In the United States of America ethnic groups demanded the revision of textbooks to make them reflect the diversity of people in the United States (Banks, 1994 in Lemmer, Meier \& Van Wyk, 2006:4 and Gorski, 1999). This observation is also relevant to Zimbabwe where an attempt has been made to accommodate learners from diverse cultural backgrounds in curriculum instructional materials. Positive portrayal of students in curriculum instructional materials is part of multicultural education. Learners' diverse cultural backgrounds therefore need to be portrayed in curriculum instructional materials that are used. Ideally in the Zimbabwean context the experiences of ethnic groups such as the Tonga, Kalanga, Venda, Sotho, Nambya, Shangaan and others should be included in the curriculum and instructional materials used countrywide ( Muchenje, 2008:14).

Representation and portrayal of the different social groups in the curriculum instructional materials serves as a source of motivation. This enhances the chances of all learners to achieve which is another goal of multicultural education. Gollnick \& Chinn (2012:310) state that if students seldom see representations of themselves, their families or their communities, it becomes difficult to believe that the academic content has any meaning or usefulness for them; it will appear that the subject matter has been written and delivered for a different group of students. This has implications for the practice of multicultural education in Zimbabwe where the need to accommodate learners from diverse cultural groups assumes major importance. In China, Wang (2003) as cited by Wang \& Phillion (2009:10) made similar observations. Building on the work done by Apple \& Smith (1991) and Banks (2007) 
he theorised that the exclusion of minority groups' knowledge, language and cultures from school textbooks conveys a message to both minority and Han students that minority knowledge, language and culture are not important and not worth learning. This observation is also applicable to the Zimbabwean situation in the practice of multicultural education.

This is an area that needs to be attended to in the practice of multicultural education in Zimbabwe through curriculum reform. Curriculum reforms should ensure that all social groups in Zimbabwe are portrayed positively in the content of curriculum instructional materials.

\subsubsection{CLASSROOM PEDAGOGY AND THE ACCOMMODATION OF STUDENTS’ CULTURAL DIVERSITY}

All the participants were of the view that teachers accommodate classroom diversity in their teaching methods. This is done when designing appropriate classroom pedagogy through the examples that are given to learners when teaching. This should be seen as a form of content integration according to Banks's (2009:20) dimensions of multicultural education. These examples given also accommodate learners' different learning styles. The views of the participants show that the different examples used in teaching are drawn from the sub cultural experiences of the learners.

Accommodation of classroom diversity in terms of pedagogy can be through utilisation of teaching methods that appeal to the different learning styles of learners. This is done in an attempt to ensure that all learners have an equal opportunity to achieve. One participant had this to say about teaching methods:

Teaching methods accommodate the children because eh, these children are different. Their way of grasping, their way of accepting, their way of understanding is different. So the moment we use the different methods of teaching one child will be able to grasp, while one will grasp faster when 
using another different method. So the different methods which we use, they make us, we can also identify that these children are able to do this; these children understand more when I do this. (Participant 15, School 4)

In the teaching of languages for example Shona diversity can be accommodated through the use of different dialects to enhance learners' understanding of terminology used for example in a story. The task of the teacher in accommodating the different dialects was emphasised by another participant who suggested;

The methods of teaching must include all the pupils. For example if you are teaching a story, the other time I gave you stories that I teach my Shona pupils. For example the terms and the terminology in that story may come from a different dialect. Then you can explain to the children what the other terms in that story mean, by so doing you are including everyone. I explain these terms in their own dialect. Students' diverse cultural backgrounds and experiences can be included through drama, role play. For example I can stage a drama on the payment of lobola by the Shonas. I can explain how the Ndebeles do it and how the Korekores do it. By so doing I am including everyone, those pupils from the Korekore subculture will now participate when you talk about the Korekore subculture and the Ndebeles will participate when you talk about how they do it in their culture. (Participant 4, School 1)

Diversity can be accommodated in the classroom by giving learners equivalent terms

in different dialects for the same item or concept. According to a third participant;

When giving examples in the classroom we include pupils' cultural backgrounds. We use their experiences for the benefit of the rest of the class. For example in Shona, eh, dikita (sweat) is what we know it in Zezuru, but in Chipinge (Manicaland), if you go to Chipinge it is called chifundi. So in that case we use the experience of the children, we use their language, their knowledge of the language to help the whole class. Because when questions are asked in examinations, they don't only ask in Shona, I mean Zezuru questions, they also ask words pertaining to Karanga, Ndau, Manyika and Korekore. So the children in our class, I really am happy if I have different pupils from different cultures, because it makes my teaching easier. (Participant 11, School 3)

Teaching methods can be tailor made to suit the setting of the school and thus accommodate learners' cultural diversity. This enables learners to learn in a familiar environment as another participant stated;

I think the methods which are used by the teacher become important. Let's say you are talking about the site of the school, you talk about whether it is a rural, peri urban, a farm school or otherwise. Now the methods which are going to 
be used by the teacher are going to accommodate everyone. In their methods the teachers will look at the school whether it is a farm school or a mine school or whatever. So the methods which are going to be used by the teacher are going to help the children. Let's say for here it is a farm school, you will look at the background of the children. In a farm situation you will talk about the compound where they live. Most of the pupils here live in compounds so the methods which you are going to use should be drawn from a compound setting. (Participant 7, School 2).

Similar views were expressed during focus group discussions. The importance of knowing each learner as an individual was emphasised. The need for child study was emphasised by a participant who propounded that;

Um, like I have already said we do child study. We have a social record where we look at the background of the child, religion and culture. That is meant to ensure that when we deal with our pupils we accommodate their sub cultural experience. (Participant 9, School 3)

The importance of accommodating all cultures in the teaching approach was emphasised as a way of accommodating all learners in terms of pedagogy. Another participant observed that;

They also accommodate multi-cultures whereby if it is the teaching of RME or whichever subject, whichever topic, the teacher is supposed to accommodate all those pupils knowing that I have pupils of this culture, pupils of this race. His/her methods of teaching should also accommodate that. This happens in all subjects just because there is no other subject to say eh, I should not apply this special method of teaching. All subjects are taken as if they are just the same. (Participant 20, School 5)

In accommodating classroom diversity there are some issues that need to be considered. The need for teachers to be familiar with the backgrounds of their learners was emphasised. A strategy to ensure the accommodation of cultural diversity was summarised by a participant who said;

I think the best way of accommodating children in the classroom is to actually have an adequate research on the backgrounds of the children so that for example, examples given are relevant to children in the community instead of the teacher giving his/her own examples from his/her own background, from other backgrounds which are alien to the local children. So I think the best method, they are OK ,but now the way they are executed will tell a story whether or not the children's culture are integrated in the method the teacher uses. ( Participant 6, School 2) 
The teacher's personality was seen as an issue that presents challenges in terms of accommodating learners from diverse backgrounds in the classroom. This has implications for pedagogy as one participant believed that;

At times it is a challenge. Because you might have your teacher who is a personality. He/she has his/her own culture. For example myself I am a Christian I try by all means to mix the cultures. But at times you find that some of the things I don't believe in it is very difficult for me to teach those. So automatically there is a challenge in this area. (Participant 8 , School 2)

The responses of the participants show that classroom pedagogy tends to accommodate classroom diversity. This is seen in terms of teacher learner interaction as well as some of the diverse examples given in teaching. These examples are drawn from diverse learners' cultural backgrounds. This affirms the views of Wang \& Phillion (2009:10) who emphasise the importance of curriculum knowledge constructed from the perspectives of minority groups. In the effective implementation of multicultural education pedagogy has to accommodate and acknowledge learners cultural diversity as a form of content integration. It reflects polyvocality as Bakhtin cited in Agger (2006:34) advises that postmodernism is characterised by polyvocality which suggests that everything can be said differently indeed in multiple ways that are not inherently superior or inferior to one another. The views of the participants affirm that polyvocality is practised in the classrooms. This enables the voice of the learner to be heard in the classroom.

From the responses of the participants content integration (Banks, 2009:20) is being practised in the design of pedagogy in Zimbabwean primary schools. It appears that content integration features prominently in the languages particularly in the teaching of Shona where reference is made to different dialects as well as cultural practices. The teaching of Religious and Moral Education was also cited as an area where content integration is also practised. Although some subjects were cited as enabling 
content integration the desirable situation is one where content integration cuts across all the eleven primary school subjects.

Accommodation of learners' cultural diversity as is happening in the schools in the sample should be seen as a form of culturally responsive teaching (Mugisha, 2013:5; Gay, 2000 in Maatta 2008:22; Castagno \& Brayboy, 2008). It is also an affirmation of the principles of postmodernism. With reference to Zimbabwe it appears that teachers are aware of the need to accommodate learners' cultural diversity as shown by the different responses of the participants. It is a form of content integration that should also enhance equity pedagogy which is another dimension of multicultural education (Banks, 2009:20). Content integration as well as other issues discussed so far show that a start has been made in the implementation of multicultural education in Zimbabwe. This is in agreement with the views of Gadamer in Ghosh (2002:3) who posits that multicultural pedagogy must create new spaces in a fusion of horizons Content integration is also one way to fulfil some of the goals of the Dakar Framework of Action of 2000 (Little, 2002:13). This can come about by providing students with an empowering school culture (Banks, 2009:20). Such a culture recognises and accommodates learners' cultural diversity positively.

Multicultural education attempts to cater for students' cultural diversity and give students with different characteristics an opportunity to learn (Banks, 2009:25). This can be achieved in part through the design of classroom pedagogy that accommodates learners' cultural diversity in the classroom In this regard the school must not create the 'Other' by making boarders around group differences (Ghosh, 2002:6). All learners must feel included in terms of content integration. Moll et al (1992) and Gonzalez, (2004) cited in de Souza (2010:3) state that when teachers get to know 
their students and find ways to incorporate their home based expertise or 'funds of knowledge' in the classroom, students are better able to make connections between topics and across languages thus maximising learning.

Postmodernism has been particularly important in acknowledging the multiple forms of 'otherness' as they emerge in differences in subjectivity, gender and sexuality, race and class, temporary configurations of sensibility and spatial geographic locations and dislocations (Huysenns (1984) in Harvey, 2001:176). Accommodation of learners' cultural diversity through content integration as is happening in the schools in the sample is part of the knowledge construction process where the focus is to emphasise to pupils that knowledge is socially constructed. This is in agreement with the views of Lyotard cited in Kirby et al (1997:719) who argues that all knowledge is relative; all is good as any other. Lather in Slattery (2006:27) concurs and posits that society is in the midst of a shift away from the concept of an objective, knowable world 'out there' towards a concept of constructed worlds where knowledge is contested and partial.

Knowledge construction is another dimension of multicultural education (Banks, 2009:20). The schools in the sample appear to value the cultural diversity of their learners. This brings with it some advantages .Within the school therefore; cultural diversity should be seen as an asset (Lemmer, Meier and van Wyk, 2006:4-5). Cultural diversity can be utilised in designing pedagogy that appeals to learners from diverse cultural backgrounds. Slattery (2006:23) argues that whether critics like it or not, society has become a global plurality of competing subcultures and movements where no one ideology and episteme (understanding of knowledge) dominates. Kincheloe (1993) in McGovern, (1999:17) argues that a foundational principle of 
postmodern theories states that there is no universal knowledge beyond that which is developed within political, ideological and economic conditions of particular social and cultural formations. The need to accommodate learner diversity becomes very important in the knowledge construction process.

Accommodation of learners' cultural diversity enables learners to appreciate the plural character of knowledge. This enhances appreciation and tolerance of those who are culturally different. This is the goal of multicultural education. Nieto (2002: 35) argues that mono-cultural education is at best partial education; it deprives students of the diversity that is part of our world. Content integration as is practised by the participants in this sample is one way of ensuring that the practice of education in Zimbabwean primary schools is not mono-cultural. The school curriculum should be unbiased and should incorporate the contributions of all cultural groups. Therefore in postmodernism different sources of knowledge are valued and acknowledged (Punch 2004:141). In this context this is achieved through content integration. This should result in high achievement for all students which is a goal of multicultural education (Banks, 2009:12).

Responses of the participants reveal that learners' cultural diversity is valued in the classroom. This has advantages some advantages in the practice and implementation of multicultural education. This approach is in harmony with current views in the practice of multicultural education. It has been found out that classrooms that value students and their culture foster a feeling of self worth, a sense of belonging and higher academic performance (Heath, 1993; Nieto, 1999; Thomas, 1998; cited by Ndura, 2006:1). Banks (2005) in Runhare \& Mulaudzi (2012) advises that multicultural education guides young learners to immerse themselves in other 
cultures, engage with difference and acquire diverse cultural competence. Content integration should therefore be seen as an approach that enables learners to learn about other cultures. This builds the spirit of tolerance and appreciation of those who are culturally different. In this case the practice of multicultural education in the schools in the sample affirms to Nieto's (1997:46; 2002:42) views that multicultural education is critical pedagogy.

However, there are also some challenges that have been observed in the practice of content integration that were highlighted by some of the participants. Lack of knowledge of learners' cultures is an issue that was cited. The need for adequate research into the learners' cultures in the school cannot be overemphasised so as to enable teachers to get more knowledge of learners' diverse cultures. It is a necessary prerequisite in effective content integration. Murrel (2001) in de Souza (2010:9) advises that teachers must become' community teachers' by acquiring knowledge of the culture of the students they serve so they can draw on this knowledge to create core teaching practices necessary for effectiveness in their diverse settings. Therefore the effectiveness of multicultural education is also determined by the teacher's understanding of the different cultures in the classroom. This also hinges on the teachers' perceptions of diverse cultures in the classroom.

Teachers need to examine their attitudes towards those cultures that are different from their own in order to create a conducive classroom environment for all learners. Manning and Baruth (2008:47) have identified three models of teacher perceptions to difference. These models have an impact on how teachers will integrate different subcultures in the design of equity pedagogy. 


\subsubsection{VIEWS ON TEACHER SENSITIVITY TO PUPILS DIVERSE}

\section{CULTURAL BACKGROUNDS}

Most of the participants (17) felt that teachers are sensitive to pupils' diverse cultural backgrounds. This is shown in the nature of teacher learner interaction the accommodation of learners, cultural beliefs as well as pedagogy that is employed in the classroom. One participant was of the view that she exercises sensitivity in terms of pupils' social class background. This guides the nature and course of teacher learner interaction. She remarked;

Sometimes, I think they are sensitive to other children. Like if I have a child who is poor, if he sometimes, if I notice that the child is dirty in the classroom I cannot shout at him in front of the class. Even if I have to say something nasty to the child, I have to talk to him and make sure others don't hear it. Or I will try to make others accommodate him especially if there is that person who is poor. I will try to make the pupils accommodate him. If the pupil is dull, I will try to make others accommodate him instead of telling him that you are dull. (School Participant 14, School 4)

With regards to teacher sensitivity to learners' cultural backgrounds the teacher's cultural upbringing was seen to have an impact on his/her sensitivity to learners' cultural diversity. Another participant had this to say about the influence of the teachers' background on sensitivity;

Yah, I think they are, but there is need for continuation in terms of making teachers aware of the need to be sensitive. Because one may also be affected by the pressures of his/her own culture, but as a teacher remember you are teaching all the cultures. So you should have no culture yourself, but you should have the culture of the class as your culture. So one must be knowledgeable in those cultures and appreciate them so that maybe when you are teaching you can use for example the Ndau culture, the Karanga subculture, the Ndebele culture. (Participant 5, School 2)

The teacher has a role to play in ensuring sensitivity to diverse subcultures in the classroom. This promotes positive learner to learner interaction in the classroom as a participant remarked;

Teachers are sensitive, they do not mock kids. Like in my class, last year I used to have kids from the Islamic community, kids from the Islamic culture. 
Their culture is a bit different from ours, that was about maybe not just last year but about three years ago, I had some again. And nowadays for example circumcision is prevalent but those days it was not, it was usually people from that culture who used to be circumcised. So you find some kids want to mock them and do whatever. I would actually sit down with them and explain that it is their culture, just like you have your own culture. So they try to accommodate them. (Participant 10, School 3)

Although teachers make an attempt to be sensitive to learners' cultural backgrounds they also encounter some challenges. These challenges impact negatively on their efforts to be sensitive to diverse cultural backgrounds. Lack of knowledge on handling diverse subcultures appears to hinder efforts directed at accommodating pupils from diverse cultural backgrounds. One participant felt that;

Teachers are sensitive but also we teachers are not equipped enough, equipped in terms of materials, in terms of knowledge of how to do it, or maybe from how we were trained. (Participant 12, School 3)

Similar views were expressed during focus group discussions. The need to learn from other subcultures was emphasised. One participant had this to say about teacher sensitivity;

Yah, at this moment teachers are becoming sensitive because like I have given you an example in Shona, they are sensitive because they know that if one comes from a certain ethnic group it doesn't necessarily mean that he knows what is happening in another group. So they become sensitive, they accept the existence of these pupils in their classes and they make use of that. (Participant 11, School 3)

The need to accept diverse learners' cultural beliefs was seen as a way of showing sensitivity to learners' diverse cultural backgrounds. One participant made the following observation with regard to cultural beliefs;

Teachers are very much sensitive to pupils' cultural backgrounds. Because you find that a child comes to school with charms tied to his body or some body parts. I think it is for protection. You as a teacher cannot do anything about that and you cannot dissociate yourself from that child. Because you also want to help that child to prosper in education. (Participant 8, School 4)

However some participants felt that teachers are not sensitive to learners' diverse cultural backgrounds. In their view this is due to lack of knowledge about other 
cultures as well as the ideals of multicultural education. Teachers' cultural backgrounds were seen as presenting an obstacle in efforts directed towards sensitivity to diverse cultural backgrounds in the classroom. One participant contradicted the preceding views about teacher sensitivity to learners' cultural backgrounds. He said;

I think, it is half- half. Because sometimes, teachers are expected to tolerate children's backgrounds in spite of their own. Sometimes, teachers put an effort to do that, but you realise that sometimes teachers are overwhelmed by their backgrounds such that they won't be able to accommodate different children. For example, we have children from Christian denominations, we also have an Islamic centre, but you realise that children from the Islamic centre I don't really think they are accommodated to the maximum state in respect of their culture, their way of worship and so on (Participant 6, School 2)

Lack of adequate knowledge of the diverse pupils' cultures present in the classroom tends to present challenges in the design of equity classroom pedagogy. Commenting on teachers' lack of knowledge on learners' cultures a participant expressed the following concerns;

We are not sensitive. Teachers are not sensitive because it appears that they are also not aware, or they are not well versed in those different cultures. A teacher sometimes sticks to his own culture; this is also what he delivers to the pupils that he will be working with. So there is really no teaching of other cultures. The teacher follows the line which he comes from; his culture is what he is delivering to the children. (Participant 13, School 4)

Teacher sensitisation on multicultural education was seen as a way of enhancing teacher sensitivity to diverse learners' cultural backgrounds. A participant in support of the above concerns said;

Teachers need to be more sensitised on multicultural education. Because long back in teaching, teachers were not aware of the need to be sensitive. They just knew that one was a teacher who had to teach what he knew because one could teach in his own home area. Now because Zimbabwe is a multicultural nation it means teachers have to be trained so that they should be able to teach children from diverse backgrounds. (Participant 4, School1)

The responses of the participants show that teachers are sensitive to their learners' cultural backgrounds although there are some challenges that have to be addressed. 
Their views are in agreement with Campbell (1996:26) who argues that from a multicultural perspective the task of the teacher is to respect the culture the child brings from home, to guide the students' learning of the basic skills and attitudes of the dominant culture, and to nourish the students' self esteem. Thus Montgomery (1997) cited in Stoicovy, Fee \& Fee, (2012:4) advises that teachers should gain knowledge of the culture represented in the classroom and to translate these into instructional practice. Sensitivity to learners' diverse cultural backgrounds should be seen as a form of culturally responsive teaching. Culturally responsive teaching is important in multicultural education when one considers the shifts that have taken place in the field (Maattai in Vandeyer, 2003:195). Within research culturally relevant teaching has emerged as a good strategy to improve student achievement (Schemechel, 2012:211). Culturally responsive teaching acknowledges students' diverse cultural backgrounds (Gay, 2000 in Maatta, 2008:22; Rose \& Potts, 2011:3; Montgomery, 2001 in Maatta, 2008:23 Herrera, Holmes \& Kavimandan 2012:2). The views of the participants show that culturally responsive teaching is practised in the different schools to a certain extent.

Culturally responsive teaching is part of multicultural education. These findings tend to contradict the findings of Vandeyer (2010:348) who found that in South Africa there seemed a general apathy and non committal among the majority of teachers in terms of creating a warm and welcoming environment for all students. Cultural sensitivity on the part of the teacher is very important in the implementation of multicultural education (Nkomo, Vandeyer, Malada, Phatlane, Thabane \& Phurutse, and 2009:43). Accepting every child as a valuable individual is a foundation for multicultural education and a significant goal for teachers (Jokikoko, 2005; Koppinen, 
1999 cited by Maatta, 2008:14). This sensitivity enables the teacher to accommodate all learners from diverse cultural backgrounds without 'othering' (Mustafa, 2006:86). It can be argued that in the practise of multicultural education in Zimbabwean primary schools cultural sensitivity is observed.

Teaching is a cross cultural encounter. All teachers have their cultural baggage, their backgrounds, values and customs, perhaps prejudices which are brought into the learning and teaching situation (Manning \& Baruth, 2008:8). Therefore, teachers should make an effort to avoid being biased towards their own culture in their interaction with pupils (Rios, 1996, in Meier \& Hartell, 2009:187). This makes sensitivity to diverse cultural backgrounds a very important issue. The participants also raised some challenges that are encountered in culturally responsive teaching. These arise from a situation in which teachers are heavily influenced by their cultural backgrounds and these tend to affect their interaction with learners. This may result in a situation in which teacher sensitivity to learners' diverse cultural backgrounds tends to be compromised.

It is important to recognise that teachers' sensitivity to learners' cultural backgrounds is also influenced by the way they perceive cultural differences. Manning \& Baruth, (2008:50) has identified three models of teacher perceptions of difference. These are the cultural deficit model, the cultural mismatch model and the culturally different model. These models of perceptions of difference will to a great extent influence teachers' sensitivity to diverse learners' cultural backgrounds. The responses of the participants show that teachers in the sample tend to view cultural differences in the cultural mismatch and the culturally different models. 


\subsubsection{LANGUAGE IN EDUCATION POLICY AND ACCOMMODATION OF}

\section{LEARNERS' LINGUISTIC NEEDS}

Most of the participants (15) were of the view that current language policy in education addresses the needs of learners in a linguistic diverse society. In their view this is shown through the use of English as the official language, instruction in the mother tongue for infant classes (lower grades) as well as the teaching of marginalised minority languages in areas where they are traditionally spoken.

The language in education policy has accommodated marginalised indigenous languages by teaching these. This is a departure from the policy that was pursued before independence and this motivates learners. A participant opined;

I think that one is very good as it accommodates all children. They will feel that they are recognised in their country rather than just using Zezuru languages as if all children are Zezurus. I think the moment when they learn that their language is also recognised, in those books, for example there is this Shona, Pindukai textbook ( a primary school Shona reader) which has also some other kinds of dialects, they will have an interest in learning because they will appreciate that they are being represented. (Participant 18, School 5)

Another participant expressed similar sentiments by acknowledging that marginalised minority languages are being taught. These are taught in those areas where they are traditionally spoken. He said;

Eh, well you find that what is there is not enough. To some extent there is empowerment that if you go to Hwange (Matabeleland North) now, Nambya language which is spoken widely there is being tested at grade seven level. If you go to Binga (Matabeleland North), Tonga is being tested at grade seven level, if you go to Beitbridge (Matabeleland South); Venda is now part of the curriculum. Until this latest constitution which is now recognising languages such as Chewa, I think something is going to be done about it. It means that in Chewa speaking communities, Chewa is going to be taught. (Participant 1, School1)

In agreement another participant presented a more elaborate view on the accommodation of marginalised minority languages when he stated that;

I think maybe starting last year, eh, if I may quote the grade seven examination, I think the Ministry showed great interest or a new approach to 
try and be accommodative. Because for the first time, they are now enforcing that these minor languages children be taught up to grade three using their own languages. Because for the first time they are gradually introducing examinations in those languages at the national level at grade seven. So I think it is a positive step by the Ministry. Our school is in a Chewa (Malawian subculture language) speaking community and our pupils are supposed to be accommodated. But then I think it will depend more so on each school in the sense that we do not have a teacher who is knowledgeable in that specific language. So because of that many schools are just using the main language Shona if they are in a Shona speaking environment or Ndebele. But a positive step is that most schools in a pilot project are introducing Ndebele teachers if the enrolment is above 500, you apply for, a Ndebele teacher. Then he/she will just teach Ndebele lessons from ECD (Early Childhood Development) up to grade seven. The same for schools in Matabeleland, they can ask for a Shona teacher whose task is only to teach Shona in the school. So I think it is a positive step but it depends more on the school system. (Participant 5, School 2)

Another participant concurred and proffered the following views;

Um, Yah, it is accommodating again in the sense that our main languages that we use depending with the area are being taught for example you find Shona and English mostly in the Shona speaking areas. If you go to Ndebele speaking areas they also have Ndebele lessons there, Ndebele books they are catered for there. And then if you go to areas like Binga (Matabeleland North) where they do not learn Ndebele they also do their Tonga lessons. Um, so I think most of these are catered for, eh, and again in our schools here, we also have students who have moved from a Ndebele speaking, Ndebele teaching school to a Shona teaching school. We also have a Ndebele teacher for that to cater for such pupils and it is not that Ndebele speaking pupils are only found in Matabeleland. They are also found in say Mashonaland. So we have a Ndebele teacher to cater for those students. Should a grade seven Ndebele speaking pupil from Matabeleland transfer to our school we can request for the Ndebele paper to be sent to our school for the examination. It will be too late to start to teach this one, this pupil Shona. It is logical that the pupil proceeds with Ndebele. So I think it is fair to ask for that paper so that the child completes his/her primary education learning Ndebele. This applies to all other languages. (Participant 9, School 3)

Similar views were expressed during focus group discussions. The views of the participants emphasised that the current language in education policy caters for different ethnic groups and shows that Zimbabwe is a multicultural nation. The language in education policy currently in use is different from the one that was in place before independence. 
The current language in education policy is a departure from the pre-independence policy. The teaching of marginalised minority languages was once more emphasised.

A participant argued;

Before independence you find that mostly the English language was the one which was encouraged. But nowadays after independence you find that pupils are now being encouraged to learn some of these things in their own languages, especially our Shona language and Ndebele language of which other minor languages are being incorporated. This is done so that pupils are made to understand whatever they are learning first from their mother tongue and later in languages we are not used to. (Participant 13, School 3)

Acknowledging the teaching of marginalised indigenous languages another participant noted;

We now have the use of different languages. Before independence we used to have Zezuru. Now this time most of the dialects are catered for, taking for an example the Tonga people in Matabeleland North. They use their dialect when they want to communicate in their mother language but they also use English as well. Right, if we move to Chiredzi (Masvingo province), they have their dialect there which is Shangaan. They use it at school, so I think there is a shift in policy from the one that was there before independence. If you look at the examinations for grade seven that is being given to schools these days, there is room for Tonga, Ndebele, Kalanga, there are all the dialects. Pupils are writing examinations in their own dialects so their culture or language is catered for. (Participant 9, School 3)

However some participants observed shortcomings in the language policy particularly the use of English as the official language as well as the medium of instruction. The emphasis on English as a medium of instruction presents achievement related challenges for some learners due to lack of proficiency in the language. One participant observed the shortcomings of this policy by saying;

I think on that one it is a challenge to our Ministry because you find that in Zimbabwe there are Shonas and others. Our children especially at primary school level they understand Shona better than the second language which is English. But the policy says pupils should use English in about $99 \%$ of the subjects. Shona is only used during Shona lessons, and this is the language they understand better. So I think if there is any other way of correcting that, I think it is better for children to be taught in their mother tongue, so that they will understand most of what you are teaching about than to use a second language which they do not understand. (Participant 8, School 2) 
The emphasis on English as the medium of instruction tends to affect the status of the mother tongue which is Shona in this case. Learners' performance in the mother tongue will leave a lot to be desired. Another participant observed the effects of this policy by pointing out that;

The language policy unfortunately considers English as the official language. By so doing we find that pupils try their best to do very well in English because they know maybe with a vernacular language, Shona they will not come to the top when they are at the higher levels and they want to pursue careers, because they have Shona without English. They will not be taken for that particular post. (Participant 10 School 3);

The responses of the participants show that the language policy introduced after independence has made some significant progress in accommodating the needs of linguistically diverse pupils in a linguistically diverse society. The language in education policy should also be seen as part of multicultural education. This has been done through the accommodation of marginalised indigenous languages into the school curriculum, although these languages are taught in those areas where they are traditionally spoken. It is a departure from the policy pursued during the colonial era. The language in education policy can be seen as part of critical pedagogy which acknowledges rather than suppress linguistic diversity (Nieto 2002:42). The language in education policy is part of curriculum reform efforts which have sought to make education relevant and appropriate to the learner. The recognition of languages particularly the mother tongue is an important part of a multicultural school curriculum as well as multicultural education. Use of the mother tongue as a medium of instruction in lower grades engenders an appreciation of their cultural values more than is the case when they are taught about the world around them in another language (Gora, Mavunga, Muringani \& Waniwa, 2010:91). 
It can be argued that use of the mother tongue as is happening in lower grades in Zimbabwean primary schools results in the appreciation of cultural values by the learners. Appreciation of cultural values is a component of multicultural education. It is also one way of celebrating differences in the context of postmodernism (Punch, 2004:144) and a recognition of multiculturalism (Lemmer, Meier \& van Wyk, 2006:5).

The UNESCO Committee of Experts in 1953 recommended the use of the mother tongue as the best medium in teaching (Ndamba, 2008:175; Fasold 1987, in Gora, Mavunga, Muringani \& Waniwa, 2010:91). This has been accommodated in the 1987 Education Act which recommends instruction in the mother tongue in the infant classes. At the present moment the use of the mother tongue in teaching is restricted to the lower classes although not all learners countrywide benefit from instruction in the mother tongue. For example marginalised indigenous languages are only taught in those areas where they are traditionally spoken. A learner who resides outside the area where these languages are traditionally spoken fails to benefit from instruction in the mother tongue. A more desirable situation is one where all mother tongue languages are taught in schools countrywide with instruction in the mother tongue extending to the last grade of the primary school.

However, Thondhlana (2002:33) advises that recognition of the 1987 Education Act is largely in word only since in Zimbabwe most schools prefer to use English which is considered the language of power and economic well being. In some schools a situation may prevail in which instruction is offered in English from the early grades. By so doing the provisions of 1987 Education Act tend to be disregarded. Mismatches between the language of learning and teaching and the linguistic resources learners 
bring with them to school create real problems of access to the curriculum for many learners (McKinney \& Soudien, 2010:11). This is the situation that may arise when instruction in the mother tongue is not accommodated. Zimbabwe's language policy in education is enshrined in the 1987 Education Act. The same Act gives the Minister room to include other marginalised minority languages such as Chewa into the school curriculum. It is hoped that more languages are going to be added to the primary school curriculum so as to accommodate all learners. In the ultimate analysis learners will benefit from instruction in the mother tongue in the early grades with the inclusion of more languages.

The 1987 Education Act is a departure from the recommendations of the Judges Commission which stated that children should learn to read and write English from the first day of grade one (Ndamba, 2010:246). Although Zimbabwe's language in Education policy has brought some changes it has resulted in subtractive bilingualism (Thondhlana, 2002:34) as well as transitional submersion for some learners (Adeyemi, 2008:24). These are issues that still need consideration in order to meet the goals of multicultural education. Negating the native language and its potential benefits in the development of student voice is a form of psychological violence and functions to perpetuate control over subordinate language groups through various linguistic forms and 'cultural invasion' (Freire in Goduka, 1998:36 as cited by Muchenje, Goronga \& Bondai , 2013). However it needs to be noted that although a start has been made in the recognition of marginalised indigenous languages, in Zimbabwe the task is not an easy one. This is due to the fact the Zimbabwe has sixteen indigenous languages (Hachipola, 1998 in Viriri, 2003; Gora, Mavunga, Muringani \& Waniwa, 2010). Therefore the task of accommodating this linguistic 
diversity is not an easy one. Banks (2009:1) argues that in order to meet the ideals of multicultural education a number of reforms are necessary and these reforms include attitudes and beliefs of the staff which should be changed in ways that will allow the school to promote educational equality for students from diverse groups. Educators therefore need to accommodate learners' diverse linguistic backgrounds as is happening in Zimbabwe.

Marginalised minority languages in Zimbabwe have been accommodated in the school curriculum on a geographical or regional basis. This is unlike the situation prevailing in China where Mandarin Chinese the language used by the educated Han Chinese who make up $92 \%$ of the population is used in formal education (Geary \& Pan, 2003 in Yao. Buchanan, Chang, Powell-Brown \& Pecina, 2009:5). Zimbabwe’s language in education policy is in agreement with the International Convention on the Rights of the child (ICRC) Article 30. In terms of article 30 minority or indigenous children have the right to learn about and practice their own culture, language and religion. Zimbabwe's language in education policy is also a recognition of linguistic rights. The Nziramasanga Commission Report (1999; 168) emphasises that there is need to recognise linguistic rights as human rights which all citizens should enjoy, there is need to protect and promote respect for all community languages regardless the number of speakers and their level of development.

\subsubsection{ENCOURAGEMENT TO COMMUNICATE IN MOTHER TONGUE INSIDE AND OUTSIDE THE CLASSROOM}

A very large number of the participants (15) felt that communication in the mother tongue inside the classroom is restricted to Shona lessons only in the case of the schools in the sample. There is also a tendency to encourage learners to communicate 
mostly in English even outside the classroom. All the participants emphasised the view that learners are encouraged to communicate in English to enable them to pass examinations. This is at the expense of the mother tongue. The mother tongue Shona in this case is only used during Shona lessons.

Learners are encouraged to communicate in English as a way of improving their mastery of the language. Outlining the benefits of this school policy a participant maintained that;

At this school actually we don't encourage speaking in L1 (mother tongue). Usually we encourage pupils to communicate in English. Just because we discovered that their English language is poor, we discovered that English language is, best learnt through acquisition so they should practise through speaking it. Their English language is so poor so we are trying to force them. (Participant 20, School 5)

In agreement another participant had this to say:

Ah, at this school, in fact nowadays we are encouraging pupils to speak in English. Because pupils are failing English and most of the subjects are tested in English. So it is like we want them to improve their speaking skills so that maybe it can help them when the need comes to written work. Instead of advocating for the speaking of Shona we punish those who speak in Shona (laughs), we are saying speak in English. It disadvantages pupils in so far as L1 (mother tongue) is concerned because they should be able to express what they want in their mother tongue and it will be clear than they do in English. I think the teaching of English in Zimbabwean schools is somehow promoted somewhere. (Participant 12, School 3)

The rationale for encouraging communication in English was emphasised by one participant who asserted;

Eh, we do encourage communication in the mother tongue but there is a challenge at primary school level. Our kids do not have the exposure to L2 and everything that is done in terms of the grade seven examinations is in L2 except only for the local language itself. So as a school we are forced to try and probably ask children to speak in English most of the time so as to improve their what, the pass rate. But otherwise we assume that at home they never use the other language, they always speak in their local language. But in our case it is very tricky. Because we do not offer Chewa, we offer Shona, and at home maybe they speak a mixed language. So in Shona they also need to practise in Shona which is offered at school level. (Participant 5, School 2) 
School 1 is a former white only school where the medium of instruction has always been English and communication in English is seen as part of the school's tradition. Communication in English is therefore encouraged as it is considered to bring some benefits to the learners and the school. A participant highlighted some of these benefits by saying;

They are encouraged to communicate in English. English is emphasised because our school is a former Group A school (whites only) so the medium of instruction is English. It is our school policy that they should communicate in English. We have seen that there are a number of advantages for example our pupils are doing very well in public speaking competitions, just because we are using English. Even during the grade seven examinations, most of them are doing very well. (Participant 4, School 1)

These views seem to confirm Bennett's (2003) observation that in the practice of multicultural education it is business as usual for some schools.

Similar views were expressed during focus group discussions where the need to communicate in English was emphasised. The mother tongue Shona in this case is only used during Shona lessons. English is seen to hold an important place in the school curriculum. One participant noted;

They are encouraged to use their mother tongue during Shona lessons. Because we also want them to know this English language, which is the most important language nowadays as they should be able to communicate with the outside world. (Participant 15, School 4)

Another participant expressed a similar view. She pointed out that;

Here for example the headmaster encourages pupils to speak in English because it helps them to understand other languages. (Participant 18, School 5)

However, schools in farming communities tend to face problems in so far as communication in the mother tongue is concerned. This is largely attributed to the fact that the learners' mother tongue (Chewa in this case) is not taught in the school and Shona is another second indigenous language they have to learn in the school system. Such learners, therefore, lack proficiency in the indigenous language that is taught in 
the school since it is not their mother tongue and this presents achievement related challenges. One participant elaborated the challenges faced by schools in farming communities by expressing the following view;

Yah pupils are encouraged; you know this place has a different background. Most children have parents who are Malawian or Zambian descendants. So you realise that the requirement of the school curriculum which requires them, to do Shona presents challenges. In Shona you will realise that they struggle in spoken as well as written Shona, in listening and other macro skills. Because at their homes their way of speaking is diluted by the way they were raised in their mother tongue. Their mother tongue, I can't really say they speak their mother tongue, for example I can't say they speak Chewa or I can't say they speak their languages from their mother countries. But as they try to speak Shona you realise that some kind of vocabulary starts to crop up. So you realise the way we expect them to speak, the way we expect them to write is different from what they know and from what they experience and it is very difficult to accommodate their vocabulary. You will realise that their vocabulary has no place in what, in the mother tongue languages that are considered in Zimbabwe so that is the challenge to us. (Participant 6, School 2)

Another participant expressed a similar opinion. She elaborated;

Ah, we encourage them to speak in their mother tongue but especially in this area Kensington (not its real name) there are so many pupils from different cultures especially from Malawi, Zambia and some from Zimbabwe. So you find that their language has changed a bit. They are now using a mixed language; something mixed which you cannot particularise. Most of the pupils at this school if they want you to draw a line in their books they say 'Madam ndidirireiwo mutsetse' (Literary translated as Madam please pour me a line). So automatically they are using Shona in the wrong way because you do not 'pour' a line. So you find that this language issue is quite a challenge especially here in Zimbabwe because we have some people who come from outside Zimbabwe, those who do not speak our Shona language. (Participant 8 , School 2)

The views of the participants show that English (L2) is emphasised at the expense of the mother tongue in the schools in the sample. This tends to confirm the view that in schools there is a bias towards English (Thondhlana, 2002:33). All the schools in the sample are in a province where Shona is the predominant indigenous language taught and spoken. However, learners are encouraged to communicate in the mother tongue in Shona lessons only. It should also be noted that for some of the learners in the 
sample Shona is not their mother tongue. Therefore learners need to be given an opportunity to communicate in their mother tongue to enable them to develop proficiency in these languages. It should also be seen as an attempt directed towards cultural preservation. Schools need to draft policies that give room for communication in the mother tongue. In this regard schools need to change their attitudes towards minority language (Banks, 2009:1).

It is also a way of raising the status of these languages in the eyes of the learners. After all a language is a reservoir of culture and part of one's cultural identity. Emphasising English at the expense of the mother tongue as is happening in the schools in the sample may develop feelings of its superiority compared to the mother tongue. It results in subtractive bilingualism (Molosiwa, 2009:4; Ndamba, 2008:172) for children who come from linguistically diverse backgrounds. In Zimbabwe as elsewhere in Africa, bilingualism has tended to be subtractive (Thondhlana, 2002:34).

What is required is a policy of additive bilingualism which refers to the maintenance of the home language alongside effective acquisition of the additional language (McKinney and Soudien, 2010:12). This observation is applicable in Zimbabwe when the situation prevailing in the schools is considered. Children from minority groups experience transitional submersion (Adeyemi, 2008:24). In the context of this study this happens to all those learners whose mother tongue is not taught in the primary school. Learners whose mother tongue is not taught in the school tend to be disadvantaged. The emphasis on English as is happening in schools in the sample has a historical origin which can be traced through the colonial era. Colonial language policies engendered a situation in which western languages and culture were 
considered to be more important than indigenous languages (Treftgarne, 1978 in Rwantabangu, 2011: 2; Spencer 1971 in Rwantabangu 2011:2).

Pedagogical principles are being sacrificed by the need to ensure that pupils pass examinations which are mostly set in English. Learners in farming communities where Chewa is predominantly spoken tend to face a disadvantage and their situation demands urgent review. They find themselves in a situation where opportunities to learn their mother tongue are limited if not nonexistent in the school environment. Hence they experience transitional submersion (Adeyemi, 2008:24). There is therefore need for such learners to be provided with opportunities to communicate in their mother tongue as well as learn their mother tongue in the school environment. This should be considered as a way of raising the status of their mother tongue. The emphasis on English particularly at some former white only schools like the one in the sample shows that some schools have not changed their policies, for most of these schools it is business as usual (Bennet, 2003:24). Banks (1975) cited in Nkomo, Vandeyer, Malada, Phatlane, Thabani \& Phurutse (2009:45) recommends that schools should respect the cultural and linguistic capital of students and change the curriculum so that it can reflect the learning and cultural styles of students' in order to enhance learning.

\subsubsection{THE TOTAL SCHOOL ENVIRONMENT AND THE REFELECTION OF CULTURAL DIVERSITY}

All the participants were of the view that the total school environment at their schools reflects the cultural diversity of the nation. The total school environment in the schools is seen as a multicultural or plural environment. This diversity is to be found 
in the following areas: staffing patterns, assembly programmes, selection of prefects and participation in co-curricular activities.

\subsubsection{STAFFING PATTERNS}

The participants were of the view that the composition of the staff at their schools is multicultural; it reflects the nation's cultural diversity. Staff members are drawn from different ethnic groups in Zimbabwe though not all ethnic groups that constitute Zimbabwean society are represented on the school staff in the different schools that made up the sample. The participants emphasised that there is no discrimination on whatever grounds in the recruitment of school staff and this leads to multicultural staffing patterns.

In the schools teachers are recruited from the different parts of the country and this tends to bring teachers from different parts of the country onto the school staff. The absence of discrimination in terms of recruitment was seen as ensuring the presence of a multicultural school staff. A participant highlighted some of the regions where teachers at school come from by saying;

There is no discrimination on staffing. You find people from different areas. I know people from Mberengwa (Midlands province) down there, is it in Midlands? We have people from Chipinge, Mutare (Manicaland province) over there. I come from Mount Darwin (Mashonaland Central province) for example and I am here. We are a group of staff, a staff that is made up of different people from different areas. (Participant 11, School 3)

Another participant concurred by saying;

We have got teachers from Manicaland who speak Manyika, Korekore people (Mashonaland West province) myself; we also have Ndebele people (Matabeleland province). We also have people from Zambia, Malawi, the Bandas you were talking to, and they do not originally come from Zimbabwe. So I think the government is trying its best to accommodate people from different areas. (Participant 2, School 1)

In agreement a third participant expressed the following view; 
Yes, if you look at our staff we do not discriminate. We just accommodate any teacher trained as long as one holds relevant qualifications. The teachers come from various backgrounds which is a way of accommodating cultural diversity. We have got the Shona, Ndebele, Karanga, they are here. When we are holding our subject committees meetings and for example in Shona it is composed of teachers from various dialects. (Participant 3, School 1)

The multicultural staffing patterns were also observed at School 4 which is a church school. Recruitment onto the school staff at this school is open to all teachers from all backgrounds with relevant qualifications. A participant elaborated;

This school is a Catholic school. Even those non Catholic teachers are welcome. It is not compulsory that every teacher should be Catholic but nonCatholics are also welcome. I am a Catholic teacher myself, but some of my friends are non-Catholics, but we are just the same. Since there are rules to be followed and since we are at a Catholic school, we just induct each other so that they know what is to be done. That doesn't mean they are forced to be Catholic. Teachers come from different ethnic groups. (Participant 15, School 4)

It appears that there is no deliberate school policy to ensure the existence of a multicultural school staff as recruitment is done by the district office. One participant outlined the role of the school in terms of recruitment of teachers by elaborating that;

Eh, staffing patterns, we do not have much say concerning staffing patterns. Perhaps on that one we can recommend that we may need a specialist at music, or a teacher with a flair in a certain subject. But the challenge is that we are not offering Chewa language. So normally, the assumption is that when we get a teacher he/she can teach the main language taught in that province that is Shona in our case. The composition of the school staff is a mixture in the sense that it is a mixture by coincidence. Because if one applies when there is a vacancy one gets it. Those who apply are also considered they reflect our cultural diversity. On our staff we have got have got the Karanga (Masvingo province) we have a bit of Zezuru (Mashonaland) and Ndebele (Matabeleland). (Participant 5, School 2

Similar views were expressed during focus group discussions. The presence of teachers from various ethnic groups on the school staff was seen as evidence of a multicultural school staff. One participant had this to say about the composition of the school staff at her school; 
The staffing pattern is multicultural because the teachers some of them are from Matabeleland South, Manicaland, some are Zezurus (Mashonaland). They come from different cultural backgrounds. (Participant 17, School 5)

Another participant expressed similar views by saying;

For example, I am from Malawi and am teaching here in a school which is basically from the Shona culture. So we have teachers who originated from other countries. We also have teachers from Matabeleland, we also have teachers from Manicaland and we also have the Zezurus (Mashonaland). So I think it is a mixed bag. (Participant 10, School 3)

From the responses of the participants it can be seen that staffing patterns tend to be multicultural in terms of ethnic backgrounds though there is need to ensure that at least all ethnic groups are represented on the school staff. This is in agreement with the observations of Gollnick \& Chinn (2012:12) who argue that one characteristic of a multicultural school is that the composition of the faculty, administration and staff would accurately reflect the composition of society. The need for a multicultural school staff was an issue in the United States during the Civil Rights movement in the 1960s. Ethnic groups demanded that schools hire more black and brown teachers so that their children could have more successful role models (Banks, 1994 in Lemmer, Meier \& Van Wyk 2006:3; Gorski, 1999). A multicultural school staff serves to motivate all learners from diverse backgrounds when they see their ethnic or gender group represented. This provides ethnically diverse learners with a source of motivation.

Schools in this sample tend to meet these requirements though there is need to ensure that most of the ethnic groups that make up Zimbabwean society are also represented on the school staff. Such a situation can come about as a result of the presence of a deliberate government policy to ensure that staffing patterns in schools truly reflect the multicultural character of the nation. A multicultural school staff is a requirement for the effective implementation of multicultural education. All the schools in this 
sample have a multicultural staff in terms of ethnicity and gender though what can be debatable is the extent to which all ethnic groups are represented on the school staff. This serves to ensure prejudice reduction which is also a dimension of multicultural education (Banks, 2009:20).

\subsubsection{SCHOOL ASSEMBLY PROGRAMMES}

All the participants said that their school assembly programmes are multicultural. This is shown by the languages used in conducting assemblies, the nature of stories told at assembly and pupil participation in assembly programmes. However there is a challenge in the conduct of assembly as there tends to be a bias towards Christianity. One participant explained the rationale of emphasising Christianity by saying;

"Yes we emphasise Christianity (in assembly programmes). I think it is because most teachers are Christians. So there is that sort of bias (laughs), most teachers are Christians" (Participant 10, School 3)

Learner participation in school assembly programmes as well as the languages used at assembly were seen as ways of accommodating cultural diversity in the school and nation. The participation of learners in assembly programmes was explained by one participant who stated;

Usually our assemblies are child centred. We prepare our skits and these are child centred, guided by the teachers. So through that interaction we are getting the kids from various places, from various ethnic groups to participate. As a result through pupil- pupil interaction, they can communicate better, sharing the various languages and various experiences. We do not discriminate on the basis that this child is Ndebele and so forth and so forth, they are all accommodated. So during assembly time they are able to present their skits in various languages. We have seen skits in Shona; we have seen some in Ndebele, some in English and so forth, which means that it is a form of accommodation. We used to have a Ndebele teacher and so pupils could present in that language. And also our Resource Unit (for children with special needs) at times presents something before the kids during assembly time which is a form of accommodation and multiculturalism. Assembly programmes are presented in a Christian context. Even when we talk of our Sunday school, it is interdenominational which means we are trying to accommodate all the kids who come from various denominations which is a form of multiculturalism. (Participant 3, School 1) 
The use of different languages was cited as evidence of the multicultural nature of school assembly programmes. Commenting on the languages used at assembly a participant remarked;

When we conduct assembly, we mix the languages used sometimes, because we want to our pupils to have a good understanding. We sometimes use English and also Shona for the benefit of small kids who do not understand a lot of English, and we also give examples in other languages or cultures. So it accommodates every child at this school. We emphasise Christianity at assembly though not at the expense of other religions. We do, generally because Zimbabwe is a Christian country, ah, but we don't degrade other religions. We accommodate them. (Participant 11, School 3)

In a similar vein another participant said that;

The assembly programmes are usually conducted in English. We accommodate cultural diversity found in the school. Usually the teacher on duty at assembly usually gives a theme, usually based on RME lessons. Usually these are the ones that are usually given. So they usually accommodate each and everyone. Some are Christian stories generally. (Participant 20, School 5)

Similar views were expressed during focus group discussions. The use of different languages was cited as a way of accommodating the cultural diversity of the nation.

According to a participant;

Assembly programmes are conducted in English and Shona. If the Ndebele teacher is around she helps in the programme. Even the stories told at assembly, some of them can be moral stories from other world religions. (Participant 12, School 3)

Another participant was of a similar view. He maintained that;

At assembly we have pupils who dramatise using different languages; it is not only English that is used. They can either use English, Shona or Ndebele in dramatising their stories. (Participant 2, School 1)

School 4 appears to face challenges with multicultural school assembly programmes.

The school is a Catholic Church school which places a lot of emphasis on Catholic ethos. School assemblies are therefore conducted in that context. A participant had the following to say; 
Our assembly programmes do not embrace the multicultural character of society. We only teach the children according to the Roman Catholic Church ethos. These are the ones we are encouraged to dish to the children. No matter whether the child comes from another church, from another religion, here at our school they say once you come here you ought to do what the Catholics do. So we are encouraged to instil in children the ethos of Catholicism. (Participant 13, School 4)

In agreement another participant observed;

At assembly we have a Catholic assembly book, but we don't only concentrate on that book. For example at assembly we read a story from the assembly book then we discuss. From there we also talk about other issues which teach the children, which benefit the children. (Participant 15, School 4)

A similar view emerged during focus group discussions where the emphasis on Catholic ethos was once more reiterated in the conduct of assembly. A participant stated that;

During assembly time, this is a Roman Catholic school we usually follow the Roman Catholic ethos. During story telling we use the assembly book which brings out the moral values for all children without catering for Catholics only, but all children. (Participant 14, School 4)

The views presented by the participants show that school assembly programmes tend to be multicultural save for the church school in the sample. This observation reinforces the views of Manning \& Baruth (2008:243) who posit that ethnic diversity should be reflected in assembly programmes and this is seen as a way of accommodating cultural diversity. There is a challenge that has been observed in the assembly programmes. They tend to have a bias towards Christianity and this may marginalise other religions in the content of the assembly programme. Such a bias towards Christianity may marginalise other learners who do not come from a Christian background. School assemblies should be conducted in such a way that they embrace the multicultural character of the nation. Ghosh (2002:3) has observed that multicultural education must deal with the total culture of the school and it must be 
aware of students who have very dissimilar experience because of certain differences based on race, gender, culture or class.

This observation emphasises the need for school assembly programmes to accommodate all learners in the school. Gay (2006) states that if students feel that the school environment is alien and hostile toward them or does not affirm and value who they are (as many students of colour believe), they will not concentrate as thoroughly as they might on academic tasks. This has a bearing on learner achievement. Therefore school assembly programmes need to embrace the cultural diversity found in the school. It should be acknowledged that presently attempts have been made to make school assemblies multicultural. However much more needs to be done so that such assembly programmes embrace the ideals of multicultural education.

\subsubsection{SELECTION OF PREFECTS}

Most of the participants felt that the selection of prefects in their schools acknowledges the multicultural character of society. This is because the selection of prefects in the different schools is based on the following learner attributes: behaviour, academic performance, and gender and leadership qualities. Therefore in principle any learner irrespective of his/her cultural background is eligible for selection. However, there are some schools like School 4 that have put in place mechanisms to ensure that the selection of prefects is representative of the student body in terms of the school's catchment area. An attempt is made to ensure that prefects body is representative of the learners' body. A participant gave an insight into the selection of prefects at her school. She remarked;

Then we go to our prefects we also have few boys they are almost $50-50$ boys and girls. Their backgrounds are different. Some of them we cannot say they are rich; they are in a better state (laughs) than others. Some of them are coming from very poor backgrounds. Some from middle backgrounds, some 
from a bit better background. I think they are mixed. Some of them in as far as education is concerned they, I am talking about their ability in the classroom some of them are very good and some of them are not that good. So we are mixing, just to look at their characters, we are trying to find something that makes them a bit different, then they are appointed. (Participant 8, School 2)

In some schools selection is based on academic performance and leadership qualities.

According to a participant;

We look at their academic performance. We look at the leadership qualities. We also look at their areas of excellence, where they are doing very well. Maybe the child is good at sports, that child can also be considered. (Participant 4, School 1)

In some schools certain strategies have been put in place to ensure that cultural diversity is accommodated in the selection of prefects. A participant had this to say on the selection of prefects;

Selection of prefects is spread out in all the corners the children come from. So I can say cultural wise they are represented because from each and every farm where these children come from there is a representative who also sees to it that they are coming to school, they are well protected. So here I can say culturally children are well represented. (Participant 13, School 4)

Similar views were expressed during focus group discussions. Learners' diverse cultural backgrounds are not considered in the selection of prefects. These views show that cultural background is not considered in the selection of prefects. In this regard one participant said;

Everyone is given an opportunity as long as somebody is capable. We don't select on cultural aspects even if he/she is Chewa, Ndebele, everybody is given an opportunity. (Participant 10, School 3)

In agreement another participant insisted that;

When selecting prefects we do not look at the child's culture. We look at their academic performance, their discipline and their leadership qualities. Selection in this area is open. (Participant 2, School 1)

From the point of view of the participants the selection of prefects accommodates the cultural diversity of the school and nation. In other words, the composition of the prefects body is multicultural and thus reflects the nation's plural character. It appears 
that the cultural background of the learner is not considered in the selection of prefects. In the selection of prefects there is need to consider the cultural background of the learner. This is so because all the attributes/criteria used in the selection of prefects in the schools in the sample are influenced by one's cultural upbringing. Culture refers to people's values, language, religion, ideals, artistic expressions, patterns of social and interpersonal relationships, and ways of perceiving, behaving and thinking (Manning \& Baruth, 2008:44). The attributes referred to such as behaviour, and academic performance are to a large extent determined by one's culture. It becomes important to consider learners' cultural backgrounds in the selection of prefects.

It should be noted that schools create a culture of either empowerment or denigrating conformity to the status quo (Ndura, 2006:2). The selection of prefects which does not consider the learner's background makes a contribution in this regard. It should be noted that schools should be organised for the needs of children, not for the benefit of educational administrators (Ghosh, 2002:69). Among the variables that need to be examined in order to create a school culture that empowers students is the social climate of the school and staff expectations for student achievement (Brookover, Beady, Flood, Schweitzer \& Wisenbaker, 1979 cited in Banks, 1993:5). Some school policies such as the selection of prefects tend to affect learners negatively. In Canadian schools Ghosh (2002:69) found that some students who are different experience a 'chilly climate' in school. The hostile climate results not only when some students are excluded from the content and method of learning but also from the culture of the school through messages that they are unimportant and have second class status. This observation, although made in a Canadian context, is applicable to a 
situation that may prevail in Zimbabwean primary schools. A situation may be engendered where learners from certain ethnic groups may not have the opportunity to become prefects and they tend to experience a feeling of alienation. Consideration of learners' cultural backgrounds in the selection of prefects becomes important. It is in this context that a change in school policy regarding the selection of prefects is called for.

Therefore cultural diversity has to be accommodated in each and every respect within the school environment. The school has an important role to play in the creation of a democratic society. For it is within the confines of the school as a microcosm society that seeds of a socially just and democratic society are planted, germinate and are nurtured to blossom into a healthy and flourishing tree that would weather any storm and provide magnanimous shade against the harsh rays of the sun (Vandeyer, 2010:356). Therefore there are a number of reforms that should be undertaken in the schools.

\subsubsection{PARTICIPATION IN CO-CURRICULAR ACTIVITIES.}

All the participants felt that participation of learners in co-curricular activities reflects the nation's multicultural character. This is shown through the provision of different sporting disciplines as well as cultural sensitivity in terms of learner participation.

In some schools learners' preferences on religious grounds are accommodated as a participant had this to say:

Yah, we have pupils from other cultures who say that we don't participate in certain disciplines. We don't force them because our job is not that of forcing pupils. We identify talent. If that child has the talent, it is that talent that has to be nurtured and then if someone says my religion does not permit then we don't include that one because of cultural differences. (Participant 9, School 3) 
Some school policies on co-curricular activities tend to accommodate all learners irrespective of cultural backgrounds. Outlining the co-curricular programme in his school a participant said;

Our co-curricular programme at the moment, it accommodates all children. Because we are trying to shift to that in the sense that, we are no longer doing sport for competition. It is more so now for participation so that we normally have to select the team at the end, but before that in sports houses every child participates. So by so doing it is a bit accommodative. We have also increased the number of activities done at primary school level. (Participant 5, School 2)

In some schools the range of sporting activities offered include those disciplines which were previously dominated by the whites. Such sporting disciplines are now open to all learners. A participant outlined the sporting disciplines on offer in her school. She stated that;

When we come to co-curricular activities the children are given chances to choose their disciplines. They have got hockey, rugby, soccer, volleyball, lawn tennis. All disciplines are offered here. So through that we know some of the games were only done by the whites long back but right now the blacks are also participating in these. We involve all various teams, so the child has to choose the discipline he/she wants. (Participant 3, School 1)

The views made by the participants show that in the schools, participation in cocurricular activities is multicultural. It appears that learners are given an opportunity to participate in the various co-curricular activities. Multicultural education requires a number of reforms (Banks 2009:24) which should include extra-curricular activities where all learners should be given the chance to participate. In this regard the need to achieve integrated pluralism in the schools (Bennet, 2003:25) should be emphasised.

\subsubsection{EVIDENCE OF THE SCHOOL AS A MULTICULTURAL}

\section{INSTITUTION}

Most of the participants (14) were of the view that their schools can be characterised as multicultural institutions. In their view the multicultural nature of their schools is reflected in multicultural enrolment patterns as well as the harmonious relations that 
prevail among the learner body. Multicultural enrolment patterns were seen as evidence that the school is a multicultural institution. Commenting on the multicultural character of his school a participant said;

Our school is a multicultural institution. Just because we have those pupils who are Christians, gure (Zambian sub cultural dance) people, I think we accommodate them they are here. There is nothing visible that enables a visitor to identify the multicultural nature of the school. We don't have a Culture hut but we are in the process of building one. It is one of the things that are on our agenda, on our projects. (Participant 20, School 5)

Another participant was of a similar opinion. She emphasised the presence of multicultural enrolment patterns in the school by stating;

When enrolling pupils they do not select according to the surname. For example you have asked me if I speak Ndebele. It is just that my father who is Ndebele died when I was young, my mother is Zezuru. That is why I don't speak Ndebele; he died whilst I was still young. The way they enrol pupils they do not select. The way the children play, if one of them starts speaking in Ndebele or another language they don't laugh or comment. They are even interested in learning because I have noticed that there are pupils from Masvingo, there, they speak Karanga language and there are some who have transferred from the Ndau area (Manicaland) who also speak that language. (Participant 17, School 5)

In some schools there was little evidence to suggest that the school was a multicultural institution. A participant felt that there is little evidence to suggest that her school is a multicultural institution. Her concern was that;

There is little evidence, though we have been trying here at school 3 to have a Culture hut where we would display artefacts from different cultural backgrounds. We have been trying but we have not been able to make one. We built the structure but it has no artefacts inside. But I think that was going to be the starting point where we would then display so that if someone comes into the school he/she would see that this represents the Ndebele. That is one area, as of now there is nothing I can say is multicultural. (Participant 12, School 3)

Similar views were expressed during focus group discussions. Multicultural enrolment patterns were emphasised as evidence that the school is a multicultural institution. According to a participant; 
This school is a multicultural institution because we have children who are coming from different backgrounds. This is a school made up of different cultures Chewa, Ndebele people, and Shona people so I can say it is a multicultural society because we have people of different languages coming to learn at this institution. Apart from the enrolment activities done at this school, the cultural activities like traditional dance show cultural pluralism. Here where we are, we have got the gure (Zambian sub cultural dance) people, they perform their activities, and we have got the jiti (Korekore sub cultural dance) and people from different cultures. So whenever we are having a gathering sometimes, these people show or display their cultural activities. (Participant 13, School 4)

Absence of any forms of discrimination in the school environment were cited as evidence that the school is a multicultural institution. One participant described how his school is a multicultural institution. He had this to say;

By teaching and treating all the pupils like one person, I think it portrays that we are not discriminatory. All the staff members are equipped in such a way that they don't discriminate the pupils. So I don't think at this school we are having such a situation and most of the schools have adopted the system of teaching the pupils and treating all the pupils equally. At the school we can see how members of staff are living; you can see there is no room of saying that those from Matabeleland should stay there, those who are speaking a certain language this is their house. It's like just accommodating every staff member as well as the pupils. (Participant 19, School 5)

While multicultural enrolments affirm that the school is a multicultural institution there are some issues that also need to be considered. The responses of the participants also reflect their level of conceptualisation of multicultural education in Zimbabwean primary schools. This becomes apparent when one considers that the multicultural character of the different schools is conceptualised in terms of enrolment patterns and harmonious relations that prevail among the school staff and learners' body. Other tangible issues that point towards multiculturalism were not mentioned. These include things such as notices on bulletin boards and notice boards, labels on buildings and trees among many others. These views are in agreement with the observations of Lemmer, Meier \& Van Wyk (2006:4-5) who state that the implementation of multicultural education requires the total reform of the school 
environment. The schools in the sample are still to initiate a number of reforms in the school environment so that the multicultural character of the school is seen. This is in agreement with Meier \& Hartell (2009:181) who argues that research studies show that schools' response to diversity and changes are inadequate.

There is need to ensure that notices on bulletin boards, notice boards and school buildings should be in the languages used by learners in the school. In the Zimbabwean context such languages should include: English, Shona, Ndebele and other marginalised indigenous languages in use in the school. For example the schools in the sample are located in a predominantly Shona speaking area. So such notices should be in English and Shona as well as Chewa for those schools in farming communities. In the schools in the sample this was found to be absent and the participants' conceptualisation of multicultural education did not focus on this important dimension. Trees in the school environment should also be labelled in English as well as indigenous languages used by all the learners in the school. This can be seen as one way of promoting the languages used by learners particularly the mother tongue. This should be seen as a way of reinforcing multicultural education developments taking place inside the classroom. Nieto (2000) in Gorski (2006:165) argues that multicultural education is pervasive, it should permeate the school climate, culture, practice that it must be visible everywhere. This observation is valid and the practice of multicultural education in Zimbabwean schools has to live up to this challenge.

Gollnick \& Chinn (2002) cited in Maatta (2008:9) define multicultural education as a strategy in which pupils' cultural backgrounds are used in order to develop effective school environments and classroom instruction. In terms of this definition the need to 
provide pervasive multicultural education cannot be over emphasised. Therefore the multicultural character of the school has to be visible and evident in the school environment.

The schools' multicultural enrolment patterns are in harmony with the provisions of the 1987 Education Act which outlaws discrimination of pupils on any grounds. These enrolment patterns are also part of multicultural education. Multicultural school enrolment patterns as practiced in the schools in the sample and generally in Zimbabwe should be seen as a form of integrated pluralism (Bennett, 2003:25). Integrated pluralism recognises the diverse racial and ethnic groups in society but does not denigrate them (Bennett, 2003:25).In the context of these enrolment patterns it can be argued that multicultural education is being practised in Zimbabwean primary schools.

\subsubsection{PARENTAL PARTICIPATION IN SCHOOL ACTIVITIES AND THE NATION'S MULTICULTURAL CHARACTER}

Most of the participants (16) were of the view that parental participation in school activities reflects the multicultural nature of Zimbabwean society. This participation is shown through the support that parents give to the school in a number of areas including co-curricular activities. According to one participant;

Parents who are invited to the school are taken from anywhere in Zimbabwe and they speak to other parents and also to pupils representing the nation, not just this particular school. So we find that this shows that people who are invited to the school be they parents or guests of honour at functions are from different cultures. The school does not select only from the culture of those within the school environment. (Participant 10, School 3)

Parental involvement in school activities is also found in co-curricular activities particularly in the teaching of traditional dance. The role of parents in co-curricular activities such as traditional dance was highlighted by a participated who said; 
The participation of parents in school activities shows that Zimbabwe is a multicultural nation. By their participation some parents come and train pupils for example in traditional dance. They train them different ways of dancing such as for example this Ndebele dance, I have forgotten the name. But we invite different people from different backgrounds to train for example shangara (Karanga sub cultural dance) from Masvingo, jiti (Korekore sub cultural dance) from Murehwa. We also invite nyau (Chewa subcultural dance) trainers. (Participant 4, School 1)

Parental participation in school activities also involves attending some school functions. Parents attend important school functions such as the Culture Week. Another participant had this to say about parental participation at such functions;

Participation of parents in school activities shows a multicultural approach. For example sometime about two or three weeks ago we had a Culture day. The parents and children were showcasing, all different things like modelling; music from different cultures for example Malawian dances, Shona dances and even some Christian dances. Parents participated in different genres of traditional dance. (Participant 8, School 2)

Yet another participant expressed similar views by saying;

When we mix with parents, we can talk of cultures coming out. When there are days like the prize giving day parents are asked to perform their cultural activities of which we have the nyau (Chewa sub cultural dance) doing their act, the jiti (Korekore sub cultural dance) people doing their act. Here culturally there is a lot of diversity that is shown. (Participant 13, School 4)

Similar views were expressed during focus group discussions where parental participation in co-curricular activities was highlighted. Parental involvement in the teaching of traditional dance genres was emphasised by one participant who noted that;

Yah, parental participation does to a certain extent accommodate all parents. There was one time when some parents came and assisted in teaching traditional dance. So it means that parents are involved in teaching their own culture. When we have got a certain dance in traditional dance, we look for parents who have that knowledge in that kind of dance. So I think that shows that we are a multicultural institution. (Participant 11, School 3)

Some participants felt that parental participation in school activities tends to be minimal. They felt that there are some challenges encountered. A participant complained that; 
To be honest here, I think here parental participation is minimal. But you realise that when you have a certain function, the way they attend sometimes is not pleasing. (Participant 6, School 2)

It appears that parental participation in the different schools is largely in the area of co- curricular activities especially traditional dance. This gives parents an opportunity to transmit their own skills, knowledge, attitudes and values to learners (MacDonald in Lemmer, Meier \& Van Wyk, and 2006:132). In this study the participants revealed that parental involvement was mainly in the area of co-curricular activities. The involvement of parents in school activities affirms Nieto's (2002:39) view that families and other community people must be visible in the schools because they would offer a unique viewpoint. Parental involvement in school activities is also part of the implementation of multicultural education. Cultural diversity should be reflected in terms of parental participation. However, there is need to involve parents more in those areas where teachers have limited expertise, both inside and outside the classroom. Participation of parents in school activities should therefore transcend participation in co-curricular activities.

The community is a reservoir, containing many educational resources which the school can tap (Nziramasanga Commission Report (1999: 31). Banks (2009:419) advises that parental involvement in school activities is important because it acknowledges the importance of parents in the lives of the children. Schools need to motivate parents so that they see the need to take a keen interest in school activities. This provides learners with an opportunity to see multiculturalism in practice. Therefore the school needs to be multicultural in every respect. 


\subsubsection{COMPOSTION OF THE SCHOOL DEVELOPMENT COMMITTEE}

All the participants felt that the composition of the School Development Committee in their schools reflects the nation's multicultural character in terms of ethnic origin, gender, religion and social class. Some of the schools in the sample have put in place deliberate policies to ensure that the composition of the School Development Committee (SDC) is representative of the parental body.

The composition of the School Development Committee was seen to be multicultural as the members come from different parts of the country and reflect diversity in terms of socio economic status. A participant explained the multicultural composition of the School Development Committee at his school as follows;

These members (pointing to portraits on the wall) can you see these members? The chairperson comes from Mhondoro (Mashonaland West), that other one comes from Mutare (Manicaland); the others come from different places, all parts of Zimbabwe. There is only one person in the committee who is well to do and he is our treasurer Mr. Tsoko (not real name) an accountant. But the rest, two women are full time housewives, the other one is a Red Cross worker and the other one works in the commercial security sector and one is working for the local town council. The chairperson is not employed, he was retrenched sometime ago; so all people are accommodated. (Participant 9, School 3)

Some schools have put in place mechanisms to ensure adequate representation of the parental body by focusing on the school's catchment area. Another participant elaborated the mechanism used by his school to ensure multicultural representation by saying;

We normally look at representation of the catchment area and normally that caters for all cultures that are in the school. We have seven catchment areas and from each we have got a member. But because Kensington (not real name) because of its numbers in terms of pupils it has two members in the SDC. So every area has got representation. In Texas (not its real name) farm there are mixed cultures, because they get workers from everywhere and also at Mainway, (not its real name) and Highway (not its real name). So using this method every culture is catered for. (Participant 5, School 2) 
In some schools membership is determined by the manner in which the parent supports the school. According to a participant;

The SDC, the members are just selected according to how they support the school, how active they are and not according to where they come from. Membership of the SDC represents all social as well as ethnic groups because they don't specify, they don't question the people. (Participant 17, School 5)

Similar views were expressed during Focused Group Discussions. The views of the participants emphasised that there is no marginalisation of parents in terms of participation in school activities. One participant pointed out that;

We do not have marginalisation of parents here. We accommodate everybody. (Participant 10, School 3)

Another participant concurred;

As it is right now, there is no social group that is marginalised, there is no social group that most of the parents are looking down upon, because each and every social group is taken as one and equal. So most social groups are treated equally. (Participant 20, School 5)

In agreement another participant gave an overview of how parents are selected for membership in the School Development Committee. He had this to say;

All parents are catered for in the sense that in elections we use representation from all the catchment areas. We can say there are children who come from Kensington (not its real name) we may have two SDC members, from areas like Huntington (not its real name) we have one and so on. So they are catered for. (Participant 5, School 2)

The composition of the SDC in the schools in the sample tends to accommodate the cultural diversity found in the nation. All these schools are complying with the provisions of Zimbabwe Statutory Instrument Number 70 of 1993. The composition of the SDC and SDA is in agreement with the views of Ghosh (2002:72) who posits that all school committees, teams and organisations should be representative of the diversity of students, staff and communities and all members must have equal status and equal power to speak and be heard. This observation presents challenges in the selection of parental representation bodies as the cultural backgrounds of parents have 
to be considered. Consideration of the cultural backgrounds of parents enables the prevalence of equity in terms of membership.

\subsection{CHAPTER SUMMARY}

This chapter has presented the findings of the study. Some of these findings are similar to the findings of research studies carried out elsewhere. These findings show that some form of multicultural education is being practised in Zimbabwean primary schools though teacher perceptions of multicultural education as a concept tend to be narrowly focused. From the views of the participants this is being done through: the content of some subjects like Social Studies, the languages and Religious and Moral Education, instruction in the mother tongue in infant classes, the teaching of, marginalised indigenous languages as well as classroom pedagogy. Classroom pedagogy, portrayal of students in curriculum instructional materials, the language policy and the total school environment were seen to be accommodating the multicultural character of Zimbabwean society. It was also established that there are some challenges that have to be overcome in the implementation of multicultural education in Zimbabwean primary schools. Some of the challenges observed include the continued use of some textbooks that are not truly multicultural as well as the absence of a policy framework to regulate the practice of multicultural education in Zimbabwean primary schools. The form of multicultural education being practised can be described as being at the additive level in terms of Banks (2009:239) levels of approach to multicultural education. These findings therefore emphasise the compelling need to develop a policy to regulate the practice of multicultural education in Zimbabwean primary schools. This is the case in other countries like South Africa. These findings thus provide the context in which such a policy can be formulated. In 
this way this study makes an original contribution to the practice of multicultural education in primary schools in Zimbabwe.

The next chapter presents a summary of the findings, conclusions and recommendations. 


\section{CHAPTER 5: SUMMARY, CONCLUSIONS AND RECOMMENDATIONS}

\subsection{INTRODUCTION}

The previous chapter presented the findings of this study. These findings were analysed and discussed in the context of the literature review carried out in Chapter 2. The aim of the study was to explore teacher perceptions on the implementation of multicultural education in Zimbabwean primary schools. This chapter presents a summary of the major findings, conclusions and recommendations of the study.

\subsection{SUMMARY}

This study sought to answer the following main research question:

What are the perceptions of primary school teachers on the implementation of multicultural education? (See Section 1.3).

The following research questions were the sub-questions:

a) How do curriculum instructional materials currently in use reflect the nation's plural character?

b) How does classroom pedagogy reflect and accommodate cultural diversity in the classroom?

c) How does the current language in education policy of the Ministry of Education, Arts, Sports and Culture address the linguistic needs of culturally diverse students?

d) How does the total school environment reflect the pluralistic character of the nation?

e) How does the participation of parents in school activities accommodate society's cultural diversity? 
The first chapter presented a background to the study, the research problem and research questions as well as research methods. In this chapter it was argued that there is need for the implementation multicultural education in Zimbabwean primary schools. This observation arises out of Zimbabwe's colonial experience where the black African learner was subjected to an alien curriculum that did little, if not nothing, to validate the child's cultural background and identity. Hence with the attainment of independence in 1980, curriculum reform was inevitable.

Chapter 2 presented the literature review. Postmodernism as the guiding theoretical framework was presented. A brief background of multicultural education was given. Various definitions of multicultural education were given. Approaches to multicultural education such as models by Gibson's (2010:95-113; 1984:113-115), Grant and Sleeter (2009:62-68); and approaches by Bruch et al. (2004) cited in Zimmerman (2004:2-4), by Nieto (1992:46; 2002;31-46) and Banks (1993:13; 2009:237-249) were also discussed at length. Curriculum issues in multicultural education in Zimbabwe were discussed so as to enable the evaluation of the extent to which multicultural education has been implemented in Zimbabwean primary schools. A critique of multicultural education as well as the challenges in the implementation of multicultural education was discussed.

Chapter 3 presented the research method and research design. The research method chosen was qualitative research with a phenomenological research design. Data collection methods were discussed as well as procedures to be adopted in the analysis of data. Trustworthiness and ethical issues were presented.

Chapter 4 presented and discussed the research findings. It was established that a start has been made in implementing multicultural education in Zimbabwean primary 
schools. This is shown through the teaching of some subjects such as the languages, Religious and Moral Education, Social Studies, the language policy, particularly the teaching of marginalised minority languages and co-curricular activities such as Music and traditional dance. The participants were of the view that their schools are multicultural institutions and the participation of parents in school activities reflects the plural character of Zimbabwean society. The next section looks at a summary of findings from literature review pertaining to: origins of multicultural education, definition of culture and multicultural education and curriculum issues in multicultural education.

\subsubsection{SUMMARY OF FINDINGS FROM LITERATURE REVIEW RELATING TO THE ORIGINS OF MULTICULTURAL EDUCATION}

Literature review, (Section 2.3) reveals that multicultural education originated in the United States of America out of the Civil Rights movement in the late 1960s (Haynes Writer, 2008:3; Yao, Buchanan, Chang, Powell-Brown \& Pecina, 2009:3, Cushner McClelland \& Safford 2008:20 Civil Rights activists demanded an end to segregation and discrimination in various spheres of life which include education. The Brown versus the Board of Education of 1956 in the United States of America provided the impetus for the adoption of multicultural education. The Supreme Court in Brown v Topeka Board of Education (1954) ruled unconstitutional, the segregation of black and white learners (Manning \& Baruth, 200:12). As a result Civil Rights, activists demanded curricular reform to enable their achievements and contributions to be reflected in curricular texts.

The success of the Civil Rights movement encouraged other groups who were also marginalised to make similar demands. These included Mexican Americans, Puerto 
Ricans, American Indians and Asian Americans (Banks 1993:10). Since then, multicultural education has continued to grow and expand to other countries. The implementation of multicultural education can thus be categorised into four phases (Banks, 1993:10-11; Gollnick \& Chinn, 2012:28; Lemmer, Meier \& van Wyk, 2006:4; Vandeyer, 2003:195; Manning \& Baruth, 2008:12).

\subsubsection{SUMMARY OF FINDINGS FROM LITERATURE REVIEW RELATING TO THE DEFINITION OF CULTURE AND MULTICULTURAL EDUCATION}

The literature being referred to in this study demonstrates the complexity of arriving at a universal definition of culture and multicultural education. As a result of numerous definitions of these two related concepts the practice of multicultural education is characterised by numerous approaches. The concept of culture defies a single definition as there are many definitions that have been put forward (2.4). As far back as 1952, Kroeber and Kluckhohn had identified 160 definitions of culture (Keating, Martin \& Szabo (2002) in Dunne (2011:610). This view seems acceptable in the context of postmodernism. Culture can be seen as referring to peoples' values, language, religion, ideals, artistic expressions, patterns and social and interpersonal relationships, and ways of perceiving, behaving and thinking (Manning \& Baruth, 2008:44). Culture therefore can be seen to refer to the way of life of a social group; it is unique to a particular social group. Therefore, the imposition of one's cultural code onto another people's culture is a debilitating experience that leads to gross alienation or 'culturocide' (Galtung cited in Vandeyer, 2003:192). A society with many cultures is a multicultural society. It is apparent that all societies world over are multicultural. 
Multiculturalism seeks to create an environment in which different sub cultural groups accommodate and tolerate each other (Lemmer, Meier \& van Wyk, 2006:4). It is in this context that multicultural education is seen to play an instrumental role in promoting multiculturalism or pluralism. Just like culture, the concept of multicultural education defies a single definition (Section 2.4). The concept of multicultural education today is considered multidimensional, embracing issues such as race, ethnicity, gender, socioeconomic status, disability and equal opportunity (Banks, 2001, Pang, 2001 in Gwirayi, 2010:13). Gollnick \& Chinn (2002) in Maatta, (2008:9) define multicultural education as a strategy in which pupils' cultural backgrounds are used in order to develop effective school environments and classroom instruction. Therefore, multicultural education has to accommodate diverse pupils' cultural backgrounds. Banks has identified five dimensions of multicultural education (Yao, Buchanan, Chang, Powell-Brown \& Pecina, (2009; Banks, 2009:20). These are; content integration, knowledge construction, prejudice reduction, equity pedagogy and empowering school culture and social structure.

These dimensions have to be addressed in the successful implementation of multicultural education. It has been observed that multicultural education requires culturally responsive teaching (Gay, 2000:30-31 in Maatta, 2008:22, and Rose \& Potts, 2011:3). Not all schools have responded to the need to implement multicultural education in the same way (Bennet, 2003:24-25). Four models have been identified, these being the business as usual, assimillationist response, pluralistic co-existence and integrated pluralism. 


\subsubsection{SUMMARY OF FINDINGS FROM LITERATURE RELATING TO CURRICULUM ISSUES IN MULTICULTURAL EDUCATION}

Literature review revealed that multicultural education has to address a number of curriculum issues which include: knowledge construction; language policy; selection of curriculum content; textbooks and curriculum instructional materials; the school environment and community involvement in the affairs of the school (Section 2.8). Post modernism places emphasis on the plural character of knowledge as well as its ephemeral nature. It should be noted that knowledge is formed during social interaction and is therefore relative. In this context, both teachers and the curriculum must validate the home and community knowledge that children bring to school (Campbell, 1996:22). This calls for content integration in terms of pedagogy. Selection of curriculum material has to be done in a way that ensures that no pupil is disadvantaged or prejudiced. A mainstream centric curriculum is discouraged (Banks, 2009:240). In the selection of curriculum content, educators should be aware of bias (Sadker \& Sadker 1978, in Gollnick \& Chinn, 2012:320-326). Textbook and curriculum instructional materials have to be multicultural in every respect.

Multicultural education, according to Banks's model, would be infused throughout education content and experiences (Yao, Buchanan, Chang, Powell -Brown \& Pecina, 2009:2). In terms of language policy, there is need to accommodate the linguistic diversity of the learners. McKinney \& Soudien (2010:11) argue that at the broadest level, mismatches between the language of learning and teaching and the linguistic resources learners bring with them to school creates the real problem of access to the curriculum for many learners. Zimbabwe's language policy is enshrined in the Education Act of 1987 although it results in subtractive bilingualism (Molosiwa, 
2009:4; Ndamba, 2008:172). Teacher attitudes and expectations have an impact on the implementation of multicultural education. Accepting every child as a valuable individual is a foundation for multicultural education and a significant goal for teachers (Jokikoko, 2005; Kopinen, 1999 as cited by Maatta, 2008:8). The school environment should be conducive for students from diverse backgrounds. Multicultural education must deal with the total culture of the school, it must be aware of the differential treatment of students who have very dissimilar experience because of certain differences based on race, gender, culture or class (Ghosh, 2002:3).The involvement of the community in the affairs of the school should reflect the cultural diversity of the nation In Zimbabwe Statutory Instrument 70 of 1993 paved the way for the establishment of School Development Associations (SDA) and School Development Committees. Members of these committees are drawn from parents who have children at the school.

\subsection{SUMMARY OF FINDINGS FROM QUALITATIVE STUDY}

\subsubsection{PARTICIPANTS VIEWS ON THE IMPLEMENTATION OF MULTICULTURAL EDUCATION IN ZIMBABWE}

Multicultural education is being practised in Zimbabwean primary schools to a limited extent (Section 4.2.1). The views of the participants reflect their narrow focus of the practice of multicultural education. From the viewpoint of the participants, implementation of multicultural education is shown in the teaching of marginalised minority languages in the areas where these are commonly spoken, instruction in the mother tongue up to grade three, multicultural enrolment patterns, and the content of some textbooks and the holding of the Cultural Week. There are some challenges that were observed in the implementation of multicultural education. The following issues 
were highlighted: the need for teacher training on multicultural education, the need for a government policy on multicultural education as well as the need for textbooks that cut across all subcultures.

\subsubsection{CONTENT OF THE PRIMARY SCHOOL CURRICULUM AND ZIMBABWE'S MULTICULTURAL CHARACTER}

The content of the primary school curriculum in Zimbabwe reflects the nation's multicultural character. This is shown through the content of some subjects such as; Social Studies, Religious and Moral Education and the languages (Section 4.2.2). Cocurricular activities such as the annual traditional dance national competitions where different dance themes are drawn from different regions of the country were seen as ways of embracing the cultural diversity of the nation. Music national competitions were considered to reflect the multicultural character of the nation as the Music pieces are written in different languages. The responses of the participants also reflect their rather narrow conceptualisation of the concept of multicultural education. In terms of their responses, multicultural education can be seen as being practised at the additive level in terms of Banks's approaches.

(a) Differences in curriculum instructional materials in use before and after independence

There is a difference in the content of curriculum instructional materials that were used before and after independence (Section 4.2.2). Curriculum instructional materials that were used before independence were described as having been discriminatory, segregatory and alien in nature as they marginalised the black African learner in terms of cultural background. With the attainment of independence, curriculum reforms were undertaken in an attempt to make the curriculum relevant to the learner and the 
cultural diversity of the learner has been considered. The introduction of subjects such as Social Studies, Religious and Moral Education was cited as attempts to accommodate the cultural diversity of the learner. In the English readers, indigenous names such as Tatenda and others are now used as a way of accommodating cultural diversity.

\subsubsection{PORTRAYAL OF ZIMBABWE'S MULTICULTURAL CHARACTER IN CURRICULUM INSTRUCTIONAL MATERIALS CURRENTLY IN USE}

Some curriculum instructional materials currently in use portray Zimbabwe's multicultural character (Section 4.2.4). This is shown in subjects such as the languages, Music, Social Studies as well as some co-curricular activities such as traditional dance. Subjects like Social Studies embrace different settings when looking at topics such as shelter. In the languages, the stories are drawn from different settings. However, some challenges were observed with readers in the languages particularly Shona. These readers tend to be regionally based as they are written for a specific ethnic group and this compromises the extent to which they accommodate the cultural diversity of the nation.

(a) Representation of students from different social groups in curriculum instructional materials

Different social groups are represented in curriculum instructional materials (Section 4.2.5). This representation is shown in the content of the different subjects such as the languages, Religious and Moral Education as well as the readers. In the languages, the stories which learners read are drawn from different settings which include rural areas and urban areas. However, some participants felt that all social groups are not 
portrayed in the content of curriculum instructional materials. As such the burden to ensure adequate portrayal falls on the teacher.

\subsubsection{CLASSROOM PEDAGOGY AND ACCOMMODATION OF STUDENTS' CULTURAL DIVERSITY}

Teachers accommodate learners' classroom cultural diversity in the design of teaching methods (Section 4.2.6). This is done in the design of teaching methods where examples are drawn from different subcultures when teaching, as well as teaching methods designed to accommodate different learning styles. Terms are also explained from the point of view of different dialects in the vernacular languages. This is a form of content integration in terms of Banks (2009:20) dimensions of multicultural education and a way to reduce prejudice, which is another dimension of multicultural education according to Banks (2009:20). In the accommodation of cultural diversity, there are some challenges that were observed. The need to conduct adequate research on the learner's cultural backgrounds was emphasised as well the need for the teacher to bracket or suspend his/her cultural background was cited.

(a) Teacher sensitivity to learners' diverse cultural backgrounds

Teachers are sensitive to learners' diverse cultural backgrounds (Section 4.2.7). This is reflected in teacher/ learner interaction as well as the teaching methods that are employed in the classroom, though the need for teachers to be knowledgeable in the different subcultures was highlighted. Some challenges in this area were also noted. The need for teachers to avoid being overwhelmed by their cultural backgrounds was cited as well as the need for teachers to be sensitised on multicultural education. 


\subsubsection{LANGUAGE IN EDUCATION POLICY AND ACCOMMODATION OF}

\section{LEARNERS' LINGUISTIC NEEDS}

The current language in education policy addresses the needs of learners in a linguistically diverse society (Section 4.2.8). This accommodation is seen through the use of English as a medium of instruction as well as the teaching of marginalised indigenous languages such as Kalanga, Tonga and Venda in those areas where these are commonly spoken. Grade seven learners who transfer to areas where these marginalised indigenous languages are not taught can have their question papers sent there. The need to add other marginalised indigenous languages such as Chewa to the curriculum were also cited. The use of English as a medium of instruction was highlighted as this was considered to engender achievement related problems.

(a) Encouragement to communicate in the mother tongue inside and outside the classroom

Learners are encouraged to communicate in the mother tongue (in this case Shona) during Shona lessons only. At all other times learners are encouraged to communicate in English as a way of enhancing their proficiency in the language. This situation was seen as desirable since all subjects besides Shona are taught in English. Learners in farming communities, the majority of whom speak Chewa face communication problems as they are not very proficient in both English and the indigenous languages taught in the school (Section 4.2.9). These learners end up speaking what can be considered a diluted form of Shona. 


\subsubsection{THE TOTAL SCHOOL ENVIRONMENT AND REFLECTION OF THE NATION'S CULTURAL DIVERSITY}

The total school environment reflects cultural diversity in areas such as staffing patterns, school assembly programmes, selection of prefects and learner participation in co-curricular activities.

(a) Staffing patterns

Staffing patterns at the different schools reflect the nation's cultural diversity. This is attributed to the presence of members of staff from different ethnic groups though not all ethnic groups are represented on the staff (Section 4.2.10.1). Schools in the sample do not play a part in the recruitment of staff as this is done at district level.

b) School assembly programmes

School assembly programmes at the different schools in the sample are multicultural and reflect the cultural diversity of the nation. This is shown by the participation of all learners in assembly programmes, irrespective of cultural background, the moral stories told at assembly as well as the languages used at times. Mostly English and Shona are used with Ndebele being used at times in some of these schools. These assembly programmes show a heavy bias towards Christianity and this tends to compromise their multicultural character (Section 4.2.10.2). One church school emphasises dissemination of Catholic ethos during assembly and thus falls short in accommodating the cultural diversity of the school and nation. 
(c) Selection of prefects

The selection of prefects reflects the nation's multicultural character as all learners in the target grades can be selected provided they meet the selection criteria. In all the schools, in the sample the following attributes are considered in the selection of prefects; behaviour, ability and leadership qualities (Section 4.2.10.3). The emphasis on these attributes tends to marginalise other learners as these attributes are largely influenced by one's cultural backgrounds. Gender equity in the selection of prefects is reflected. One school in the farming community has devised a strategy of selecting a prefect from each farm that forms the school's catchment area.

(d) Participation in co-curricular activities

Participation of learners in co-curricular activities accommodates cultural diversity (Section 4.2.10.4). This is shown through the range of sporting disciplines offered. One former whites only school continues to offer cricket, rugby and hockey which were sporting disciplines exclusively dominated by whites before independence. In another school, learners are exempted from participating in co-curricular activities on the basis of religious beliefs. Most of the schools emphasise participation in sports during house games before the final selection of school teams.

(e) Evidence of the school as multicultural institution

Schools in the sample were considered to be multicultural institutions (Section 4.2.10). The multicultural character of the schools was shown through multicultural school enrolment patterns as well as staffing patterns. Other tangible characteristics of a multicultural school such as labels on buildings and trees were not mentioned and were conspicuous by their absence (Section 4.2.11). Only one former whites only school has a culture centre where cultural artefacts are displayed. 


\subsubsection{PARENTAL PARTICIPATION IN SCHOOL ACTIVITIES AND THE}

NATION'S MULTICULTURAL CHARACTER

The participation of parents in school activities reflects the cultural diversity of the nation. Parents participate in school activities in a number of ways: being invited as guest speakers; attending school functions such as prize giving days; teaching learners traditional dance and as members of the School Development Committee. It was observed that there is no marginalisation of parents in terms of participation (Section 4.2.11).

\subsection{CONCLUSIONS}

The following conclusions are drawn from the data analysis conducted. These conclusions are given as answers to the five research questions outlined at the beginning of the study.

\subsubsection{TEACHER PERCEPTIONS ON IMPLEMENTATION OF}

\section{MULTICULTURAL EDUCATION}

Teacher perceptions revealed that multicultural education is being practised in Zimbabwean primary schools to a limited extent at the additive level in terms of Banks approaches. Implementation of multicultural education is hampered by the lack of a coherent government policy guiding the practice of multicultural education in Zimbabwe. Teachers therefore tend to have a narrow focus on the conceptualisation of the concept of multicultural education which also reflects their lack of knowledge of the concept. Zimbabwe's language in education policy is seen as evidence of the practice of multicultural education. School textbooks do not adequately cater for the cultural diversity found in the classroom, for example, in the languages. 


\subsubsection{REFLECTION OF THE NATION'S PLURAL CHARACTER IN CURRICULUM INSTRUCTIONAL MATERIALS CURRENTLY IN USE}

School textbooks in some subjects such as social studies and religious and moral education tend to reflect the plural character of Zimbabwean society. This is a reflection of Banks's additive level. The accommodation of the nation's plural character in the languages readers presents some challenges as the different ethnic groups that make up Zimbabwe's society are not fully catered for. Vernacular textbooks, particularly in Shona, appear to be written for a specific target ethnic group and they experience challenges in fully accommodating the nation's plural character. Co-curricular activities undertaken in the third term reflect the plural character of the nation through the selection of traditional dance genres from different ethnic groups as well as music pieces set in other languages other than Shona and English. Curriculum reforms undertaken after the attainment of independence in 1980 have made the school curriculum more meaningful to the learner through the accommodation of learner's cultural backgrounds. However they have not gone far enough to fully and effectively accommodate the nation's plural character.

\subsubsection{CLASSROOM PEDAGOGY AND ACCOMMODATION OF CULTURAL DIVERSITY}

Classroom pedagogy utilised by teachers accommodates pupils' cultural diversity through examples that are drawn from different cultural settings. Classroom pedagogy utilised is, therefore, a form of content integration in terms of Banks (2009:20) dimensions of multicultural education. Teachers encounter a number of challenges in content integration due to lack of adequate knowledge of the various learners' cultures 
in the classroom and school. Teachers' cultural upbringing presents challenges in teacher/ pupil interaction.

\subsubsection{LANGUAGE IN EDUCATION POLICY AND ACCOMMODATION OF LEARNER LINGUISTIC NEEDS}

The teaching of marginalised indigenous languages such as Tonga, Kalanga, Nambya and others in those areas where these are traditionally spoken is seen as a way of accommodating learners' linguistic needs in a diverse society. The language policy is seen as part of the implementation of multicultural education. Learners whose mother tongue is not part of the school curriculum do not benefit from mother tongue instruction in junior classes and are thus disadvantaged. The teaching of Chewa in the farming communities has to be considered as Chewa speaking learners do not benefit from instruction in the mother tongue and therefore experience transitional submersion. Learners are encouraged to communicate in English inside and outside the classroom most of the times in order to enhance mastery of English and boost chances of passing school examinations. Communication in the mother tongue is encouraged during Shona lessons only.

\subsubsection{THE SCHOOL ENVIRONMENT AND REFLECTION OF THE NATION'S PLURALISTIC CHARACTER}

Staffing patterns and learner enrolment patterns in the different schools are multicultural though not all ethnic groups are represented on the school staff. This might be due to the absence of recruitment and staffing policy to ensure that the composition of the school staff is multicultural in every sense. The conduct of school assembly programmes shows a heavy bias towards Christianity and this compromises the multicultural character of school assembly programmes. The selection of prefects 
in the schools based on attributes such as behaviour, ability and leadership qualities tends to marginalise learners from other ethnic backgrounds. Learners' participation in co-curricular programmes accommodates the nation's plural character. The school environment in most of the schools did not exhibit tangible evidence of the multicultural character of the school besides multicultural enrolment patterns.

\subsubsection{PARTICIPATION OF PARENTS IN SCHOOL ACTIVITIES AND THE NATION'S PLURAL CHARACTER}

The participation of parents in school activities through membership of School Development Committees in the different schools is multicultural in terms of gender and ethnicity. Parental involvement in school activities is largely felt through membership of the School Development Committees and co-curricular activities particularly in traditional dance.

\subsection{RECOMMENDATIONS}

Based on the findings and conclusions the study makes the following recommendations:

5.5.1 Need for a comprehensive policy on multicultural education. There is need for the development of a comprehensive policy on multicultural education in Zimbabwean primary schools to guide its practice. (Section 4.2.1)

5.5.2 Need to include multicultural education in teacher education curricular. There is need to include multicultural education in teacher education curricular at both college and university level in order to enhance teachers' understanding of its practice. (Sections 4.2.1 and 4.2.2) 
5.5.3 Enhancing capacity of teachers in the field through in service training. The Ministry of Primary and Secondary Education should host seminars and workshops at national, district and cluster level for teachers in the field as a form of in service training for teachers in the field (Sections 4.2.1 and 4.2.2).

5.5.4 Review of current textbooks in use. School textbooks that are being used currently should be reviewed so that they accommodate and reflect the cultural experiences of all the sub cultural groups found in the country. Multicultural education should permeate all these text books (Section 4.2.4).

5.5.5 Liaison between book publishers and the Ministry of Primary and Secondary Education. Book publishers should closely liaise with officials in the Ministry of Primary and Secondary Education in an attempt to ensure that all books embrace the multicultural character of Zimbabwean society (Section 4.2.4).Book publishers should encourage authors to write books from a multicultural perspective.

5.5.6 Inclusion of other marginalised indigenous languages particularly Chewa onto the school curriculum. The Minister of Primary and Secondary Education should exercise powers vested in him/her to include additional indigenous languages onto the school curriculum particularly Chewa for the benefit of learners in farm schools, mine schools and even some urban areas (Section 4.2.8).

5.5.7 Encouragement of communication in the mother tongue in the school. Opportunities should be created to enable all learners to communicate in the 
mother tongue in the school environment as a way of preserving the mother tongue as well as cultural identity (Section 4.2.9).

5.5.8 Need for multicultural staffing patterns. The deployment policy of qualified teachers needs to be revisited to ensure that different ethnic groups are represented on the school staff (Section 4.2.10.1).

5.5.9 Conduct of school assembly. Schools should ensure that assembly programmes are multicultural by focusing on moral themes that appeal to the diverse subcultures in the schools. The heavy bias on Christianity tends to marginalise other learners from other religious sub- cultural groups.

5.5.10 Equity procedures in the selection of prefects. Learners' cultural backgrounds should be considered in the selection of prefects as a way of ensuring that learners from all sub cultural groups stand a fair chance in terms of selection (Section 4.2.10.3).

5.5.11 Need for evidence of school as a multicultural institution. There is need for tangible evidence of the school as a multicultural institution (section 4.2.11). Notices on bulletin boards, labels on trees and buildings should be in the languages spoken by learners in the school. Culture centres should contain artefacts from the different sub cultural groups in the school community and beyond (Section 4.2.11).

5.5.12 Involvement of parents in school activities. Participation of parents in school activities should transcend involvement in co curricular activities to becoming resource persons in classroom topics where teachers are not very knowledgeable. 
I therefore propose the following policy framework for the practice of multicultural education in Zimbabwe as an original contribution of this study.

\section{PROPOSED POLICY FRAMEWORK FOR MULTICULTURAL EDUCATION IN ZIMBABWE}

\section{INTRODUCTION}

This proposed policy frame work is based on the research findings arising out of the thesis. It should be seen as the researcher's contribution to the practice of multicultural education in Zimbabwe as discussed in Chapter 1. The findings of the research showed that there is a gap between theory and the practice of multicultural education in Zimbabwe. This is not surprising considering that research and multicultural scholarship in other countries has also revealed the existence of a gap between theory and practice in the field of multicultural education. In the Zimbabwean context a gap between theory and practice has been observed in the following areas: content of textbooks and other curriculum instructional materials; teachers' perceptions and conceptualisation of multicultural education; the total school environment; absence of a national policy on multicultural education, co curricular activities and parental participation in school activities.

The effective implementation of multicultural education requires a holistic approach. In this regard all the different facets of multicultural education have to be addressed in its practice. It follows that the gaps identified above have to be addressed so that they are effectively incorporated into the practice of multicultural education. It becomes imperative that a policy on multicultural education be formulated as a way of regulating its practice. Such a policy should be comprehensive so as to accommodate all the dimensions of multicultural education. Without a proper policy blueprint multicultural education will be practised in a piecemeal approach which in the ultimate analysis results in a superficial approach in this field. This proposed policy framework contains all the different issues that need consideration.

\section{PREAMBLE}

Zimbabwe is a multicultural and multiethnic nation characterised by cultural diversity. This diversity has to be accommodated and reflected in the practice of education. Hence multicultural education becomes an important vehicle in this regard. The Constitution of Zimbabwe outlaws discrimination on any grounds. In a similar vein the Education Act of 1987 is very vocal on discrimination as it stipulates that no child should be denied entry into school on any grounds. Both the Constitution of Zimbabwe and the 1987 Education Act create a conducive environment for the implementation of multicultural education. In legal terms all schools in Zimbabwe are multiracial and multicultural. These pieces of legislation provide a conducive environment for the practice of multicultural education.

In Zimbabwe, in terms of the Constitution, education is a basic right. As such the content and practice of education has to accommodate learner diversity positively. Zimbabwe is a signatory to the International Convention on the Rights of the Child (ICRC) and the African Charter on Children's Rights. Article 30 of the ICRC 
emphasises the right of minority or indigenous children to learn about and practise their own culture, language and religion. Both the ICRC and the African Charter on Children's Rights recognise the right of all children to education. The right to education can be fully enjoyed in a school environment that has a multicultural curriculum. This emphasises the importance of multicultural education that can be effectively implemented in the context of a relevant policy framework.

In the past 32 years of independence Zimbabwe has made some notable progress in the implementation of multicultural education. However the absence of a national policy on multicultural education appears to have presented some challenges in terms of its implementation. The state of practice of multicultural education in Zimbabwe can be categorised as being at the additive level in terms of Banks's (2009) multicultural education continuum. The additive level incorporates literature about people from diverse cultures into the curriculum. Even though this is the case this is not being done effectively and in a manner that effectively accommodates the cultural diversity of the nation.

It should be observed that the United Nations (2005) Convention on the Protection and Promotion of Cultural Expressions objectives are to foster interculturality in order to develop cultural interaction in the spirit of building bridges among people; to promote respect for the diversity of cultural expressions and raise awareness of its value at the local, national and international levels. Education, through multicultural education, has a key role to play.

Zimbabwe has put in place a National Culture Policy. This policy has an impact on the practice of multicultural education.

\section{OBJECTIVES OF THE POLICY FRAMEWORK ON MULTICULTURAL EDUCATION}

The broad objectives of this policy framework are to:

3.1 enhance the effective implementation of multicultural education in Zimbabwean primary schools

3.2 raise the level of awareness of multicultural education among teachers, administrators, policy makers and other interested stakeholders

3.3 ensure that all learners irrespective of their cultural backgrounds experience equality of opportunity to learn through a multicultural school curriculum that accommodates the nation's rich cultural diversity

3.4 ensure that the content of the school curriculum and curriculum instructional materials reflect the needs and aspirations of a multicultural society, and

3.5 promote the creation of a multicultural school environment.

\section{DEFINITION OF TERMS}

4.1 Multicultural education - a transformative approach in education that seeks to accommodate learners' cultural diversity in the classroom and ensure that all 
learners experience an equal opportunity to achieve irrespective of race, gender, social class, ethnicity, gender, ability/ disability and learning styles.

4.2 Culture- a way of life of a people in a given society which influences how people think, behave and perceive people and events.

4.3 Sub- culture- a social group in society which accepts the dominant culture but is distinguished by its own peculiar norms and values.

4.4 Multicultural society- a society characterised by the existence of numerous sub- cultures that co- exist peacefully side by side.

4.5 Multicultural topics- topics that pertain to the history, lifestyle and tradition of people different from the dominant group in society.

\subsection{CURRICULUM ISSUES IN THE PRACTICE OF MULTICULTURAL EDUCATION}

In the effective implementation of multicultural education there are a number of issues that need to be considered. Successful implementation of multicultural education requires a holistic approach where all the different components in its conceptualisation are attended to. The following issues need consideration.

\subsection{MULTICULTURAL EDUCATION CURRICULUM}

The implementation of multicultural education requires a spiral approach in terms of curriculum content. Banks's levels of implementation of multicultural education are recommended as these are a form of a step ladder approach with one level leading to the next. In the infant grades (Grade 1 -3) the contributions level is recommended. This level focuses on heroes and holidays of different ethnic groups which are inserted into the content of the curriculum. From Grades $3-4$ the additive level is emphasised. At this level literature from diverse cultural backgrounds is incorporated into the school curriculum.

From Grades 5-6 the transformative level is the focus. At this level learners should be able to view concepts and issues and problems from several ethnic perspectives and points of view. Finally in the last year of primary school, that is Grade 7, the social action level is emphasised. At this level learners should be able to understand views and perspectives of others as well as to take action to bring about social change. However it is important to note that these levels are not watertight and a lot of overlapping can occur.

\subsection{RANGE OF PRIMARY SCHOOL SUBJECTS}

Zimbabwe's primary school curriculum comprises eleven subjects as follows: Shona/Ndebele or any other indigenous language, English, Religious and Moral Education, Social Studies, Environmental Science, Mathematics, Physical Education, Music, Home Economics, HIV and AIDS Education and Agriculture and Art. All these subjects, without exception, should be taught from a multicultural perspective. The content of these subjects has to reflect the multicultural character of Zimbabwean society. Multicultural topics have to be included in all these subjects. The languages have the greatest potential in multicultural education and should be exploited to maximum advantage. 
Co- curricular activities, such as traditional dance, should be incorporated into Music. Such an approach should enable learners to experience traditional dance genres from other subcultures and music pieces in different languages at the level of the classroom. This enables learners to experience a variety of traditional dance themes as well as appreciation of Music from different subcultures by end of their primary school career.

\subsection{SYLLABI DOCUMENTS AND TEXTBOOKS}

Syllabi documents and school textbooks should show that Zimbabwe is a multicultural nation. In terms of content all social groups in terms of ethnicity, social class, gender, ability/disability and race should be positively portrayed. For example in terms of ethnicity, Kalanga textbooks should also include the experiences of all other ethnic groups in terms of the stories and other activities contained in such books. Multicultural topics should permeate all school text books in use at the primary school level.

Textbook authors and book publishers in the various languages and subjects should closely liaise with the Ministry of Primary and Secondary Education in ensuring that all textbooks in use in the primary school are multicultural in every respect. This is in order to avoid a situation where some textbooks tend to be regionally based. Textbooks that do not meet this criterion will not be approved for use in primary schools.

\subsection{CO-CURRIULA ACTIVITIES}

A wide range of sporting disciplines should be provided on the sports menu to enable learners from diverse backgrounds to participate. More sporting disciplines should be added on to the traditional ball games offered in the majority of schools. Cultural considerations in terms of learner participation need to be accommodated. National competitions in Music and traditional dance should include Music pieces and traditional dance genres from all ethnic groups and particularly from those subcultures which have always been marginalised.

\subsection{CLASSROOM PEDAGOGY AND SENSITIVITY TO PUPILS' CULTURAL BACKGROUNDS}

There should be equity in terms of the design of classroom pedagogy. Pedagogy utilised in the classroom should appeal to all learners from diverse cultural backgrounds in an exciting way. Learners' cultural backgrounds in all subjects should be reflected and accommodated in the learning and teaching process. This calls for content integration and utilisation of diverse cultural backgrounds in the learning process. Content integration should be applied across all subjects that make up the primary school curriculum.

\subsection{LANGUAGE POLICY}

Significant progress has been noted in addressing the linguistic needs of learners in a culturally diverse society. A number of marginalised indigenous languages are now part of the school curriculum. More languages should be added to the current list. The linguistic needs of pupils from Chewa speaking backgrounds have to be addressed through the teaching of Chewa those communities where it is traditionally spoken.

Language is a reservoir of culture and a medium of cultural transmission. Learners should be given opportunities as well as encouraged to communicate in the mother 
tongue in the school environment. This should greatly assist those learners whose mother tongue is not taught in the school. Time should be set aside to enable learners to use their mother tongue both inside and outside the classroom.

\subsection{MULTICULTURAL STAFFING PATTERNS}

The recruitment of teachers into the different schools should be done in such a way that at least different ethnic groups that make up Zimbabwean society are found on the school staff. The composition of school staff should be truly multicultural in terms of ethnicity, gender and disability. Incentives have to be provided to enable teachers to be deployed country-wide including remote rural areas. Teachers' colleges are tasked with the responsibility of teaching other marginalised minority languages and cultures to students so that they can operate in multiple cultural environments.

\subsection{CAPACITY BUILDING THROUGH HUMAN RESOURCES DEVELOPMENT}

The successful implementation of multicultural education requires a skilled and knowledgeable human resource base. Human resources, therefore, have to be developed to enable them to meet the challenges presented by the implementation of a multicultural curriculum.

\subsection{Inclusion of multicultural education in teacher education curriculum}

Multicultural education has to be included in teacher education curriculum. The aim is to equip pre- service teachers with knowledge and skills on the practice of multicultural education. Multicultural education should also be taught at university level. Universities are encouraged to set up multicultural education institutes or centres so as to provide a forum for dialogue in multicultural education issues.

\subsection{In- service training for teachers (INSET)}

Seminars, workshops and conferences should be organised for practising teachers to enhance teachers' knowledge on multicultural education as well as current trends in the field. These should be organised at school, cluster, and district, regional and national level. These seminars, workshops and conferences should be seen as an ongoing activity due to the dynamic nature of multicultural education.

\section{THE TOTAL SCHOOL ENVIRONMENT}

Implementation of multicultural education demands a holistic approach. The total school environment has to be considered as it plays an important role in reinforcing developments taking place in the classroom.

\subsection{Notices on bulletin boards}

Notices on bulletin boards should reflect linguistic diversity. These should be written in both English and the indigenous language taught in the school. Space permitting other marginalised indigenous languages spoken by the learners in the school could be considered.

\subsection{Labels on buildings, trees, and other school features}

As above labels on trees, buildings and other features in the school environment should be both in English and the indigenous language taught in the school. Schools in farming and mining communities or those other communities where Chewa is spoken should consider putting up such labels in Chewa for the benefit of such pupils. 


\subsection{School assembly programmes}

The conduct of school assembly programmes should be truly multicultural in terms of content. Emphasis should be placed on the moral values of the stories told at assembly without showing a bias towards any religion.

\subsection{Selection of prefects}

In the selection of prefects the idea is to achieve and maintain representativeness in terms of learners' cultural backgrounds. Learners' cultural backgrounds should be factored in the selection of prefects to ensure adequate representation.

\section{PARENTAL PARTICIPATION IN SCHOOL ACTIVITIES}

The participation of parents in whatever school activities and roles should embrace the cultural diversity of the nation in terms of race, gender, ethnicity, social class, ability/ disability. Bodies such as the School Development Committee should strive for representativeness in terms of composition. Schools should develop strategies to ensure that representativeness is achieved in terms of parental participation in school activities. The participation of parents should transcend participation in co-curricular activities and School Development Committees to engagement as resource persons in the classroom

\subsubsection{RECOMMENDATIONS FOR FURTHER RESEARCH}

5.5.13.1 Comparative studies. It is necessary to carry out comparative studies in the implementation of multicultural education in other African countries in order to check for gaps in terms of implementation.

5.5.13.2 Marginalised minority languages, particularly Chewa. Research needs to be conducted on the need to include Chewa into the school curriculum at primary school level.

5.5.13.3 Learners' perceptions on the implementation of multicultural education. Research is needed on learners' perceptions on the implementation of multicultural education in Zimbabwe's primary schools. 


\section{REFERENCES}

Adeyemi, D.A. (2008). Bilingual education: Meeting the challenge of diversity in Botswana. Nordic Journal of African Studies, 17 (1), 20-33.

Agger, B. (2006). Critical social theories: An introduction. London: Paradigm Publishers.

Aronwitz, S. \& Giroux, H.A. (1991). Post modern Education: Politics, culture and social Criticism .Retrieved 10.05.12 from

http://www.newlearningonline.com/newlearning/Chapter-7-Knowledge and learning/aronwitz-and-giroux-on-postmodern-education.

Applerouth S. \& Edles, L.P. (2008). Classical and contemporary sociology: Text and readings. London: Pine Forge Press.

Ashern N. (2007). Made in the (Multicultural) U.S.A.: Unpacking tensions of race, culture, gender, and sexuality in education. Educational Researcher 36 (65), 65-73.

Ballantine, J. H. \& Hammack, F.M. (2012). The Sociology of Education: A systematic reader Boston: Pearson.

Banks, C.A.M (2009). Communities, families and educators working together. In Banks, J. A. \& Banks, C.A.M. (Eds.) (2009). Multicultural education: Issues and perspectives (pp. 417-437). New York: John Wiley \& Sons.

Banks, J.A. (1993). Multicultural education: Historical development dimensions and practice. Retrieved 26.03.12 from http://www.sjsu.edu/edleadership/course/EDAD2021/Banks\%20J.\%20 
Multicultural\%Education\%20Histo-Windows/InternetExplorer

Banks, J.A. (1994). http://www.edchange.org/multicultural/initial/htm Retrieved 10.05 .12

Banks, J.A. (2009). Multicultural education characteristics and goals. In Banks, J.A. \& Banks, C.A.M. (Eds.) (2009). Multicultural education: Issues and perspectives (pp.2-32). New York: John Wiley \&Sons.

Banks, C.A.M (2009). Communities, families and educators working together. In Banks, J. A. \& Banks, C.A.M. (Eds.) (2009). Multicultural education: Issues and perspectives (pp. 417-437). New York: John Wiley \& Sons.

Banks, J.A. (2004). Race, knowledge, construction and education in the U.S.A.: Lessons from history. In Ladson-Billings, G. \& Gillborn, D. (Eds.) (2004). The Routledge reader in multicultural education (pp.16-34). New York: Routledge Falmer.

Barbour, R. (2008). Introducing qualitative research. London: Sage.

Bauman, Z. (2007). Liquid times: Living in an age of uncertainty. Cambridge, UK: Polity Press.

Beairsto, B. \& Carrigan, T. (2004). Imperatives and possibilities for multicultural education. Education Canada, Spring 2004, 1-5.

Beck, C. E. (1993). Postmodernism, Pedagogy and Philosophy of Education. Retrieved 21.02.12 from http://www.edu.uiuc.edu/eps/PES-Yearbook/93$\underline{\text { docs/Bek.HTM }}$ 
Bennet, C.L. (2003). Comprehensive multicultural education. Boston: Pearson Education.

Bode, P. (2010) Retrieved 05.06.12 from

http://www.education.com/reference/article/multicultural-education/

Browne, K. (2008). Sociology for AS AQA. Cambridge: Polity Press.

Campbell, D.E. (1996). Choosing democracy: A practical guide to multicultural education. New Jersey: Merril.

Caraballo, L. (2009). Interest convergence in intergroup education and beyond: Rethinking agendas in multicultural education. International Journal of Multicultural Education, 11 (1) 1-15.

Carjuzaa, J. (2012. The positive impact of culturally responsive pedagogy. International Journal of Multicultural Education. 14 (3), 1-17

Chanaiwa, D. (1980). The political economy of colonial education in Southern Africa: Summaries and conclusions. In Mugomba, T. \& Nyaggah, M. (1980). Independence without freedom: The political economy of colonial education in Southern Africa (pp. 227-241). Oxford: ABC CLIO.

Cohen, L., Manion, L. \& Morrison, K. (2011). Research methods in education. London: Routledge.

Corbin, J. \& Holt, N.L. (2011). Grounded theory. In Somekh, B. \& Lewin, C. (Eds.) (2011). Theory and methods in social research. (pp. 113-120). Los Angeles: Sage. 
Creswell, J.W. (2004). Educational research: Planning, conducting and evaluating quantitative and qualitative research. Upper Saddle River NJ: Pearson Merrill.

Creswell, J.W. (2007). Qualitative inquiry and research design: Choosing among five approaches. New Delhi: Sage Publications.

Cumming - McCann, A. (2003). Multicultural education: Connecting theory with practice. Focus on Basics: Connecting Research with Practice 6 (B), 1-6.

Cushner, K., McClelland A. \& Safford, D. (2008). Foundations for multicultural teaching. New York: Sage.

Daniel. (2002). Education in a postmodern world. Retrieved 10.05.12 from http://portal-unesco.org/education/en/ev.php-URL-ID=5908\&URL.DO=DO-

\section{$\underline{\text { Topic } \& U R L-S e c t i o n}=201 \mathrm{html}$}

De Souza. M. (2010). Teaching practices in Mexico: A way to understand Mexican English learners in the United States. International Journal of Multicultural Education 12 (2), 1-15.

Denzin, N.K. \& Ryan, K.E. (2007). Qualitative methodology including Focus Groups. In Outhwaite, W. \& Turner, S.P. (Eds.) (2007). The Sage handbook of social science methodology. (pp. 578-594). London: Sage.

Domnwachukwu, C.S. (2010). An introduction to multicultural education: From theory to practice. Plymouth: Rowman and Littlefield. 
Dorsey, B.J. (1989) Equality of educational opportunity in Zimbabwe: Past, present and future. In Dorsey, B. J. (1989). Readings in Sociology of Education (pp.144-167). Harare: University of Zimbabwe: Department of Educational Foundations.

Dunne, C. (2011). Developing an intercultural curriculum within the context of the internationalisation of higher education: Terminology, typologies and power. Higher Education Research \& Development, 30 (5), 609-622.

Ellis, S. (2002). EFA and monitoring of global targets. In Commonwealth Secretariat (2002). Commonwealth Education Partnership (pp.20-26). Norwich: The Stationery Office Limited.

Finch, H. \& Lewis, J. (2003). 'Focus Groups'. In Ritchie, J. \& Lewis, J. (Eds.) (2003). Qualitative research practice (pp.170-198). London: Sage.

Flick, U. (2008). An introduction to qualitative research. London: Sage.

Flick, U. (2009). An introduction to qualitative research. (Fourth edition). New Delhi: Sage.

Gall, M.D., Gall, J. P. \& Borg, W.R. (2007). Educational research. Boston: Pearson.

Gary, B. (1995). Varieties of multicultural education: An introduction. Eric Digest 98. Retrieved 17.05.12 from http://www.ericdigest.org/1995-1/multicultural.htm

Gay, G. (1994). Synthesis on scholarship in multicultural education. Retrieved 17.05.12 from http://www.ncrel.org/sdrs/areas/issues/educators/leadshp/leOgay.htm

Ghosh, R. (2002). Redefining multicultural education. Toronto: Harcourt Brace Canada. 
Gibson, W.J. \& Brown, A. (2009). Working with qualitative data. London: Sage.

Gibson, A. M. (2010). Approaches to multicultural education in the United States: Some concepts and assumptions. Council on Anthropology and Education Quarterly, 7 (4), 94-120.

Giddens, A. (2009). Sociology. London: Polity.

Gollnick, D.M. \& Chinn, P.C. (2012). Multicultural education in a plural society. New York: Macmillan College Publishing Company.

Gora, R., Mavunga, G., Muringani, F. \& Waniwa, F. (2010). The use of Shona as a medium of instruction in the first three grades of primary school in a Tonga speaking community: Parents and teachers perceptions. Zimbabwe Journal of Educational Research, Volume 22 (1), 87-102.

Gordon, R. (1995). Causes of girls' underachievement: The influence of teachers' expectations on the academic performance of secondary school girls. Occasional Paper Number 8. University of Zimbabwe: Human Resources Research Centre.

Gordon, R. (1995). Attitudes towards girls in Zimbabwe: A baseline study for the gender equity in education project. Harare: UNESCO.

Gorski, P. C. (1999). A brief history of multicultural education. Retrieved 26.04.12 from http://www.edchange.org/mulicultural/critical/htm

Gorski, P.C (2010). The scholarship informing the practice: Multicultural teacher education in the United States. International Journal of Multicultural Education, 12 (2), (1-22). 
Gorski, P.C. (2006). Complicity with conservatism: The depoliticising of multicultural education and intercultural education. Intercultural Education, 17 (2), $163-177$.

Gorski, P.C. (2010 b). The challenge of defining Multicultural Education. Retrieved 26.04.12 from http://www.edchange.org/multicultural/initial.html

Gorski, P. \& Covert, B. (2010). Defining multicultural education. Retrieved 26.04.12 from http://www.edchange.org/multicultural/initial.htm

Government of Zimbabwe (2013). Constitution of Zimbabwe Amendment (No.20) Harare: Government Printer.

Government of Zimbabwe. 1987 Education Act. Harare: Government Printer.

Government of Zimbabwe Statutory Instrument 70 of 1993.

Government of Zimbabwe (2004). Zimbabwe Millennium Development Goals. Harare: UNDP.

Government of Zimbabwe (2009). Zimbabwe Millennium Development Goals: 20002007 Midterm Progress Report. Harare: Government Printer.

Government of Zimbabwe (2010). Millennium Development Goals Status Report. Harare: Government of Zimbabwe.

Grant, C.A. \& Brueck, S. (2011). A global invitation: Towards the expansion of dialogue, reflection and creative engagement for intercultural and multicultural education. In Grant, C.A. \& Portera, A. (Eds.) (2011). Intercultural and multicultural education (pp 3-11). New York: Routledge. 
Grant, C.A. \& Sleeter, C.E. (2009). Race class, gender, and disability in the classroom. In Banks, J.A. \& Banks, C.A.M. (Eds. (2009). Multicultural Education: Issues and perspectives (pp 59-82). New York: John Wiley \& Sons.

Grant, C.A. \& Sleeter, C.E (1988). Critical multicultural education. Retrieved 17.05.12 from http://www.sunypress.edupdf/

Grant, C.A. \& Sleeter, C.E. (2004). Turning on learning: Five approaches for multicultural teaching plans for race, class, gender and disability. In Ladson-Billings, G. \& Gillborn, D. (Eds.) (2004). The Routledge reader in multicultural education. (pp.52-70). New York: Routledge Falmer.

Grant, C.A. (2008). The evolution of multicultural education in the United States: A journey of human Rights and social justice. Retrieved 17.05.12 from http://207.210.232.43 download/turin-paper-grantpdf

Grbich, C. (2004). New approaches in social research. New Delhi: Sage.

Gwirayi, P. ( 2010). Bachelor of Education students' attitudes, beliefs and awareness of multicultural education. The Dyke, 4 (1), 93 -104.

Hall, S. (2004). What is credibility in qualitative research? Retrieved 16.07.12 from http://www.ehow.com/info-/10055327-credibilty-qualitative-research.html

Haralambos, M. \& Holborn, M. ( 2013). Sociology : Themes and peerspectives. London: Collins.

Hartman, P.W. (1996). What is postmodernism? Retrieved 05.03.11 from http://www.naciente.om/essay15html 
Harvey, D. (2001). The condition of postmodernity. In Seidman, S. \& Alexander, J.C. (Eds.) (2001). The new social theory reader. (pp.176-183) London: Routledge.

Haynes Writer, J. (2008). Unmasking, exposing and confronting: Critical race theory and multicultural studies. International Journal of Multicultuiral Education, 10 ( 2 ), $1-15$.

Henning, E. ( 2004). Finding your way in qualitative research. Pretoria : Van Schaick.

Herrera, S. G., Holmes, M.A. \& Kavimandan, S.K. (2012). Bringing theory to life: Strategies that make Culturally Responsive Pedagogy a reality in diverse secondary classrooms. International Journal of Multicultural Education, 14 (3), 1-19.

Hesse-Biber, S.N. \& Leevy, P. ( 2006). The practice of qualitative research. London: Sage

Johnson, B. \& Christensen, L. ( 2008). Educational research: quantitative, qualitative and mixed approaches. London: Sage.

Joshee, R., Peck, C., Thompson, M., Chareka, O. \& Sears, A. (2010). Multicultural education, diversity and citizenship in Canada. Retrieved 05.06.12 from http://www.intalliance.org/fileadmin/user-upload/documents/conference-2010/NP-

\section{$\underline{\text { Capdf }}$}

Kehoe, J.W.(2004). The limitations of multicultural education and anti racist education. Retrieved 17.05.12 from http://www.caslt.org/pdf/limitationspdf

Kincheloe, J. L. (2008). Knowledge and critical pedagogy: An introduction. 
Montreal: Springer.

Kirby, M. et al. (1997). Sociology in perspective. London: Heinneman.

Kirova, A. (2008). Critical and emerging discourses in multicultural education literature: A review. Canadian Journal of Ethnic Studies, 40 ( 1), 101-124.

Kiter, M. (2003). Study guide for Andersen and Taylors' sociology: The essentials. Toronto: Thomas Learning Inc.

Kumar, R. (2005). Research methodology: A step by step guide for beginners. New Delhi: Sage.

Kurt, M. (2006). Postmodern education: Critical and border pedagogies. Cypriot Journal of Educational Sciences, 1 (2), 84-93.

Krathwohl, D. R. (1993). Methods of educational and social science research: An integrated approach. New York: Longmans.

Krefting, L. (1991). Rigor in qualitative research: The assessment of trustworthiness. The American Journal of Occupational Therapy, 45 (3), 214-222.

Legard, R., Keegan, J. \& Ward, K. (2008). In depth interviews. In Ritchie, J. \& Lewis, J. (Eds.) (2008). Qualitative research practice (pp.138-169). London: Sage.

Lemmer, E.M., Meier, C. \& Van Wyk, J.N. (2006). Multicultural education: An educator's manual. Pretoria: Van Schaick Publishers.

Lewis, J. (2008). Design issues. In Ritchie, J. \& Lewis, J. (2008). Qualitative research in practice: A guide for social science students and researchers (pp. 47-74). London: Sage. 
Lincoln, Y.S. \& Guba, E.G. (1985). Naturalistic inquiry Retrieved 07.12.11 from http://www.qualres.org/Homelinc-3684html

Little, A.W. (2002). The planning of EFA: Lessons from Sri Lanka. In Commonwealth Secretariat (2002). Commonwealth Education Partnership (pp.1229). Norwich: The Stationery Office Limited.

Maatta, S. (2008). Experience matters: Teacher perceptions of multicultural education and their competence to teach from different cultural backgrounds. University of Jyvaskalya: Department of Educational Studies.

McKinney, C. \& Soudien, C. (2010). Multicultural education in South Africa: 2010

IALEI Country Report (pp. 1-21). Retrieved 17.05.12 from

http://www.intalliance.org/fileadmin/user-upload...2010/NP-SApdf

Manning, M. L. \& Baruth, L.G. (2008). Multicultural education of children and adolescents. Boston: Allyn and Bacon.

Marchand, M. H. \& Parpart, J. L. (Eds.) (1995). Feminism: Postmodernism development. New York: Routledge.

Marshall, C. \& Rossman, G. B. (2006). Redesigning qualitative research. Thousand Oaks: Sage.

Martines, D. (2005). Teacher perceptions of multicultural issues in school settings. The Qualitative Report, 10 (1), 1-20.

Mason, J. (2002). Qualitative researching. London: Sage.

Mathai Thomas, T. (1994). Multicultural education: Reconstructionism coming of 
age. Retrieved 05.06.12 from http://www.teqjournal.org/backvols/1994/21-4/f94-

$\underline{\text { thomas.pdf }}$

Matsumoto, M. (2013). Political theorising and policy implications: The case of Rawlsian approach to multicultural education. International Journal of Multicultural Education. 15 (1), 1-12.

Mavhunga, P.J. (2008). Africanising the school curriculum: A case for Zimbabwe. Zimbabwe Journal of Educational Research, 20 (1), 30-48.

McGovern, S. (1999). Education, modern development, and indigenous knowledge. New York: Garland Publishing.

May, S. (2009). Critical multiculturalism and education. In Banks, J.A. (Ed.) (2009). The Routledge international companion to multicultural education. (pp.33-48). New York: Routledge.

Meier, C. \& Hartell, C. (2009). Handling cultural diversity in education in South Africa. SAEduC Journal, 6 (2), 180-192.

Minichielo, V. \& Kottler, J. (2010). An overview of the qualitative journey: Reviewing basic concepts. In Minichielo, V. \& Kottler, J. (Eds.) Qualitative journey: Students' and mentor experiences with research (pp. 11-31). New Delhi: Sage.

Ministry of Education, Arts, Sports and Culture (2002). Secretary's Circular Minute Number 3 of 2002.

Ministry of Education, Arts, Sports and Culture (2004). Cultural policy of Zimbabwe. Harare: Government Printer. 
Mnkandla, M. (2000). An investigation of the implementation of Zimbabwe's language policy in primary education. Zimbabwe Journal of Educational Research, Volume 12 (1), 75-93.

Molosiwa, A.A. (2009). Monocultural education in a multicultural society: The case of teacher preparation in Botswana. International Journal of Multicultural Education, $11(2), 1-13$.

Morgan, D. \& Embree, L.E. (Eds.) (2004). Phenomenology: Critical concepts in Philosophy. London: Routledge.

Moyana, T.T. (1988). Education liberation and the creative act. Harare: Zimbabwe Publishing House.

Moss, G. (2004). Provision of trustworthiness in critical narrative research: Building intersubjectivity and fidelity. The Qualitative Report, 9 (2), 359-374.

Muchenje, F. (2008). Multicultural education in Zimbabwean primary schools: An agenda of issues. Zimbabwe Bulletin of Teacher Education, 14 (2), 7-21.

Muchenje, F., Goronga, P. \& Bondai, B. (2013). Zimbabwe's language policy in education and the 'silenced voices: A case study of Nyanja / Chewa speaking pupils from Porta and Kintyre primary schools in Zvimba Zimbabwe. Academic Research International 4 (2), 500-511.

Muparutsa, T. (2012). Multiculturalism and pedagogical eclecticism: Towards a paradigm shift in Zimbabwean music education. Zimbabwe Journal of Educational Research, 24 (1), 61-68. 
Mugisha, V.M. (2013). Culturally responsive instructional leadership: A conceptual exploration with principals of three New Zealand mainstream schools. International Journal of Multicultural Education 15 (2), 1-20.

Mustafa, K. (2006). Postmodern education: Critical border pedagogues. Cypriot Journal of Educational Sciences, 1 (2), 84-93.

Ndamba, G.T. (2008). Mother tongue usage in learning: An examination of language preferences in Zimbabwe. The Journal of Pan African Studies, 2 (4), 171-188.

Ndamba, G.T. (2010). The official language policy and its implementation at infant school level in Zimbabwe. Zimbabwe Journal of Educational Research, 22 (3), 242260.

Ndura, E. (2006). Reflections of teacher's culture in the classroom: Beginning to see and hear. Electronic Magazine of Multicultural Education. Retrieved 17.05.12 from http://www.eastern.edu/publications/emme/2006fall/ndura.pdf

Newall, P. (2005). Postmodernism Retrieved 10.05.12 from http://www.galileanlibrary.org/site/index.php/page/index/html/-/essays/introducingphilosophy/12postmodernism-r28

Nieto, S. (1997). Characteristics of multicultural education. In Le Roux, J. (Ed.) (1997). Multicultural education: What every teacher should know (pp44-48) Pretoria: Kagiso Publishers.

Nieto, S. (2002). Language, culture and teaching. Mahwah N J. : Lawrence Erlbaum Associates Inc. 
Nieto, S. (2009). Multicultural education in the United States: Historical realities, ongoing challenges, and transformative possibilities. In Banks, J.A. (Ed.) The Routledge international companion to multicultural education (pp. 79-95). New York: Routledge.

Nieto, S. (2009). Diversity education: Lessons for a just world. In Nkomo, M. \& Vandeyer, S. (Eds.) (2009). Thinking diversity while building cohesion: Transnational dialogue on education. (pp. 17-39) Pretoria: Unisa Press.

Njobe M.N. (1990). Education for liberation. Braamfontein: Skotaville Publishers.

Nkomo, M., Vandeyer, S., Malada, B., Phatlane, R., Tabane, R. \& Phurutse, M. (2009). The state of pedagogy in desegregated South African schools: Peering into the classroom. In Nkomo, M. \& Vandeyer, S. (Eds.) (2009). Thinking diversity while building cohesion: Transnational dialogue on education (pp 41-61). Pretoria: Unisa Press.

Nkomo, M. \& Vandeyer, S. (Eds.) (2009). Thinking diversity while building cohesion: Transnational dialogue on education. Pretoria: Unisa Press.

Nyoni, T. \& Nyoni, M. (2010). The 'Culture Hut' concept: A case study of Danda and Chimedza schools in Zaka District. Journal of Sustainable Development in Africa, 12 (1), 146-158.

Nziramasanga Commission (1999). Report of the Presidential Commission of Inquiry into Education and Training. Harare: Government Printer.

Ogbu, J.U. (1992). Understanding cultural diversity and learning. Educational Researcher 21 (8) 14-24. 
Ornstein, A.C., Levine, D.U. \& Guter, G.L. (2011). Foundations of education. Belmont: Wadsworth Cengage Learning.

Pai, Y. \& Adler, S.A. (1997.) Cultural foundations of education. London: Prentice Hall International.

Patten, M. L. (2009). Understanding research methods: An overview of the essentials. Glendoe: Pyrczak Publishers.

Patton, M.Q. (2002). Qualitative research and evaluation methods. London: Sapes.

Peresuh, M. \& Masuku, J. (2002). The role of primary language in the bilingualbicultural education in Zimbabwe. Zambezia, xxx (i), pp. 27-37.

Plumer, K. (2010). Sociology: The basics. New York: Routledge.

Portera, A. (2011). Multicultural education epistemological and semantic aspects. In Grant, C.A. \& Portera, A. (Eds.) (2011). Intercultural and multicultural education (pp.12-32). New York: Routledge.

Punch, K.F. (2004). Introduction to social research: Quantitative and qualitative approaches. London: Sage.

Reissman, R. (1994). Evolving multicultural education. Retrieved 05.06.12 from http://www.ascd.org/publications/books/194173/chapters/Definition-of-multiculturalEducation.aspx

Ritchie, J. \& Lewis, J. (2008). Generalising from qualitative research. In Ritchie, J. \& Lewis, J. (Eds.) (2008). Qualitative research practice: A guide for social science students and researchers (pp.263-286). London: Sage. 
Ritchie, J., Lewis, J. \& Elam, G. (2008). Designing and selecting samples. In Ritchie, J. \& Lewis, J. (Eds.) (2008). Qualitative research practice: A guide for social science students and researchers (pp77-108). London: Sage.

Ritzer, G. (2009). Sociological theory. New York: McGraw Hill.

Robson, C. (2011). Real world research. Chichester: John Wiley \& Sons.

Rosaldo, C. (2006). What do we mean by managing diversity? Retrieved 17.05.12 from http://www.Edchange.org/multicultural

Rose, D.G. \& Potts, A.D. (2011). Examining teacher candidate resistance to diversity: What can teacher educators learn? International Journal of Multicultural Education, $13(2), 1-19$.

Ruane, J.M. (2005). Essentials of Research Methods: A guide to social science research. Oxford: Blackwell.

Runhare, T. \& Mulaudzi, P. (2012). Education for a rainbow nation: A desegregated school playground as a model for reconstructing social cohesion in post-xenophobic South African communities. Journal of Social Science 32 (2), 193-204.

Rwantabangu, H. (2011). Tradition, globalisation and language dilemma in education: African options for the $21^{\text {st }}$ century. International Review of Education, 1 (22), 1-15.

Sa, E. (2007). Language policy education and development in Tanzania. Retrieved 13.01.11 from http://www.swartmore.edu/SocSci/Linguistics/Papers/2007saeleuthera.pdf pp. 1-28 
Sadovnik, A.R. (2007). Theory and research in the Sociology of Education. In Sadovnik, A.R. (Ed.) (2007). Sociology of Education: A critical reader. (pp. 3-21) New York: Routledge.

Saldana, J. (2009). The coding manual for qualitative researchers. London: Sage Publications.

Sarup, M. (1993). An Introductory guide to post structuralism and postmodernism. New York: Harvester Wheatsheaf.

Scherba de Valenzuela, S. Retrieved from

http://www.unm.edu/ /devalenz/handouts/nieto2.htm 1 Retrieved 05.06.12

Sieber, J.A. (2009). Planning ethically responsible research. In Bickman, L. \& Rog, D.J. (Eds.) The Sage handbook of applied social research methods (pp 106-142). London: Sage.

Silverman, D. (2006). Interpreting qualitative data. London: Sage.

Silverman, D. (2010). Doing qualitative research. Los Angeles: Sage.

Schmeichel, M. (2012). Good teaching? An examination of culturally relevant pedagogy as an equity practice. Journal of Curriculum Studies, 44 (2), 211-231.

Shank, G.D. (2006). Qualitative research: A personal skills approach. Upper Saddle River New Jersey: Pearson Merril.

Shizha, E. (2007). Critical analysis of problems encountered in incorporating indigenous knowledge in science teaching by primary school teachers in Zimbabwe. The Alberta Journal of Educational Research, 53 (3), 302-319. 
Shenton, A.K. (2004). Strategies for ensuring trustworthiness in qualitative research projects. Education for Information, 22 (2004), 63-75.

Singleton, R.A. Jnr, \& Straits, B.C. (2010). Approaches to social research. Oxford: Oxford University Press.

Slattery, P. (2006). Curriculum development in the postmodern era. London: Garland Publishing.

Sleeter, C. \& Grant, C.A. (2003). Making choices for multicultural education: Five approaches to race, class and gender. Reviewed by McDougall, S.C. Retrieved 17.05.12 from http://www.edrevinfo/reviews/rev237htm

Sleeter, C. \& McLaren, P. (2011). Origins of multicultural education. In Grant, C.A. \& Portera, A. (Eds.) (2011). Intercultural and multicultural education. New York: Routledge.

Somekh, B. \& Lewin, C. (Eds.) (2011). Theory and methods in social research. Los Angeles: Sage

Spencer, L., Ritchie, J. \& O’Connor, W. (2008). Analysis: Practices, principles and processes. In Ritchie, J. \& Lewis, J. (Eds.) (2008). Qualitative research practice: A guide for social science students and researchers (pp.199-218). Los Angeles: Sage.

Stake, R.T. (2010). Qualitative research: Studying how things work. New York: The Guilford Press.

Stephens, D. (2009). Qualitative research in international settings: A practical guide. New York: Routledge. 
Stoicovy, C.E., Fee, R. \& Fee, J. (2012). Culturally responsive instruction leaves no child behind: The story of Juan, a Pacific special needs student. International Journal of Multicultural Education 14 (1), 1-19.

Tashakkori, A. \& Teddlie, C. (2009). Integrating qualitative and quantitative approaches to research. In Bickman, L. \& Rog, D.J. (2009). (Eds.) The Sage handbook of applied social research methods (289-318). London: Sage.

Taylor, S. (Ed.) (1999). Sociology: Issues and debates. London: Macmillan.

Taylor, P., Richardson, J., Yeo, A., Marsh, K., Trobe, K. \& Pilkington, A. (2011). Sociology in focus. Ormskirk: Causeway Press.

Thondhlana, J. (2002). Using indigenous languages for teaching and learning in Zimbabwe. In Burnaby, B. \& Reyhner, J. (Eds.) (2002). Indigenous languages across the community (pp. 31-39). Flagstaff Arizona: Northern Arizona University, College of Education.

Tichagwa, W. (1998). Beyond inequalities: Women in Zimbabwe. Harare: Zimbabwe Women's Resource Centre Network.

Trochim, W.M.K. (2006). Qualitative validity. Retrieved 07.12.11 from http://www.social/researchmethods.net/kb/qualval.php.

UNESCO (2005). Convention on the Protection and Promotion of the Diversity Of Cultural Expressions. Paris: UNESCO.

UNICEF (1990). African Charter on Children's Rights. Retrieved 23.03.12 from http://www.unicef.org/refworld /docid/3ae6638c18.html 
UNICEF(1990).International Convention on the Rights of The Child. Retrieved 23.03.12 from http://www.unicef.org/crc/files/Survival-Development.pdf

Usher, R. (1995). Postmodernism and education. London: Routledge. Retrieved 24.04.12 from Usher, R.

http://www.questia.com/googleScholar.qst?doc/d=103778005 .

Van Vuuren, H.J. \& Van Der Westhuizen, P.C. (2007). Organisational development in schools: A strategy for the management of diversity. In Van Der Westhuizen, P.C. (Ed.) (2007). Schools as organisations (pp. 338-360). Pretoria: Van Schaick Publishers.

Vandeyer, S. (2003). The jagged paths to multicultural education: International experiences and South African response in the new dispensation. South African Journal of Education, 23 (3), 193-198.

Vandeyer, S. (2010). Responses of South African teachers to the challenge of school integration. South Africa Journal of Education, 30 (3), 342-359.

Viriri, A. (2003). Language planning in Zimbabwe: The conservation and management of indigenous language as intangible heritage. Retrieved 26.04.12 from http://www.international.icomos.org/victoriafalls2003/papers/C1-5\%20Viriri.pdf

Walliman, N. (2011). Research methods: The basics. London: Routledge.

Wang, Y. \& Phillion, J.A. (2009). Minority language policy and practice in China: The need for multicultural education. International Journal for Multicultural Education, 11 (1), 1-14. 
Yao, Y. Buchanan, D.L., Powell-Brown, A. \& Pecina, U.H. (2009). Different Drummers: International perspectives on multicultural education. International Journal of Multicultural Education, Volume 11 (2), 1-17.

Zhang, Y. \& Wildemuth, B.M. (2007). Qualitative analysis of content. Retrieved 07.12.11 from http://ils.unc.edu/ yanz/content-analysis.pdf

Zimmerman, L. (2004). Teacher perceptions of multicultural education in the United States Retrieved 20.04.12 from http://www.wcu.edu/factor/mountainrise/archieve/vol13no2/html/Zimmerman.pdf Zvobgo, R.J. (1996). Transforming education: The Zimbabwean Experience. Harare: College Press. 


\section{UNISA}

\section{Research Ethics Clearance Certificate}

This is to certify that the application for ethical clearance submitted by

\section{F Muchenje [49256084]}

for a D Ed study entitled

Teacher perceptions on the implementation of multicultural education in primary schools in Chegutu district Zimbabwe.

has met the ethical requirements as specified by the University of South Africa College of Education Research Ethics Committee. This certificate is valid for two years from the date of issue.

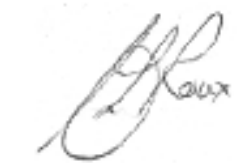

Prof CS le Roux 29 May 2013 CEDU REC (Chairperson)

Irouxcs@unisa.ac.za

Reference number: 2013 MAY/49256084/CSLR 
all communications should be addressed to

"The Secrelary for Education Sport and Cullure"

Telcphone: $734051 / 59$ and 734071

Telegraphic address: "EDUCATION"

Fax: $794505 / 705289 / 734075$
Ref: C/426/3

Ministry of Education, Sport, Arts and Culture

P.O Box CY 121

Causeway

Zimbabwe

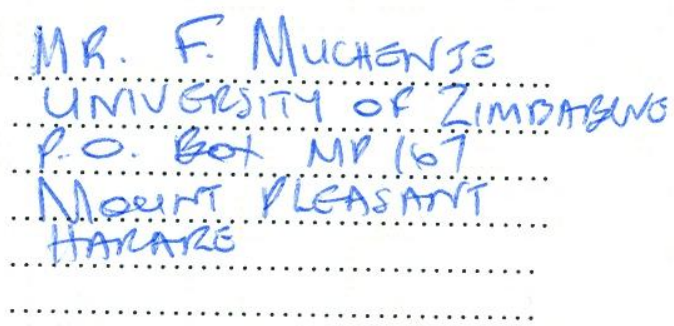

RE: PERMISSION TO CARRY OUT RESEARCH

Reference is made to your application to carry out research in the Ministry of Education, Sport and Culture institutions on the title:

TEACHER PERCEPTIONS ONTHE IMPLEMENTATION OF

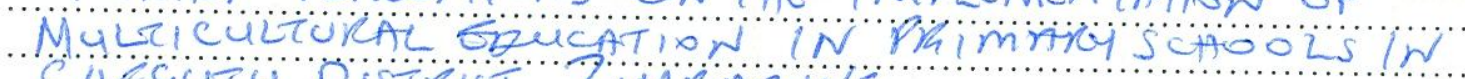

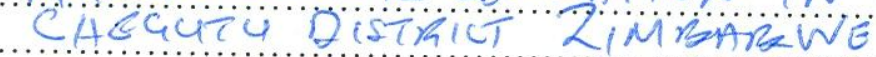

Permission is hereby granted. However, you are required to approach the Provincial Education Director responsible for the schools you want to involve in your research for assistance and permission to enter schools.

You are also required to provide a copy of your final report to the Ministry since it is instrumental in the development of education in Zimbabwe.

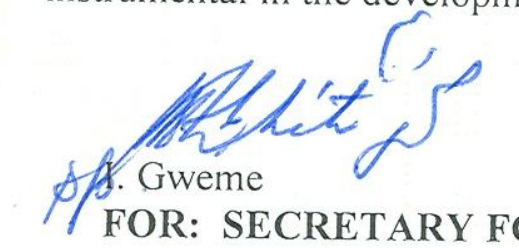

FOR: SECRETARY FOR EDUCATION, SPORT, ARTS AND CULTURE

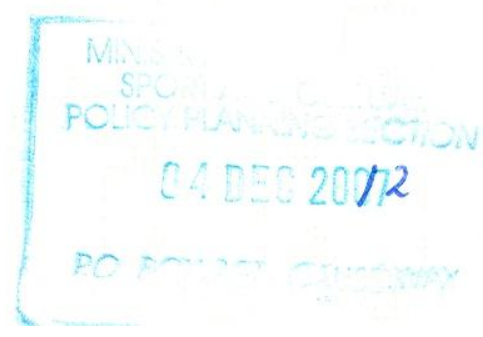


All communications should be

addressed to

"The Provincial Education

Director"

Telephone: 067-23043/25655

Fax: 067-23320

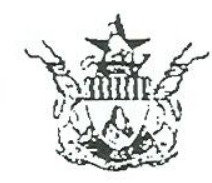

ZMMBABWE

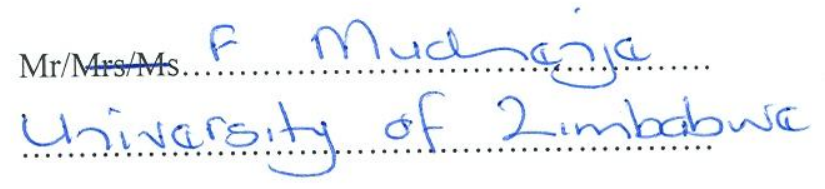

\section{Ditidity of Prinary and Secondary \\ Eduration \\ 06 DEC 2002 \\ Mntenaland West Region \\ e0: lox 328, CHention}

Dear Madam/Sir

APPLICATION FOR PERMISSION TO CARRY OUT AN EDUCATIONAL RESEARCH:SCHOOLS IN MASHONALAND WEST PROVINCE

Your application letter dated......1.21 12 .seeking authority to carry out a research/survey in schools in Mashonaland West Province refers:

Permission has been granted by the Provincial Education Director on the following conditions:-

-that the learning and teaching programmes at the targeted schools are not interrupted in any way. -that you strictly adhere to the activities and topics specified in your letter of request.

-that the permission or authority may be withdrawn at any time by this office or a higher office if need be.

Please appraise this office on your research findings for the benefit of the Province.

By this letter,all District Education Officers and Heads of schools you wish to visit are kindly requested to give you assistance in your work.

We wish you success in your research and studies.

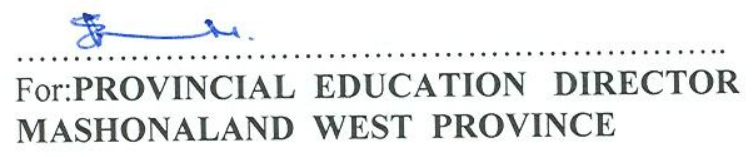




\section{APPENDIX IV}

\section{LETTER SEEKING PERMISSION FROM SCHOOL HEADS}

University of Zimbabwe

Faculty of Education

P.O. Box MP 167

Mount Pleasant

Harare

28 May 2013

The Head

RE: Permission to conduct research 'Teacher perceptions on the implementation of multicultural education in primary schools in Chegutu district Zimbabwe'

My name is Francis Muchenje and I am a lecturer in the Faculty of Education at the University of Zimbabwe. I am also a part time Doctor of Education student with the University of South Africa. I am seeking your permission to conduct the above mentioned research at your school. The research study involves conducting unstructured interviews with four teachers (two male and two female) at your school as well as conducting focus group discussions with the same teachers. The interviews should take at least thirty minutes each and the focus group discussion should also take about one hour. Every effort shall be made to ensure that minimum disruption of learning occurs during the research process.

During and after the research process the following ethical issues shall be upheld: the name of your school shall remain confidential; the confidentiality, privacy and anonymity of the research participants shall be ensured and participation is voluntary, participants are free to withdraw from the study at any time.

I have attached a copy of a letter from the Ministry of Education, Sports, Art and Culture Mashonaland West Regional office authorising this research study.

My supervisor is Dr. J.H. Heeralal and he can be contacted on telephone +27 12429 2318 or cell 27837971029 . My contact number is +263772278581 and you should feel free to contact me should any problems arise.

Your assistance shall be sincerely appreciated.

Thanking you in advance.

Francis Muchenje 


\section{APPENDIX V}

\section{INFORMED CONSENT FORM FOR TEACHERS}

My name is Francis Muchenje. I am a registered doctoral student with the University of South Africa. I am undertaking a research into multicultural education as part of my doctoral thesis and I am kindly asking you to be part of the sample in this study. This Informed Consent Form has two parts as follows:

- Information sheet ( to share information about the study with you)

- Certificate of consent (for signature if you choose to participate).

\section{Part 1: Information Sheet}

\section{Introduction}

This research study is being carried out in five selected primary schools in Chegutu district Zimbabwe.

\section{Purpose of the research}

The purpose of the research is to:

- Evaluate the implementation of multicultural education in Zimbabwean primary schools,

- Suggest ways to make the implementation of multicultural education better and more efficient.

\section{Participant selection}

Participants are selected using stratified and purposive sampling procedures.

\section{Voluntary participation}

Participation in the research is voluntary; you are free to withdraw at any stage should you so wish.

\section{Procedures}

You will be asked to attend an interview session with the researcher and join a focus group discussion thereafter. Both the interview and focus group discussion will be conducted by the researcher at your school.

\section{Duration}

The research exercise requires about one hour of your time.

\section{Risks}

You will not be exposed to any form of risk by any form of risk by participating in the interview sessions or attending the focus group discussions.

\section{Benefits}

Your participation in the research will go a long way in the design of a curriculum that takes due cognisance of learner diversity. Such a curriculum should contribute to learner achievement.

\section{Confidentiality}

The information that you provide in the interview and focus group discussion shall only be used for research purposes only. You do not need to disclose your name or the name of your school during the interview and focus group sessions. 
Right to refuse or withdraw

Participation in this research study is strictly voluntary. You are free to withdraw from the research study at any given time.

My cell phone contact number is +263772278581 . Feel free to contact me on this number should need arise.

\section{Part II Certificate of Consent}

I have read the foregoing information. I have heard the opportunity to ask questions about it and any questions I have been asked have been answered to my dissatisfaction. I consent voluntarily to participate in this study.

Print name of participant

Signature of participant

Date.

Day/ month/ year

Statement by the researcher

I confirm that the participant was given an opportunity to ask questions about the study, and all the questions asked by the participant have been answered correctly and to the best of my ability. I confirm that the individual has not been coerced into giving consent, and the consent has been given freely and voluntarily.

A copy of this Informed Consent Form has been provided to the participant.

Print name of researcher

Signature of Researcher

Date. 


\section{APPENDIX VI}

\section{UNSTRUCTURED INTERVIEW SCHEDULE}

1) How does the content of the primary school curriculum in Zimbabwe show that Zimbabwe is a multicultural nation?

2) What differences are there between curriculum instructional materials used before and after independence?

3) How is the plural character of Zimbabwean society portrayed in the curriculum instructional materials currently in use in primary schools?

4) How are students from all social groups represented in the content of curriculum instructional materials currently in use?

5) How does classroom pedagogy accommodate students' cultural diversity?

6) What are your views on teachers' sensitivity to pupils' cultural backgrounds?

7) How does the current language in education policy of the Ministry of Education, Sports, Arts and Culture address the needs of students in a society where many languages are spoken?

8) How are pupils encouraged to communicate in their mother tongue inside and outside the classroom?

9) How does the total school environment reflect the cultural diversity of the nation?

10) What evidence is there in the school environment that suggests that the primary school in Zimbabwe is a multicultural institution?

11) How does the participation of parents in school activities reflect the nation's multicultural character?

12) How does the composition of school bodies such as the School Development Committee reflect the country's plural character? 


\section{APPENDIX VII}

\section{FOCUS GROUP DISCUSSION QUESTIONS}

1) How is Zimbabwe's primary school curriculum multicultural?

2) What are your views on the implementation of multicultural education in Zimbabwean primary schools?

3) Which primary school subjects highlight the plural character of Zimbabwean society?

4) How do primary school textbooks reflect the cultural diversity found in Zimbabwean society?

5) How do teachers accommodate pupils' diverse cultural backgrounds in the classroom?

6) How do teachers utilise pupils 'diverse cultural backgrounds in designing equity pedagogy?

7) What difference is there between the language policy pursued before and after independence?

8) How does the current language policy in education acknowledge that Zimbabwe is a plural society?

9) How is your school a multicultural institution?

10) How do school policies and activities in areas such as selection of prefects, co curricular activities and assembly programmes reflect cultural diversity?

11) Which social groups of parents are marginalised in terms of participation in school activities? 


\title{
APPENDIX VIII
}

\section{UMI}

\section{DOCTORAL DISSERTATION \\ PUBLISH ABSTRACT ONLY AGREEMENT}

\author{
PERSONAL DATA \\ 1. Last Name \\ MUCHENJE \\ First Name \\ FRANCIS \\ 2. Year of Birth (Optional) \\ 06.01.62 \\ 3. Country of Citizenship \\ ZIMBABWE
}

Middle Name

4. Present Mailing Address Street address: STAND K 3041, KATANGA

\section{NORTON \\ City}

$$
\text { State/Province }
$$

Postal code

\section{ZIMBABWE}

Future Mailing Address

Street address: N/A

City

State/Province

Postal code

Country

Effective date for future mailing address (mm dd yy) N/A

E-mail address: muchenjefrancis@gmail.com

\section{DOCTORAL DEGREE DATA}

5. Full name of university conferring degree, and college or division if appropriate UNIVERSITY OF SOUTH AFRICA

6. Abbreviation for degree awarded DED

7. Year degree awarded 2014

\section{TITLE/SUBJECT AREA}

8. Enter the title of dissertation. If dissertation is written in a language other than English, please specify which language and translate title into English. Language of text: ENGLISH

Title: TEACHERS PERCEPTIONS OF THE IMPLEMENTATION OF MULTICULTURAL EDUCATION IN PRIMARY SCHOOLS IN CHEGUTU DISTRICT ZIMBABWE

9. Subject category of dissertation. Please enter four-digit code from "Subject Categories" on following page. 0282

10. Please append an abstract of no more than 350 words describing the contents of your dissertation. Your completion and submission of this form through your graduate school indicates your assent to UMI publication of your abstract. Formulas, diagrams and other illustrative materials are not recommended for abstracts appearing in Dissertation Abstracts International.

10. Please append an abstract of no more than 350 words describing the contents of your dissertation. Your completion and submission of this form through your graduate school indicates your assent to UMI publication of your abstract. Formulas, diagrams and other illustrative materials are not recommended for abstracts appearing in Dissertation Abstracts International.

Author Signature:

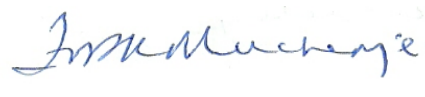

Date: JUNE 2014 


\section{APPENDIX IX}

\section{ABRIDGED CURRICULUM VITAE}

PERSONAL DETAILS

NAME:

RESIDENTIAL ADDRESS:

DATE OF BIRTH:

MARITAL STATUS:

CURRENT ADDRESS:
Francis Muchenje

Stand K 3041 New Stands Katanga Norton

06.01 .62

Married

University of Zimbabwe

Faculty of Education

Educational Foundations Department

P.O. Box MP 167

Mount Pleasant

Zimbabwe

PHONE:

+263 303211 Ext. 17027

$+263772278581$

\section{ACADEMIC QUALIFICATIONS}

M.Ed. (Sociology of Education) U.Z.

2000-2001

B.Ed. (History and Sociology of Education) U.Z.

1989-1991

Certificate in Education

Mutare Teachers' College (University of Zimbabwe)

1981-1983

OTHER QUALIFICATIONS

Diploma in Management of Training (Institute of Personnel Management Zimbabwe).

CURRENT POSITION HELD: Lecturer in Sociology of Education in Educational Foundations Department. University of Zimbabwe

\section{PROFESSIONAL EXPERIENCE}

1. Lecturer University of Zimbabwe

2006- Present

2. Part time lectureship posts

University of Zimbabwe September 2004- November 2006.

3. Lectureship in Teacher Education

Belvedere Technical Teachers'

May 2004-November 2006

4. Marymount Teachers' College

September 2002-May 2004

5. TEACHING

Dudley Hall Primary School

January 2002-September 2002

Martindale Catholic School

January 1986-December 2001

Marist Brothers Secondary School

January 1984-December 1985

\section{ADMINISTRATIVE EXPERIENCE}

Acting Head Martindale Catholic School 1996-2001 


\section{RESEARCH EXPERIENCE}

Research Assistant: School girl pregnancy and dropout in Zimbabwe (D.F.I.D.) Harare 2001 Research Assistant: Comprehensive Review of Gender Issues in the Education sector (UNICEF) Harare 2004.

Research Assistant: Globalization Qualifications and Livelihoods D.F.I.D. (Chinhoyi University of Technology) 2001-2002.

\section{PUBLICATIONS}

Eleven articles in national and international refereed journals and three book chapters. These include:

Muchenje, F. (2008). Multicultural education in Zimbabwean primary schools: An agenda of issues. Zimbabwe Bulletin of Teacher Education. 14 (2), 261-279.

Muchenje, F., Goronga, P. \& Bondai, B. (2013). Zimbabwe's language in education policy and the 'silenced voices': A case study of Nyanja/Chewa speaking pupils from Porta and Kintyre schools in Zvimba. Savap International 4 (2), 500-511.

Muchenje, F. (2013). Wastage discourse in education: Towards an agenda of action. In Shizha, E. (Ed.) (2013). Restoring the educational dream: Rethinking educational transformation in Zimbabwe (pp.76-95) Pretoria: Africa Institute of South Africa.

\section{REFEREES}

Dr. P.J.H. Heeralal. Email: Heerapj@ unisa.ac.za

Dr. O. Hapanyengwi. Email: oswelltap@gmail.com

Professor Rosemary Moyana. Email: rosemarymanasemoyana@gmail.com

Ms. R. Gordon

E.-Mail: rosegordon1@gmail.com 